\title{
Gold-Catalyzed Enantio- and Diastereoselective Syntheses of Left-Fragments of Azadirachtin/Meliacarpin-Type Limonoids
}

\author{
Hang Shi, ${ }^{\dagger}, \mid$ Ceheng Tan, ${ }^{\dagger}$, I Weibin Zhang, ${ }^{\dagger}$ Zichun Zhang, ${ }^{\dagger}$ Rong Long, Jianxian Gong, ${ }^{\dagger}$ \\ Tuoping Luo, ${ }^{* \neq}$ Zhen Yang, ${ }^{*,+,, \S}$
}

"Laboratory of Chemical Genomics, School of Chemical Biology and Biotechnology, Peking University Shenzhen Graduate School, Shenzhen, 518055, China,

${ }^{\ddagger}$ Key Laboratory of Bioorganic Chemistry and Molecular Engineering of Ministry of Education and Beijing National Laboratory for Molecular Science (BNLMS), and Peking-Tsinghua Center for Life Sciences, Peking University. Beijing 100871, China

${ }^{\S}$ Key Laboratory of Marine Drugs, Chinese Ministry of Education, School of Medicine and Pharmacy, Ocean University of China, 5 Yushan Road, Qingdao 266003, China

*E-mail: tuopingluo@pku.edu.cn.

*E-mail: zyang@pku.edu.cn. 


\section{Table of Contents}

NMR Spectra of Compounds .......................................................... 3

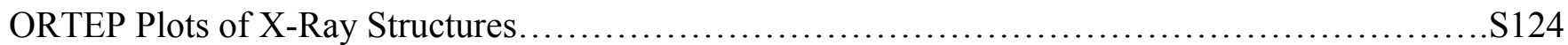

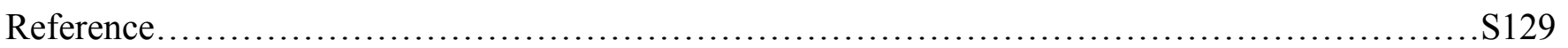



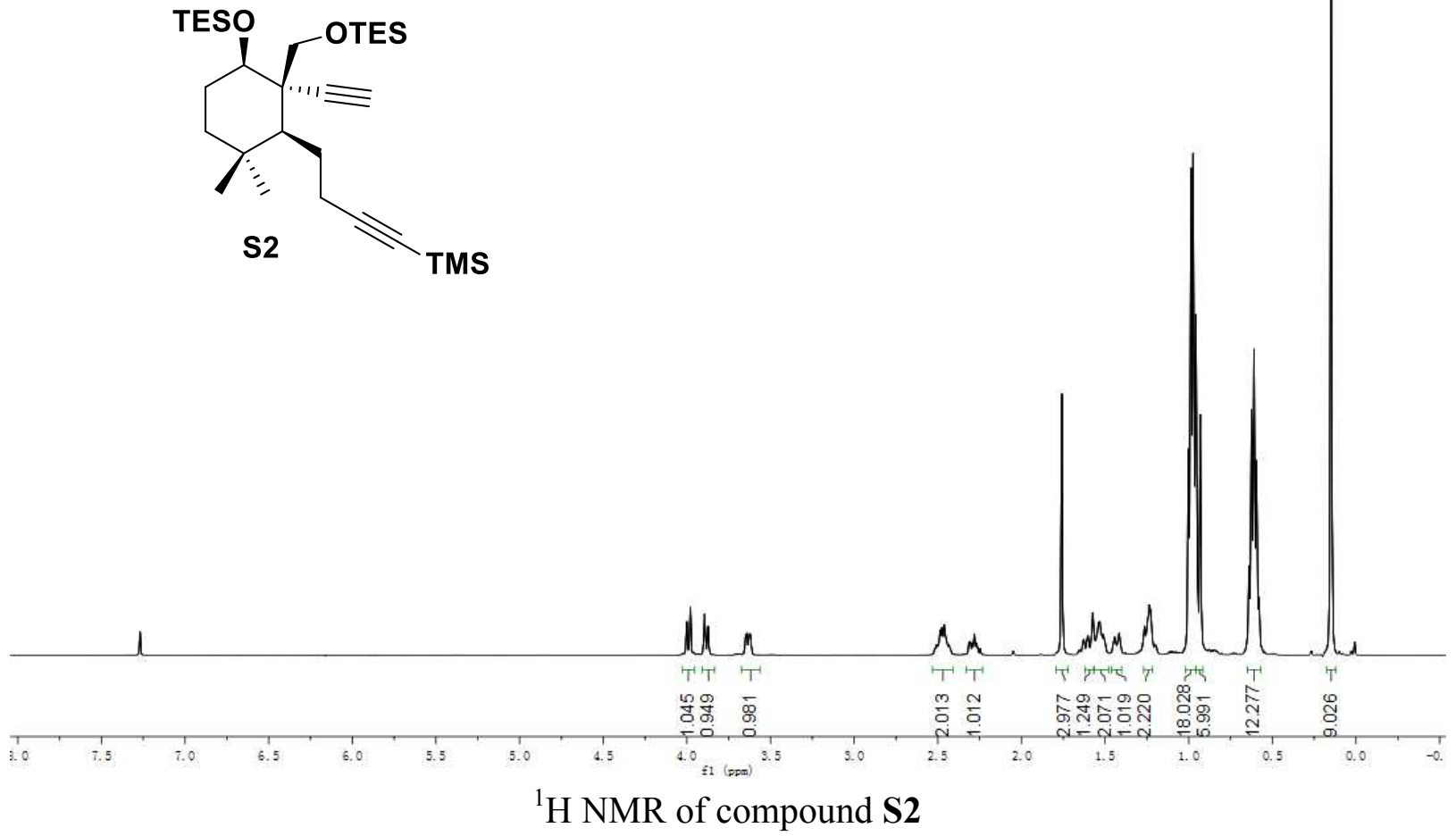

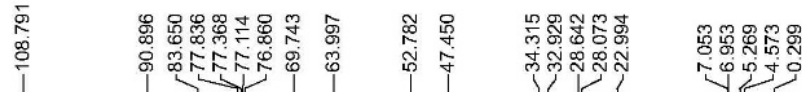
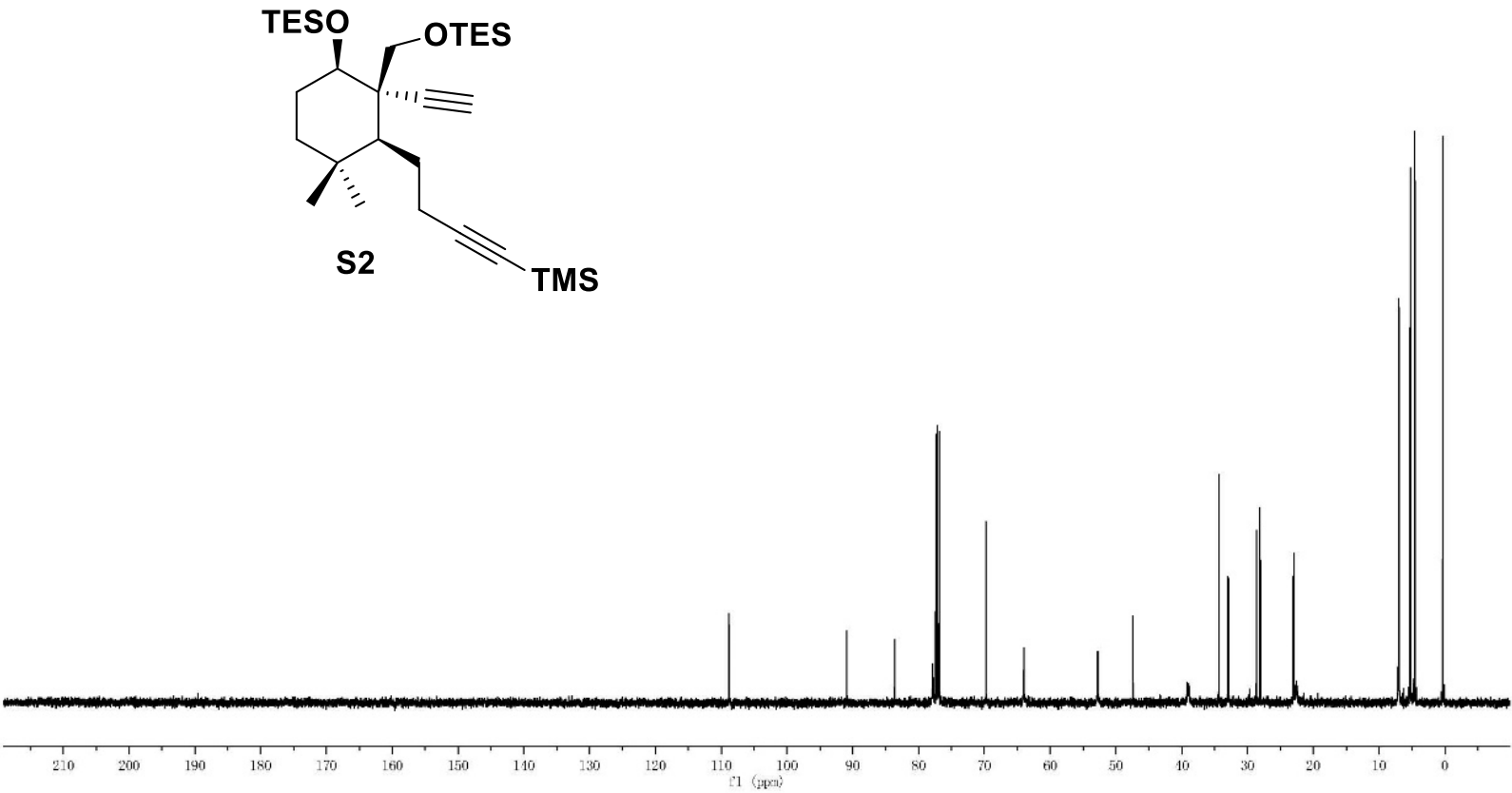

${ }^{13} \mathrm{C}$ NMR of compound $\mathbf{S 2}$ 


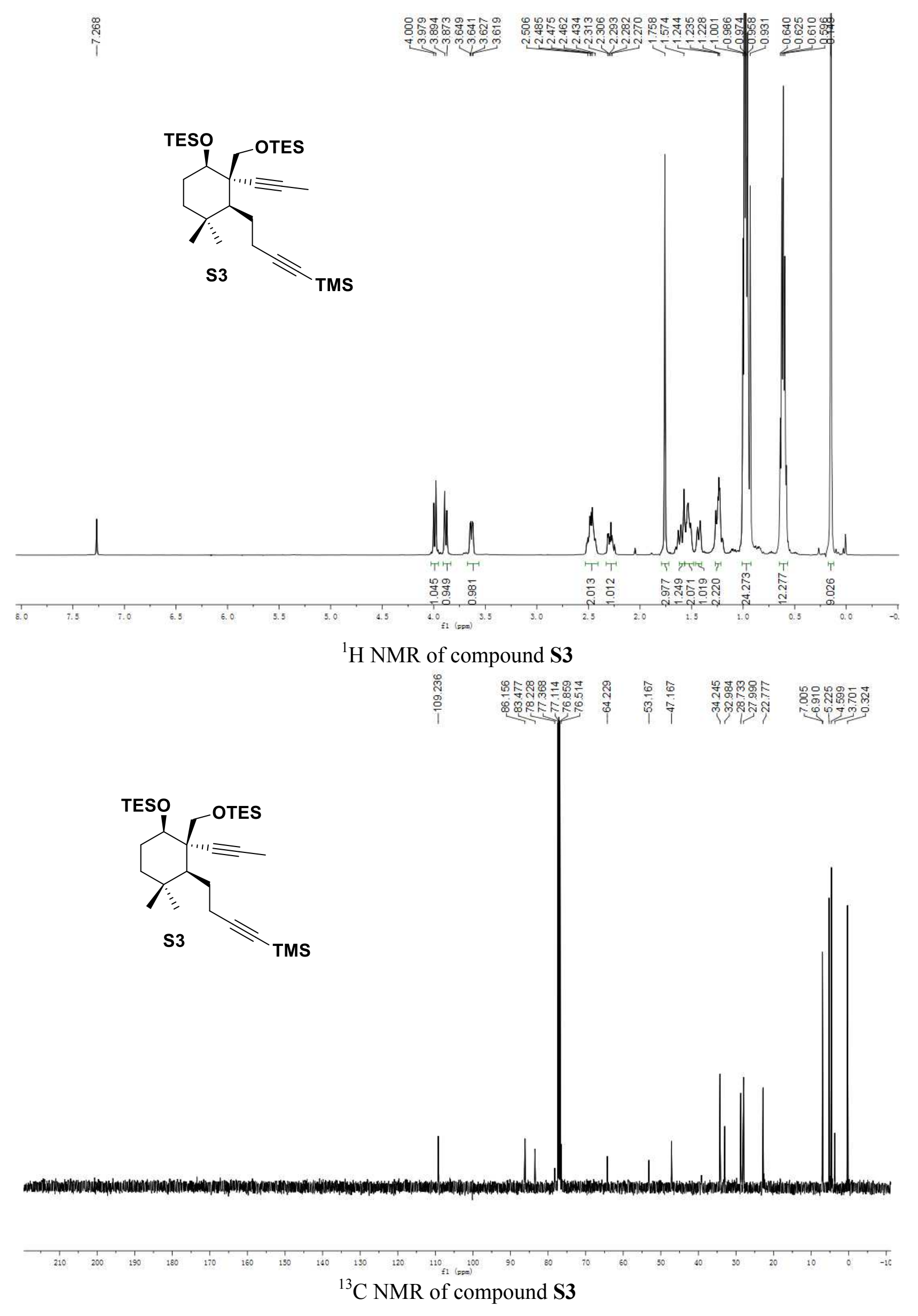



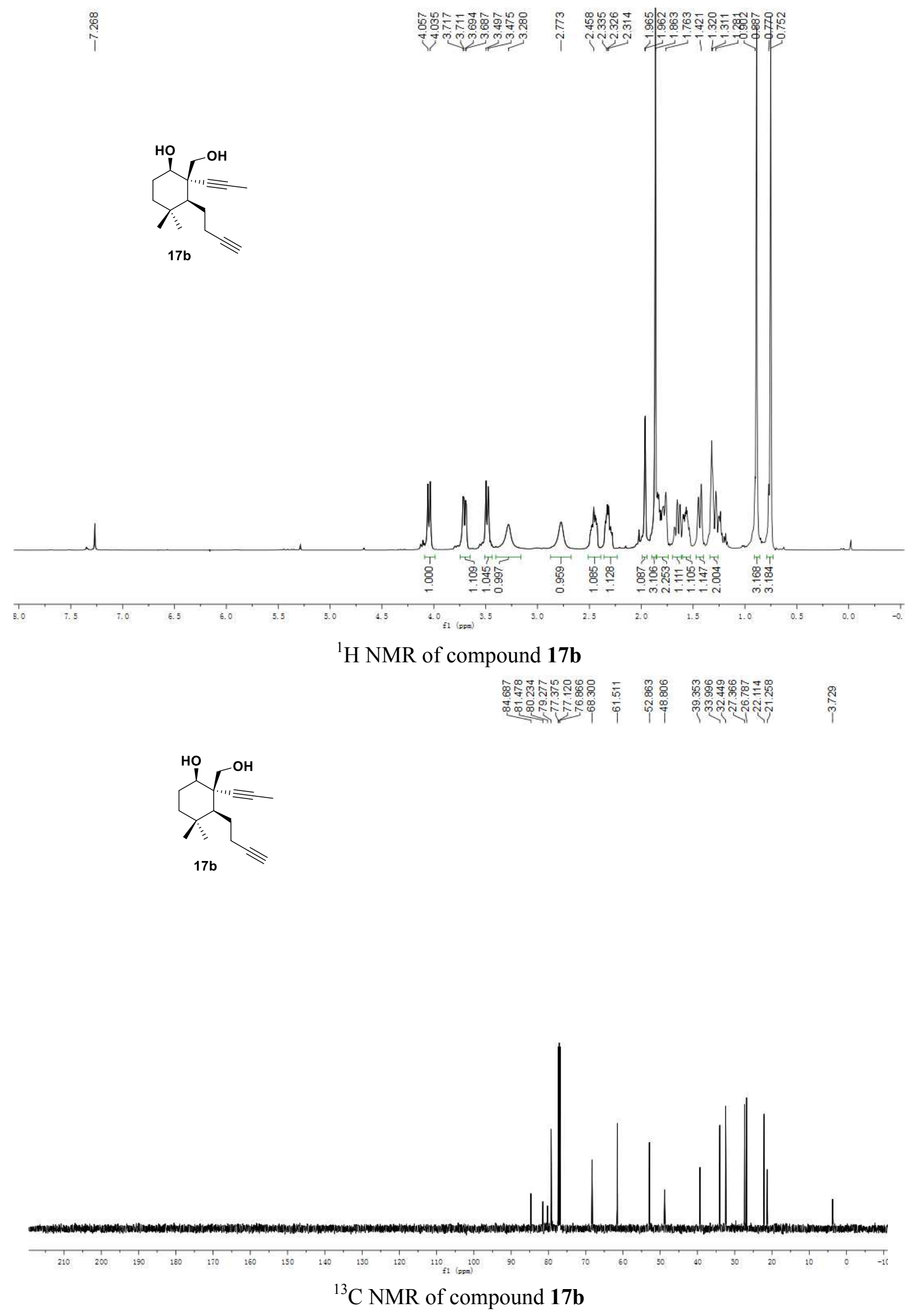

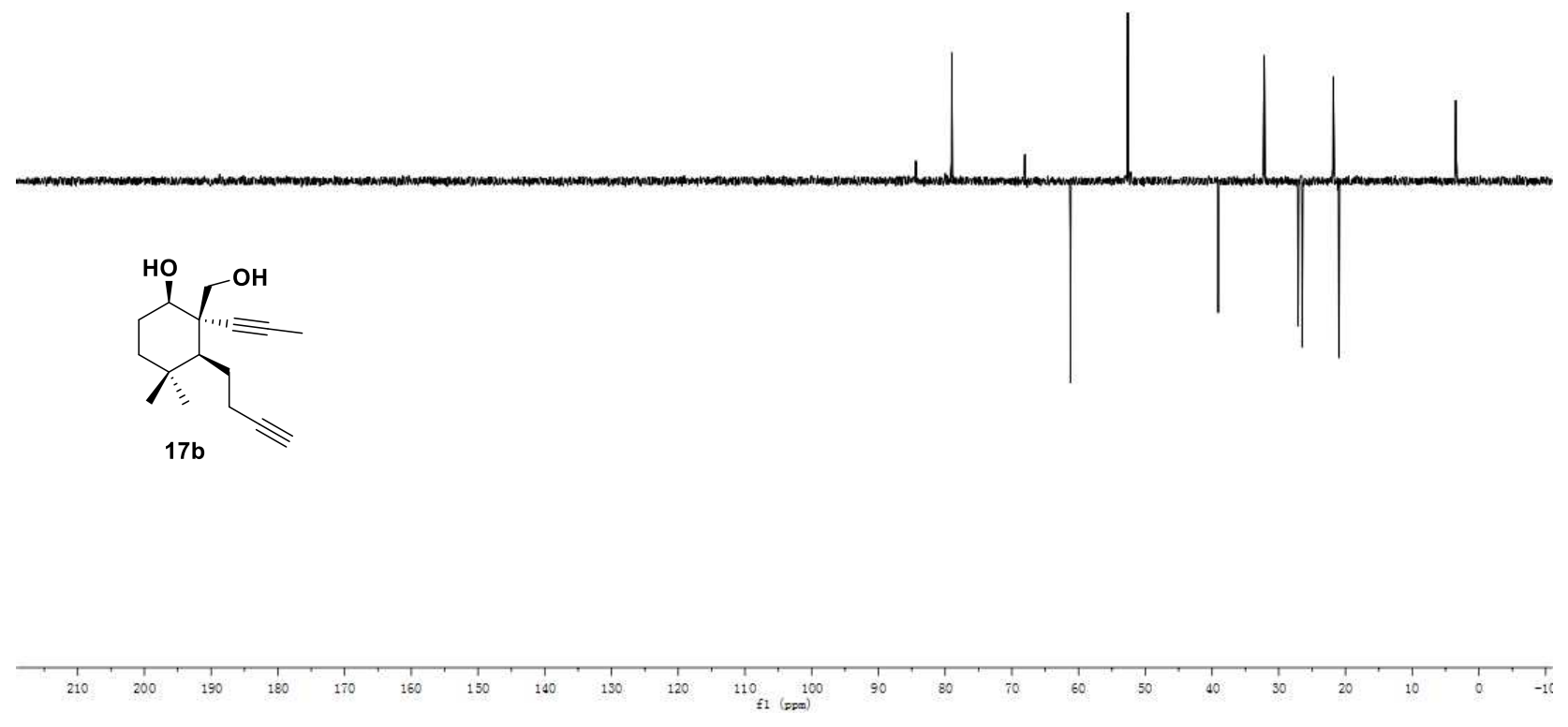

Dept135 NMR of compound 17b

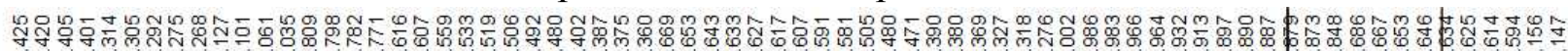

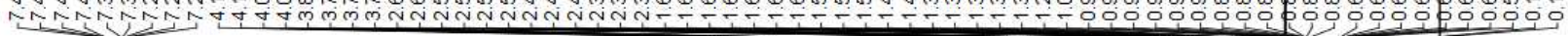

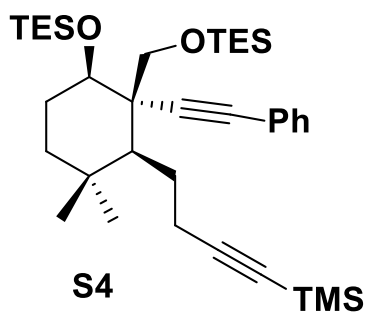

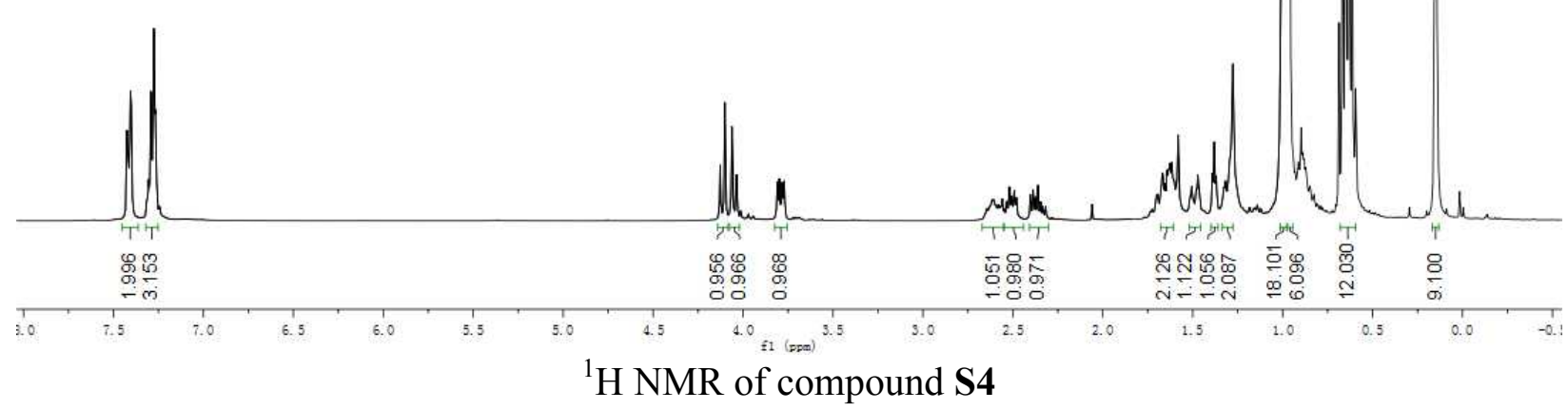




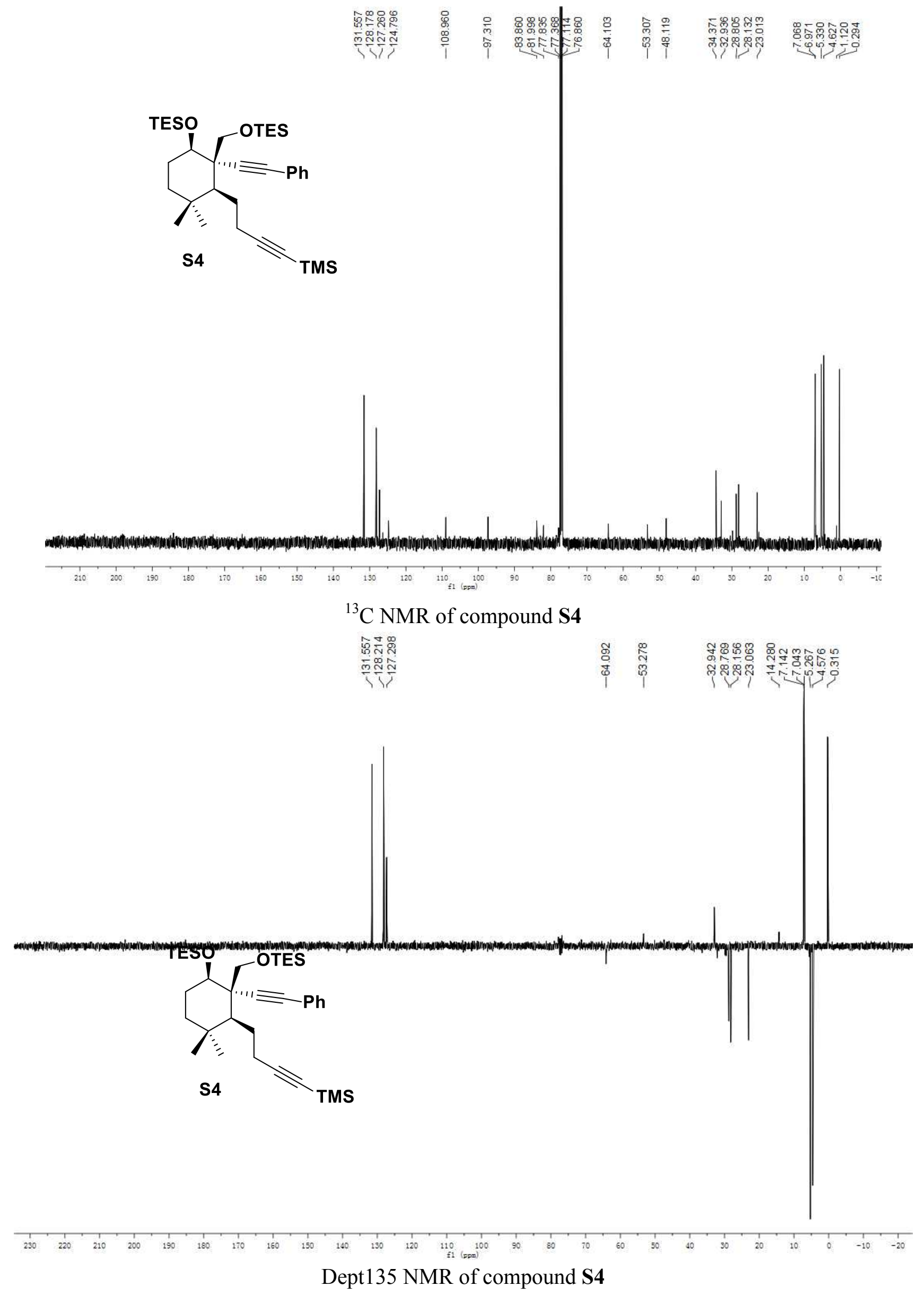



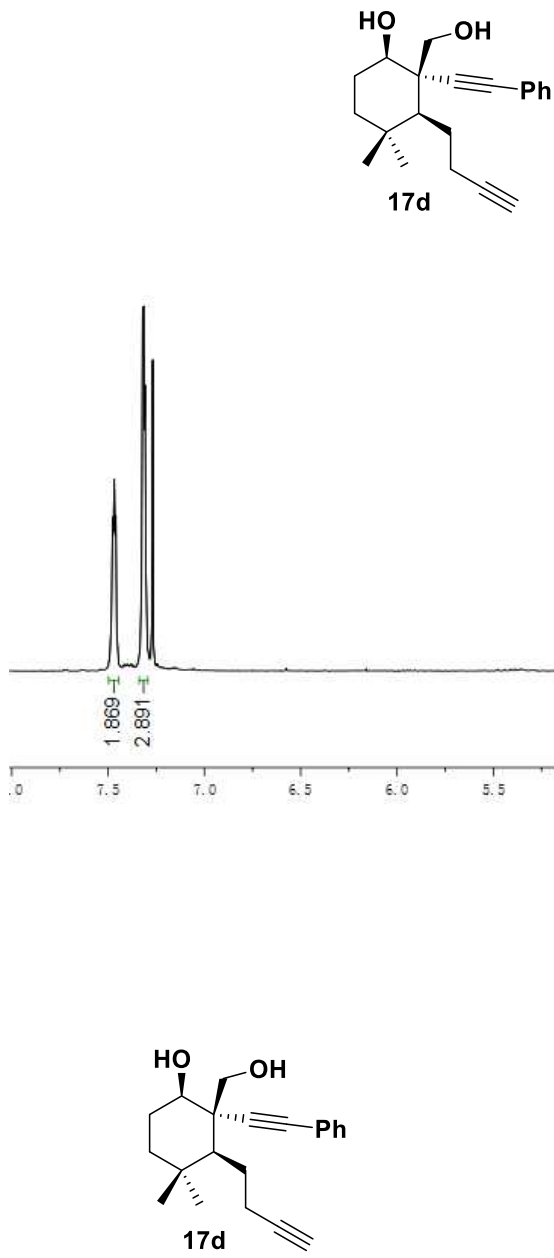

H NMR of compound $\mathbf{1 7 d}$
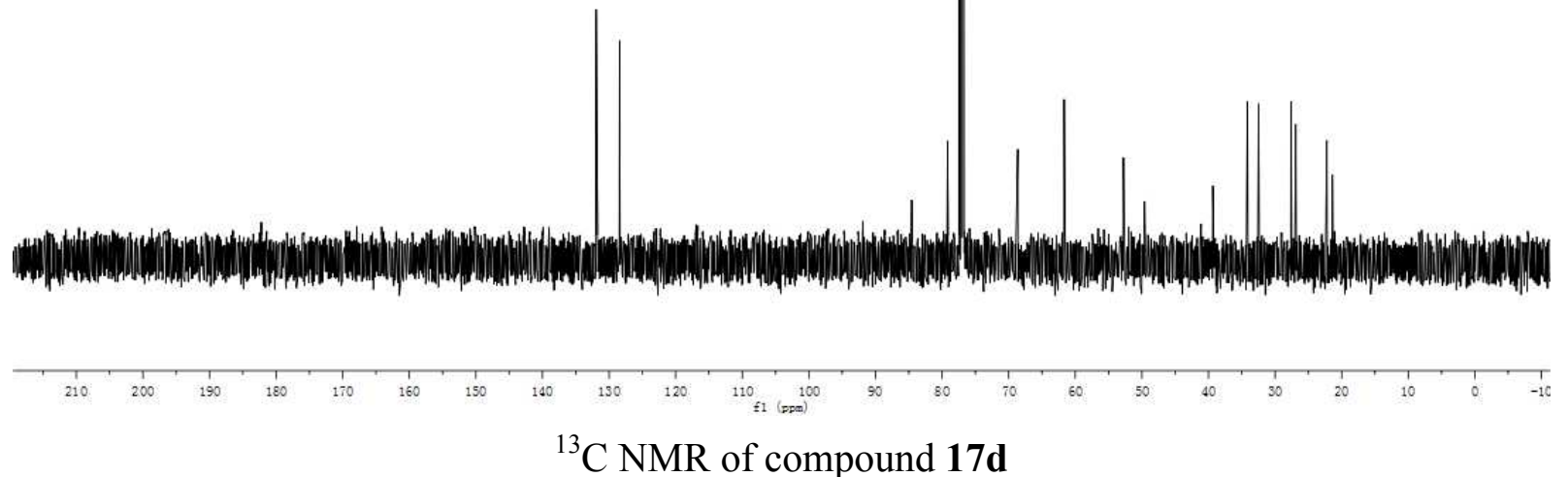

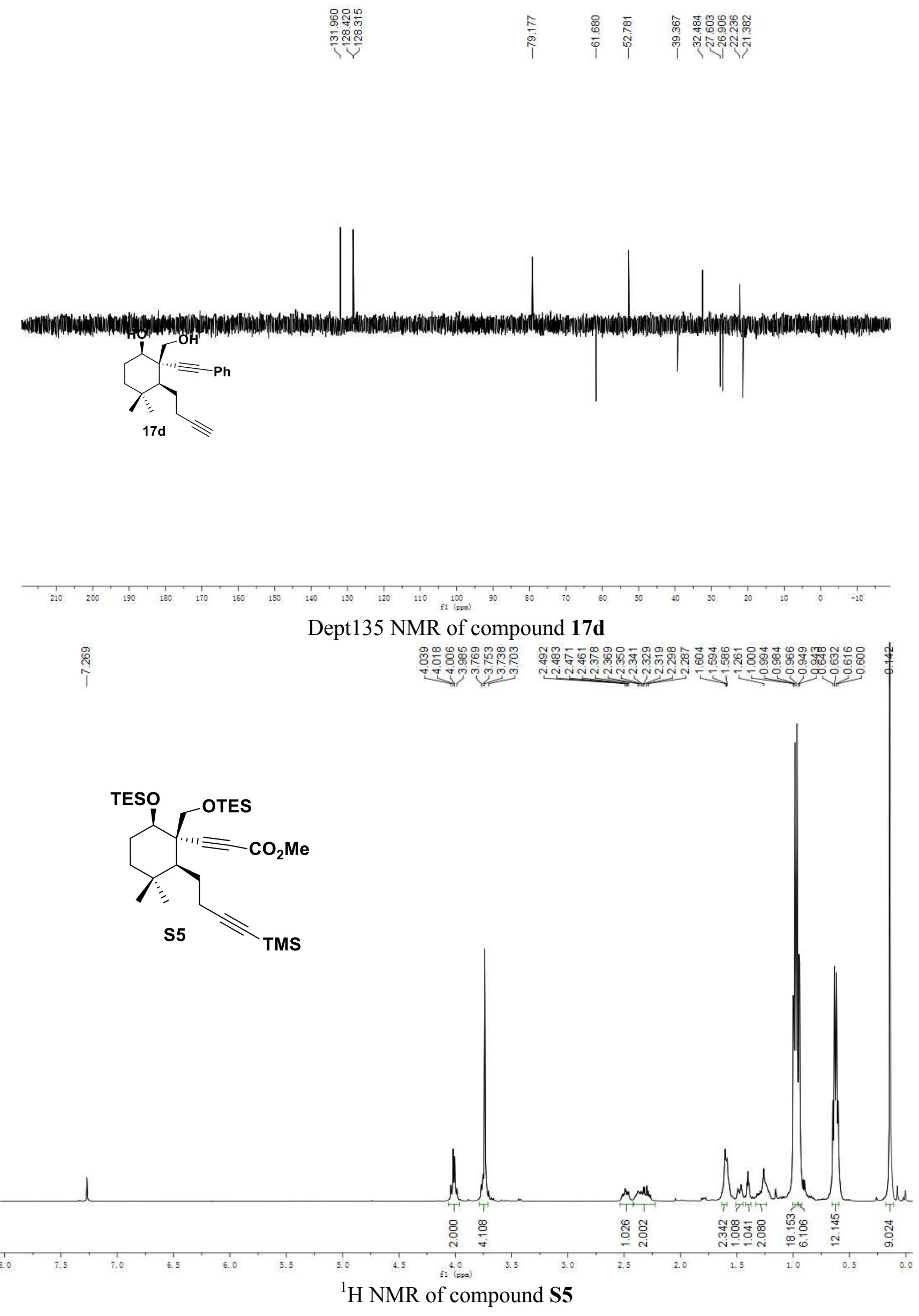


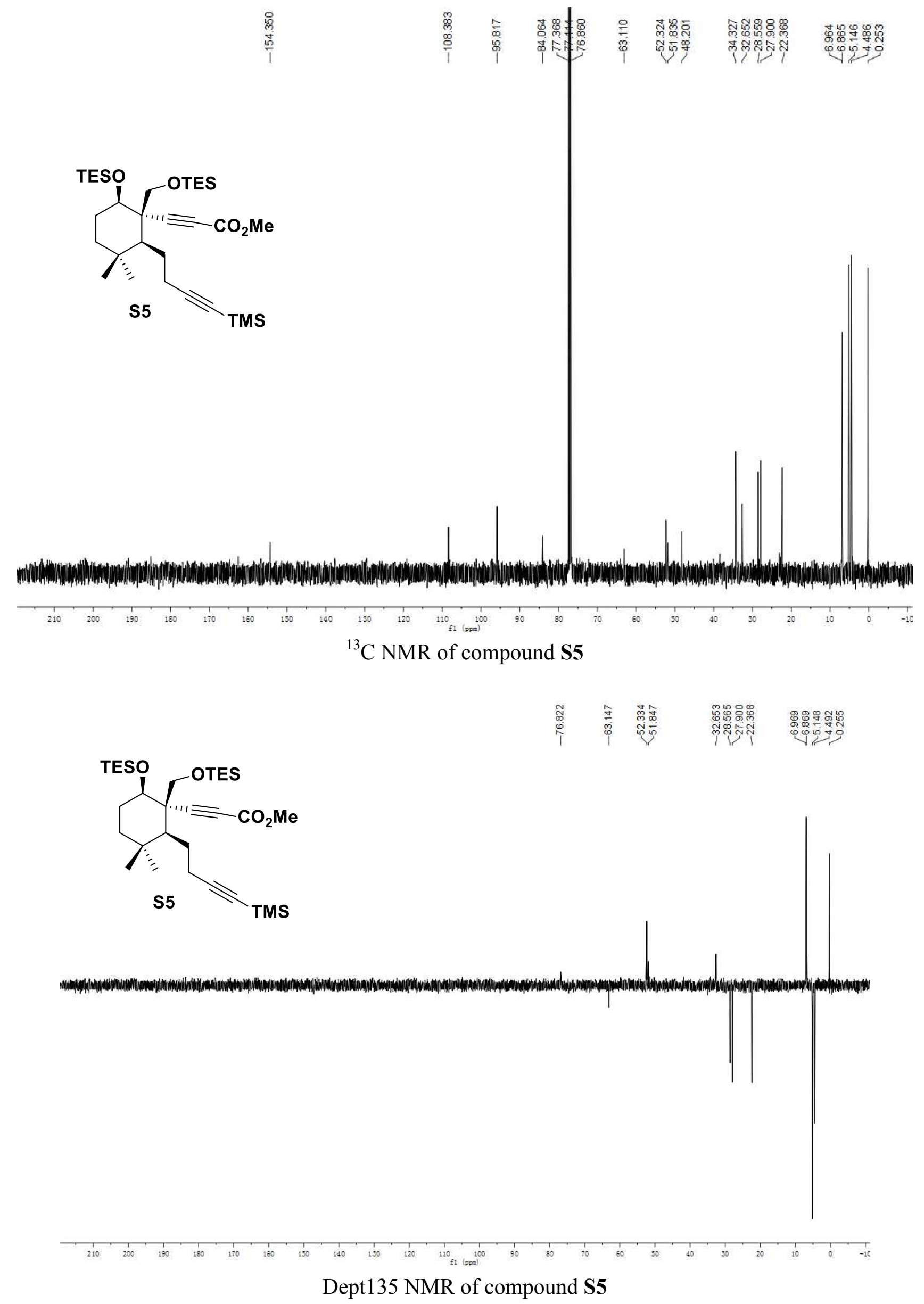



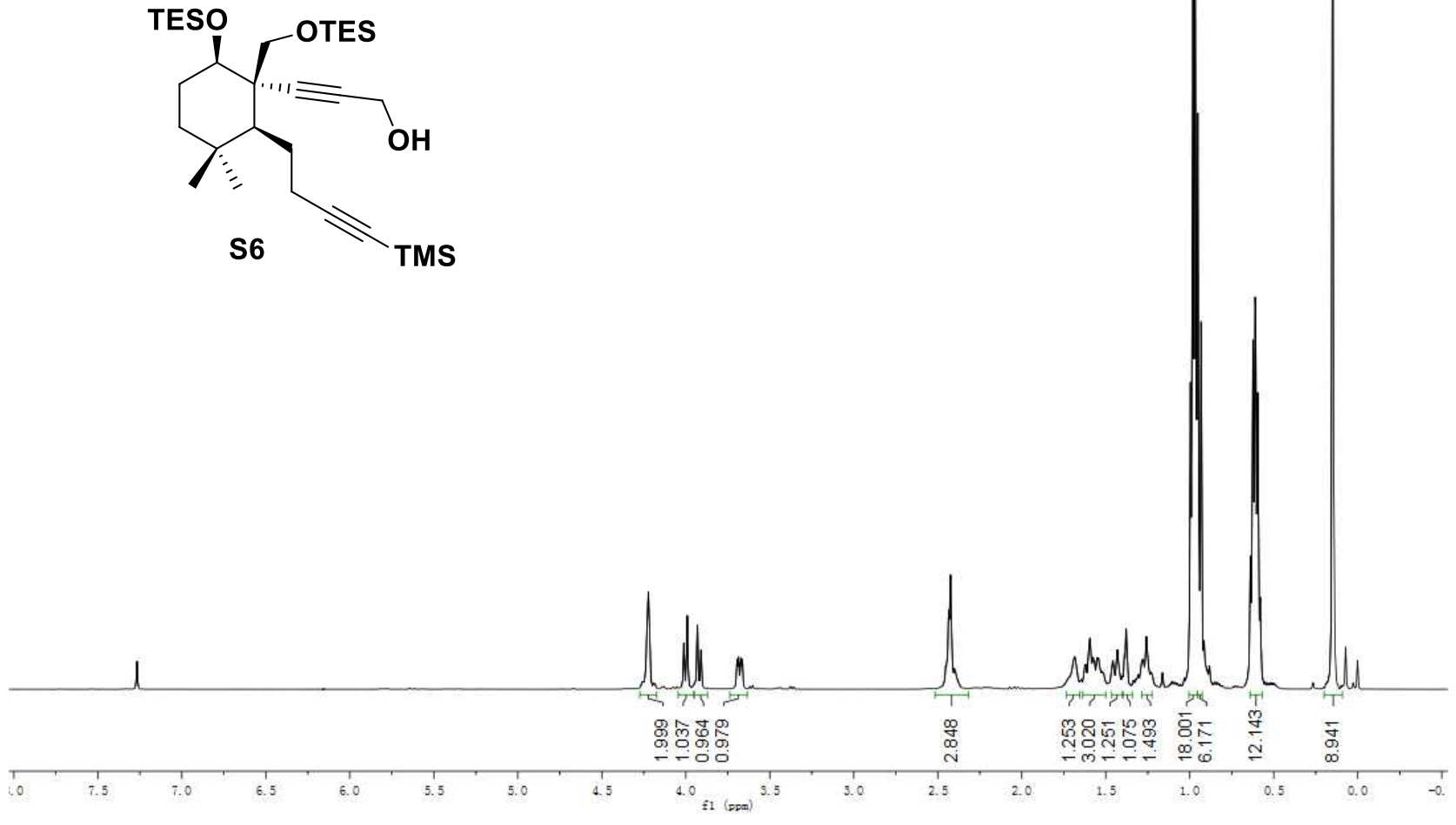

${ }^{1} \mathrm{H}$ NMR of compound $\mathbf{S 6}$

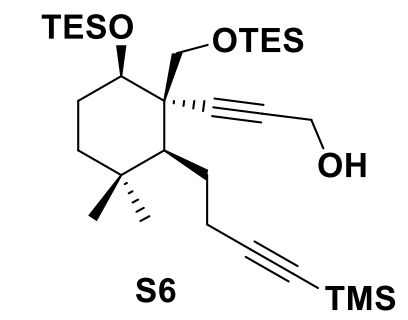

210.

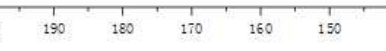

${ }^{13} \mathrm{C}$ NMR of compound $\mathbf{S 6}$ 

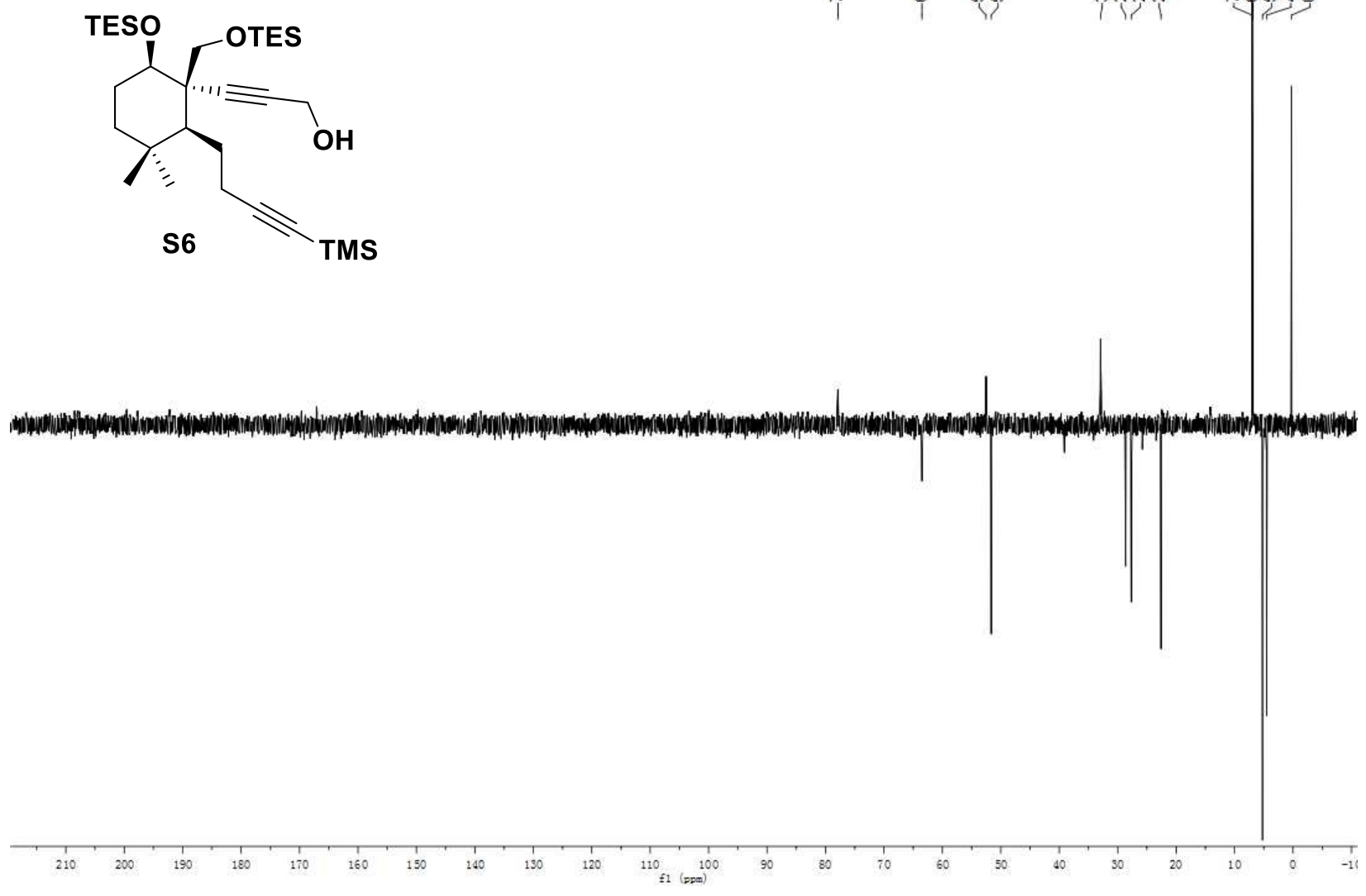

Dept135 NMR of compound S6

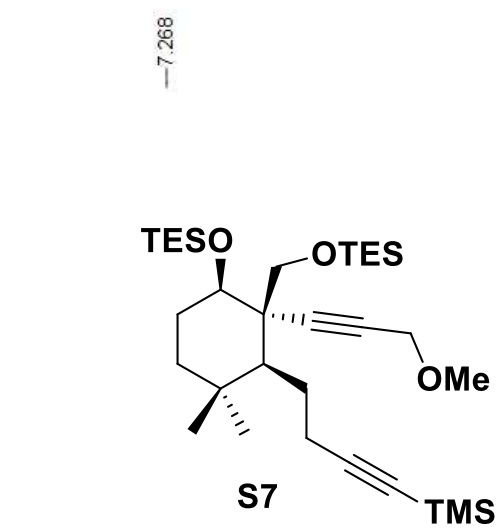

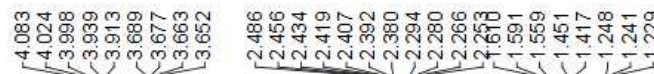




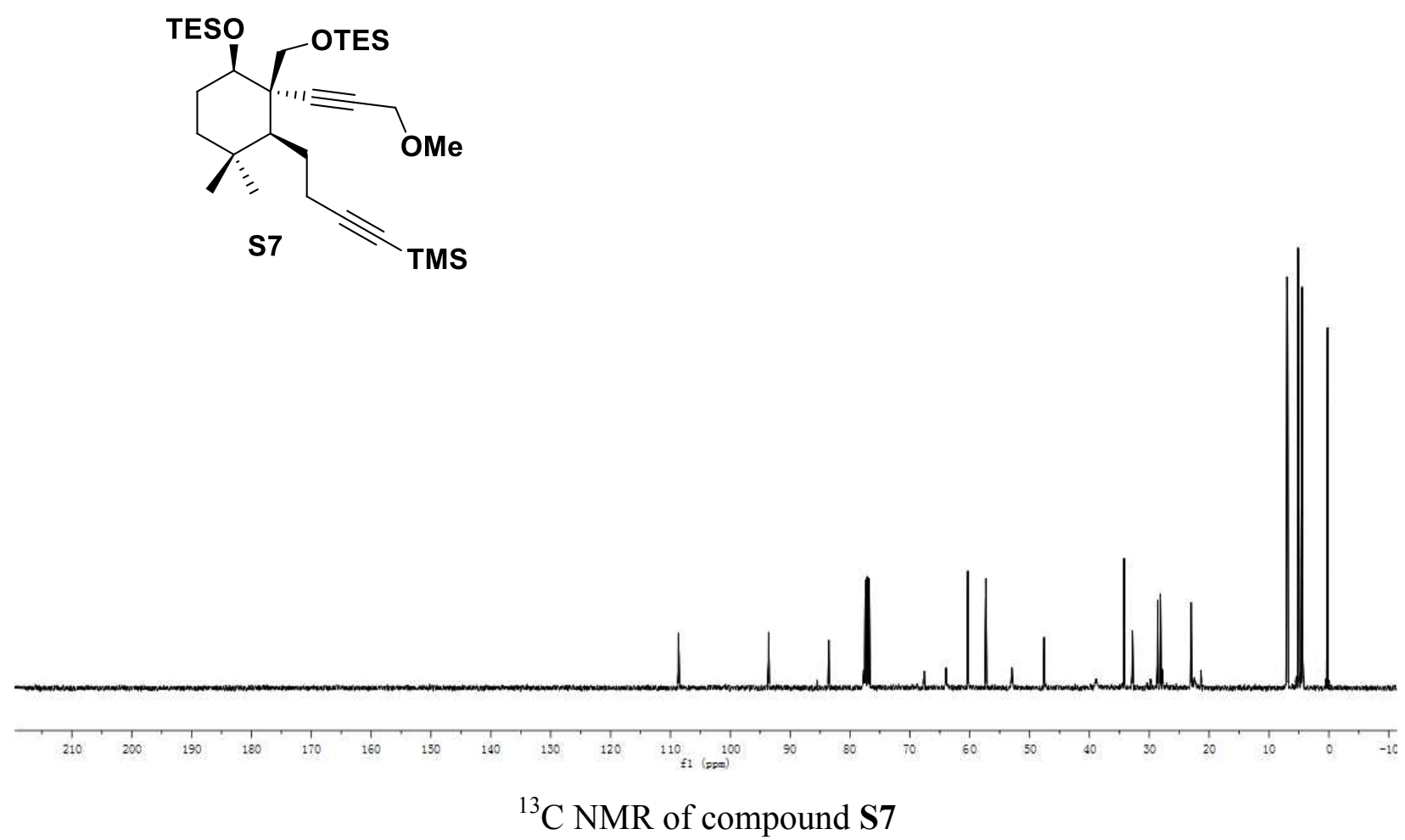

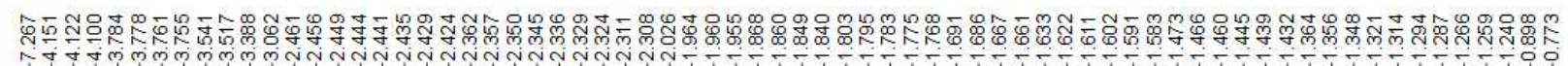<smiles>C#CCCC1C(C)CCC(O)C1(C#CCO)CO</smiles>

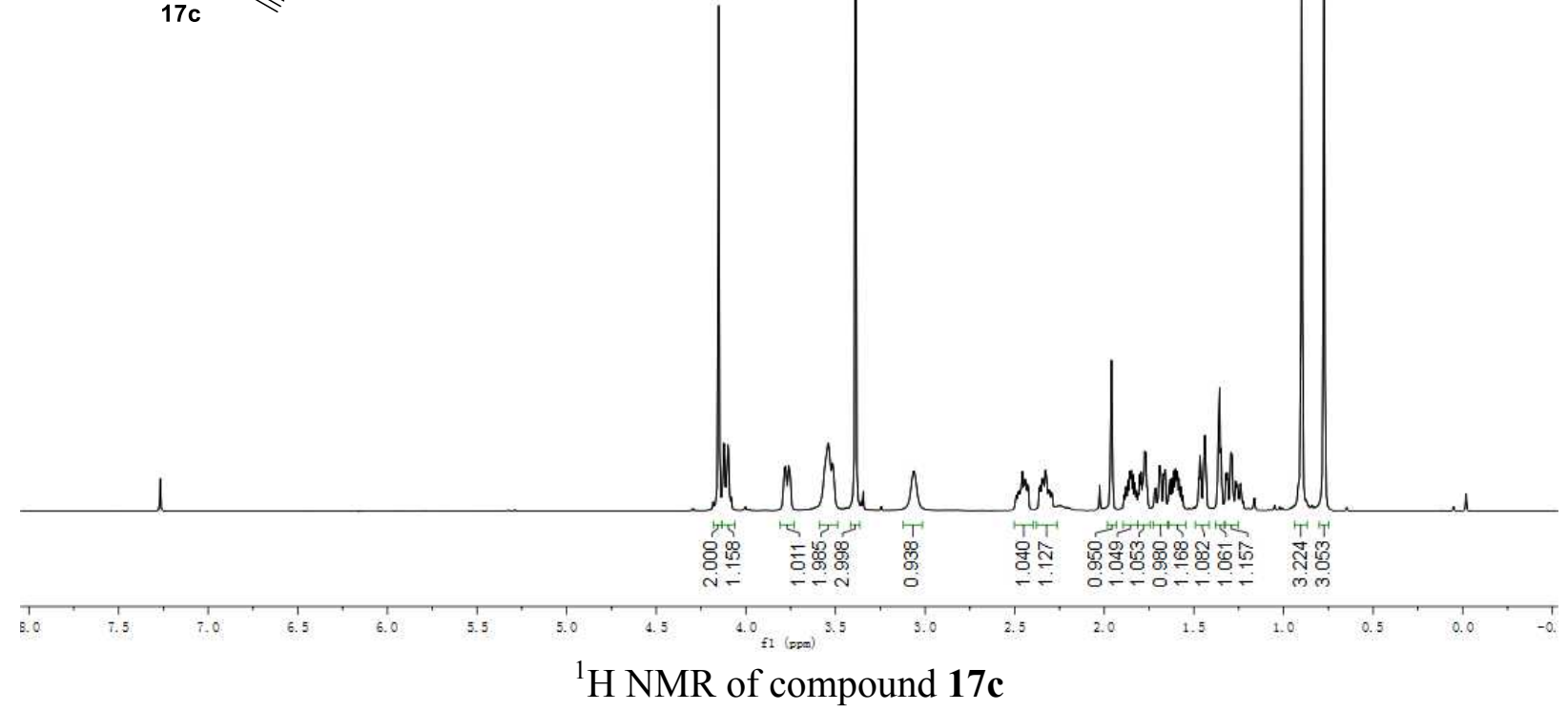


$\underbrace{\mathrm{OMe}}_{17 \mathrm{c}}$
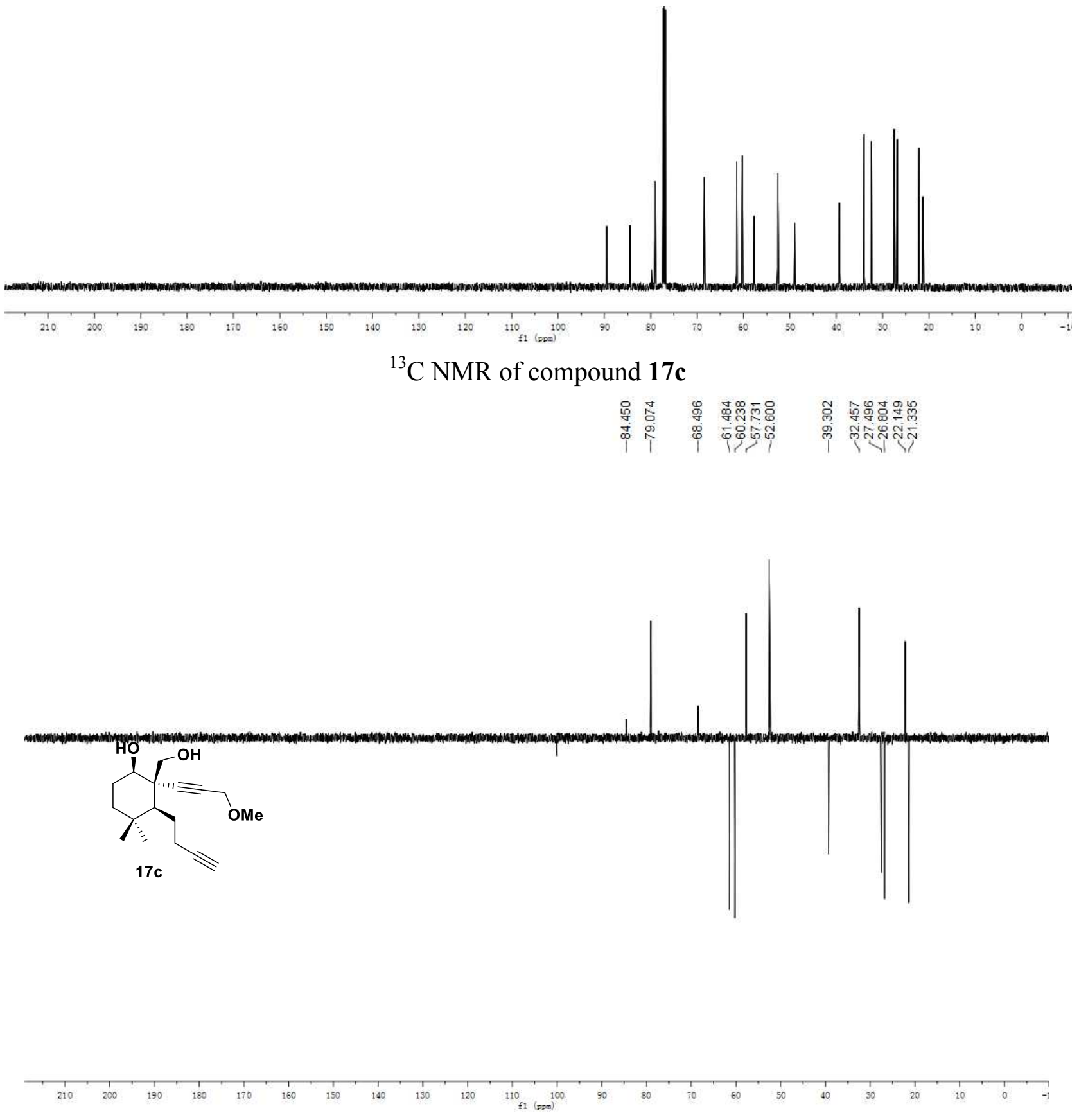

Dept135 NMR of compound 17c 

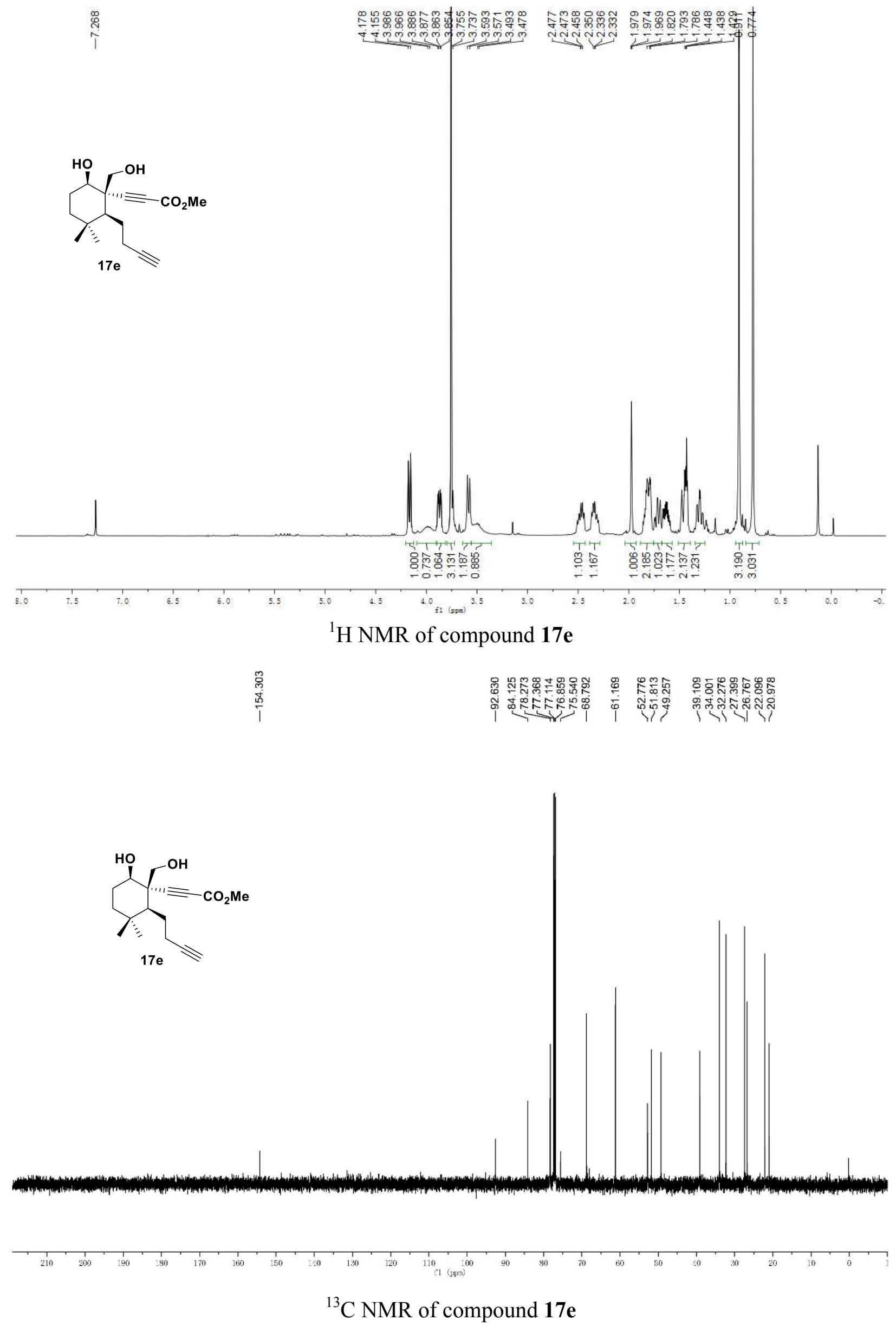

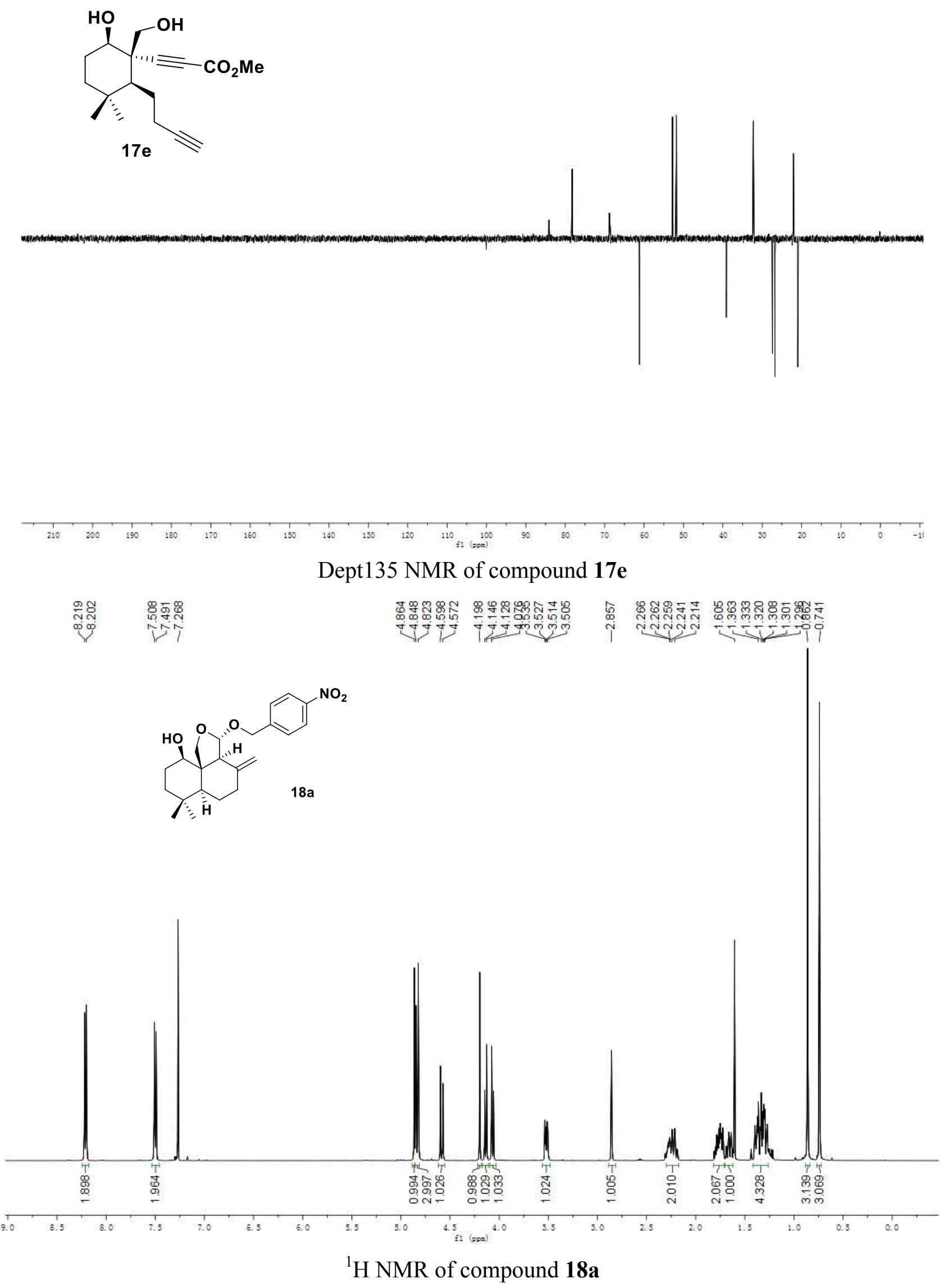


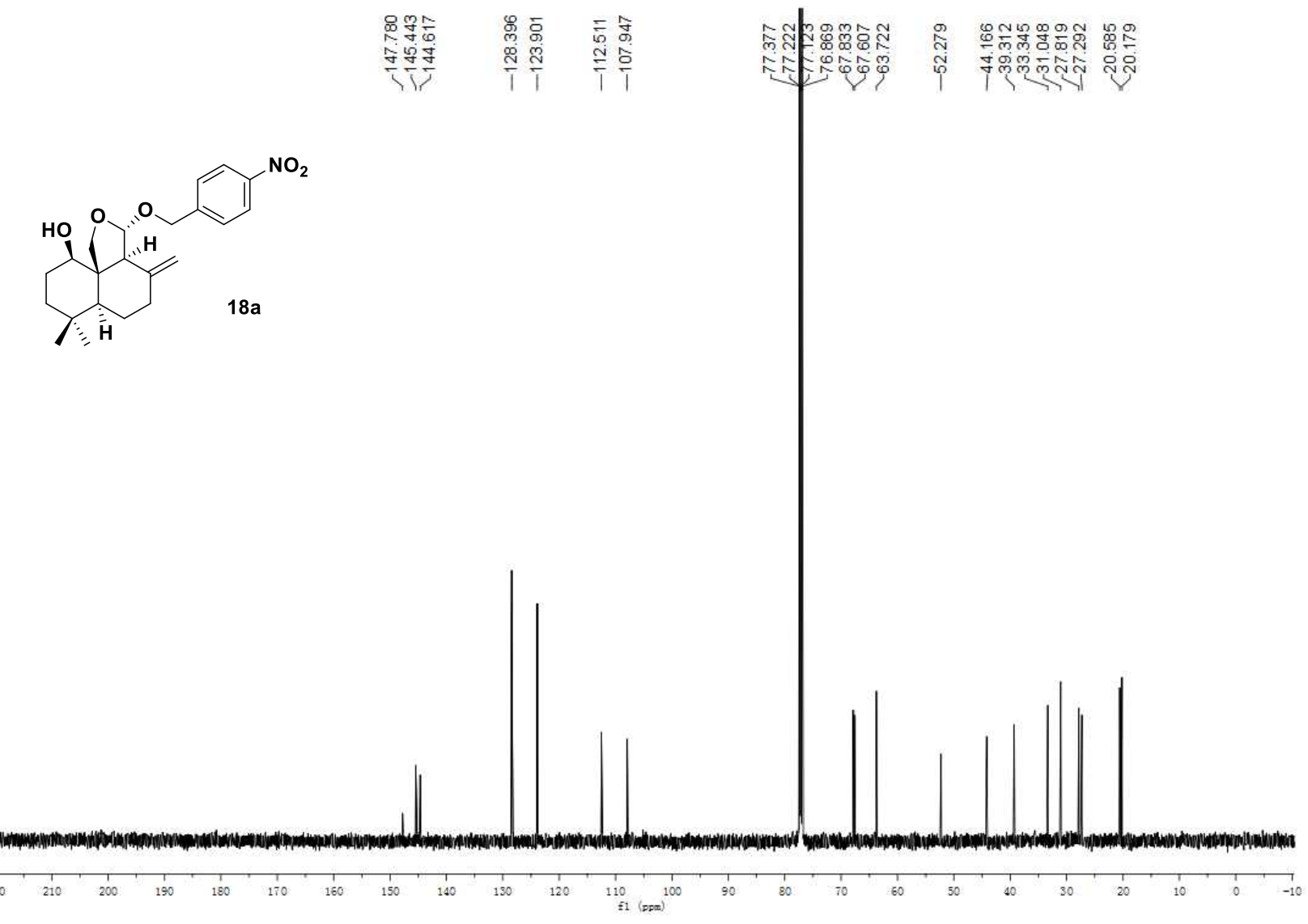

${ }^{13} \mathrm{C}$ NMR of compound 18a

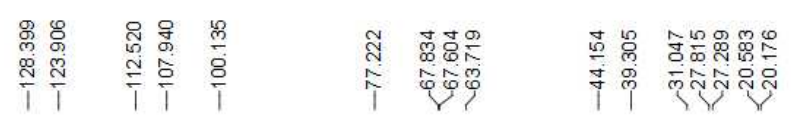
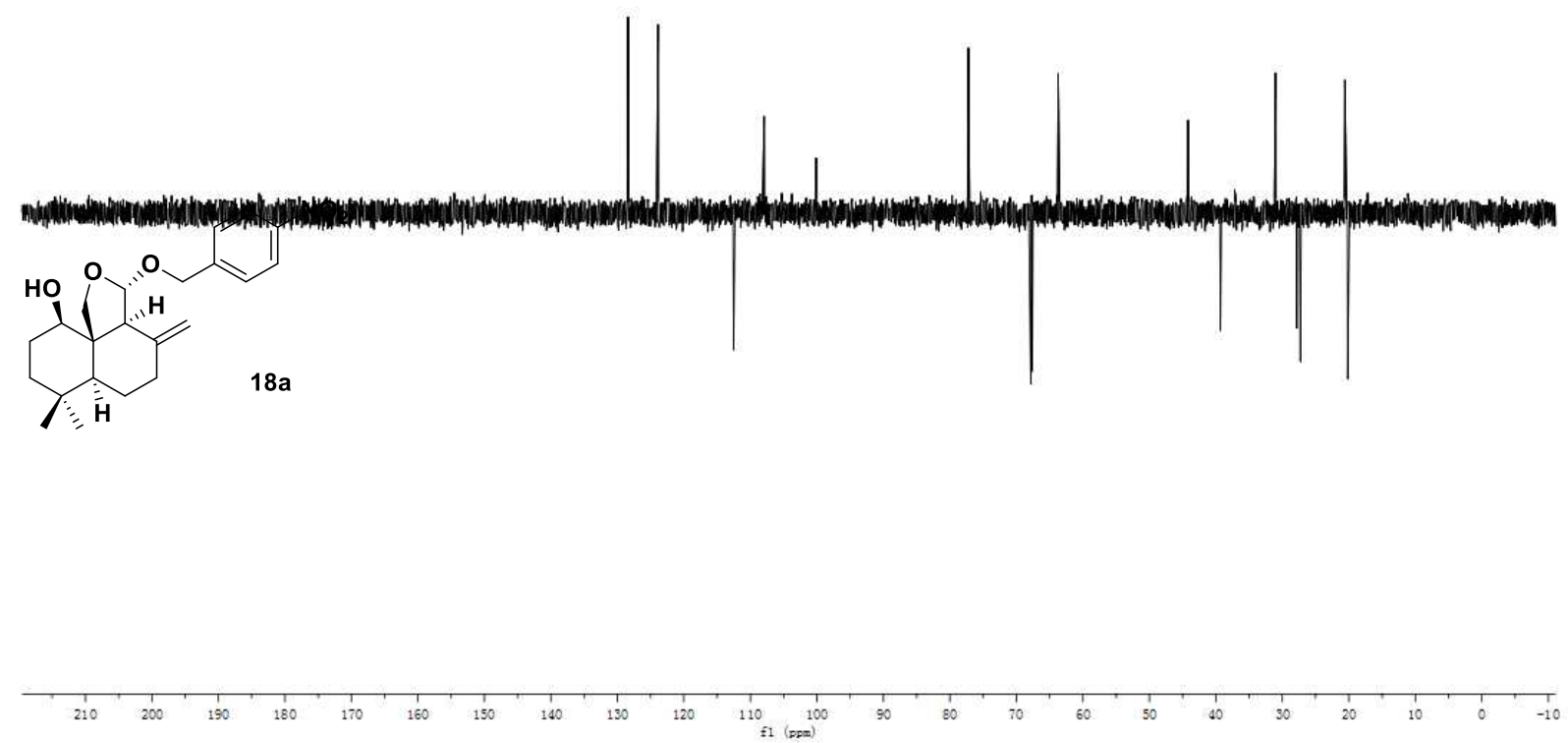

Dept135 NMR of compound 18a 

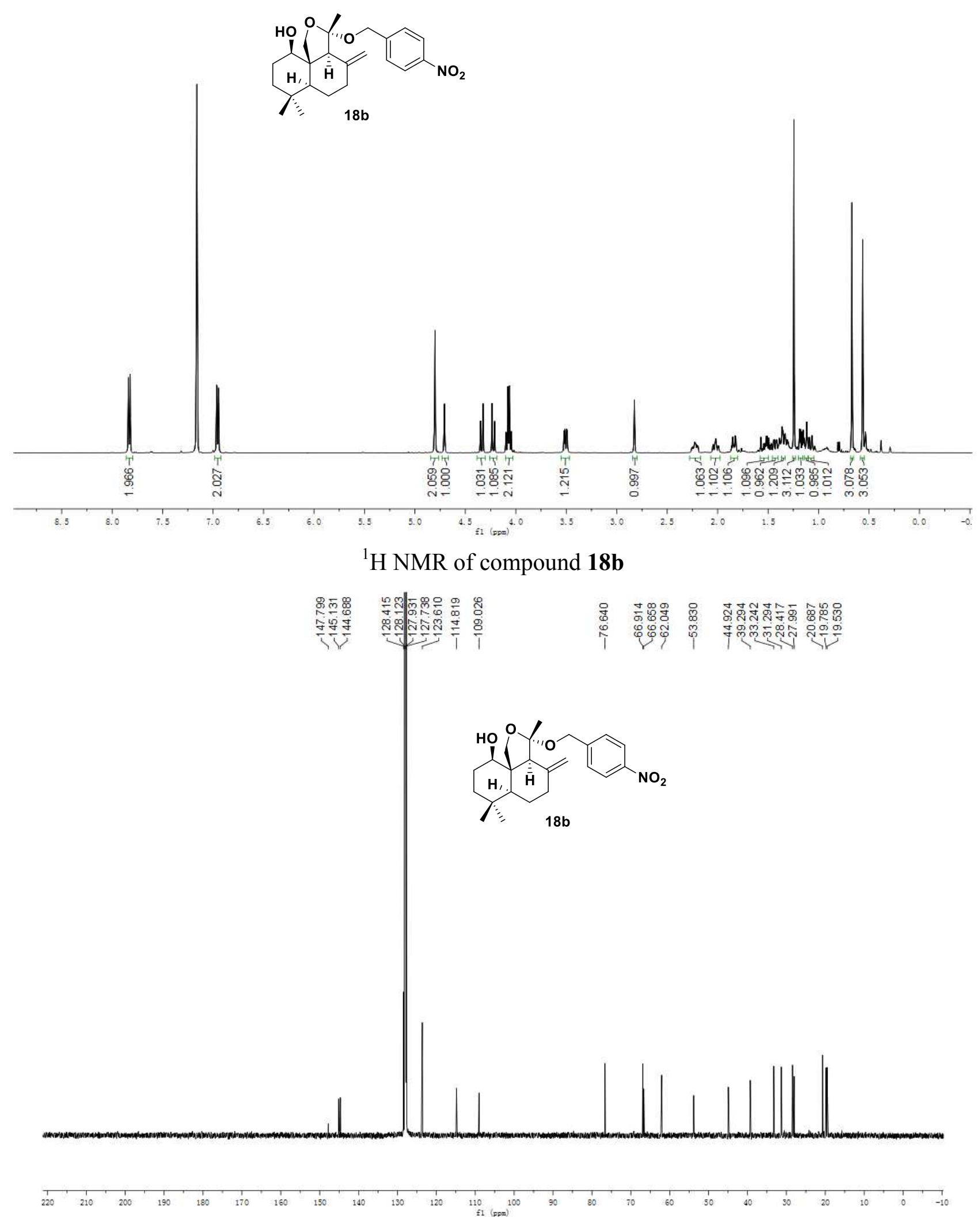

${ }^{13} \mathrm{C}$ NMR of compound $\mathbf{1 8 b}$ 

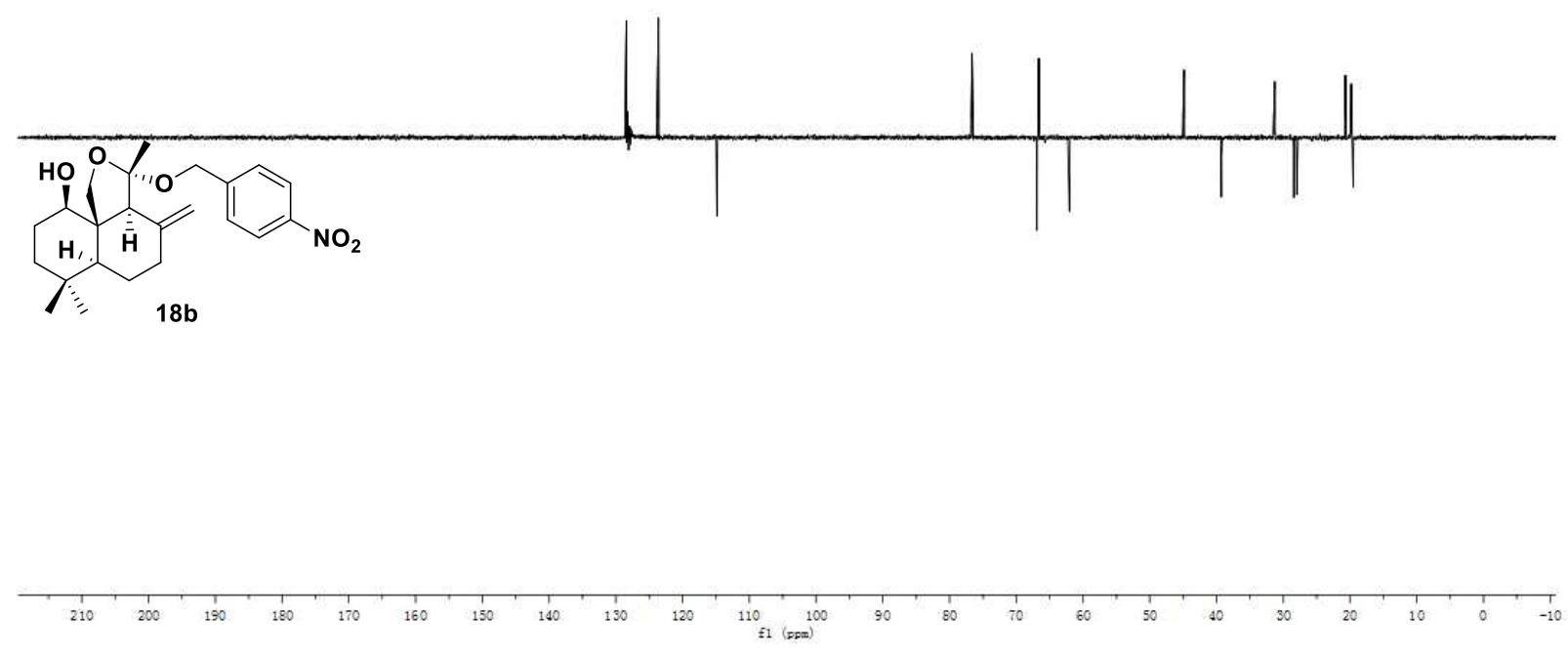

Dept135 NMR of compound $\mathbf{1 8 b}$

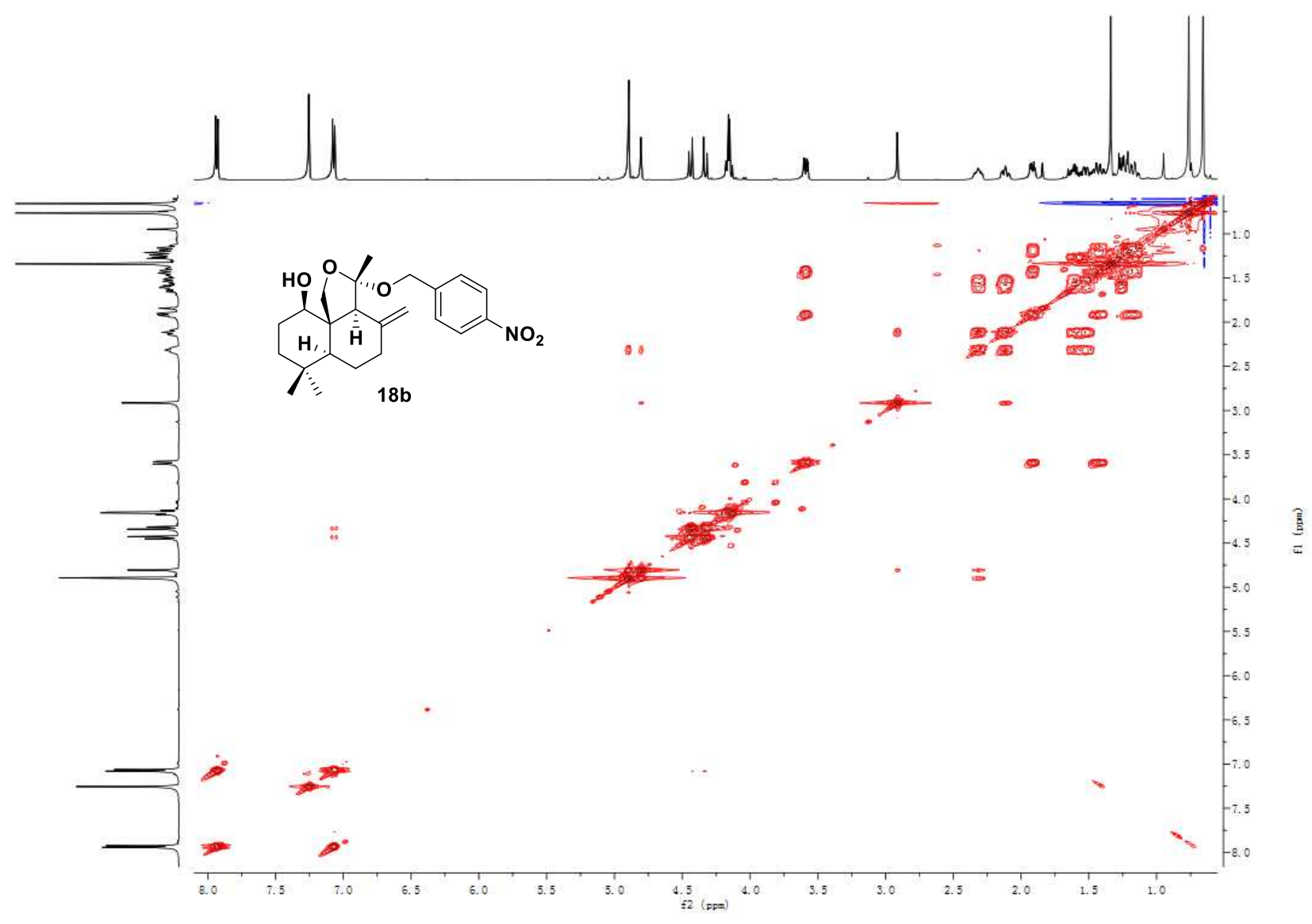

COSY NMR of compound $\mathbf{1 8 b}$ 


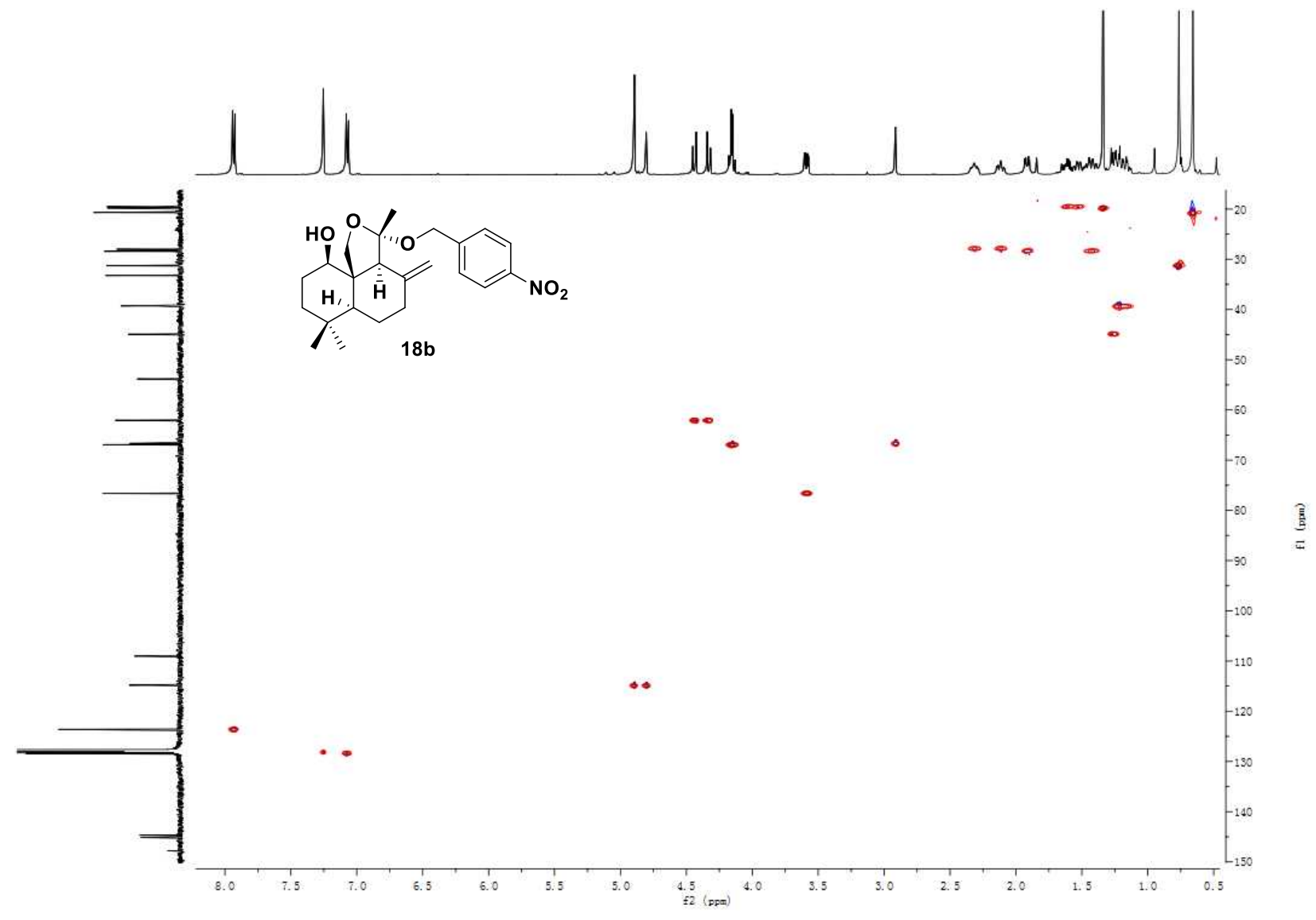

HSQC NMR of compound $\mathbf{1 8 b}$

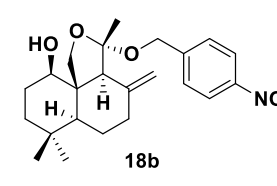




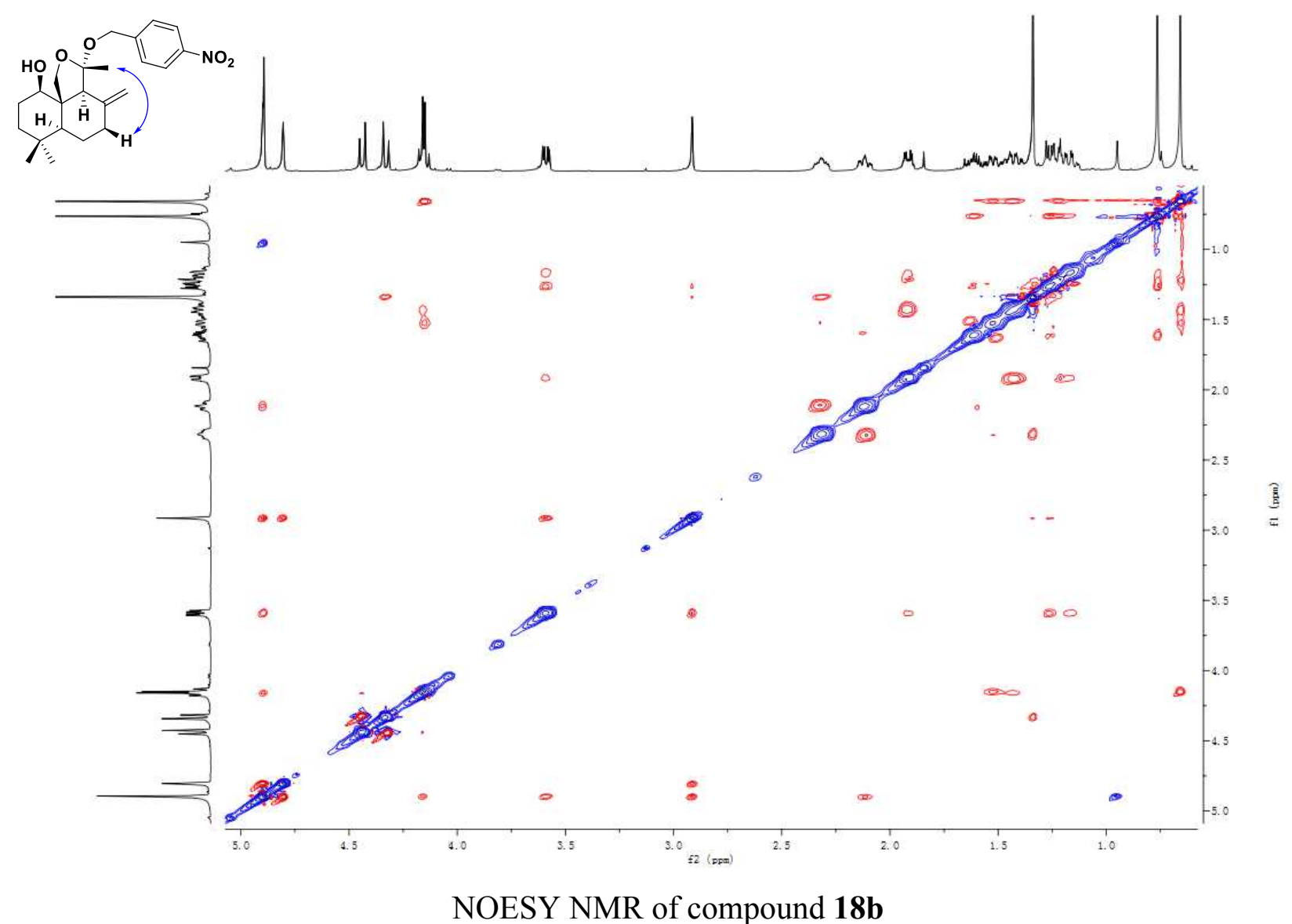

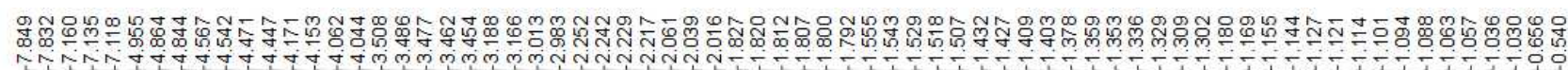

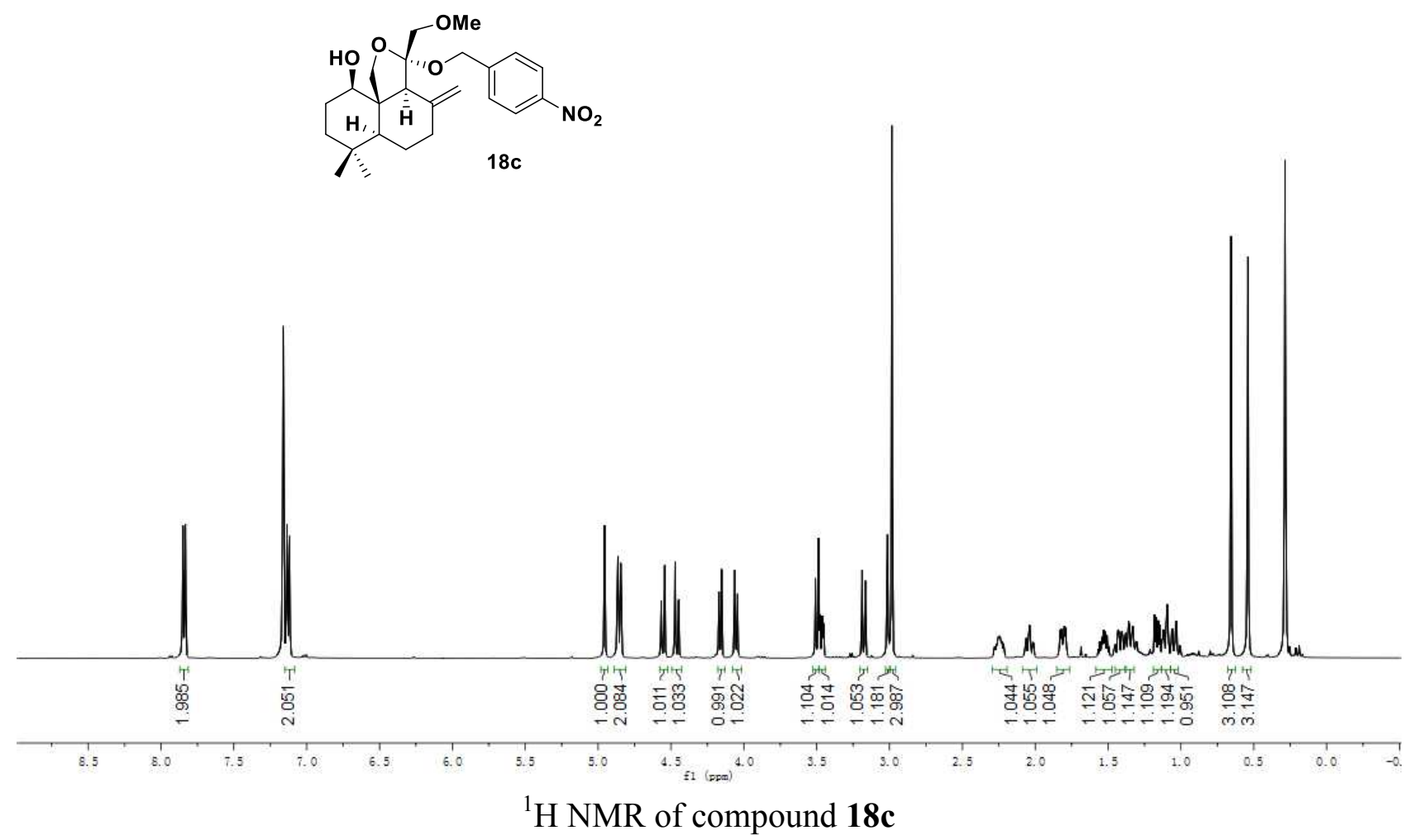



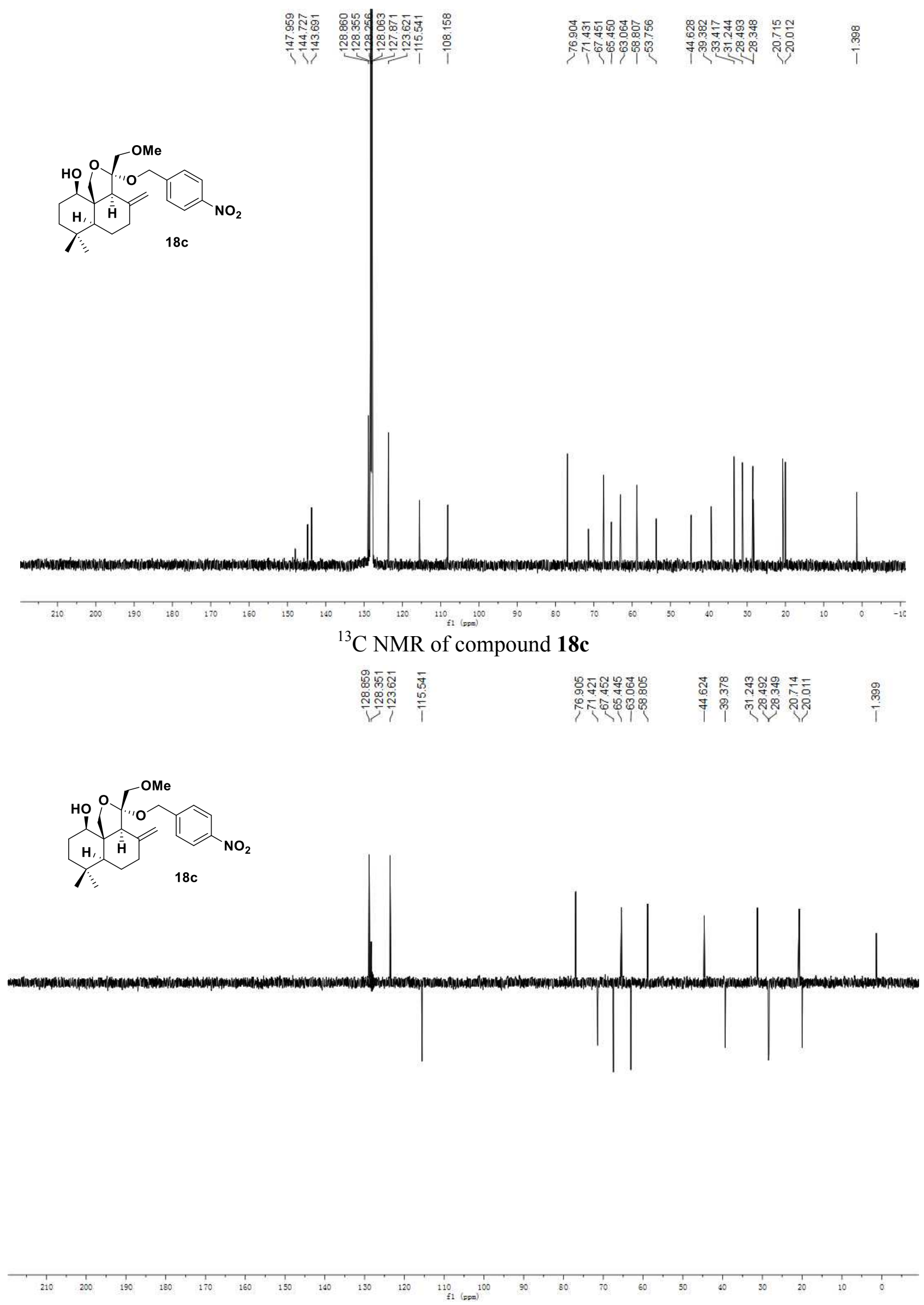

Dept135 NMR of compound 18c 


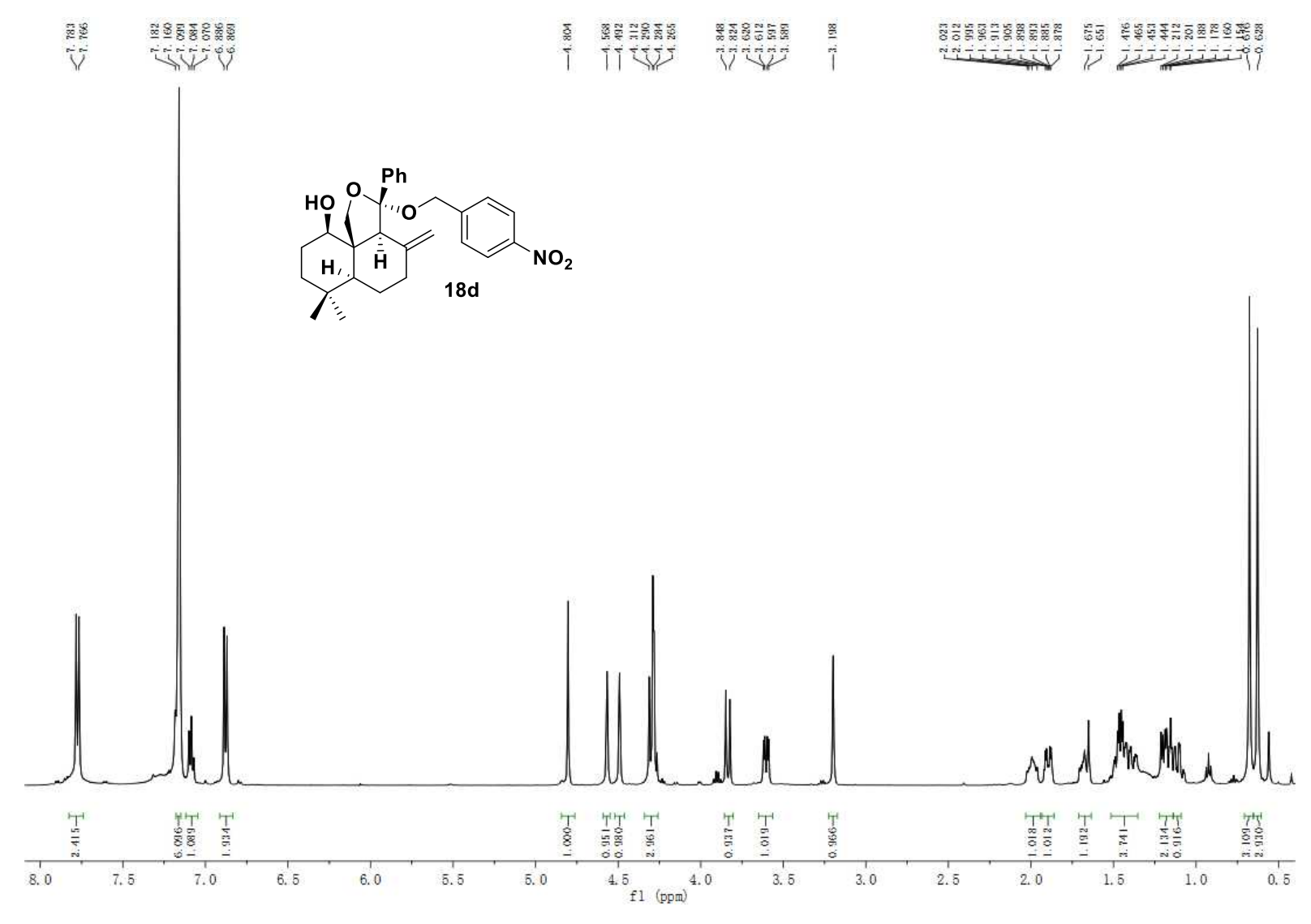

${ }^{1} \mathrm{H}$ NMR of compound 18d

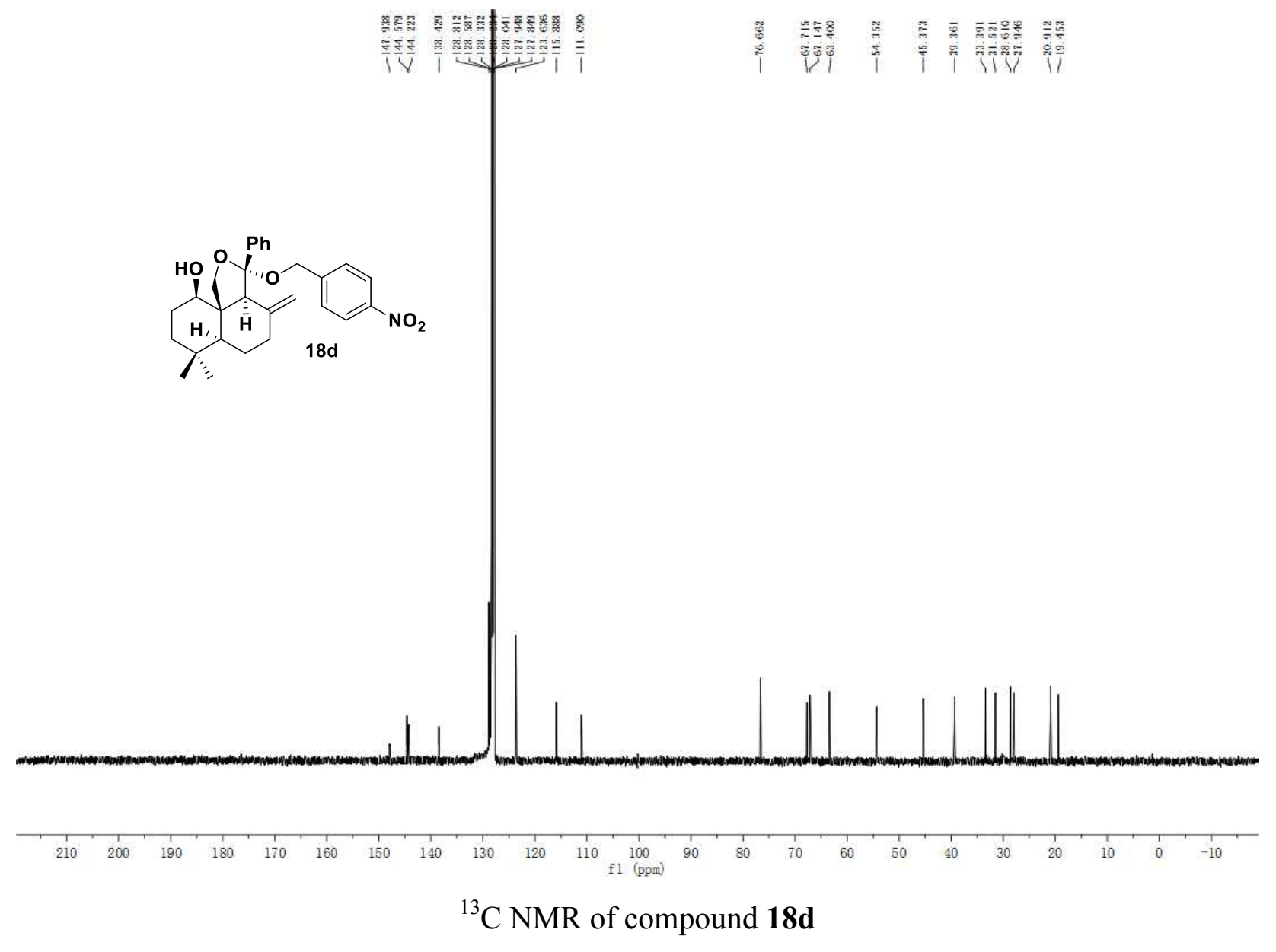




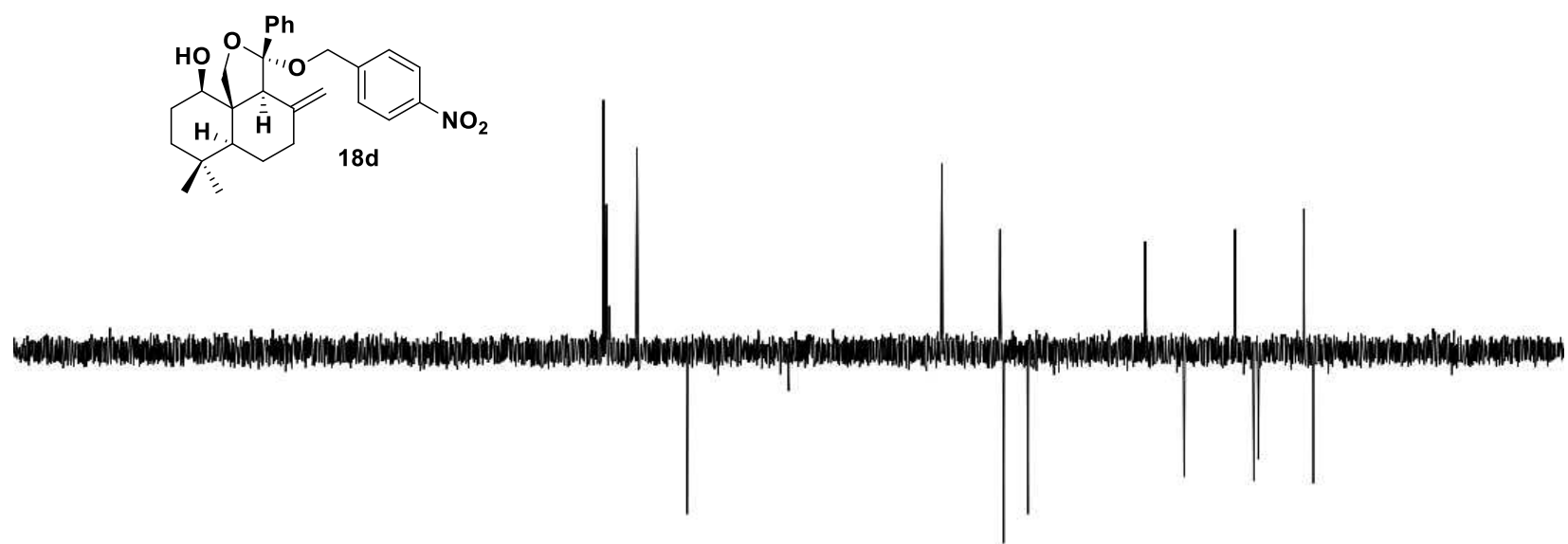

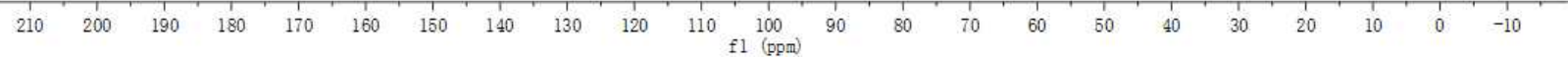

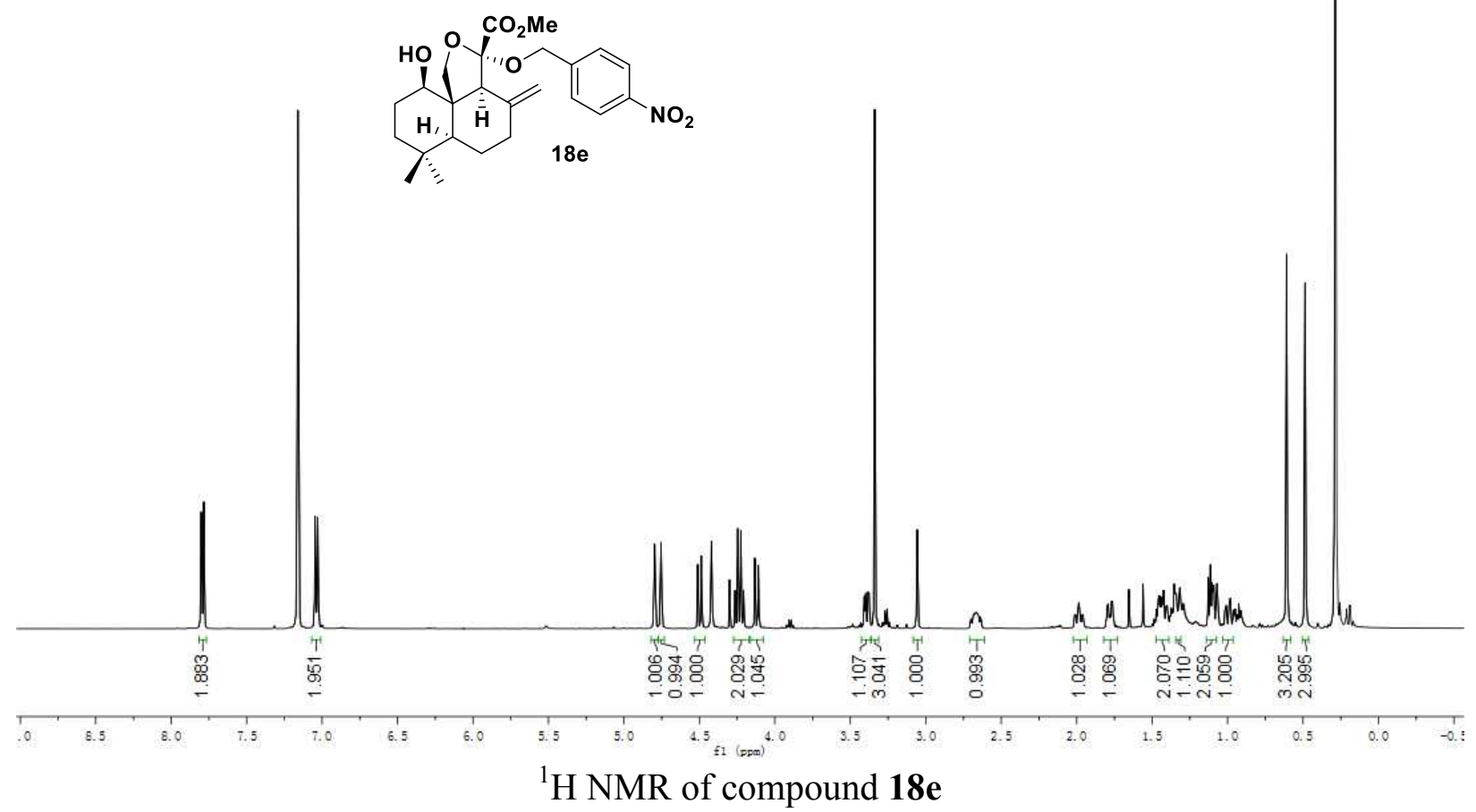



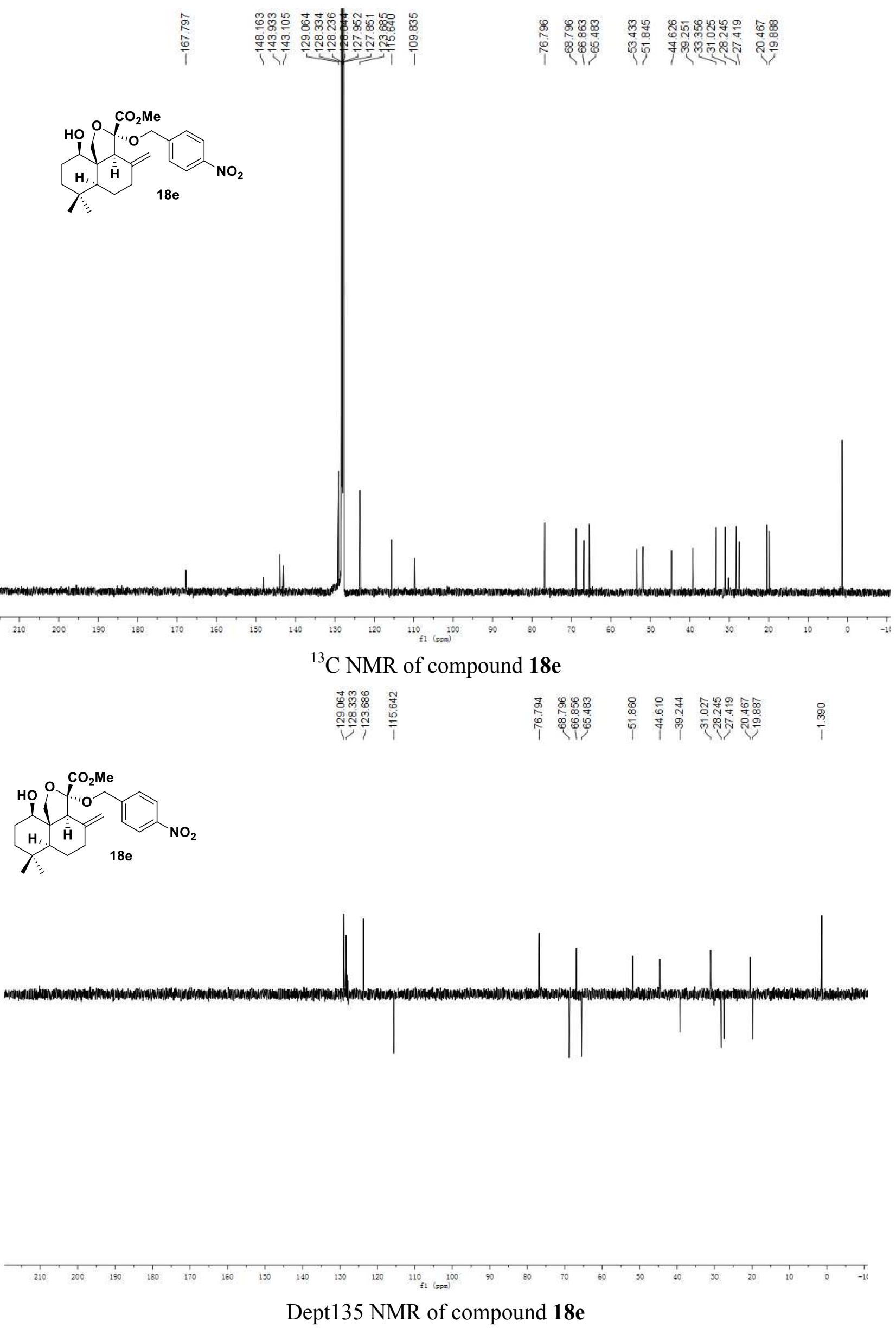

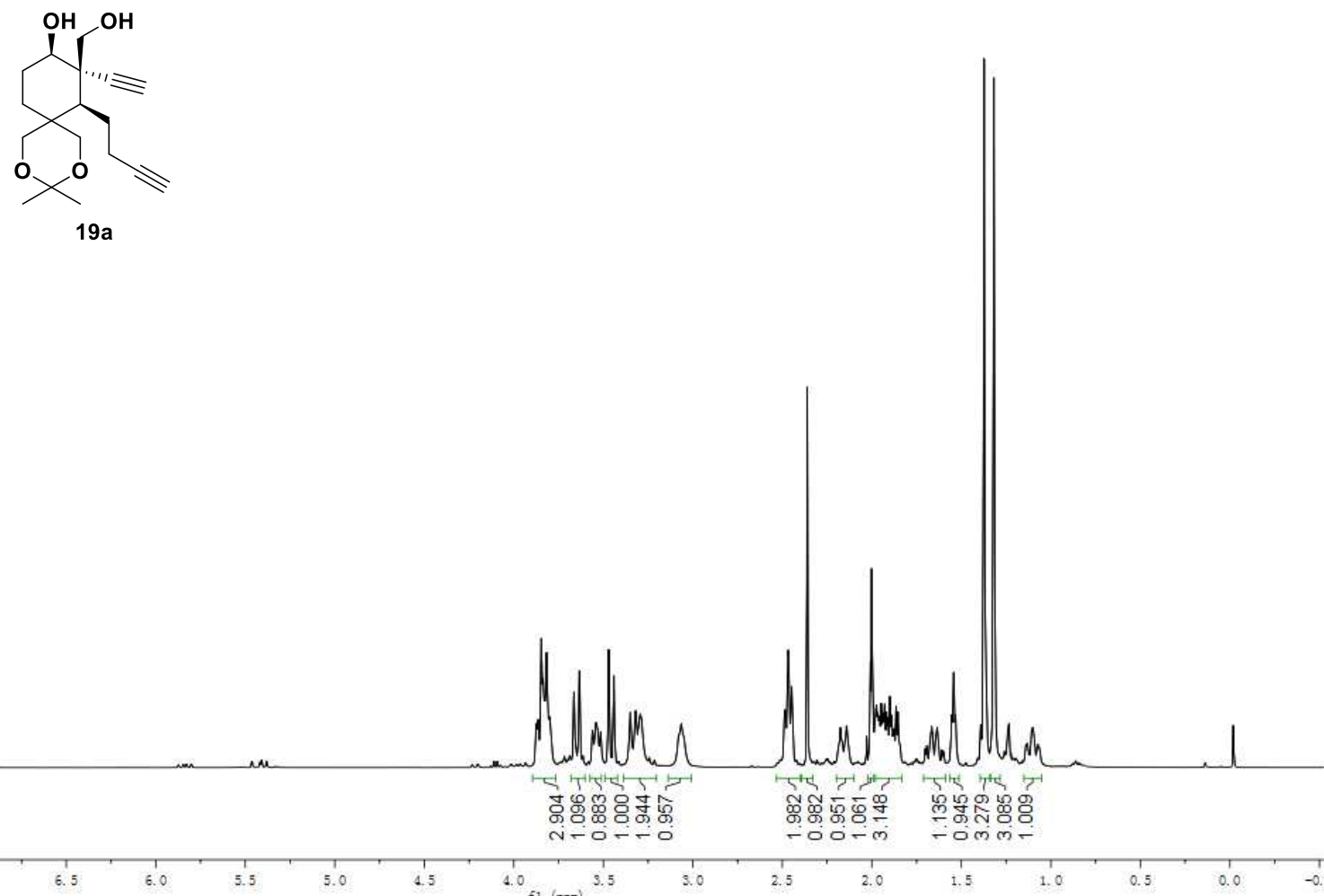

${ }^{1} \mathrm{H}$ NMR of compound 19a
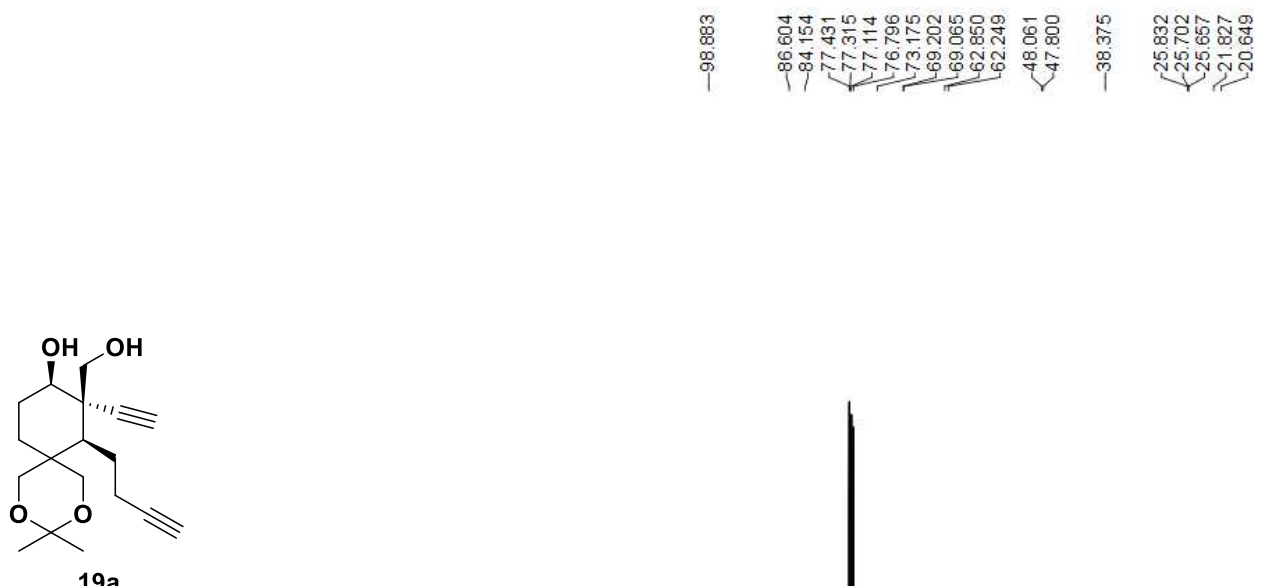

$19 a$ 


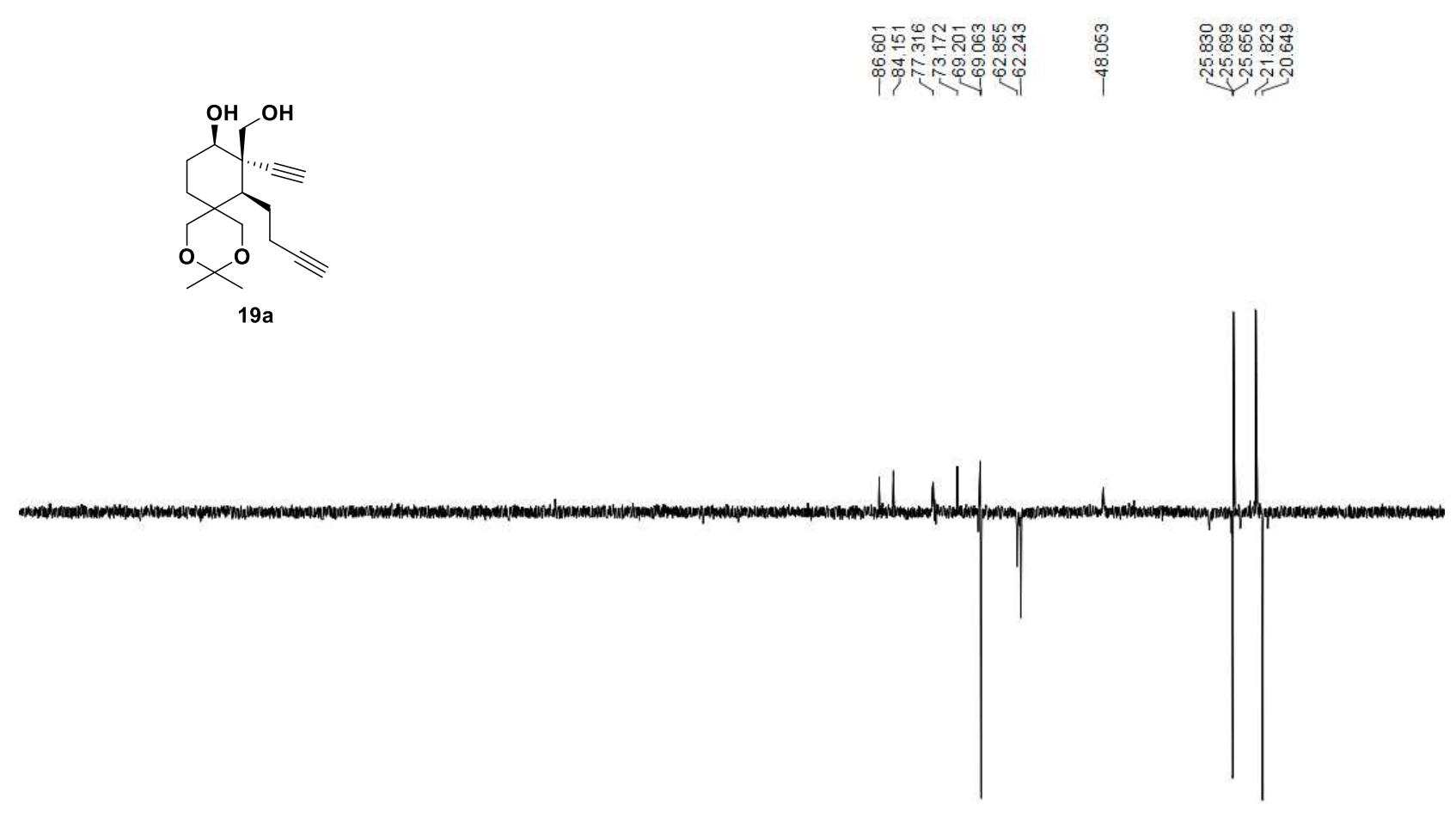

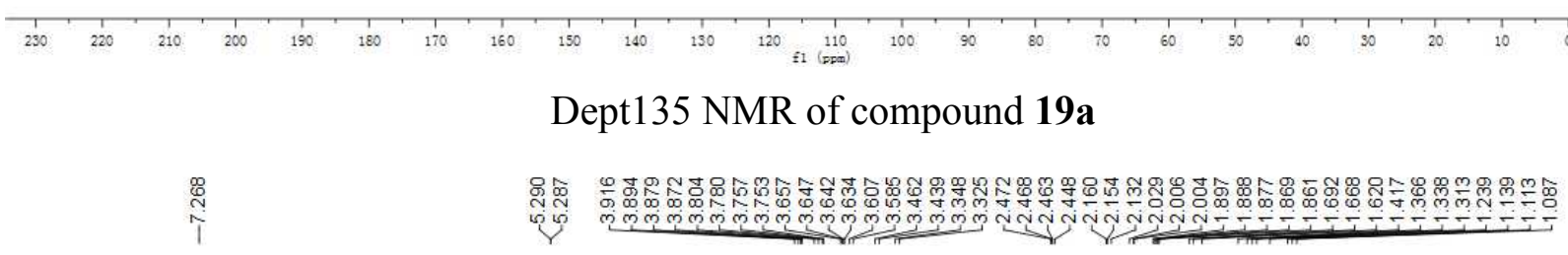
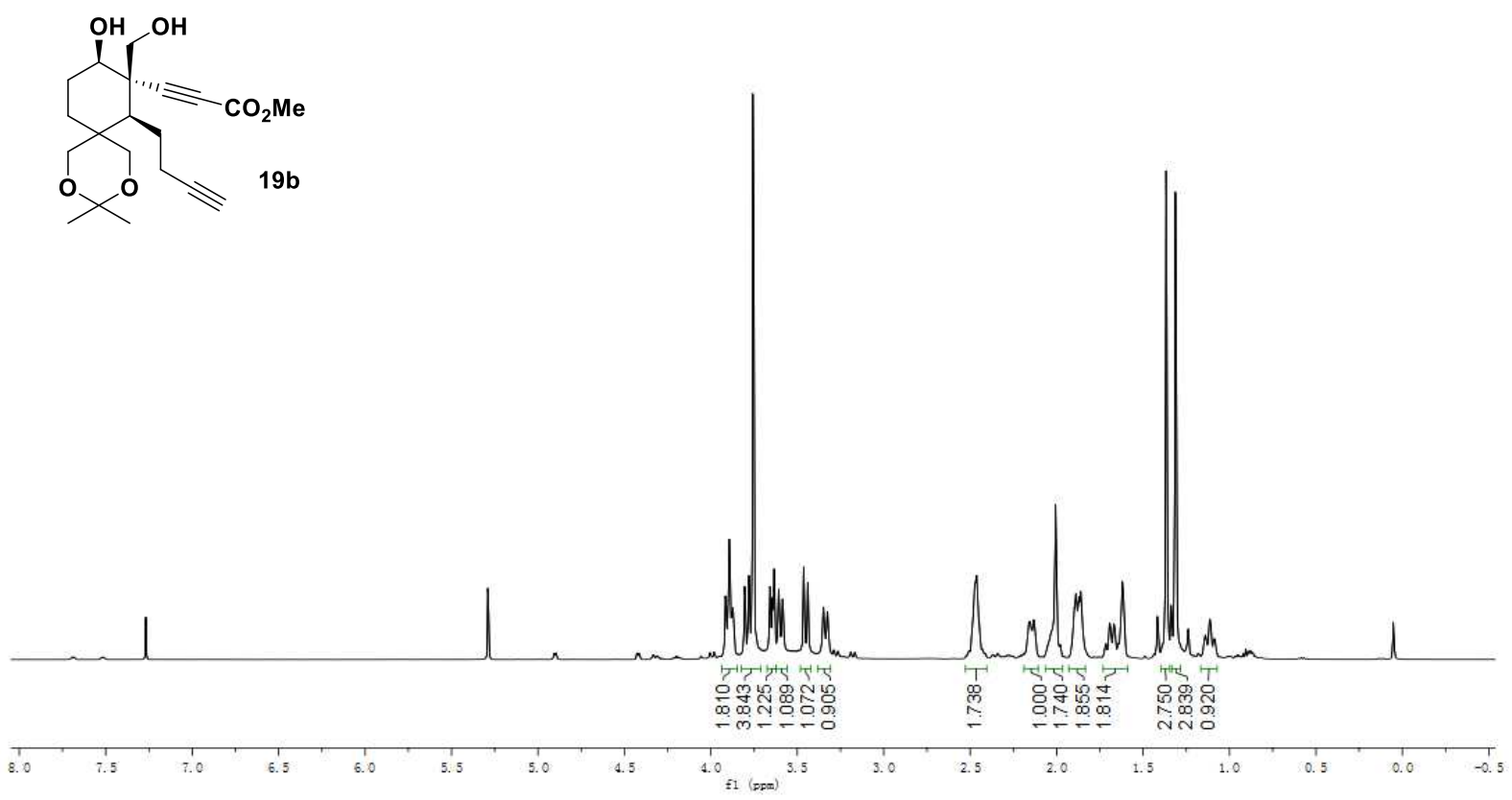

${ }^{1} \mathrm{H}$ NMR of compound 19b 

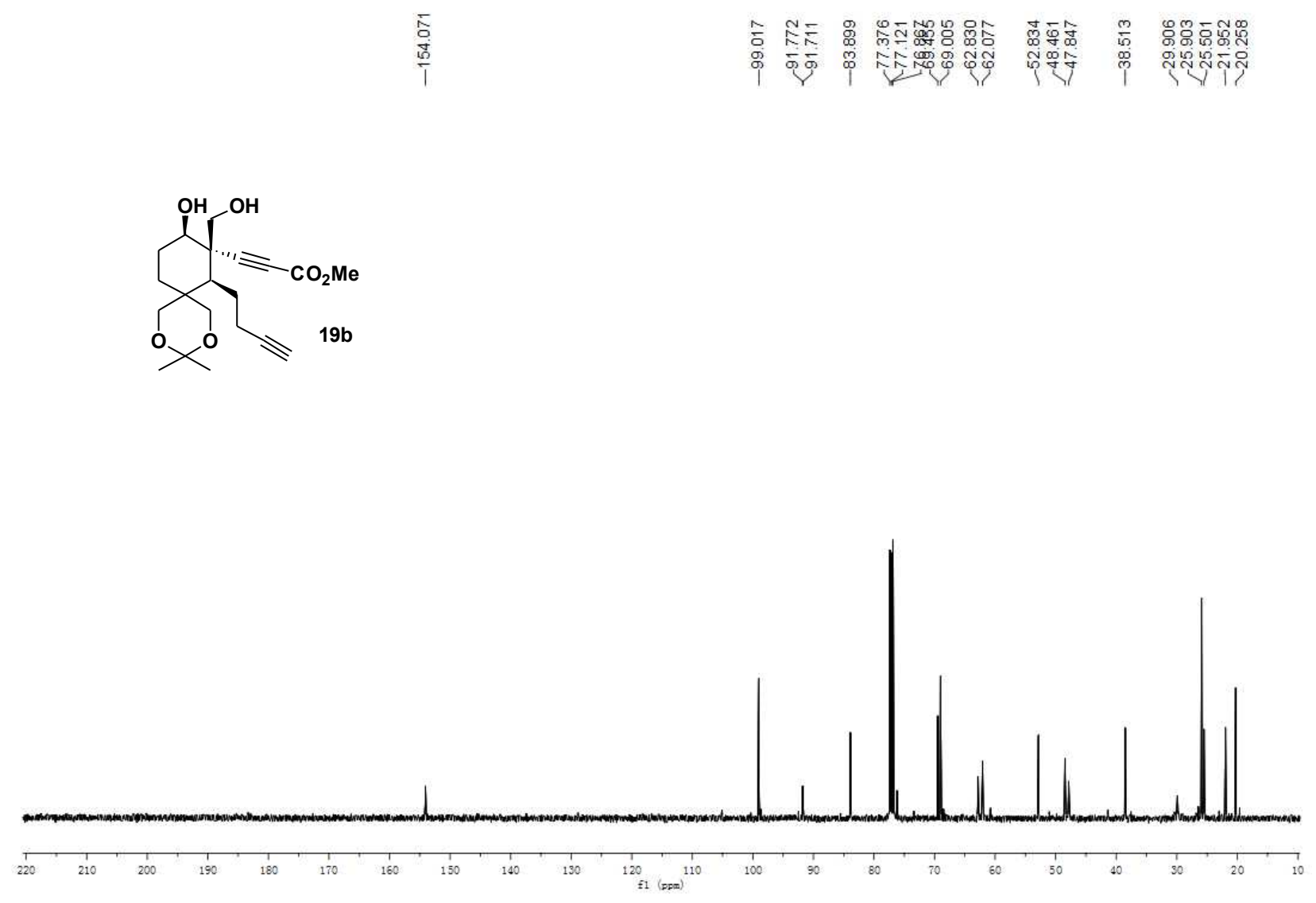

${ }^{13} \mathrm{C}$ NMR of compound 19b

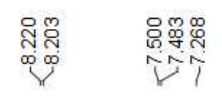

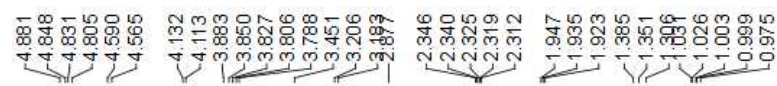
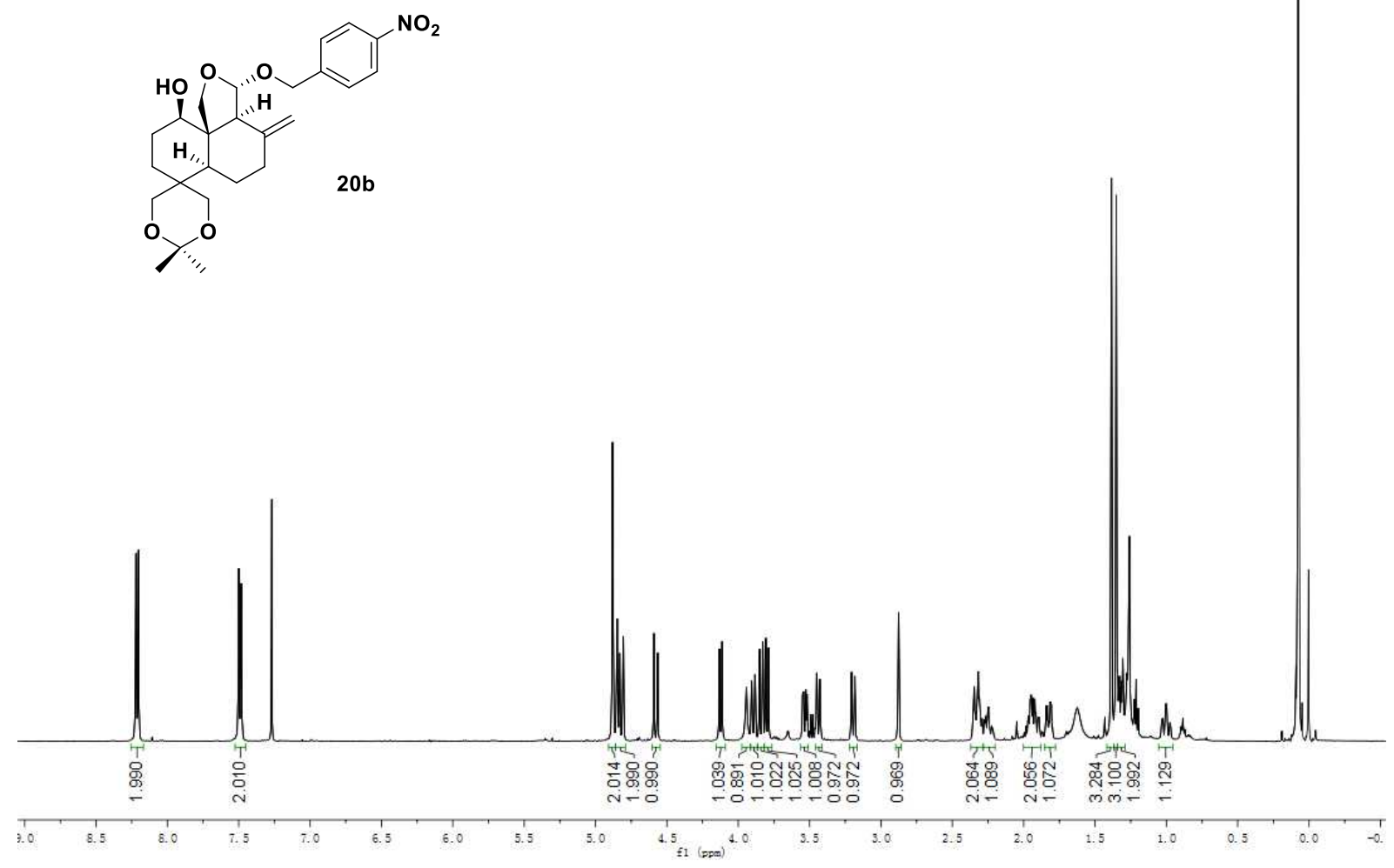

${ }^{1} \mathrm{H}$ NMR of compound 20b 


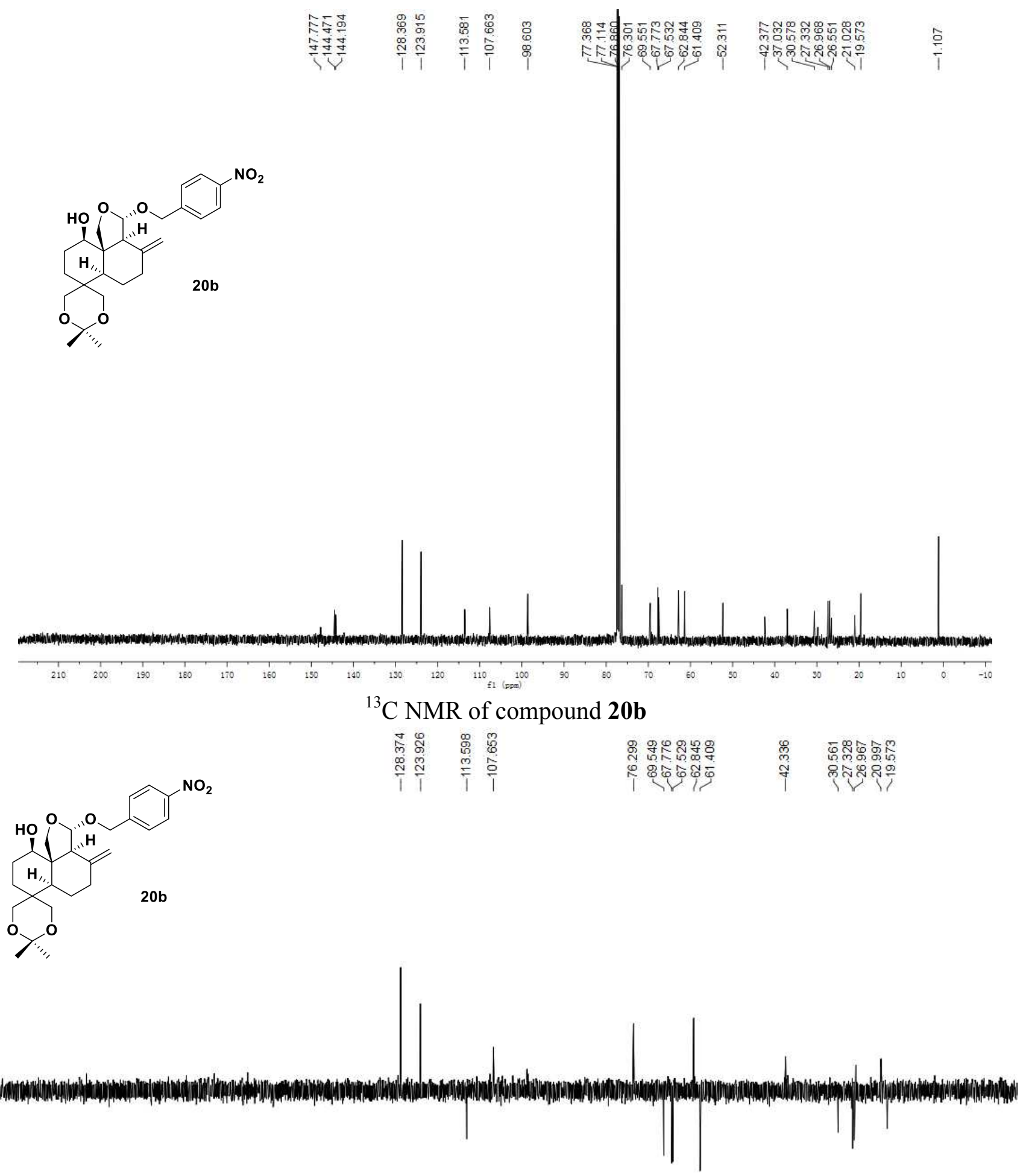

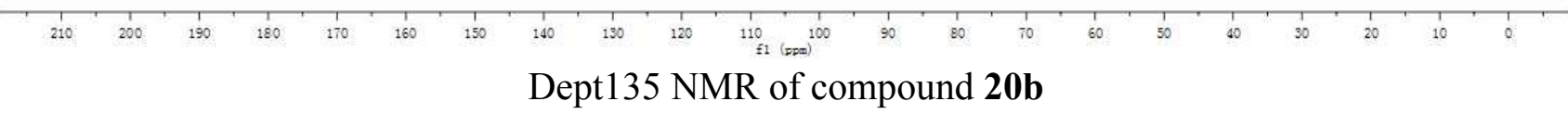



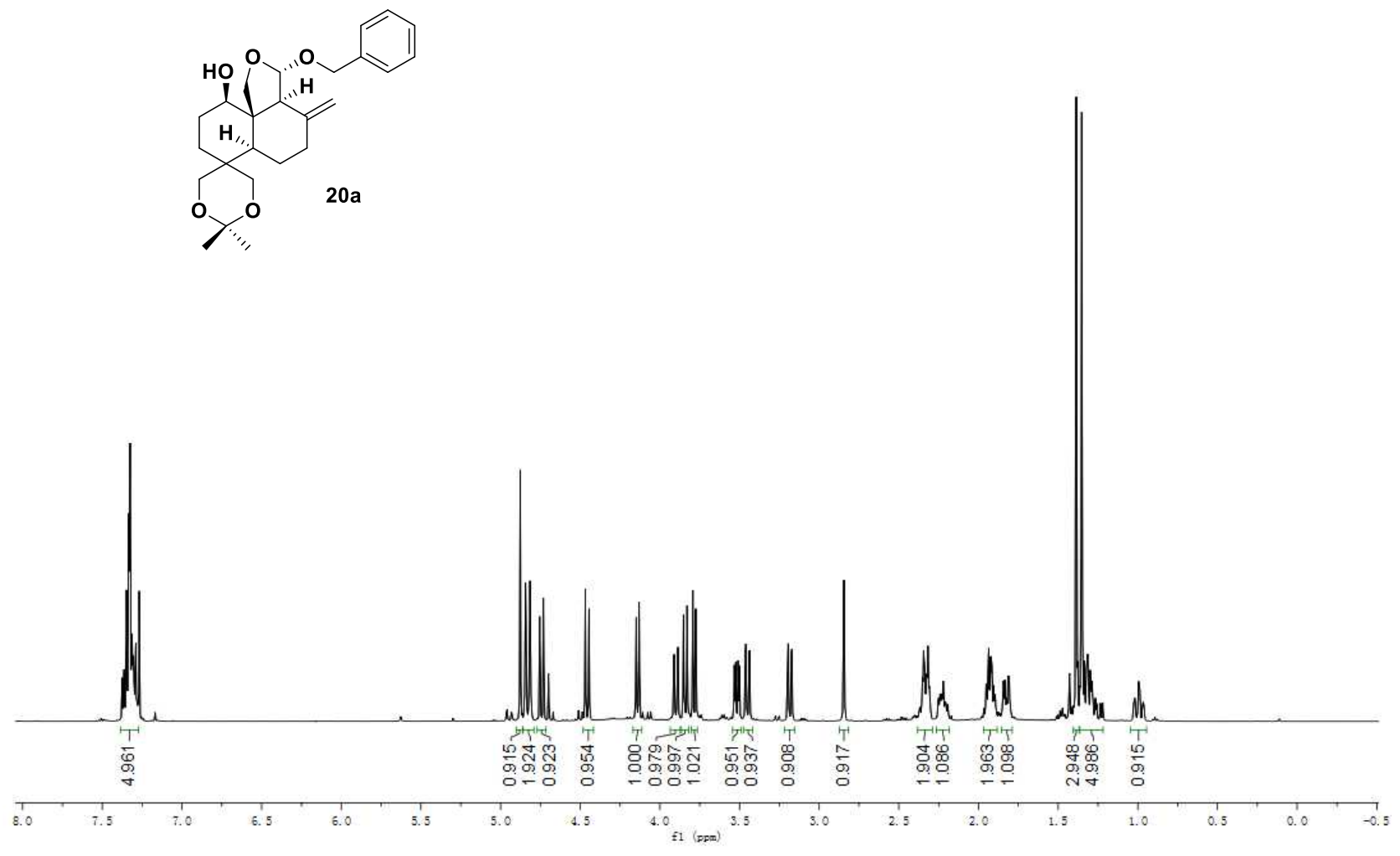

${ }^{1} \mathrm{H}$ NMR of compound 20a
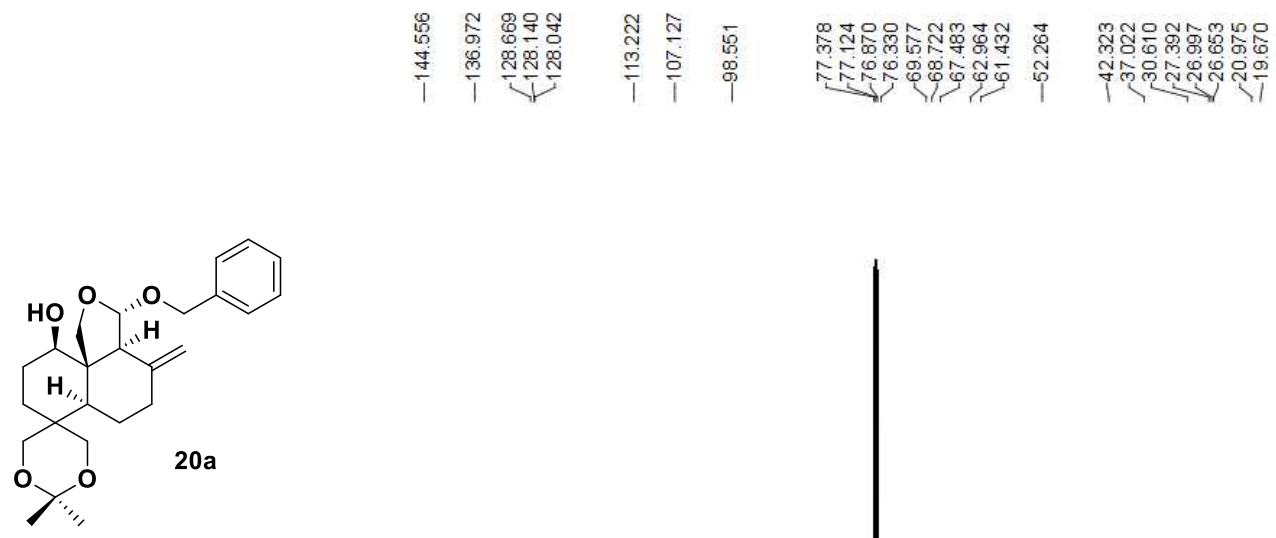

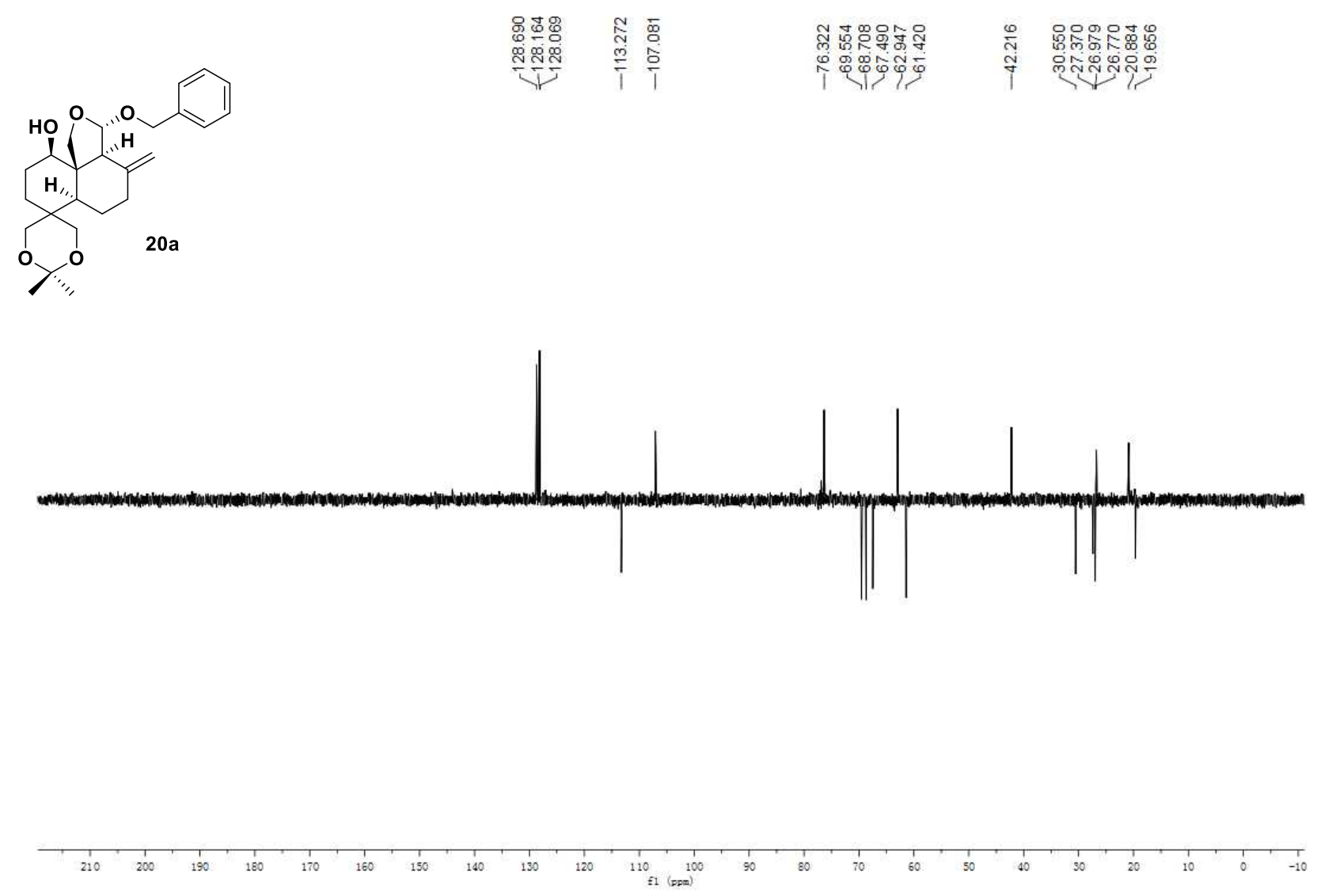

Dept135 NMR of compound 20a

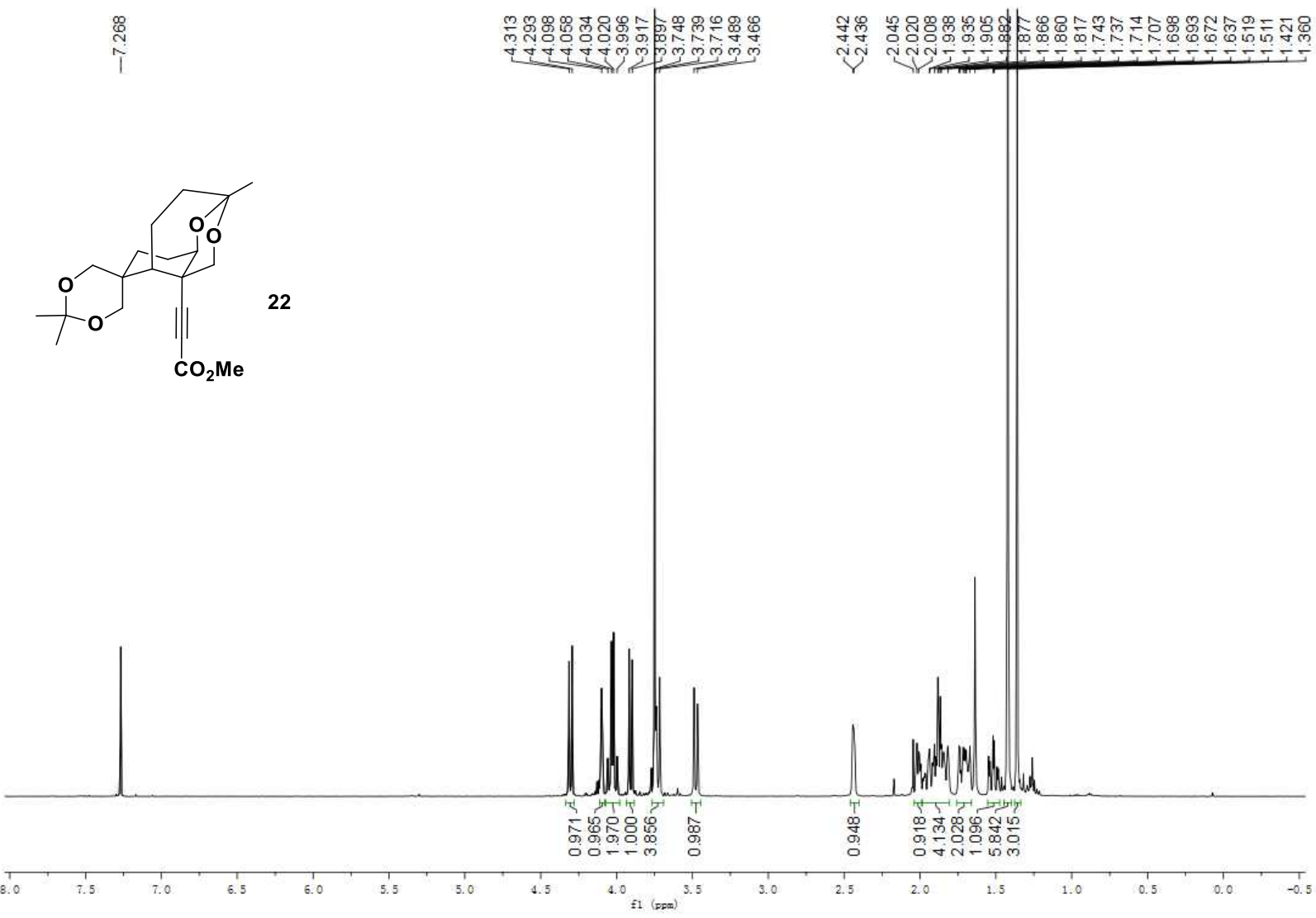

${ }^{1} \mathrm{H}$ NMR of compound 22 


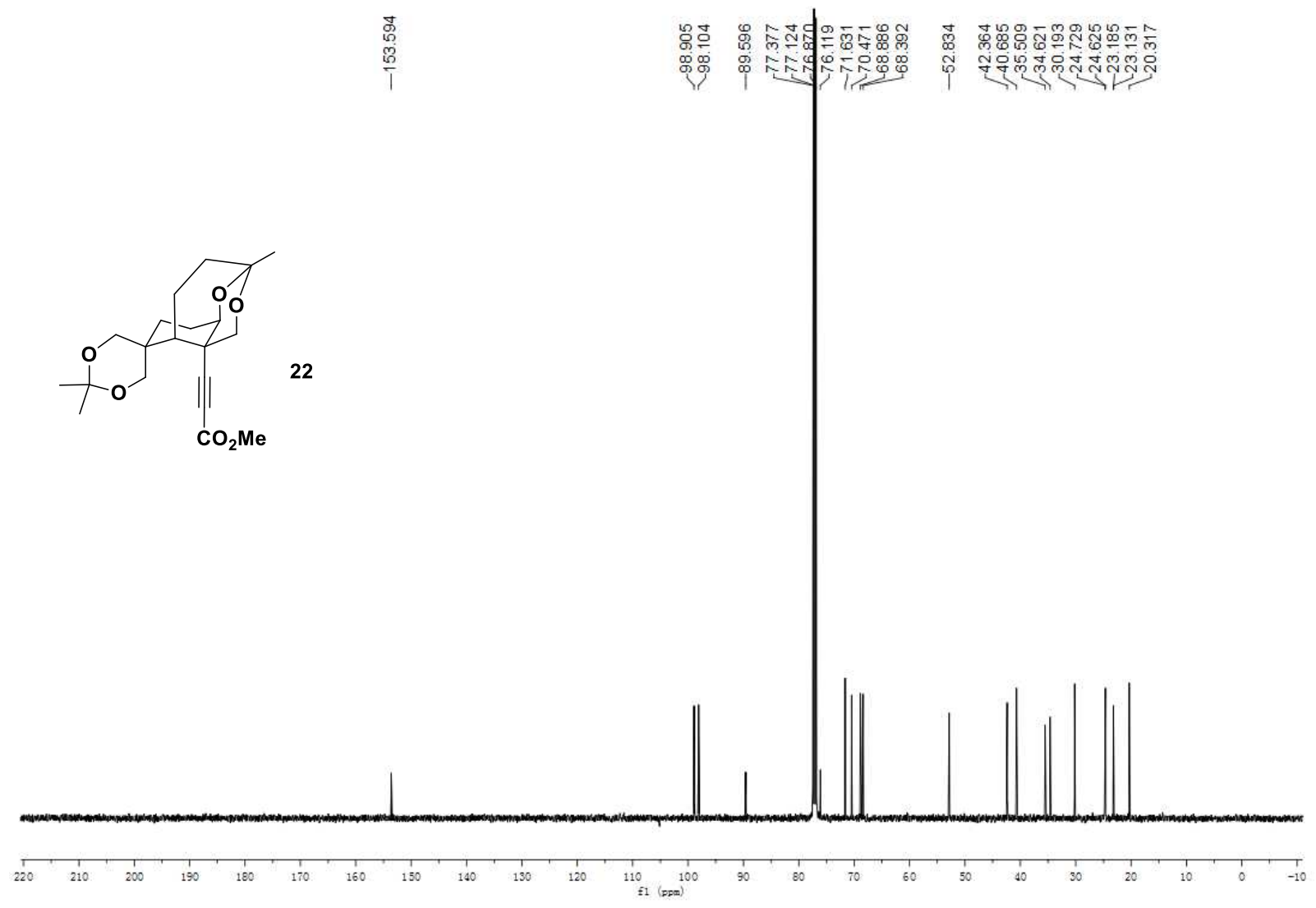

${ }^{13} \mathrm{C}$ NMR of compound 22
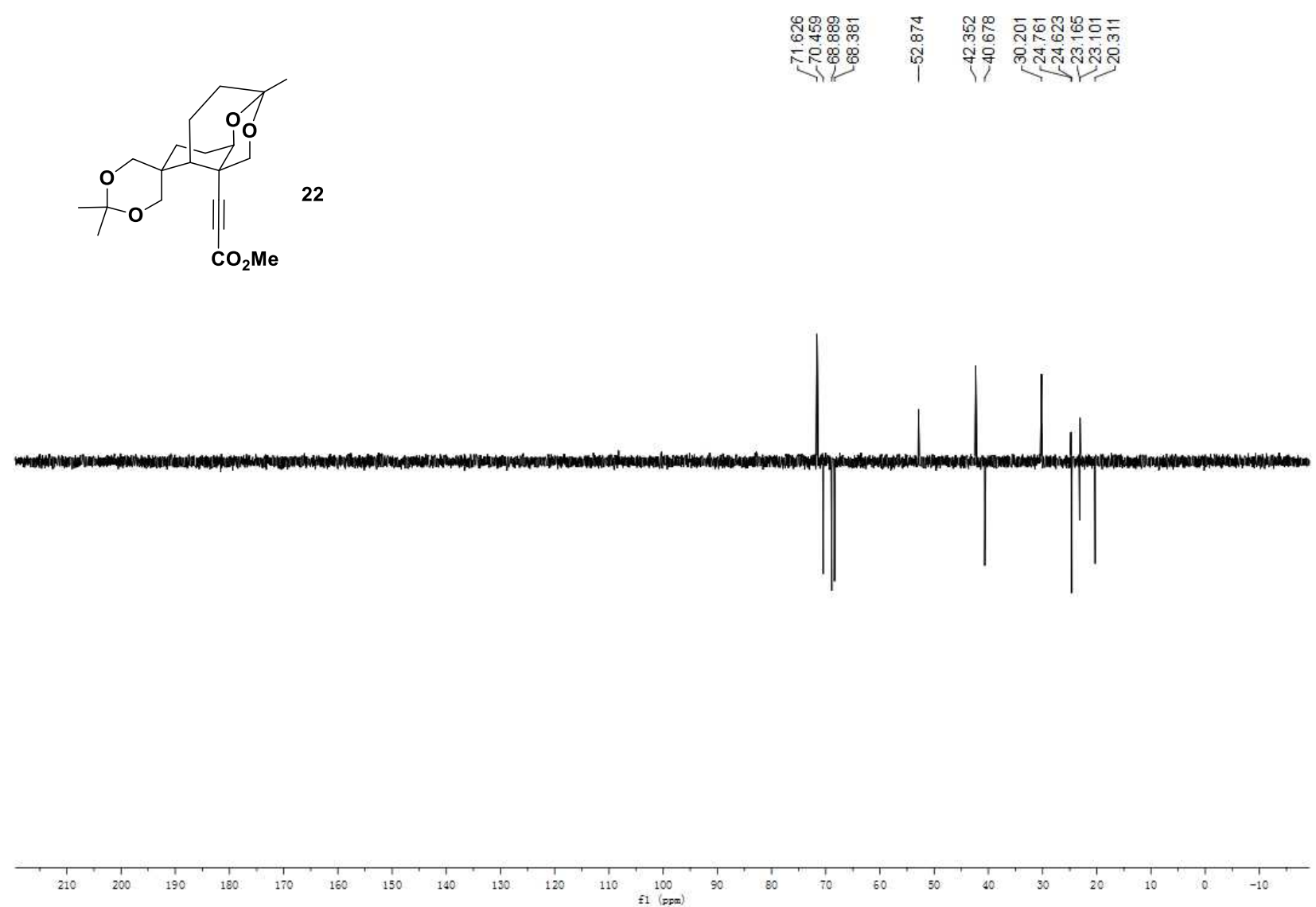

Dept135 NMR of compound 22 

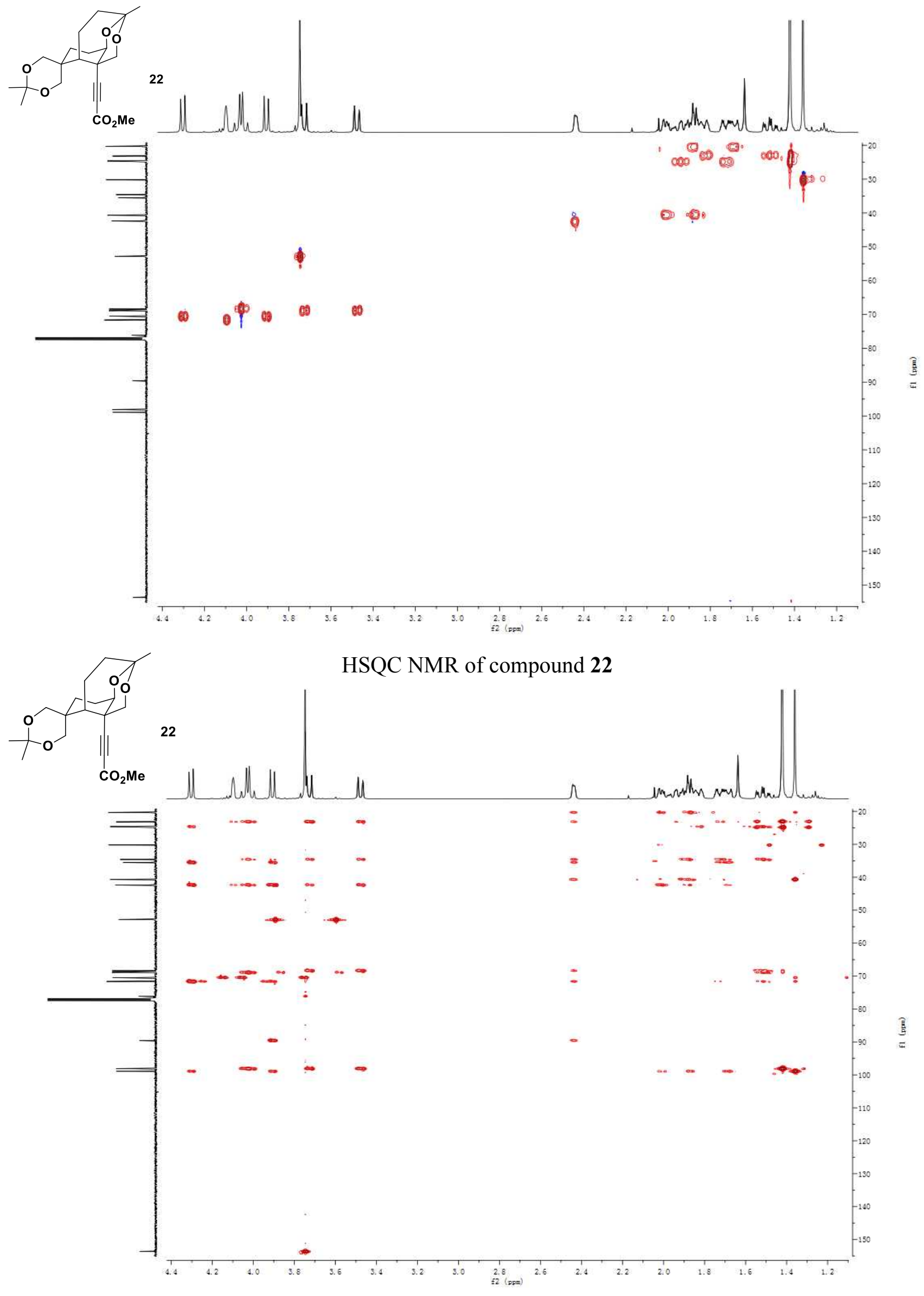

HMBC NMR of compound 22 


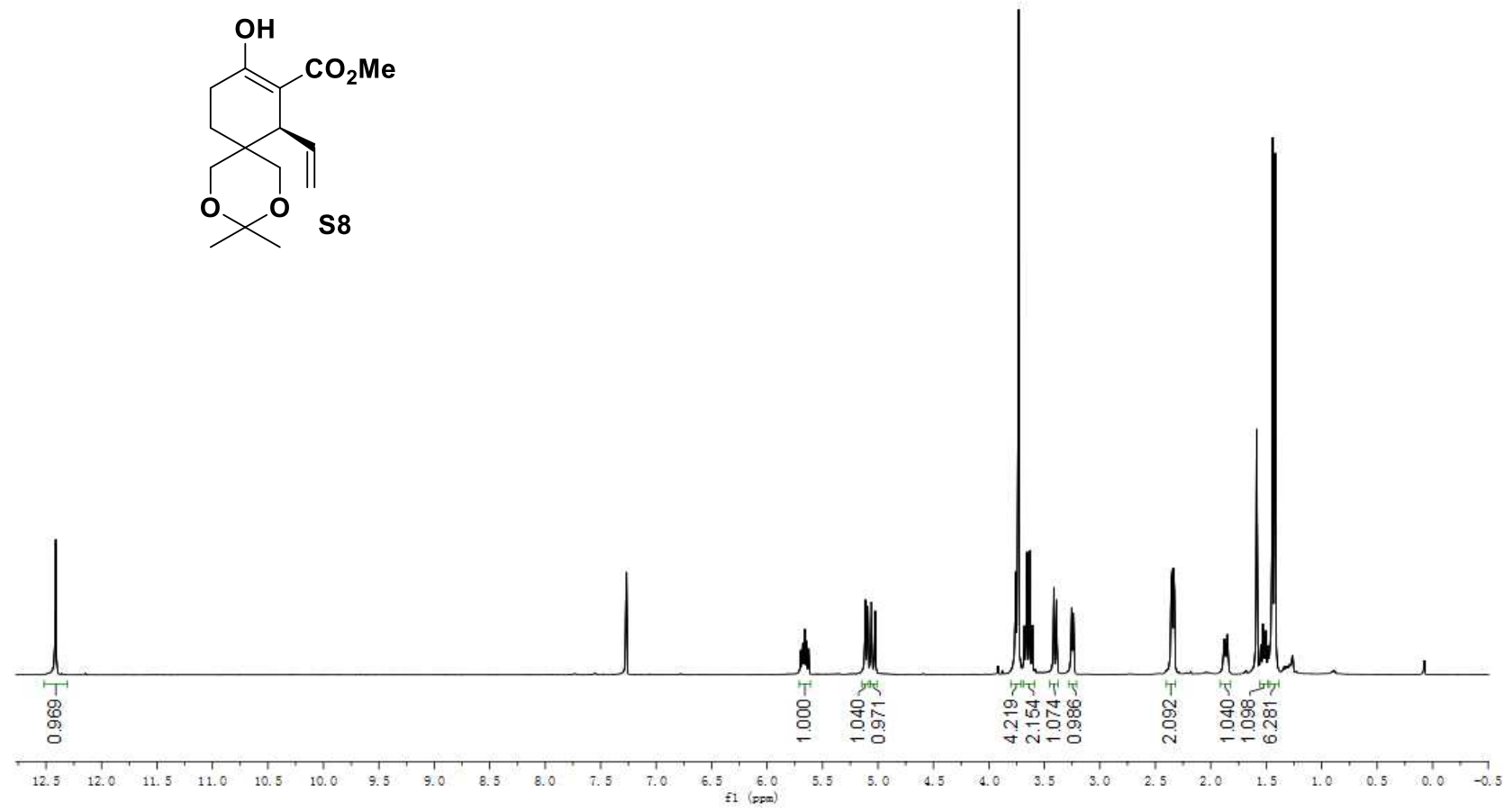

${ }^{1} \mathrm{H}$ NMR of compound $\mathbf{S 8}$

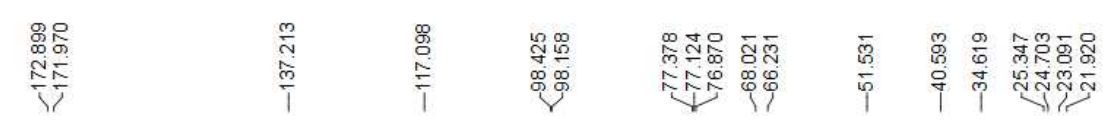<smiles>C=CC1C(C(C)=O)=C(O)CCC12COC(C)(C)OC2</smiles>

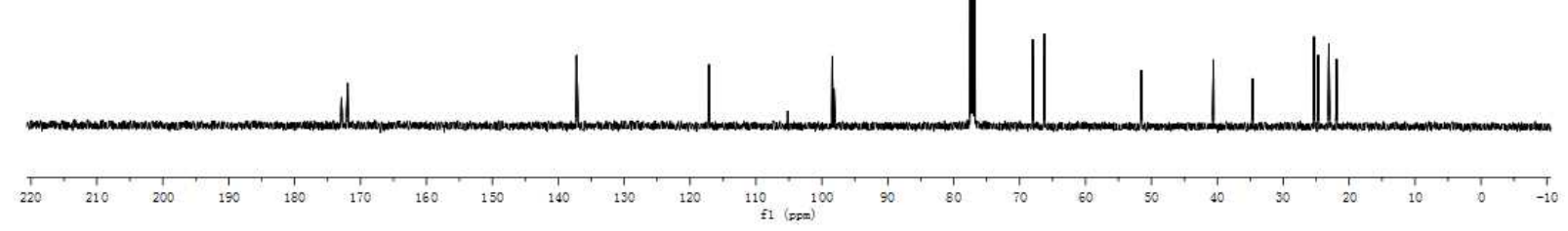

${ }^{13} \mathrm{C}$ NMR of compound $\mathbf{S 8}$ 


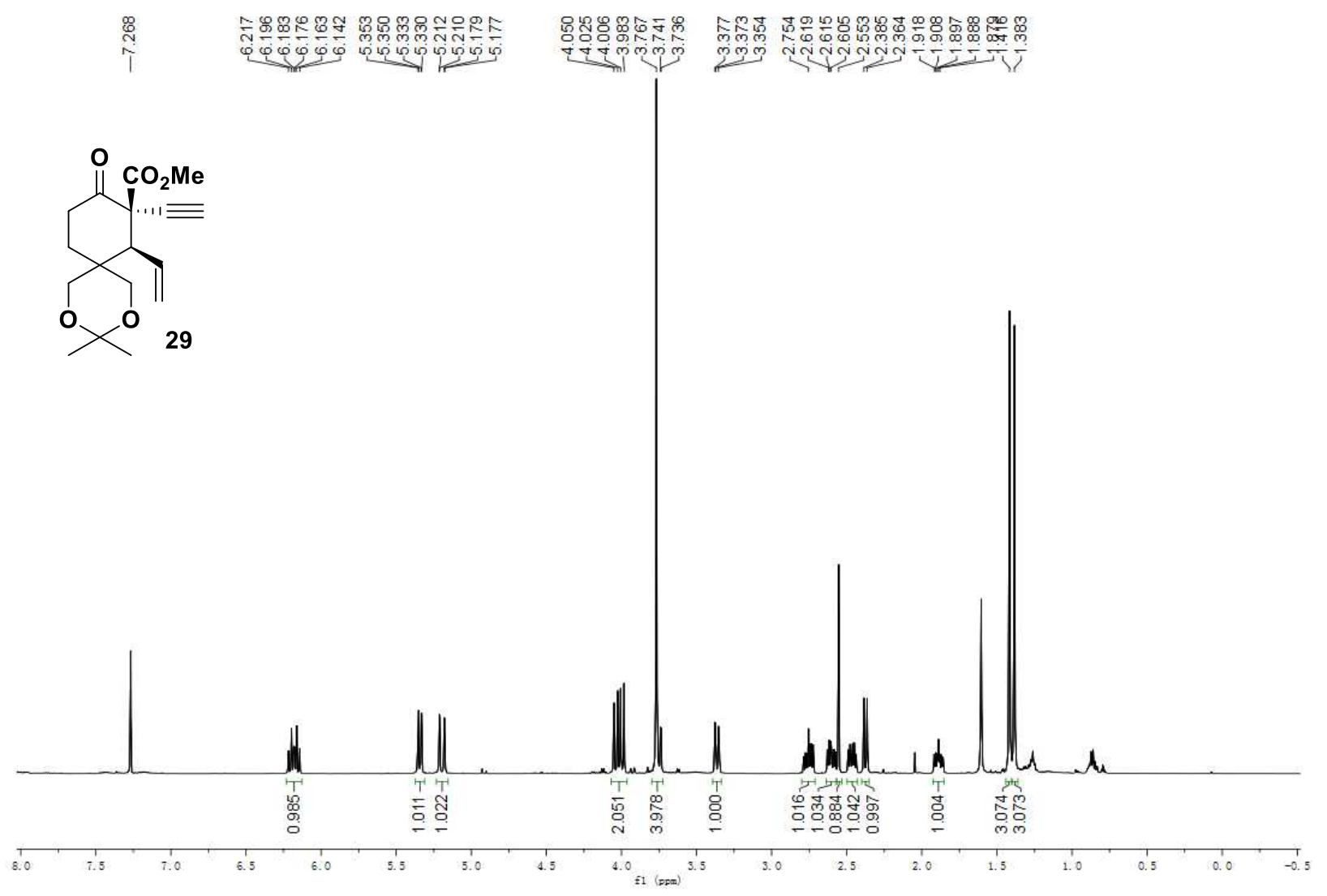

${ }^{1} \mathrm{H}$ NMR of compound 29

\begin{tabular}{|c|c|c|c|c|c|c|}
\hline 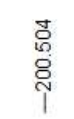 & 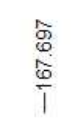 & $\begin{array}{l}\frac{8}{\circ} \\
\frac{0}{m} \\
\end{array}$ & $\underset{\substack{\mathscr{g} \\
\bar{N}}}{\bar{i}}$ & 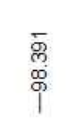 & 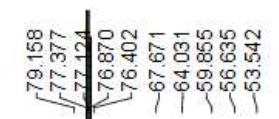 & 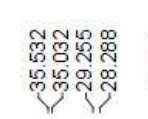 \\
\hline
\end{tabular}<smiles>C#CC1C(C=C)(C(C)=O)CCC(=O)C12COC(C)(C)OC2</smiles> 
(l)

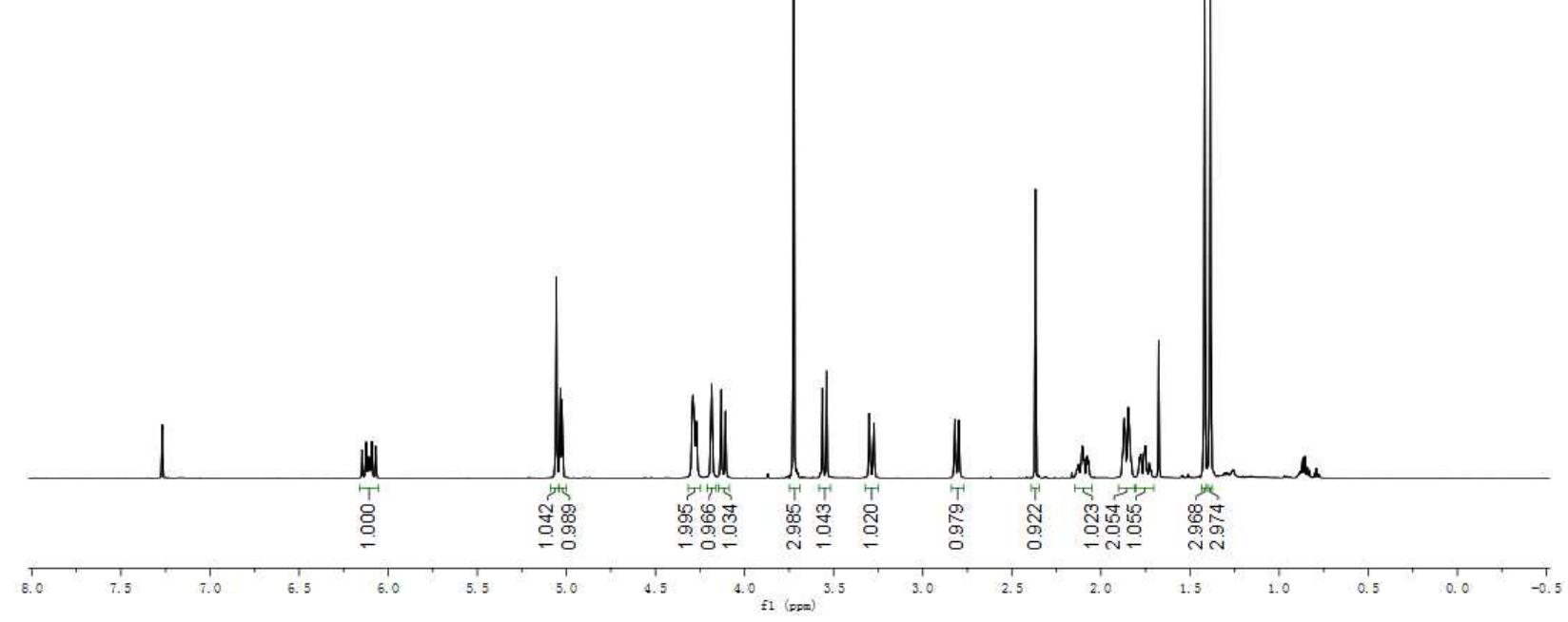

${ }^{1} \mathrm{H}$ NMR of compound $\mathbf{3 3}$

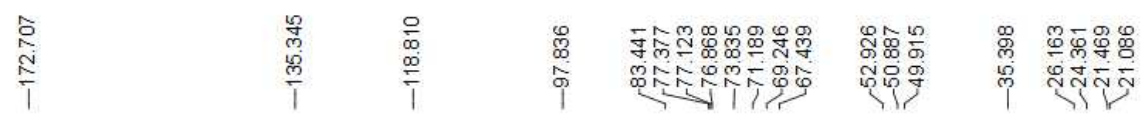<smiles>C#CC1(C(C)=O)C(O)CCC2(COC(C)(C)O2)C1C=C</smiles>
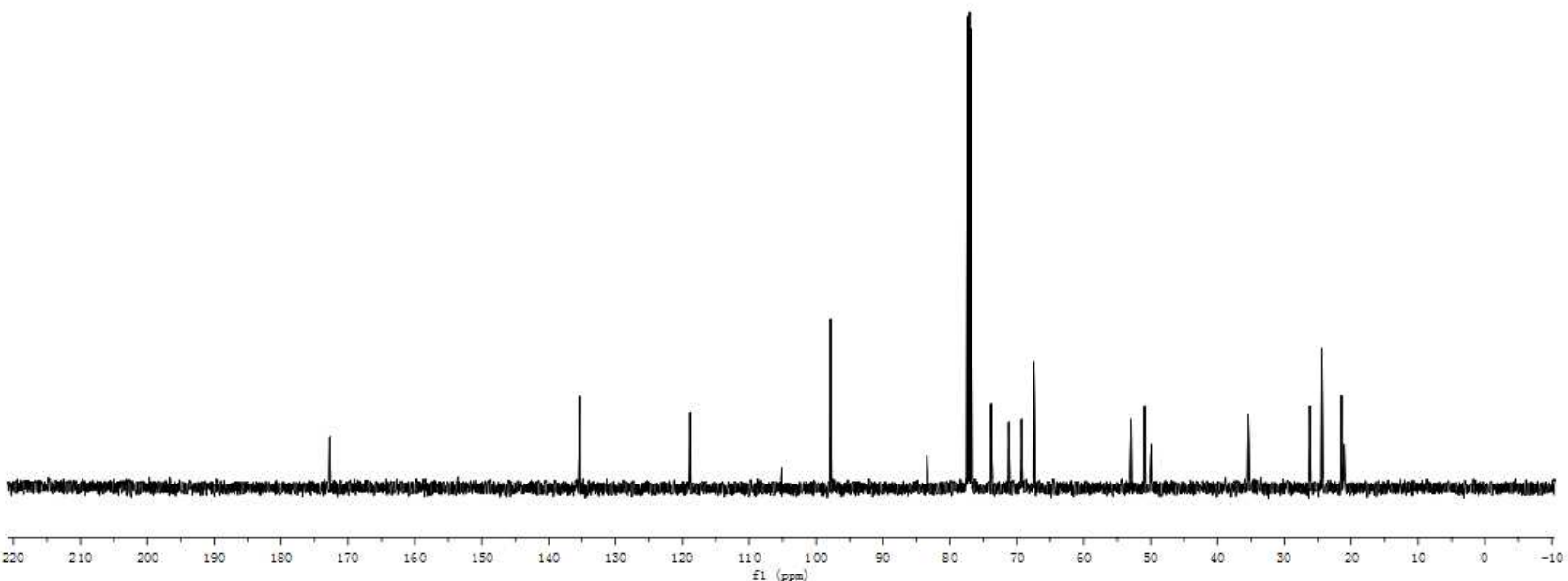

${ }^{13} \mathrm{C}$ NMR of compound 33 


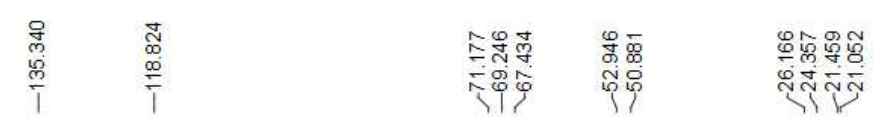

(133
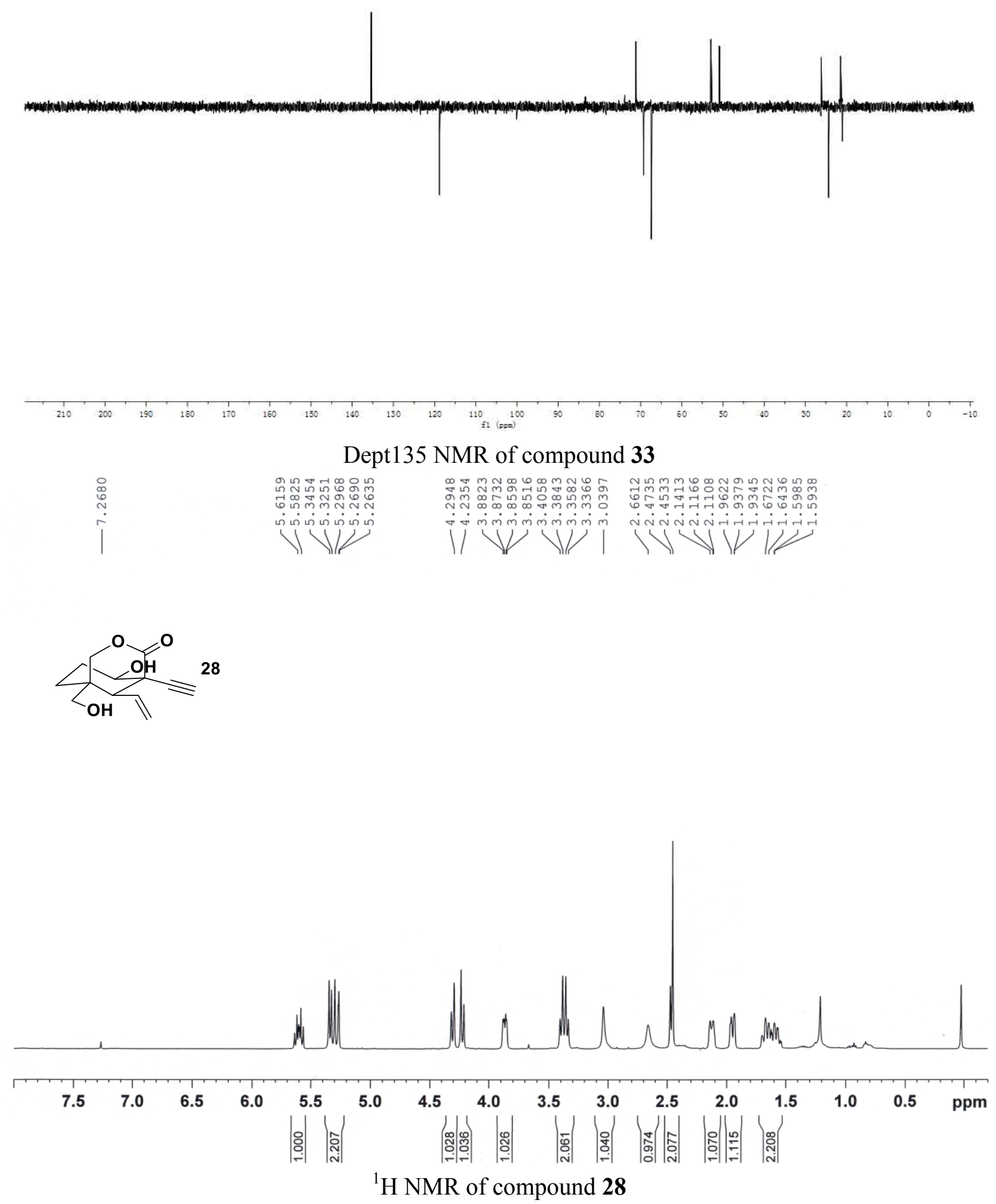

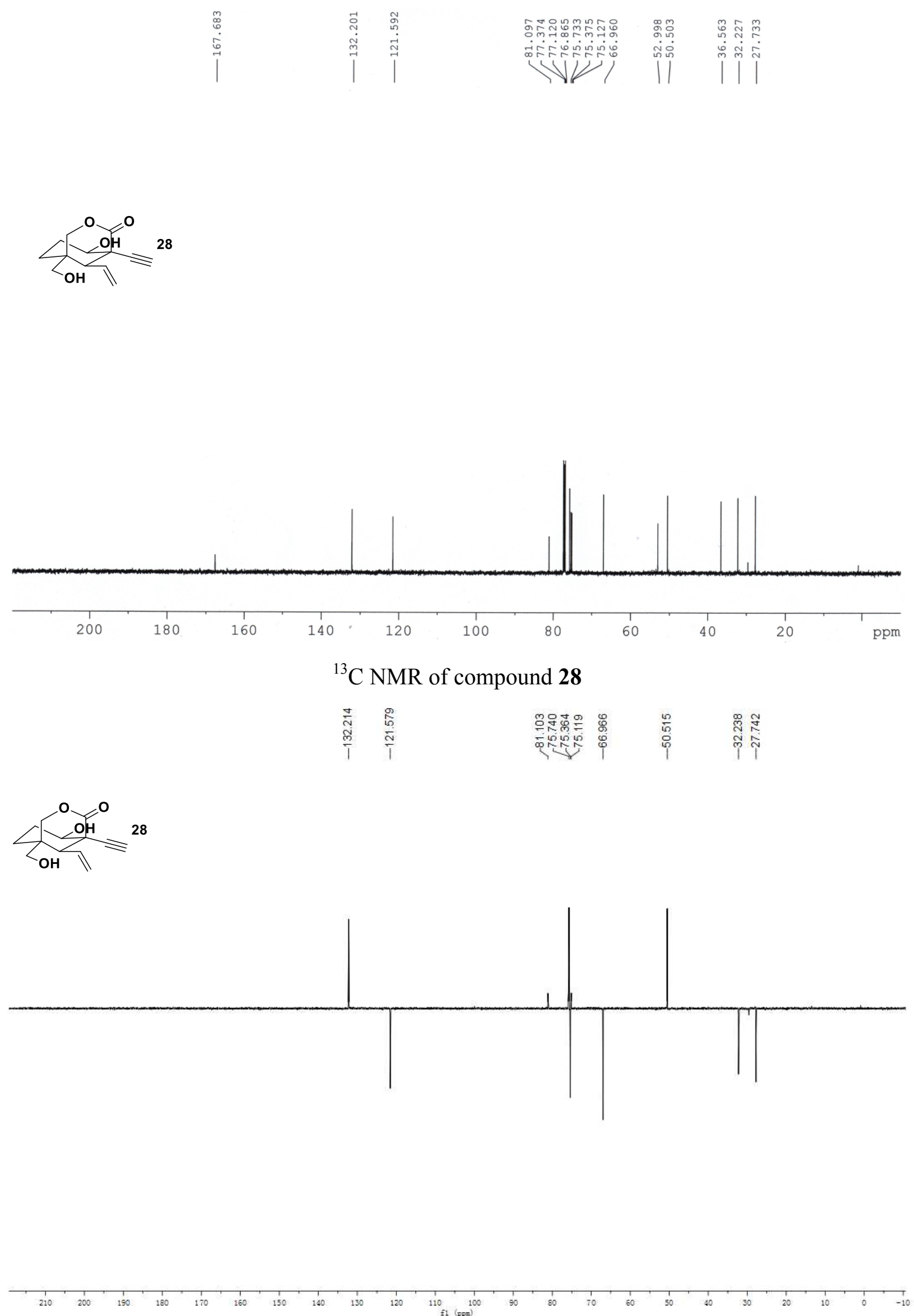

Dept135 NMR of compound $\mathbf{2 8}$ 

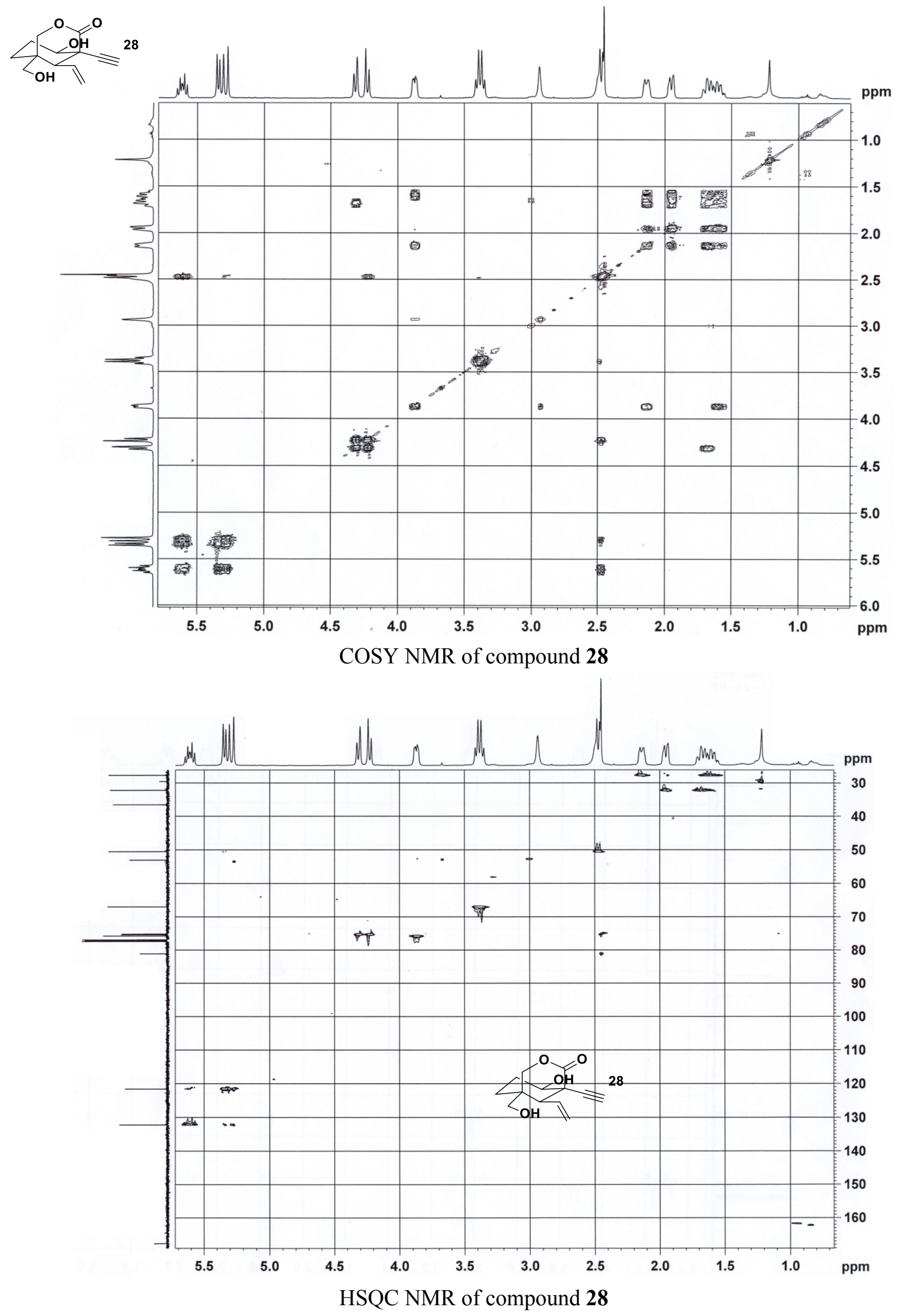

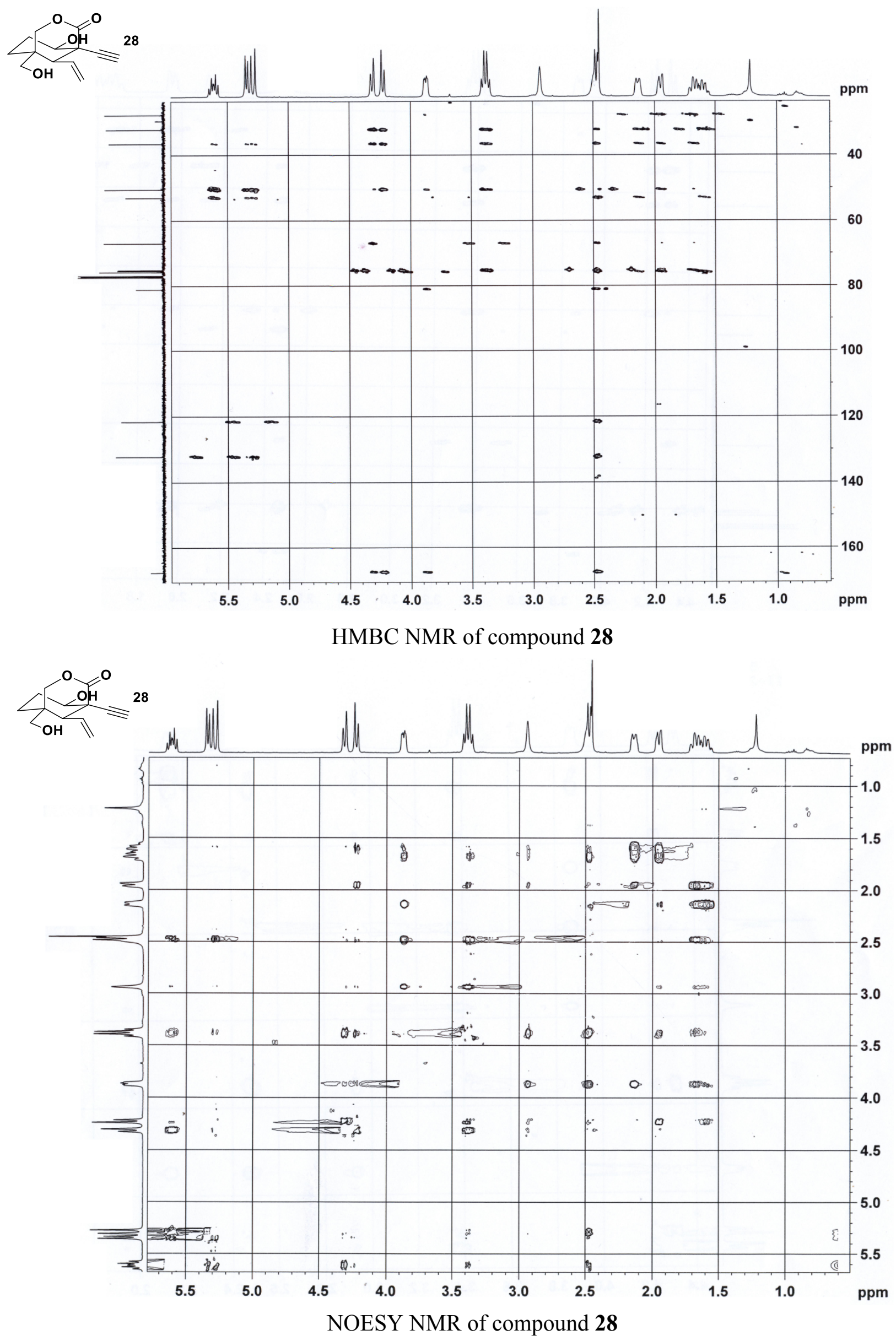


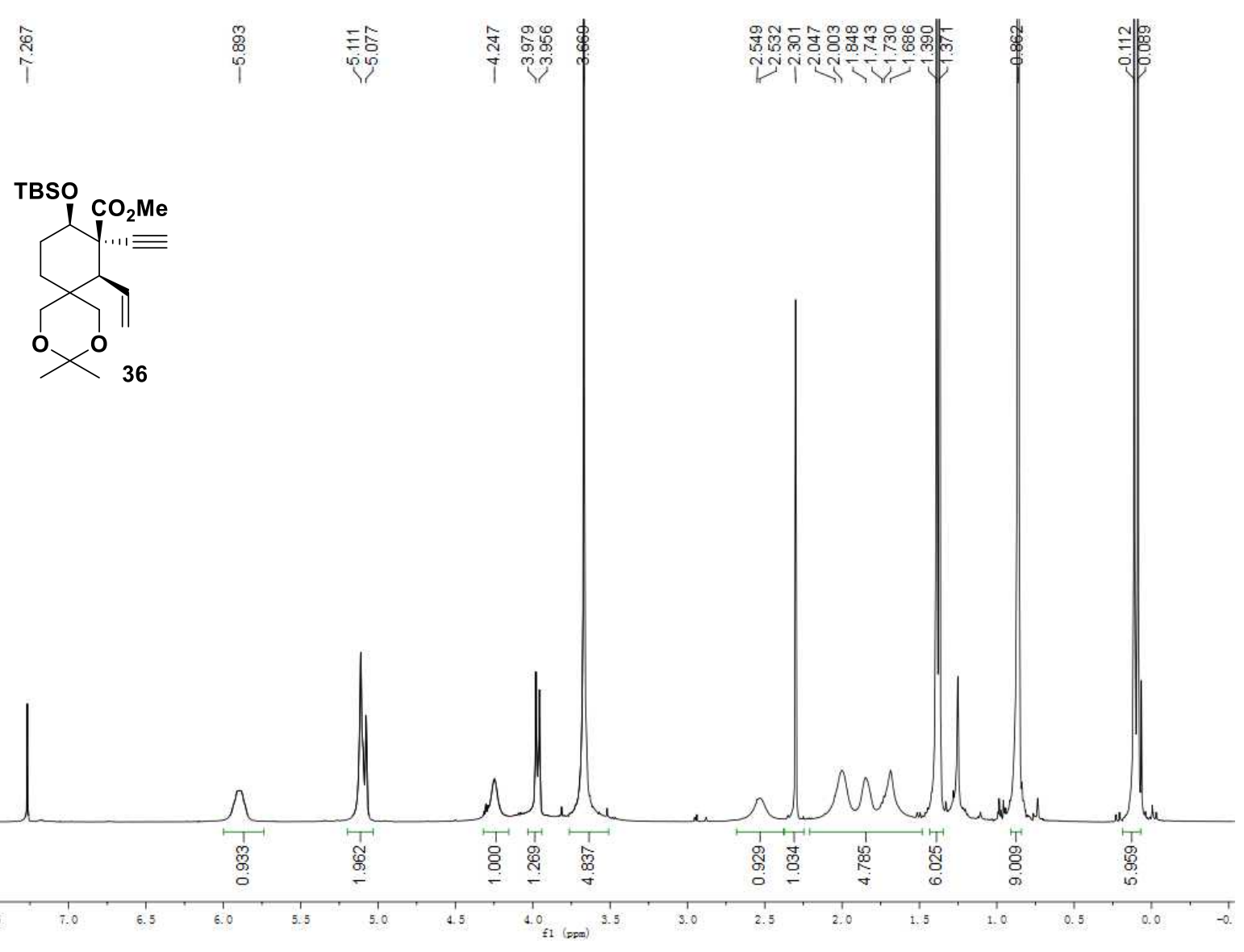

${ }^{1} \mathrm{H}$ NMR of compound 36

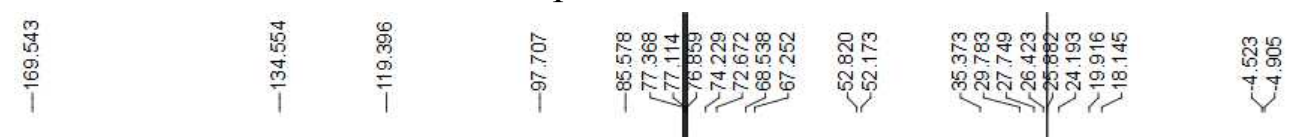

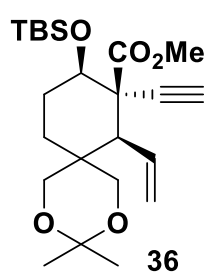

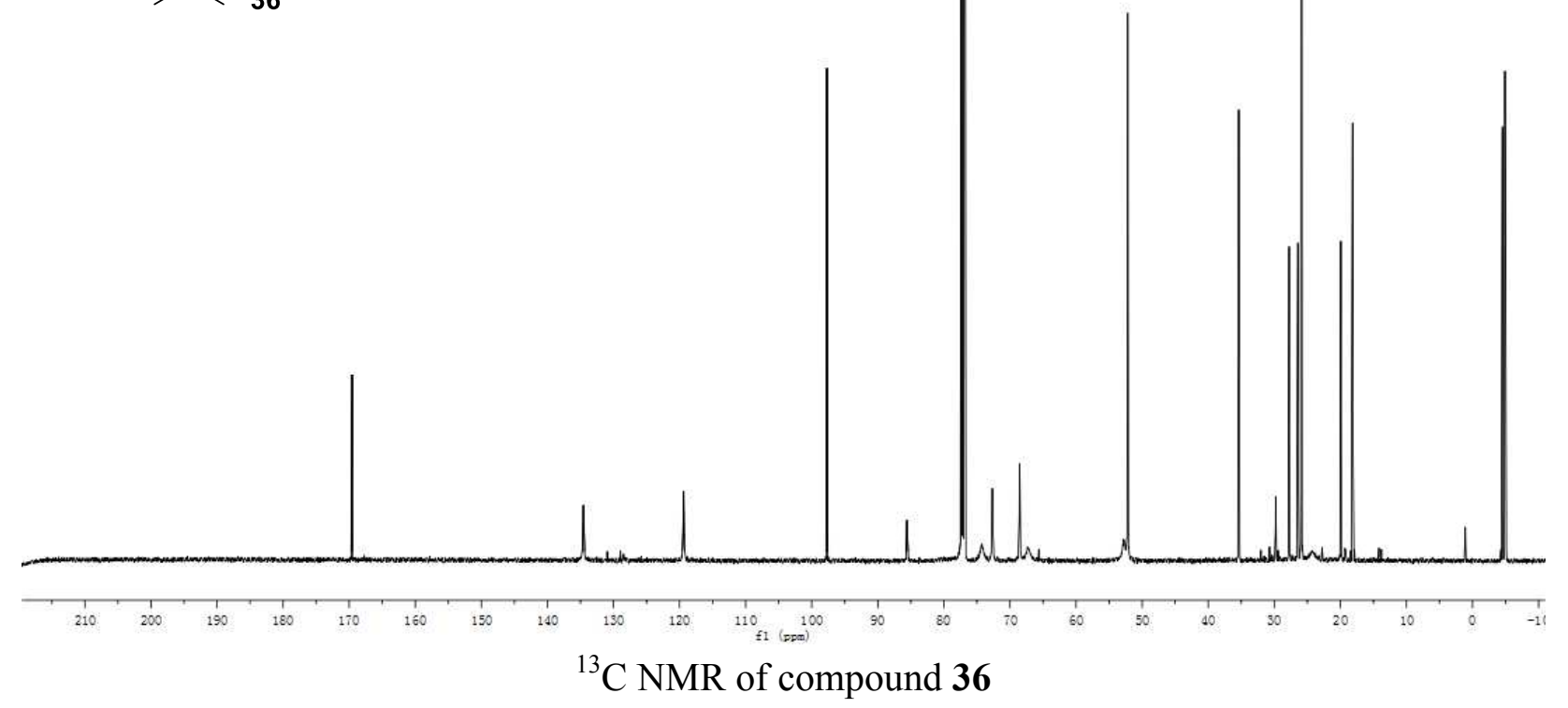


TBSO
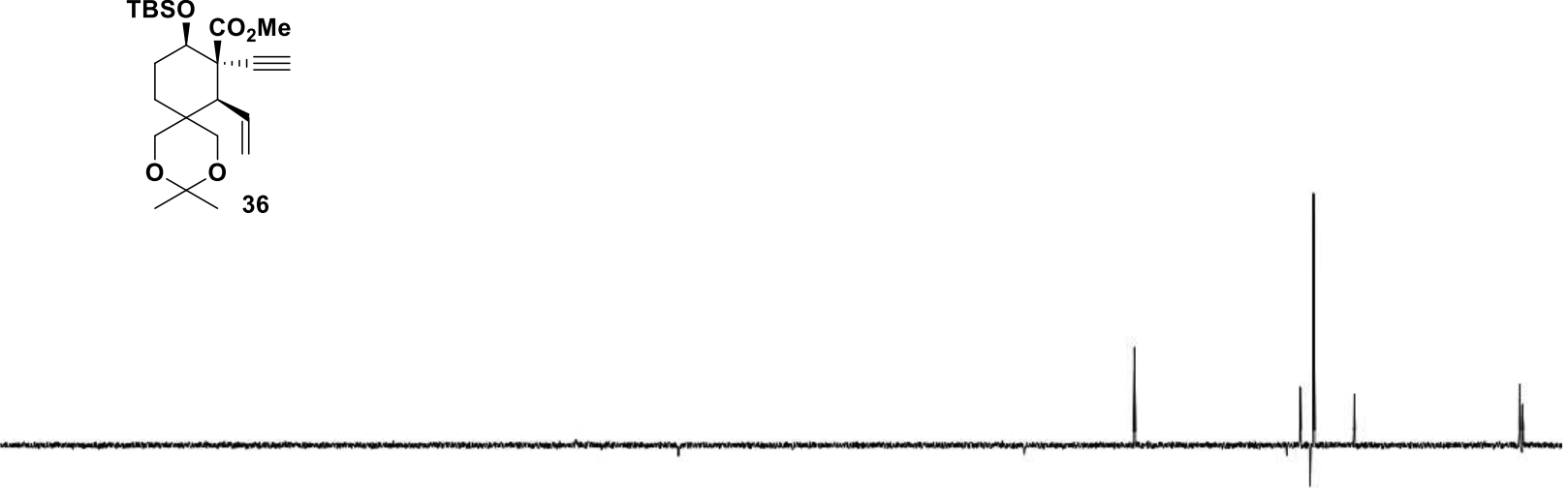

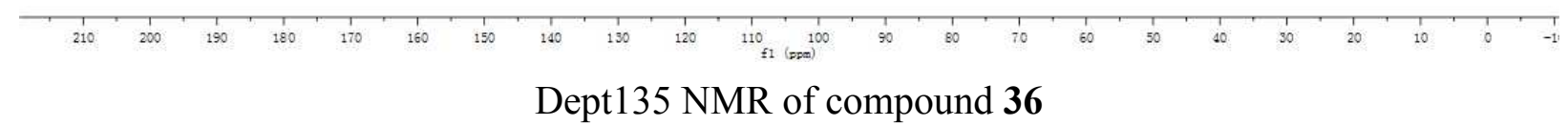

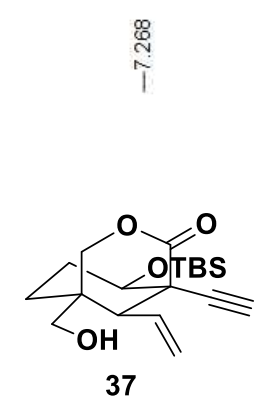

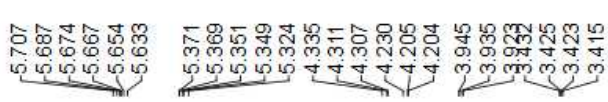

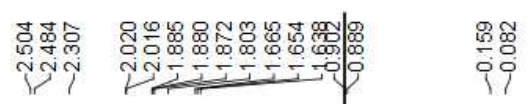
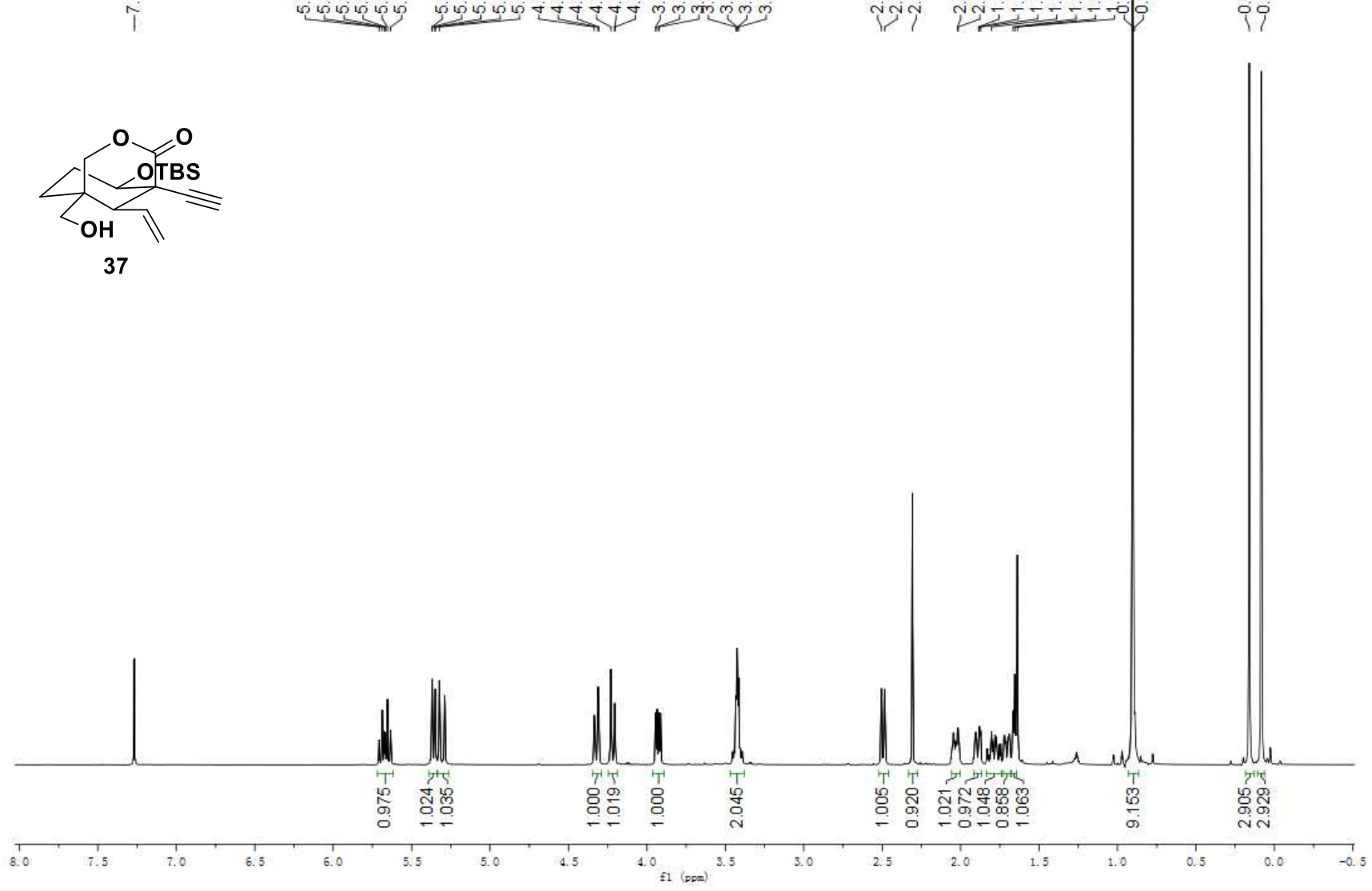

${ }^{1} \mathrm{H}$ NMR of compound $\mathbf{3 7}$ 

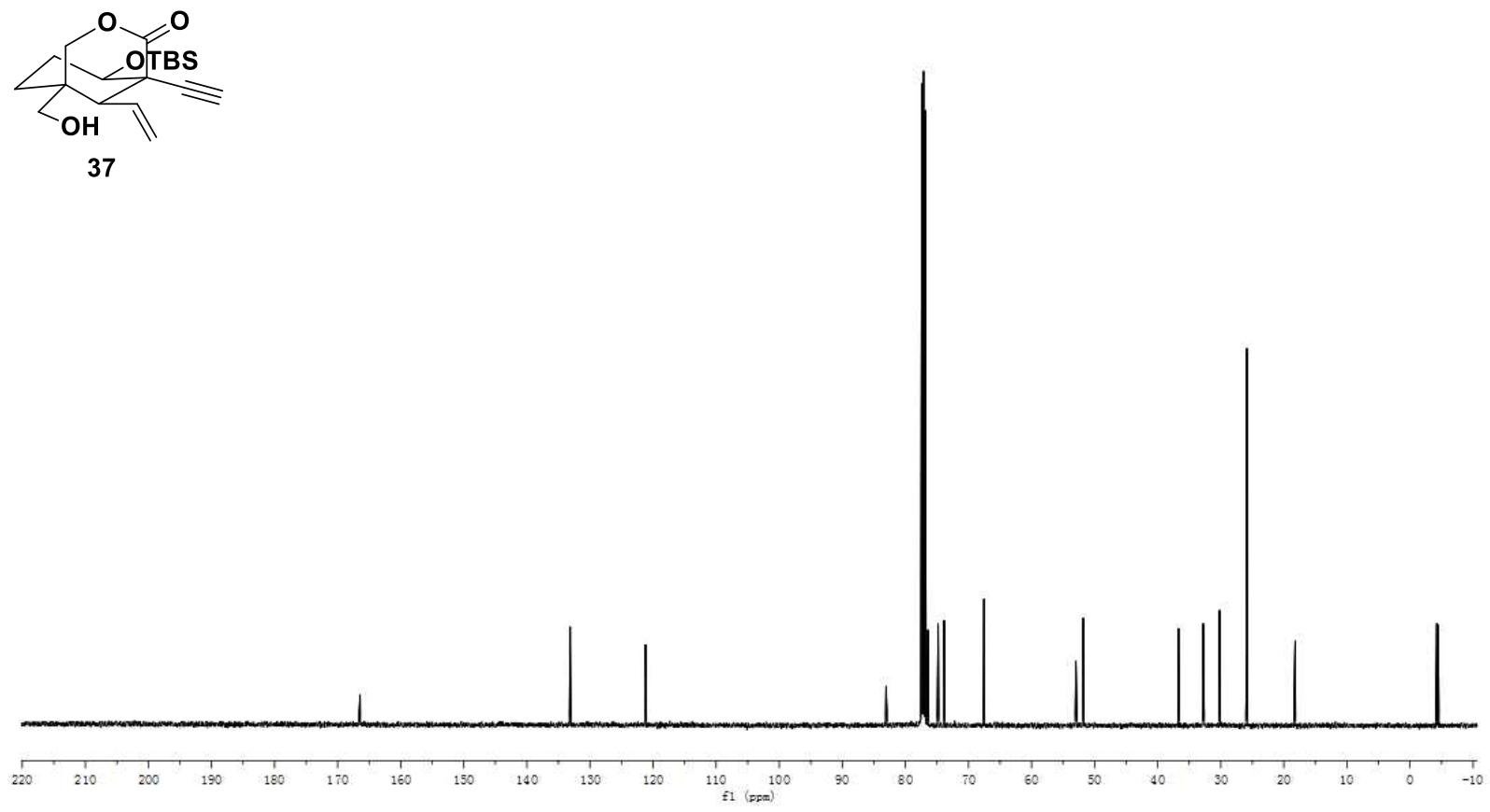

${ }^{13} \mathrm{C}$ NMR of compound 37

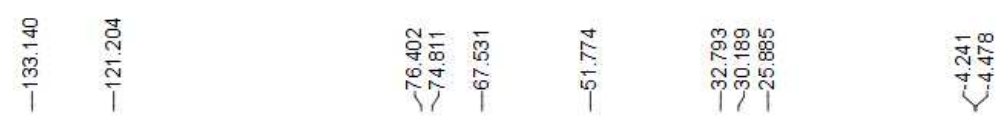
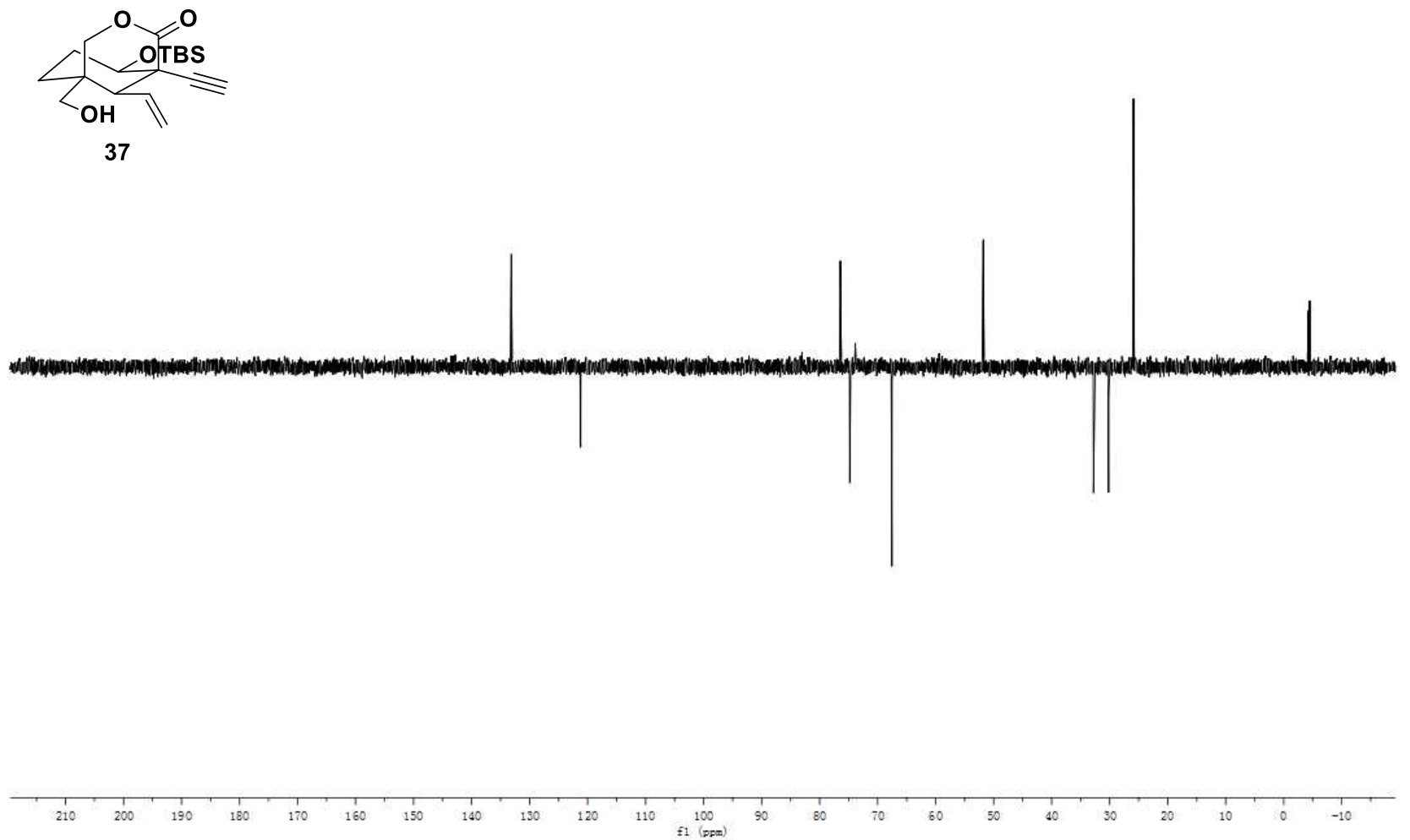

Dept135 NMR of compound $\mathbf{3 7}$ 


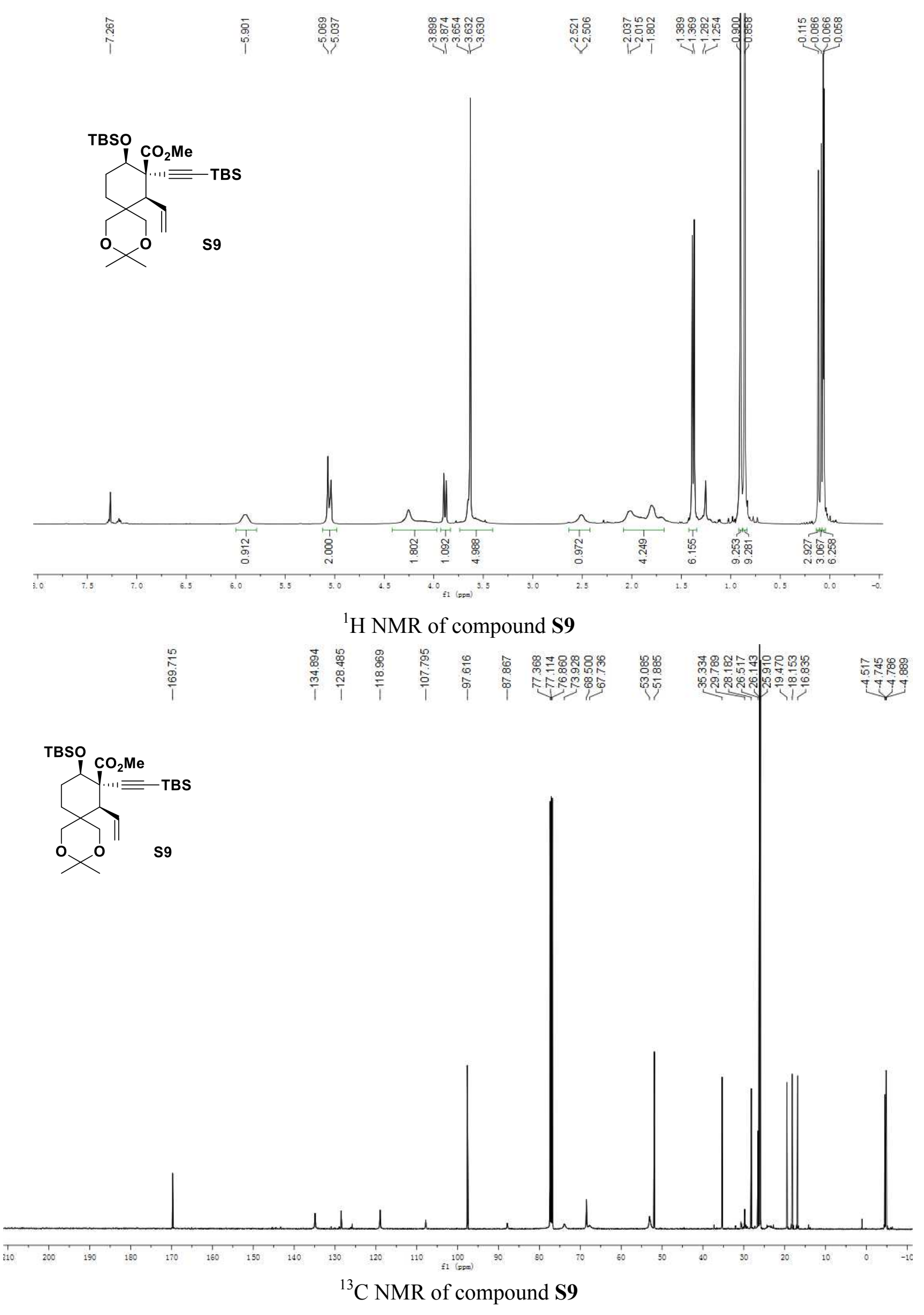



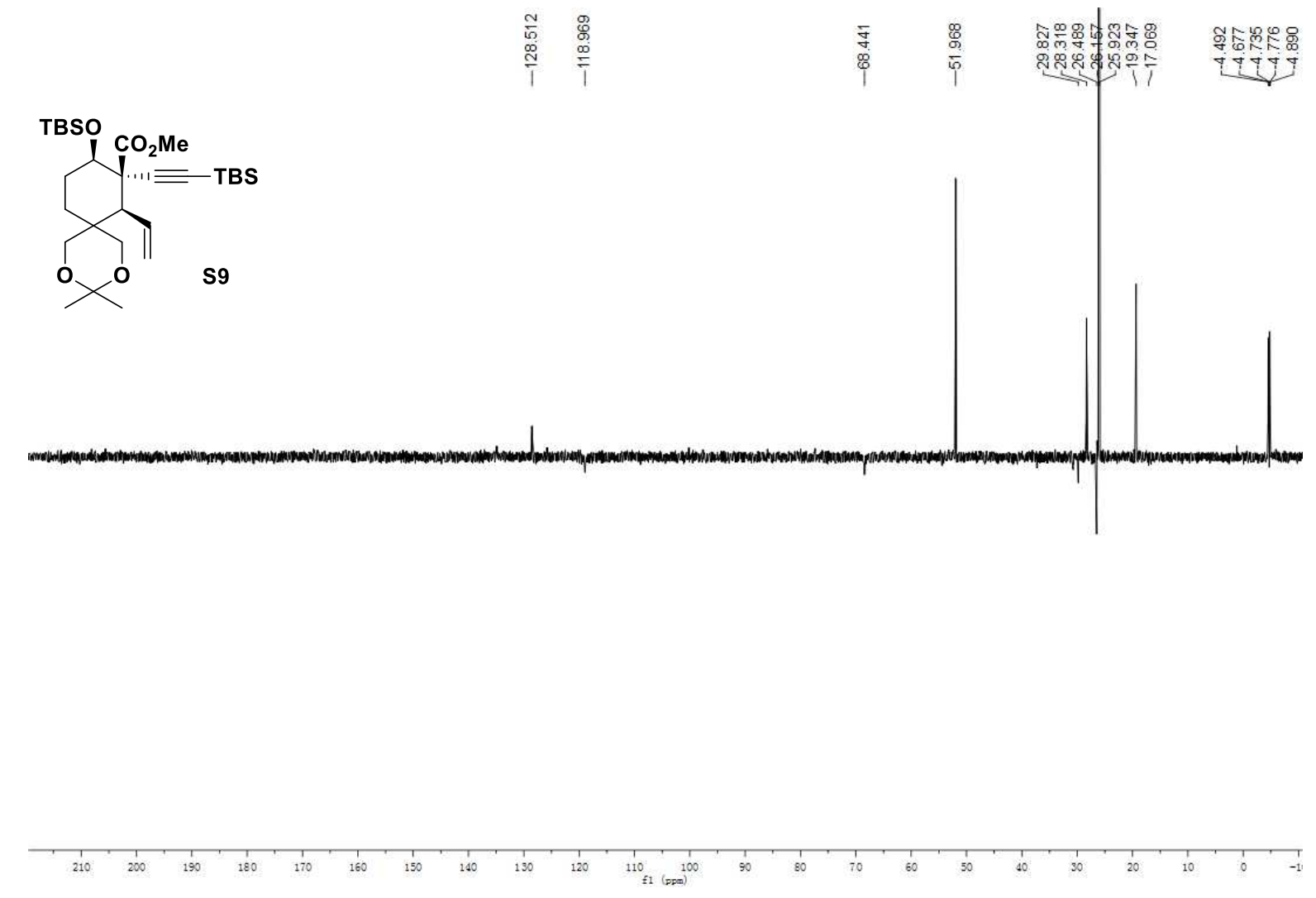

Dept135 NMR of compound S9

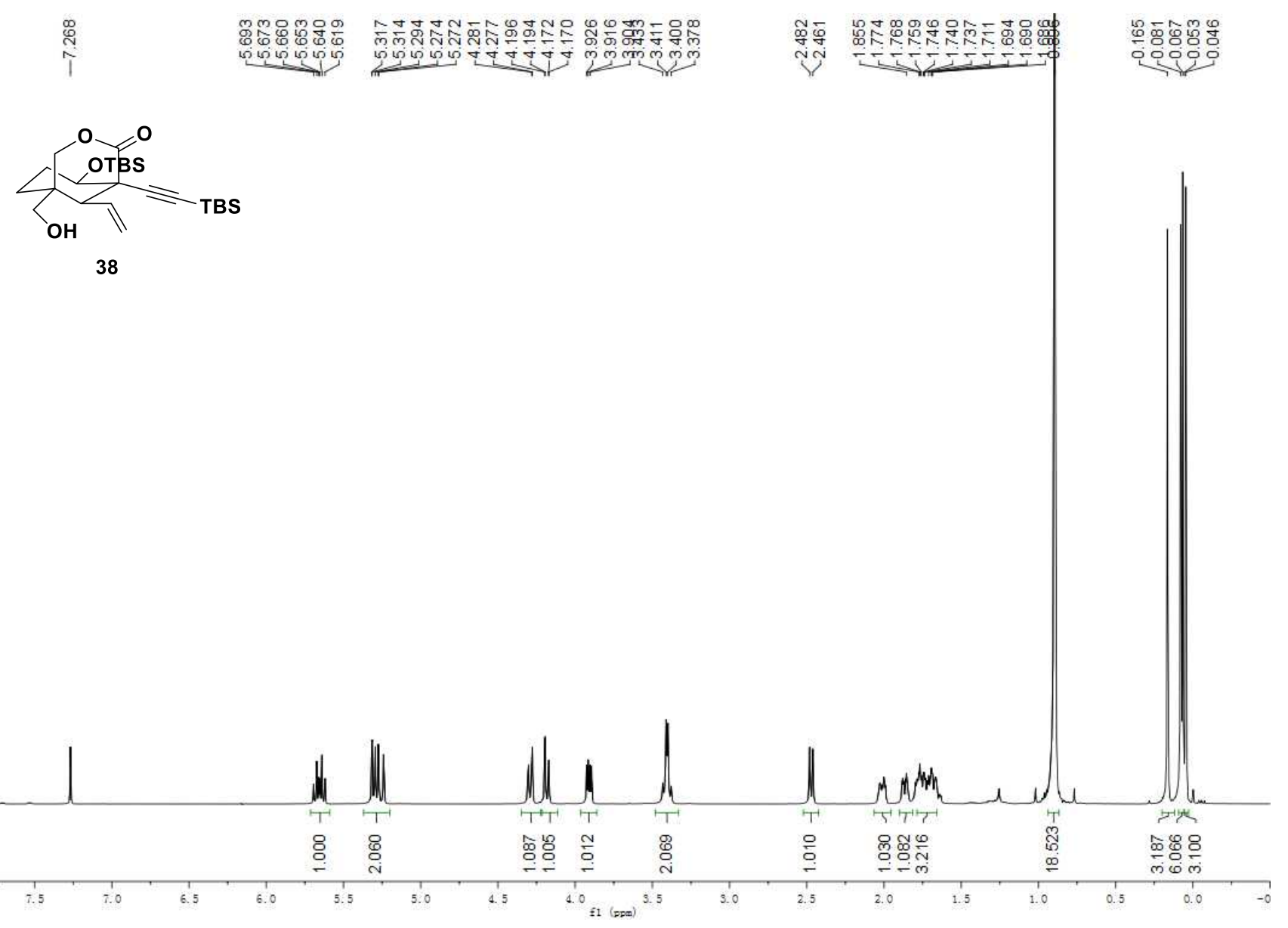

${ }^{1} \mathrm{H}$ NMR of compound $\mathbf{3 8}$ 

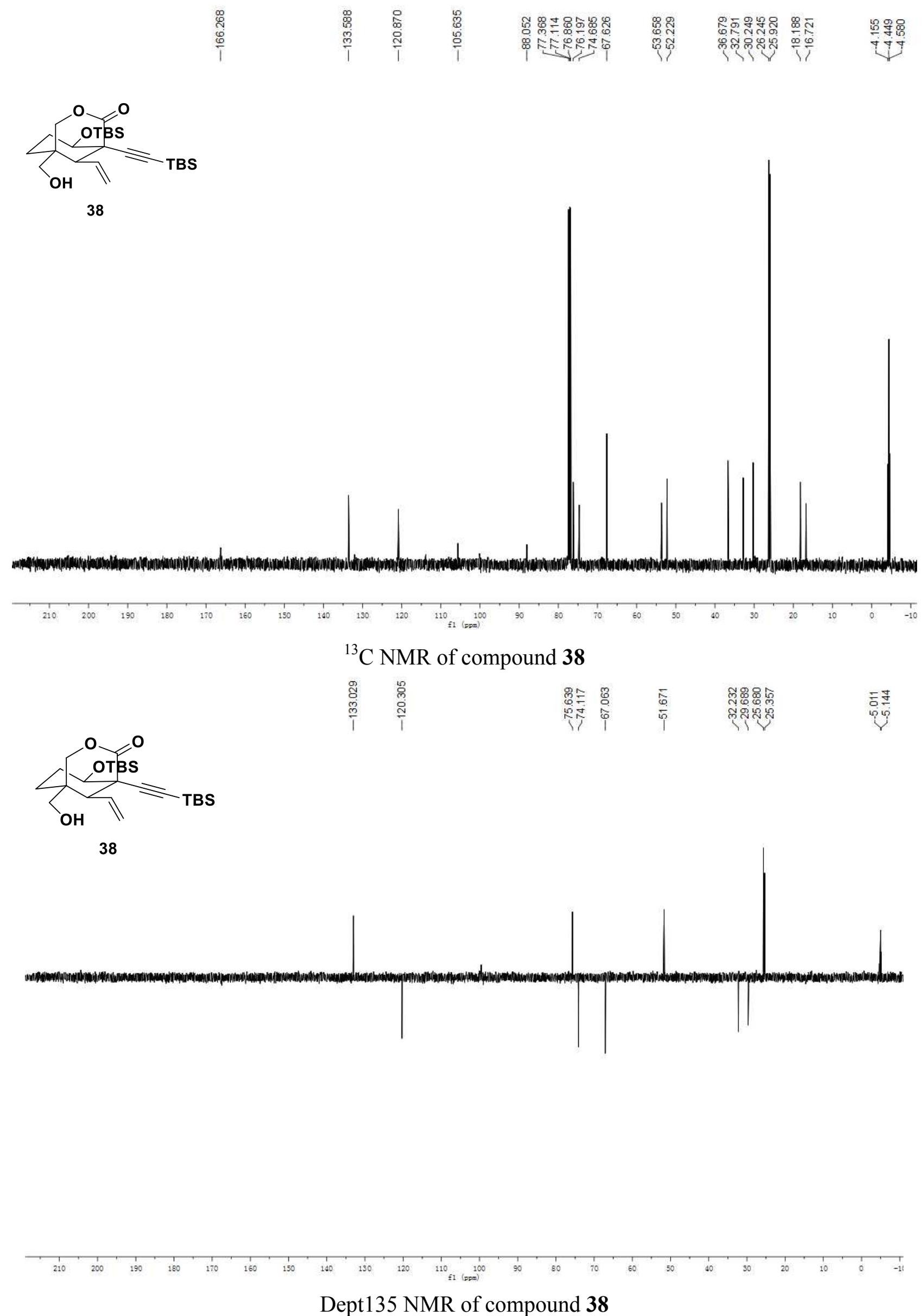


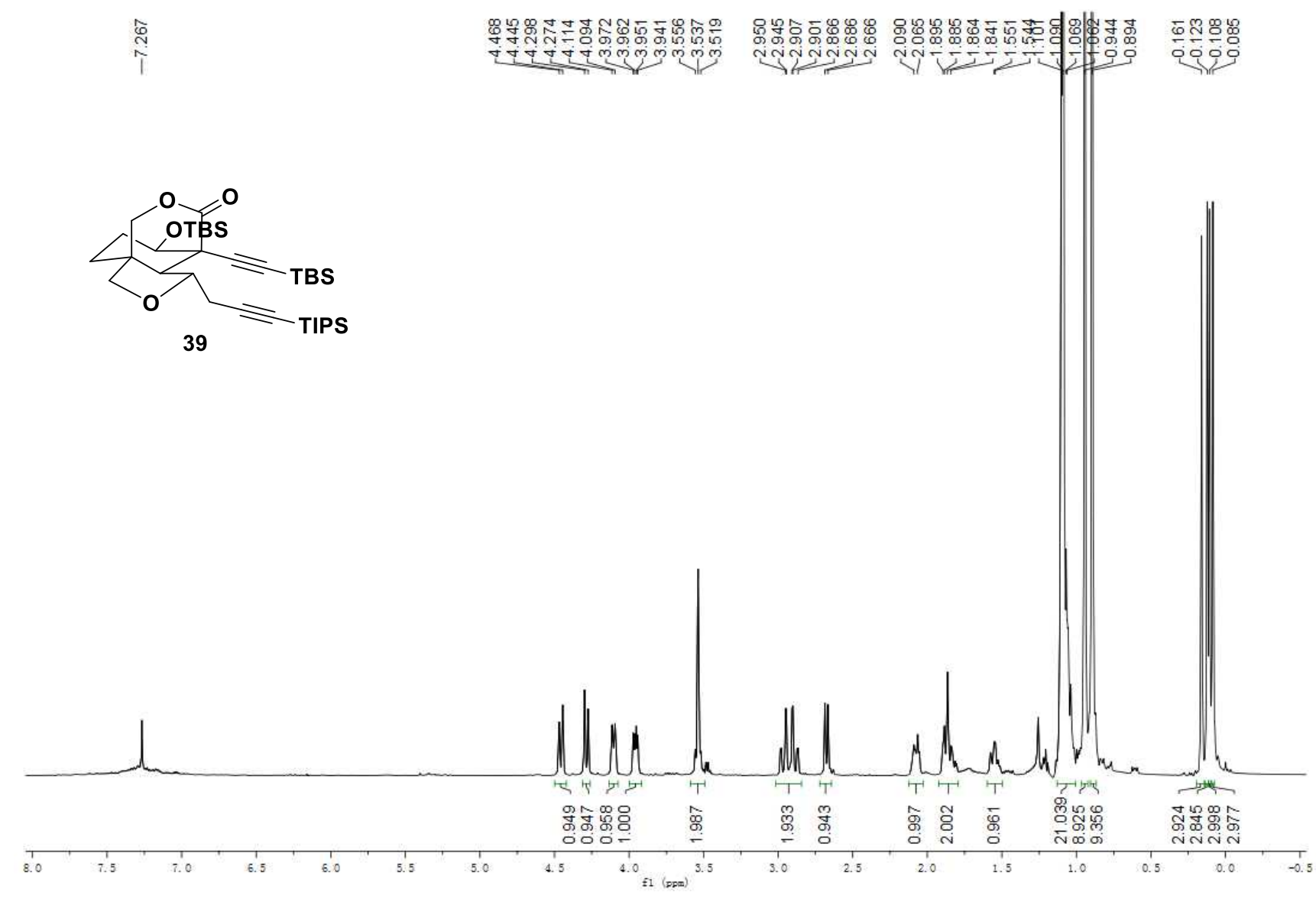

${ }^{1} \mathrm{H}$ NMR of compound 39
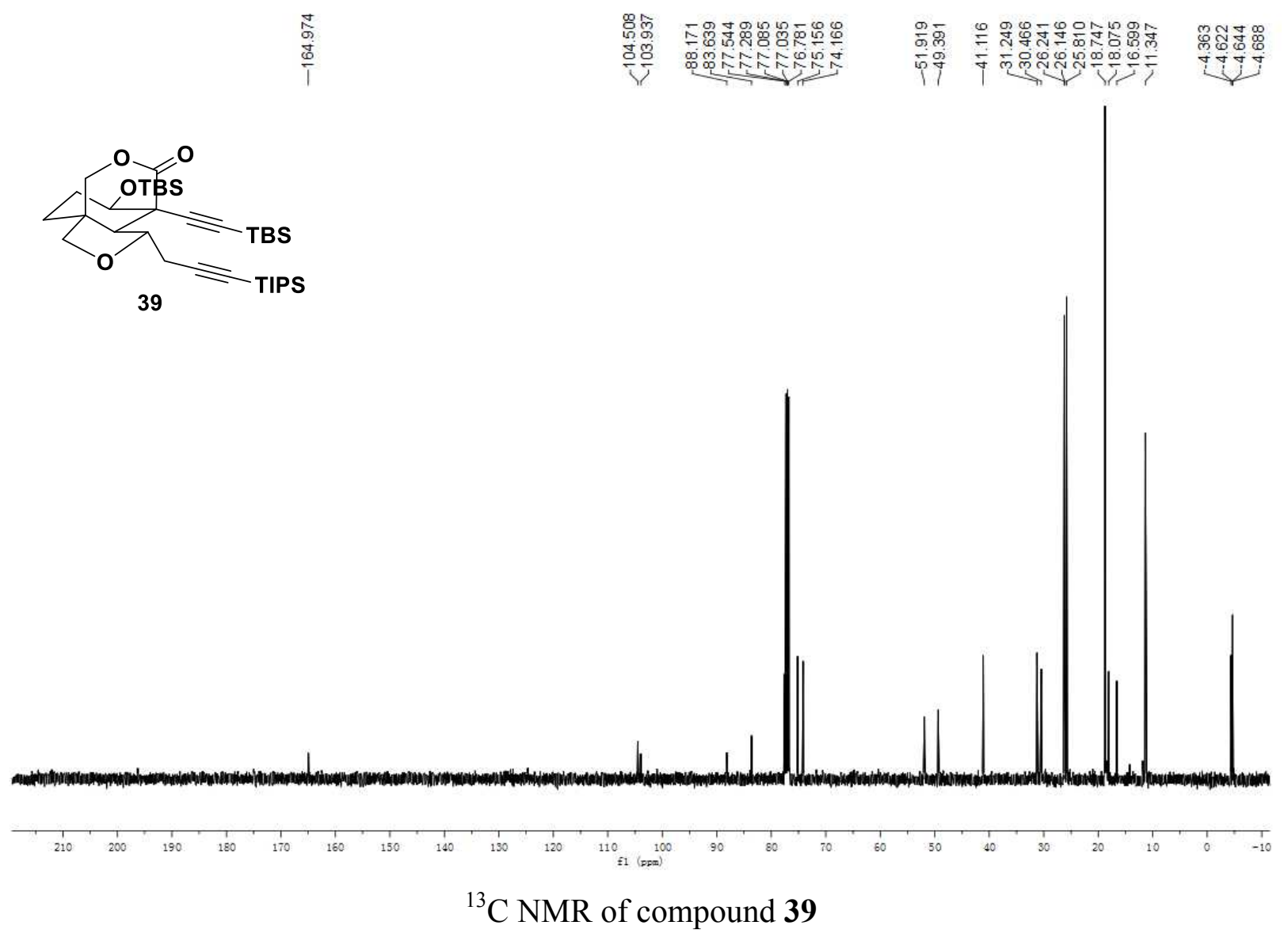

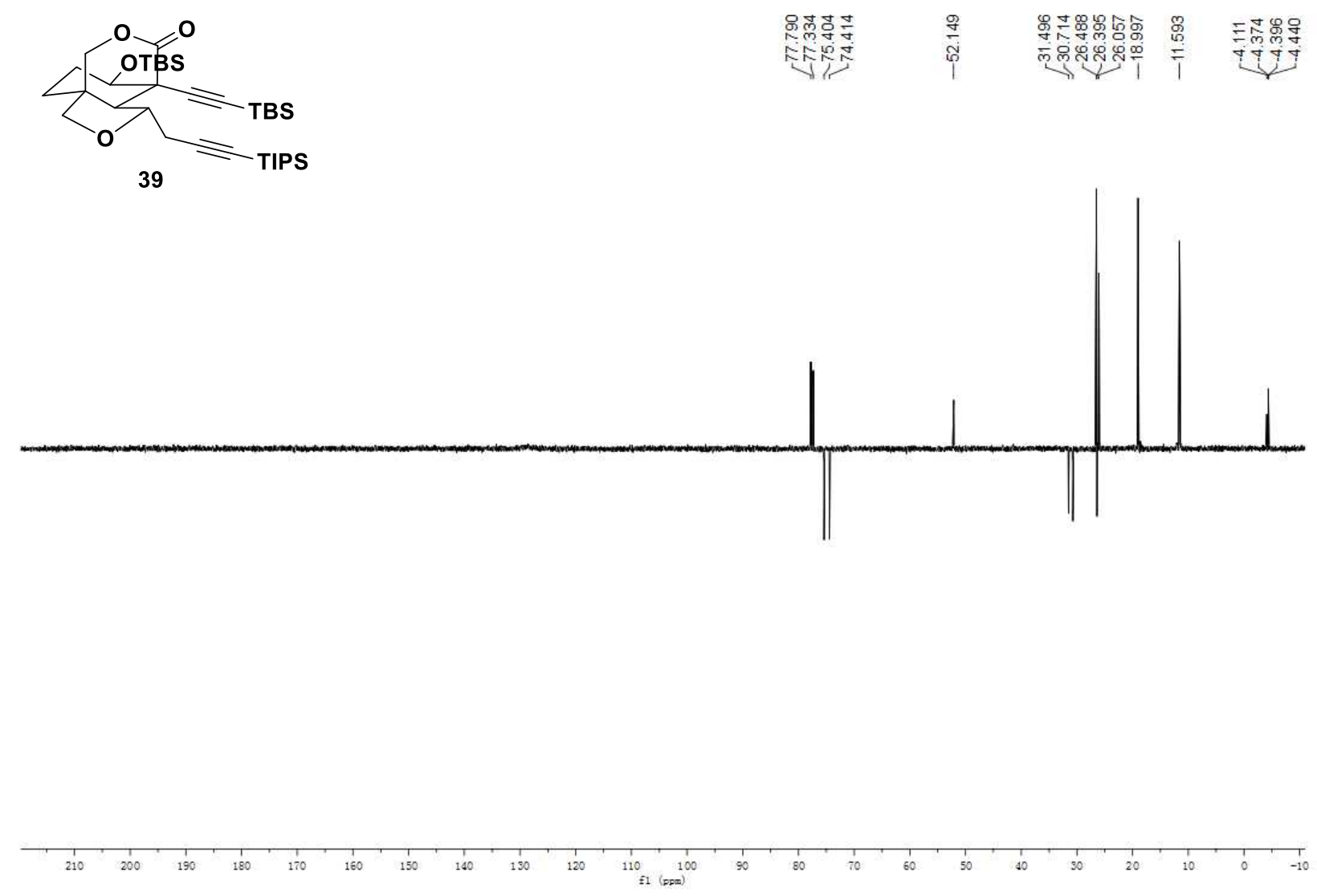

Dept135 NMR of compound 39

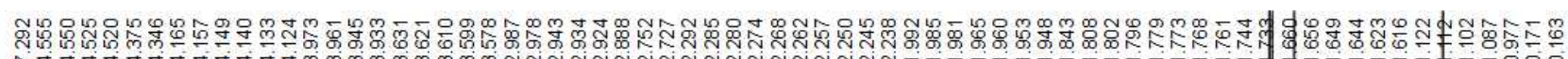

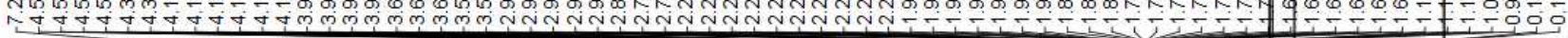

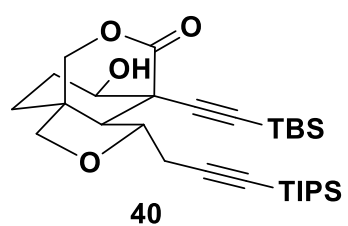

40

(1)

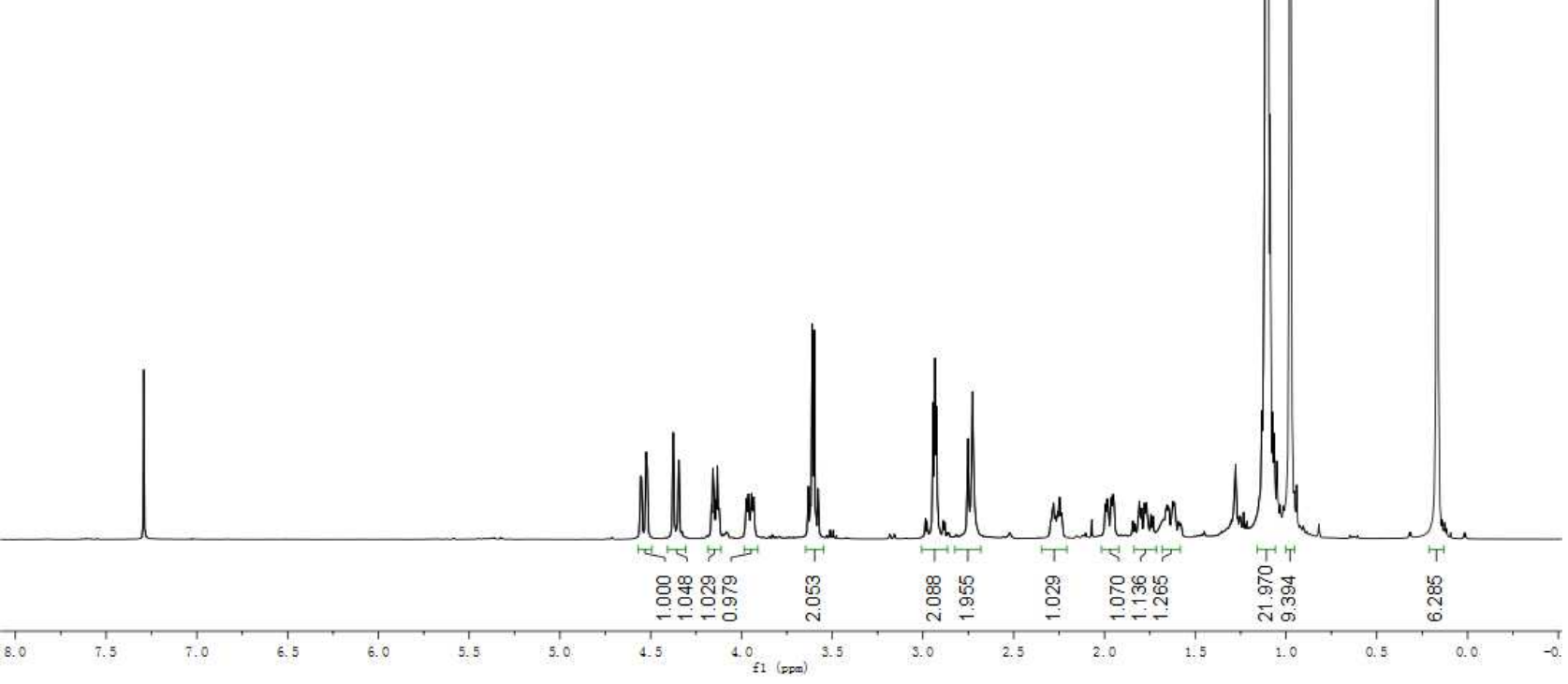

${ }^{1} \mathrm{H}$ NMR of compound $\mathbf{4 0}$ 

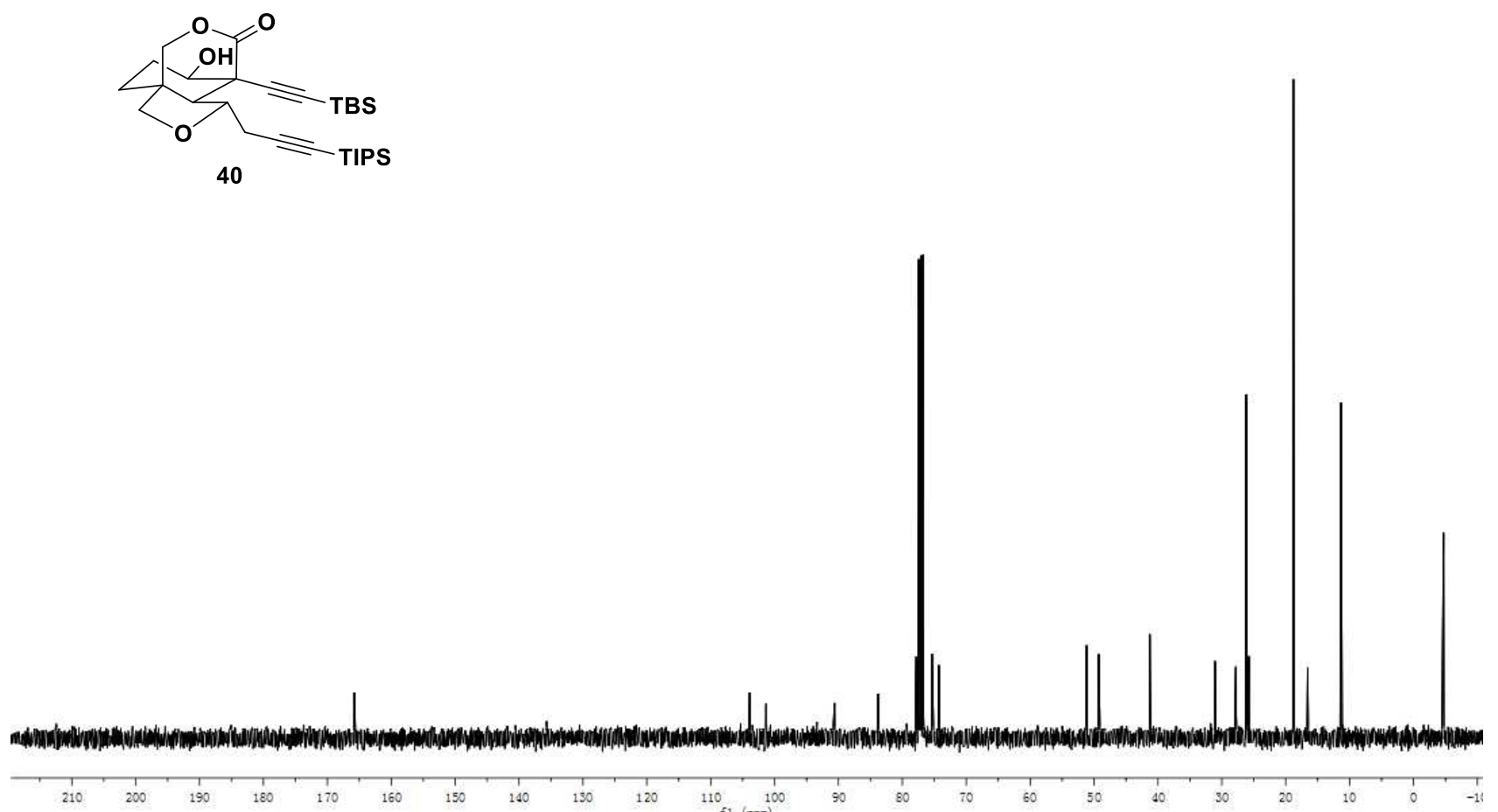

${ }^{13} \mathrm{C}$ NMR of compound 40

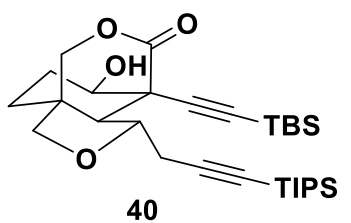

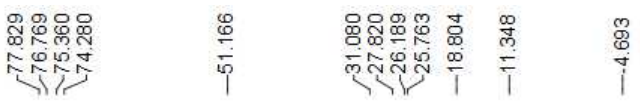
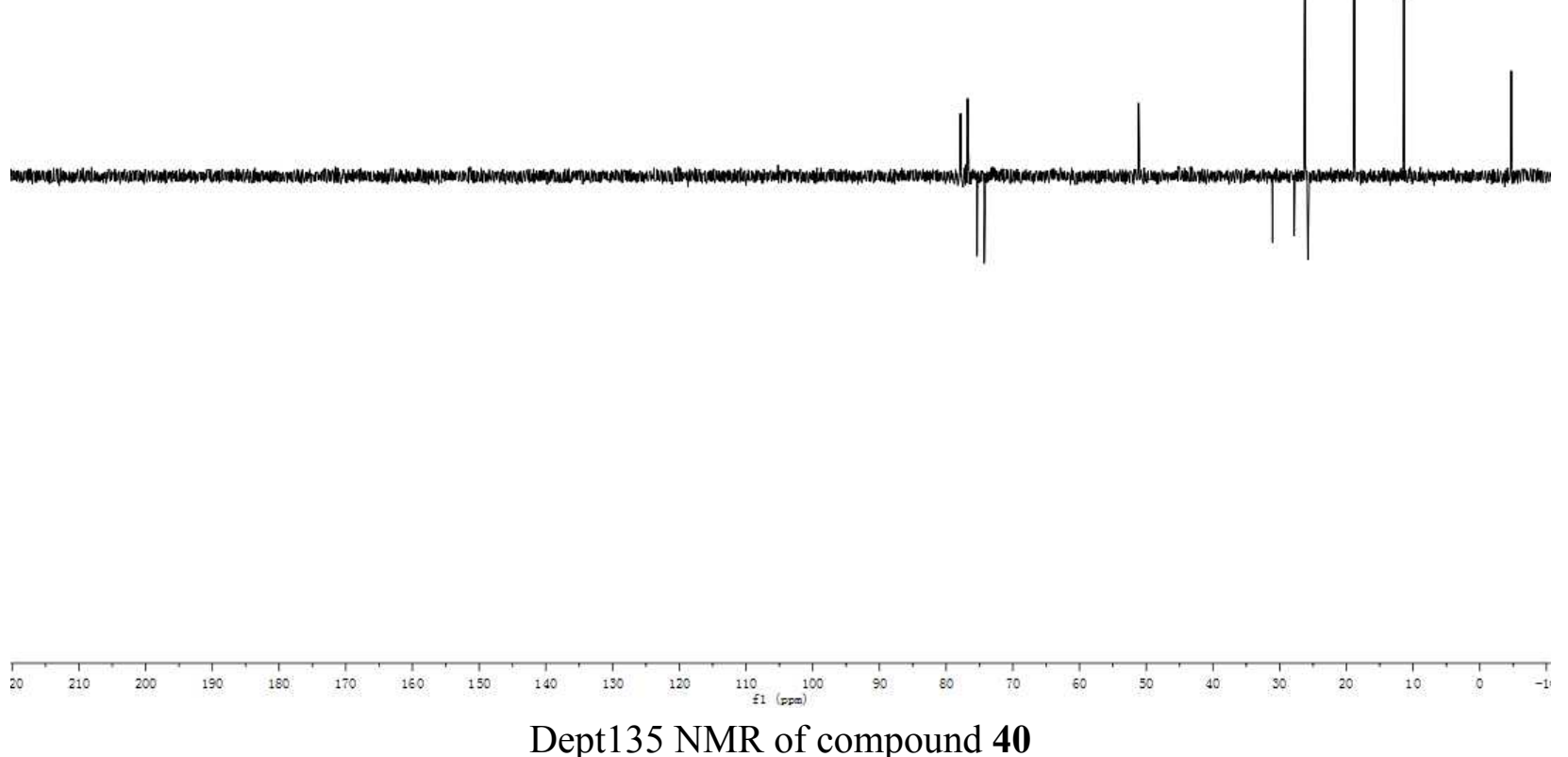

Dept135 NMR of compound 40 


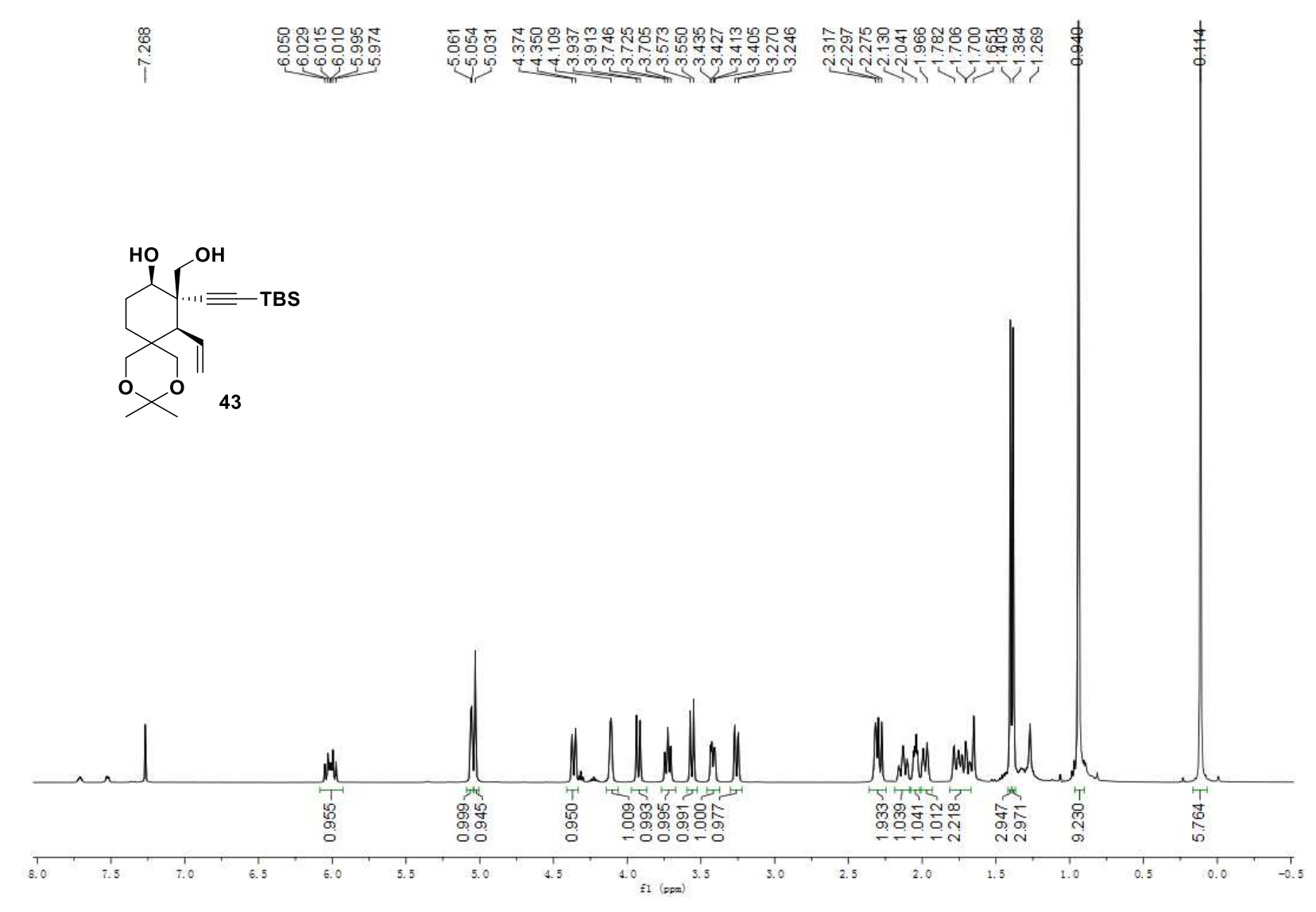

${ }^{1} \mathrm{H}$ NMR of compound $\mathbf{4 3}$

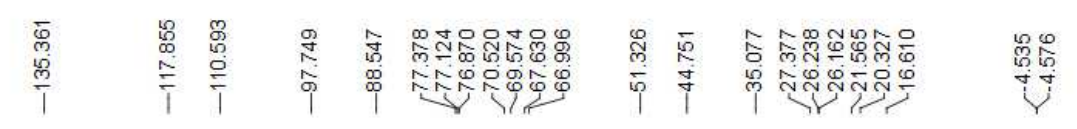<smiles>CC1(C)CC2(CCC(O)C(O)C2(C#C[131I])CO)CO1</smiles> 

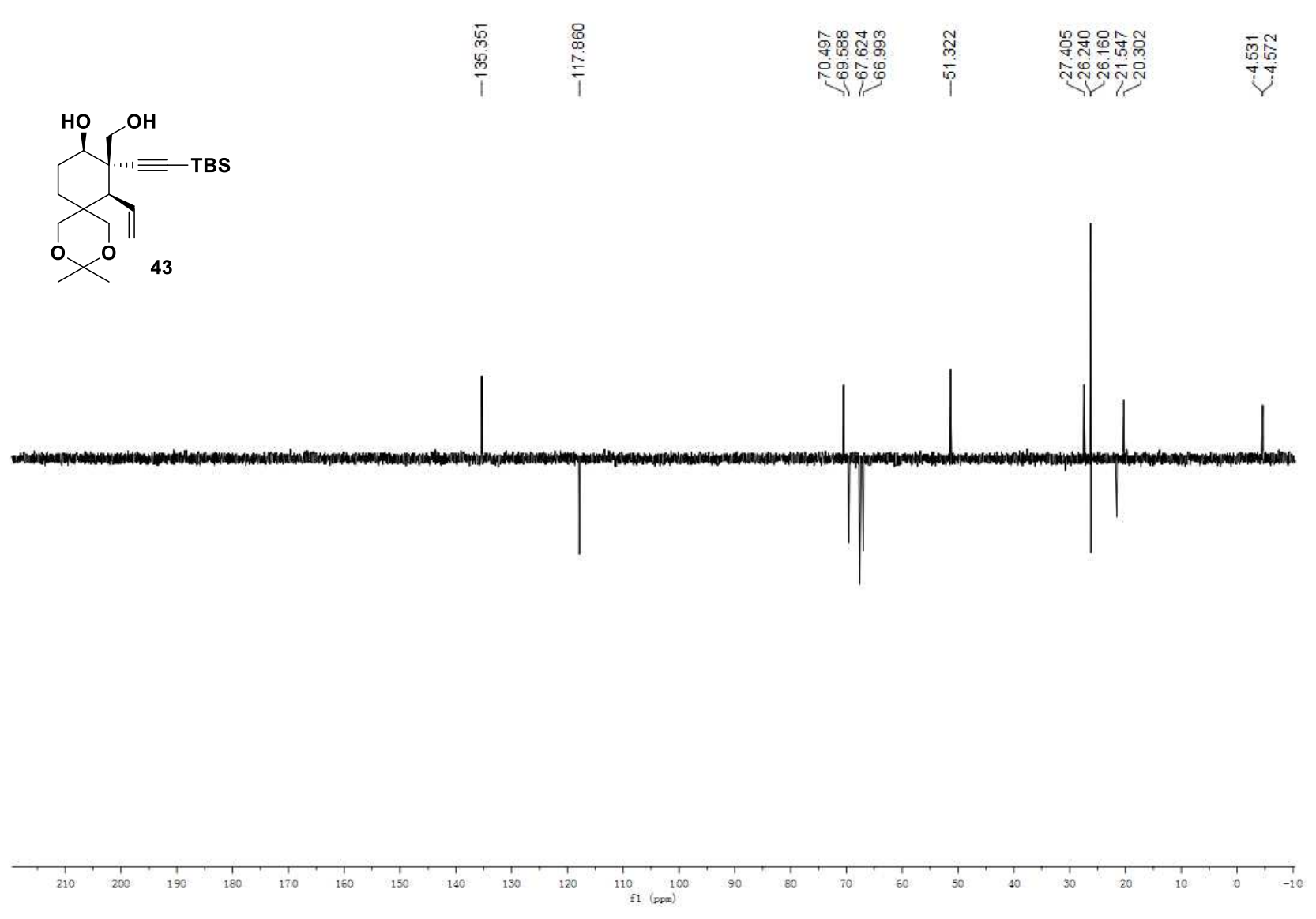

Dept135 NMR of compound $\mathbf{4 3}$

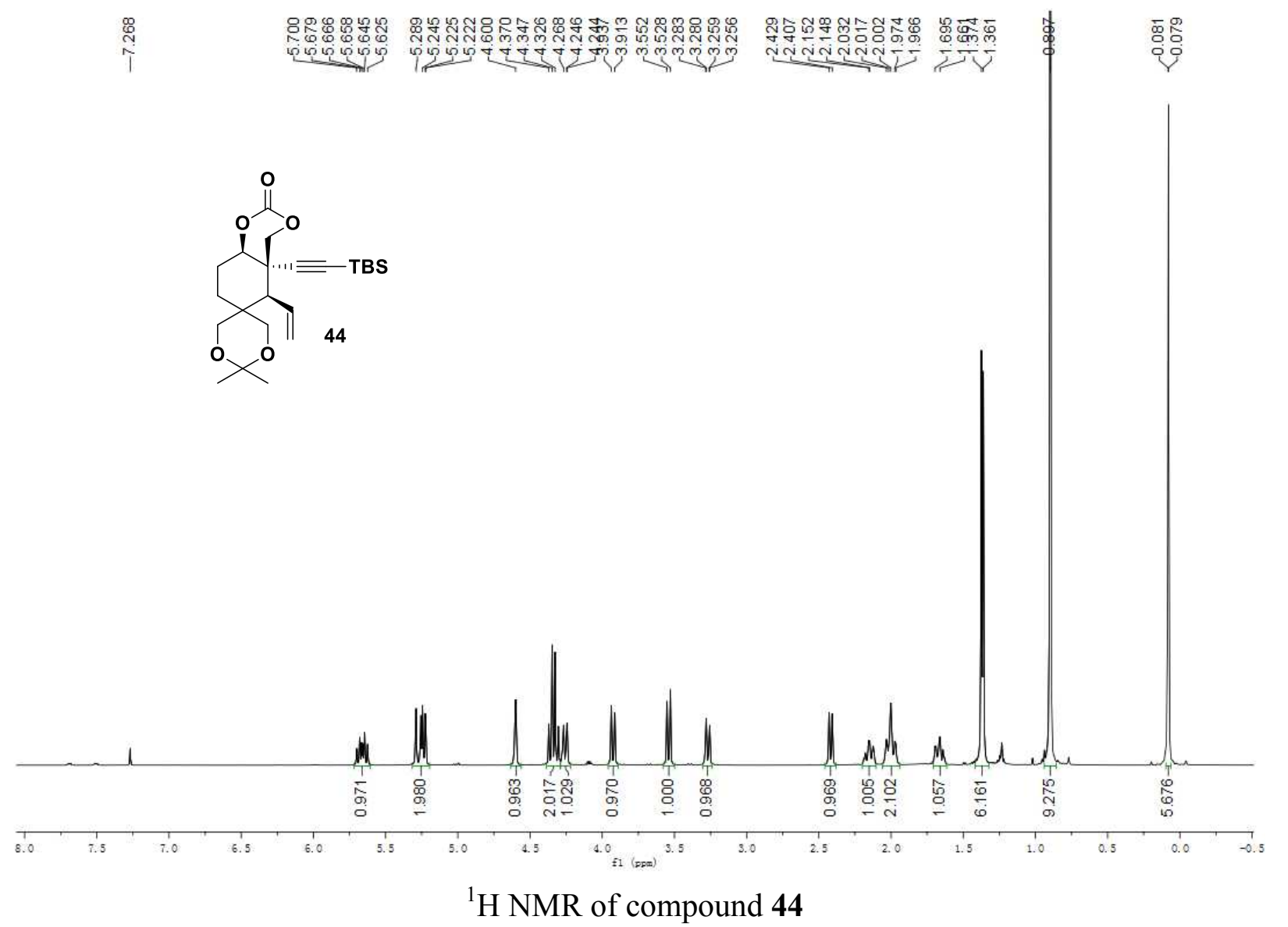



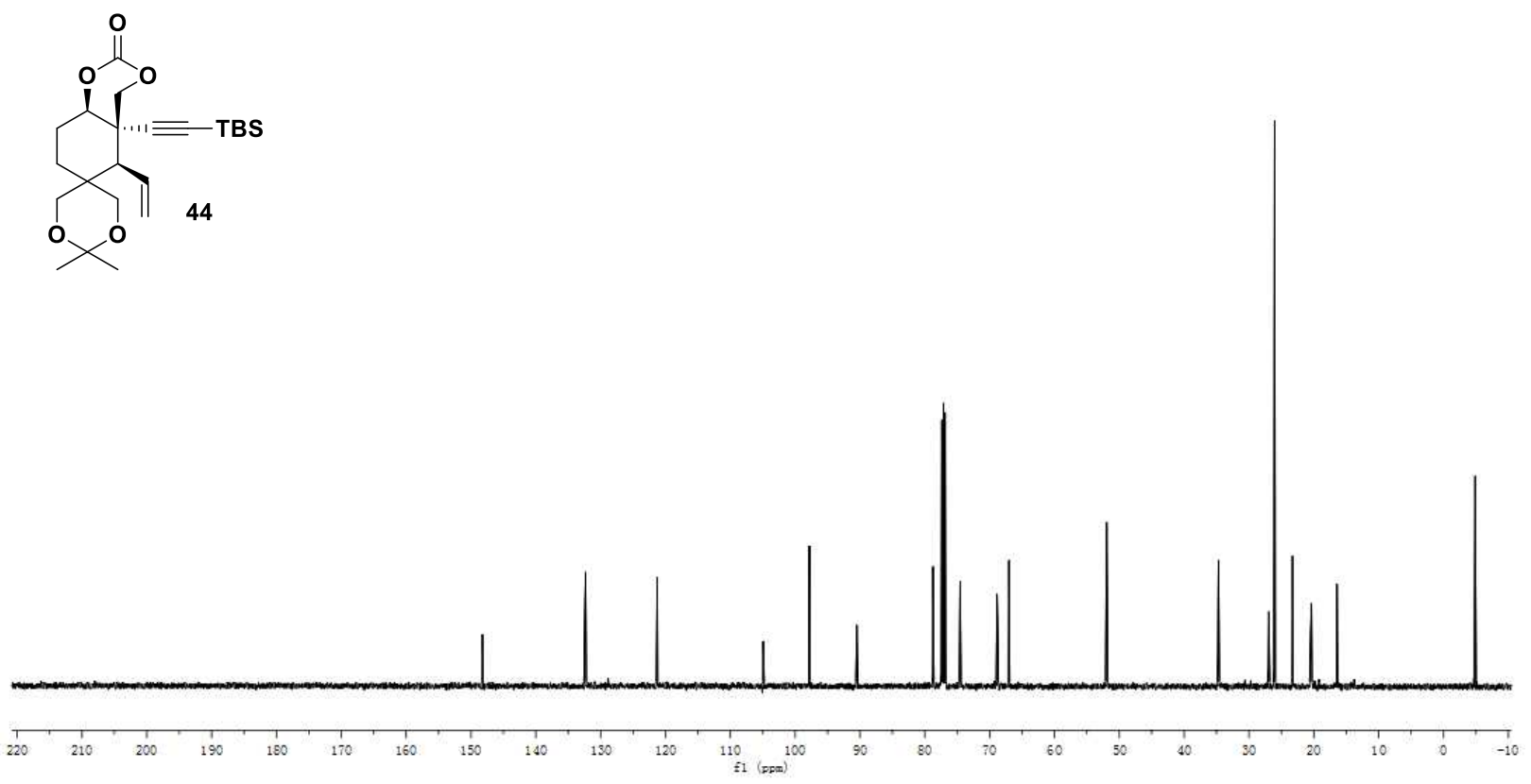

${ }^{13} \mathrm{C}$ NMR of compound 44
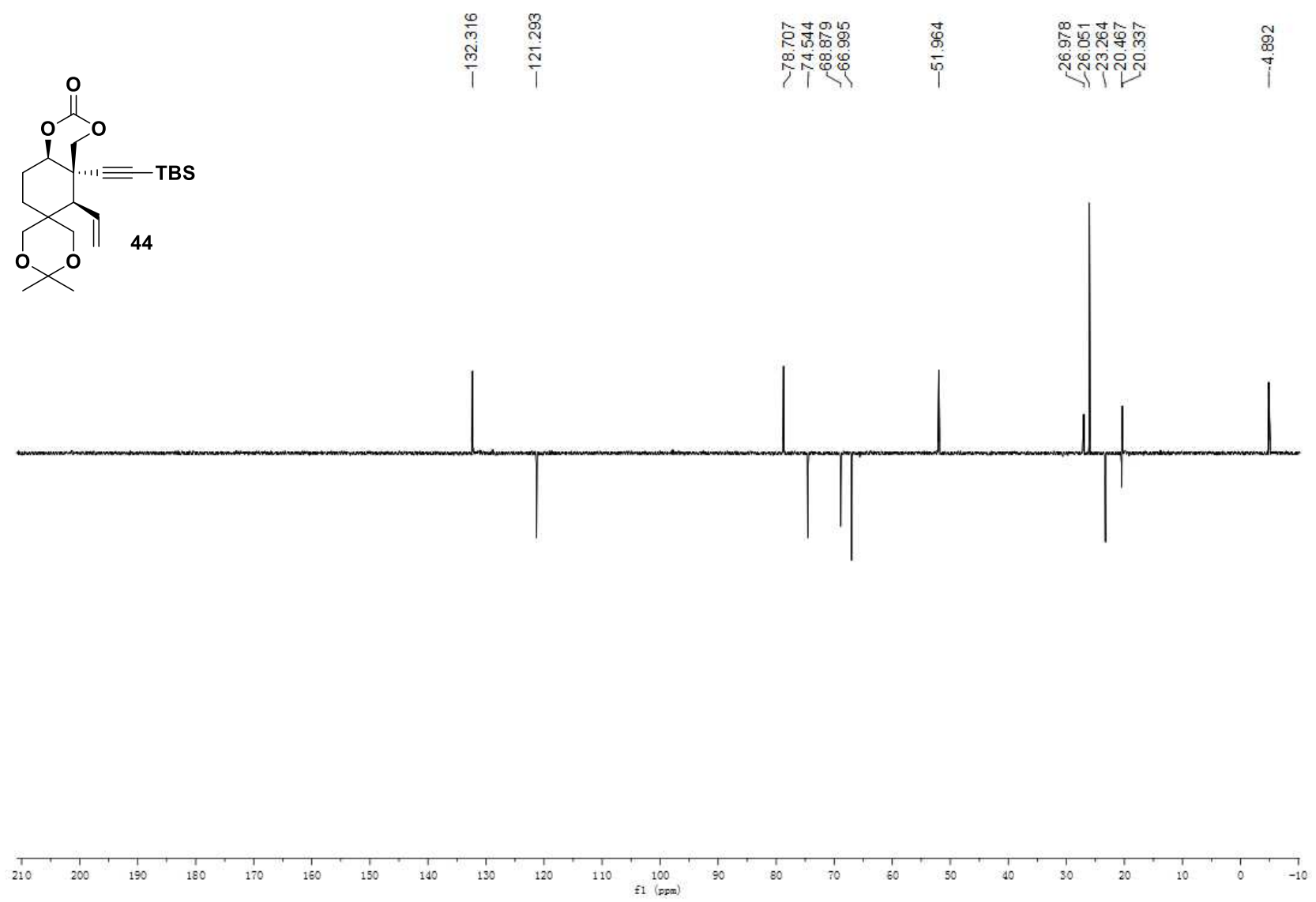

Dept135 NMR of compound 44 


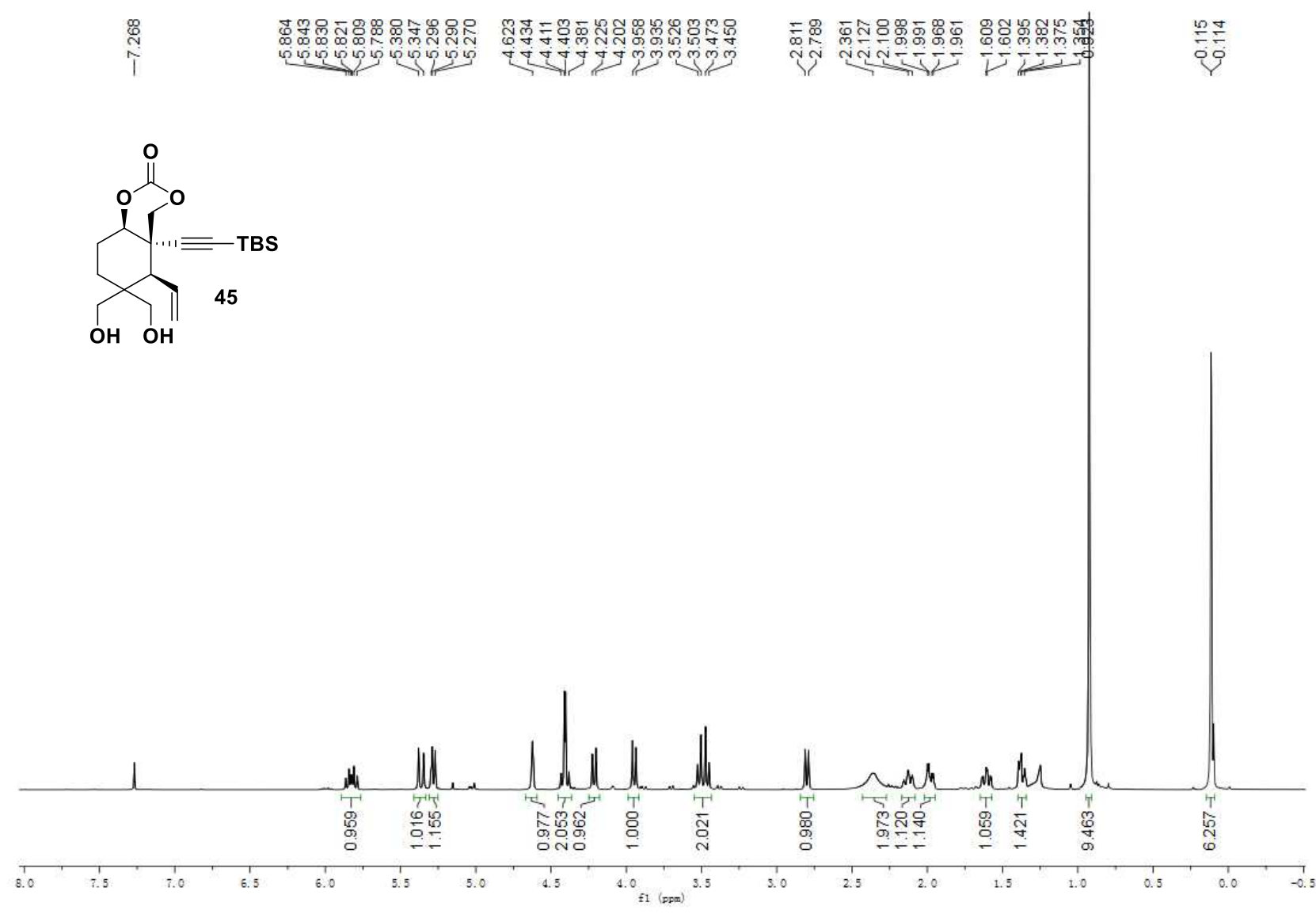

${ }^{1} \mathrm{H}$ NMR of compound 45

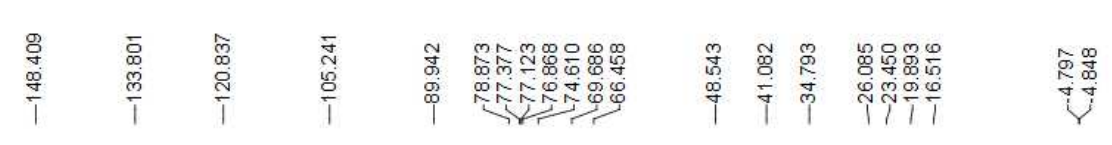

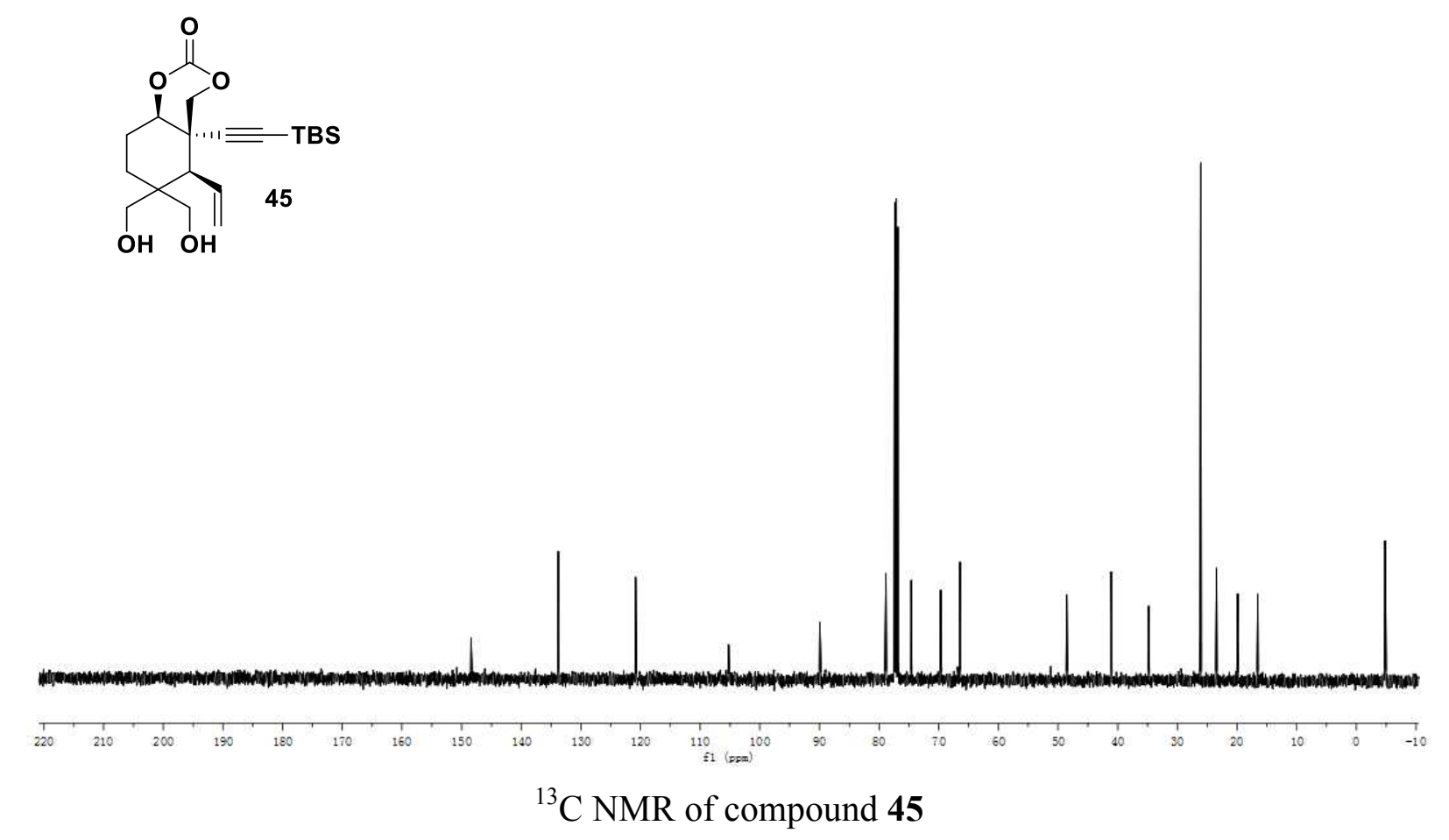




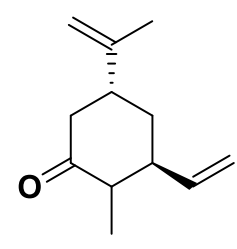

S10

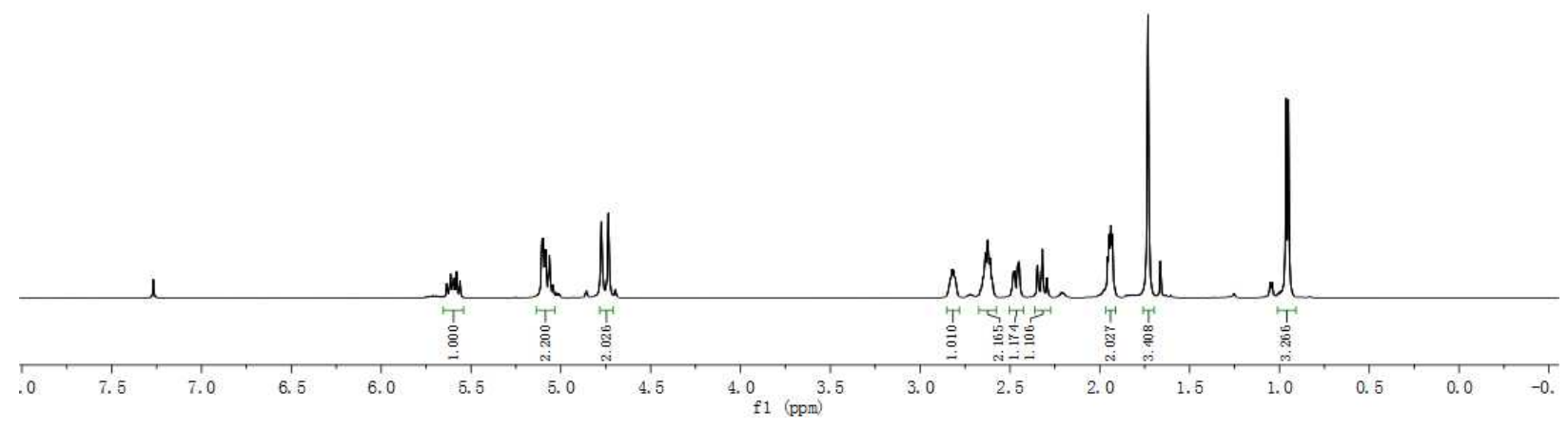

${ }^{1} \mathrm{H}$ NMR of compound $\mathbf{S 1 0}$

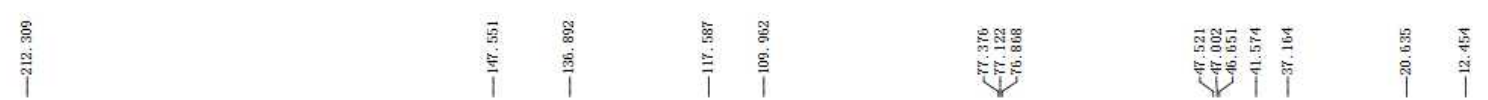<smiles>C=CC1C[C@@H](C(=C)C)CC(=O)C1C</smiles>

S10

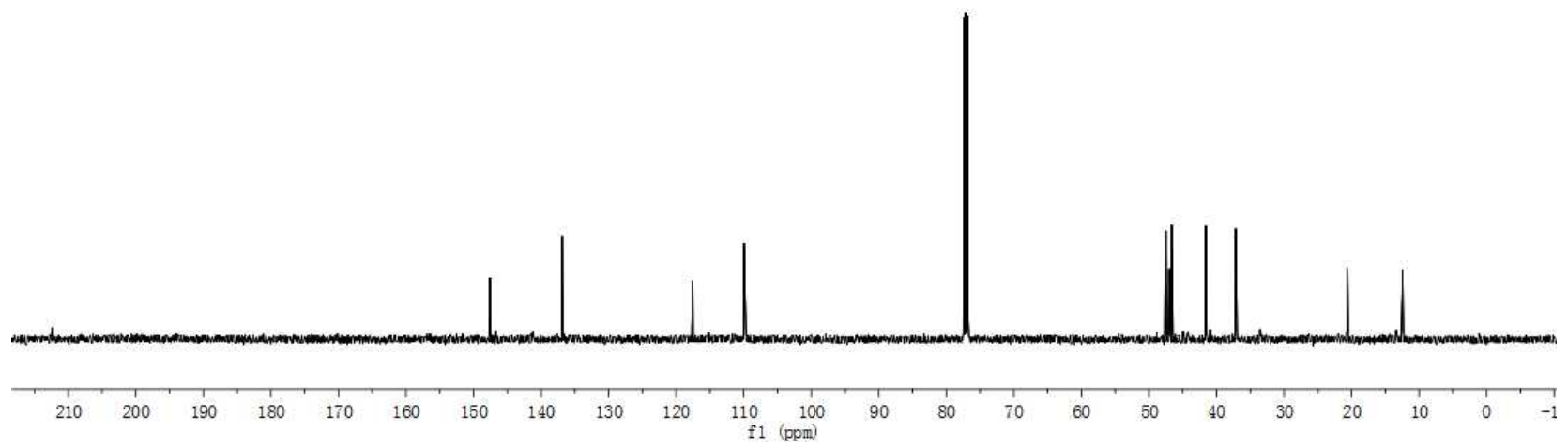

${ }^{13} \mathrm{C}$ NMR of compound $\mathbf{S 1 0}$ 


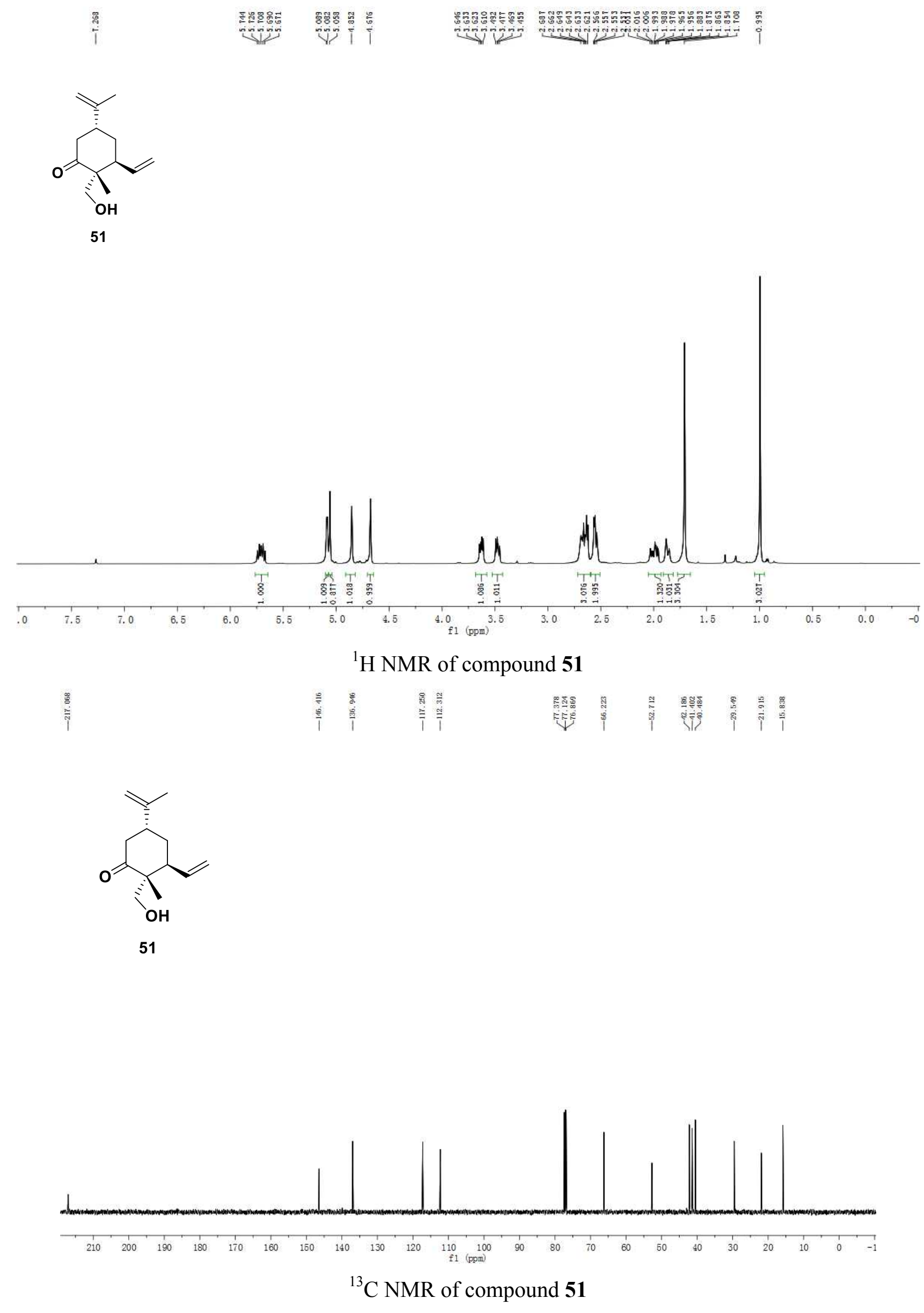




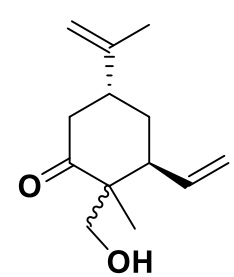

51 (마- $-\mathrm{Me}$; ? $-\mathrm{Me}=3: 10$ )

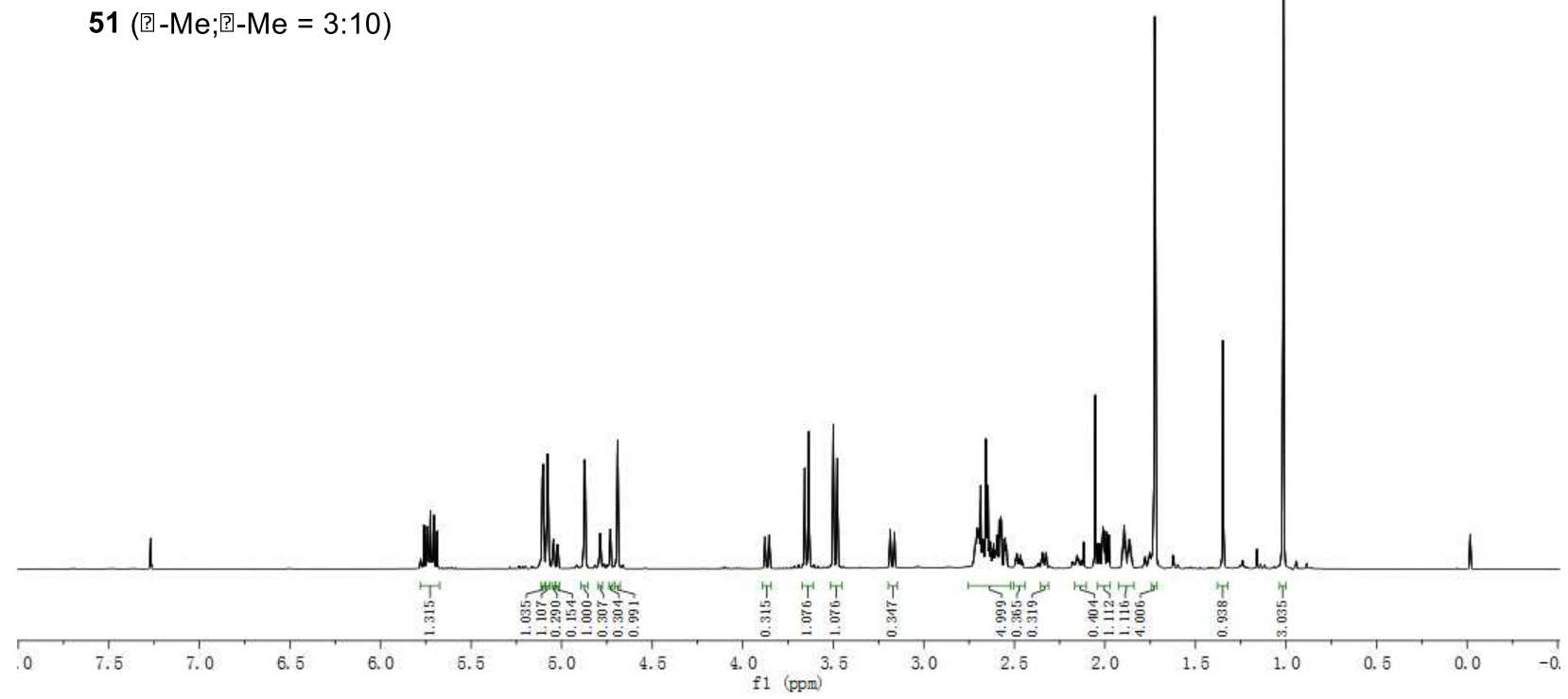

${ }^{1} \mathrm{H}$ NMR of compound $\mathbf{5 1}$

$\stackrel{\cong}{\stackrel{\overbrace{}}{\sim}}$

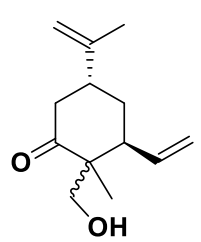

51 (?)-Me: ? $-\mathrm{Me}=3: 10$ )

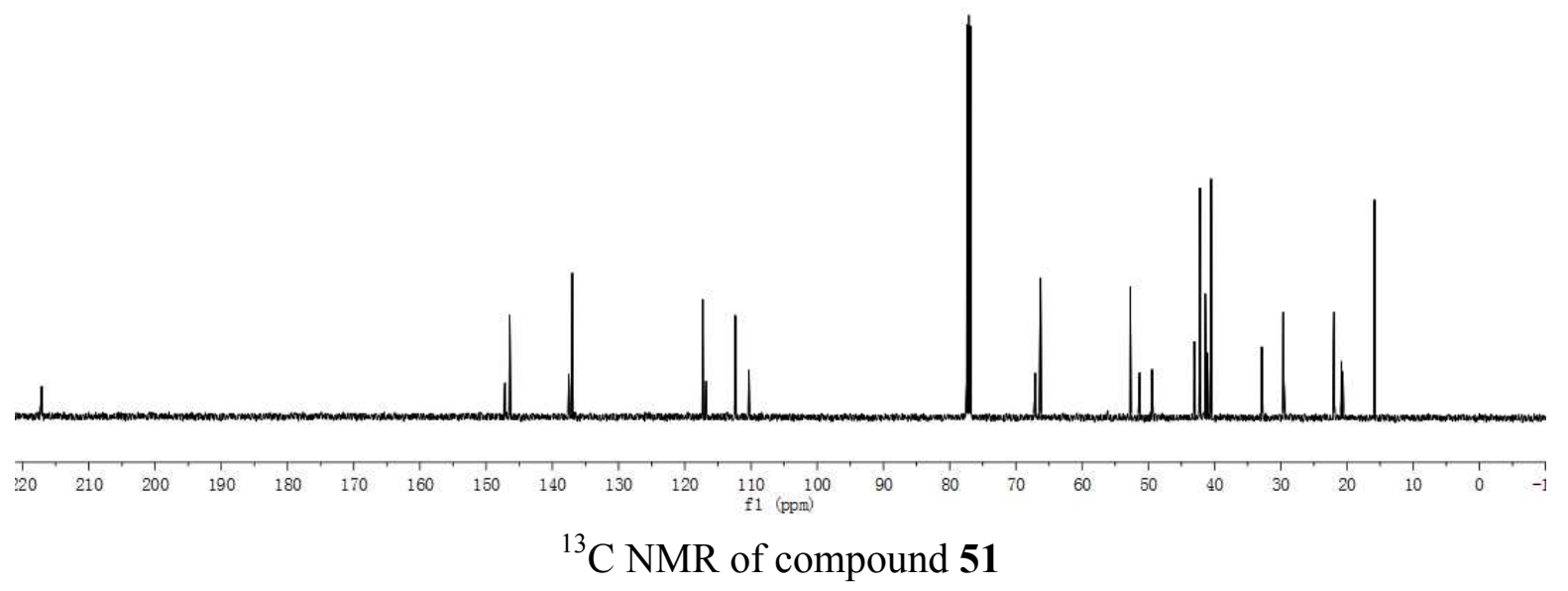




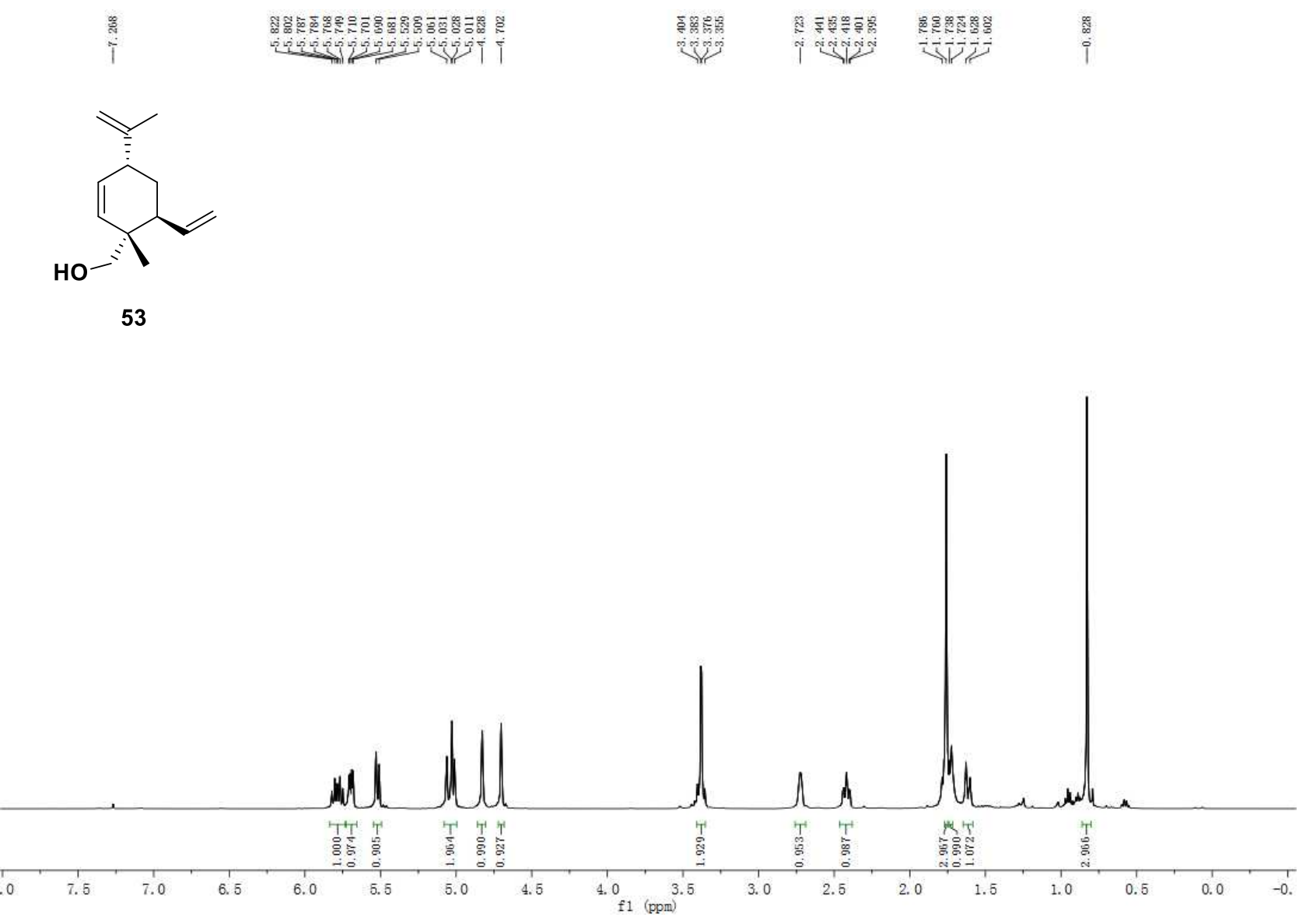

${ }^{1} \mathrm{H}$ NMR of compound $\mathbf{5 3}$
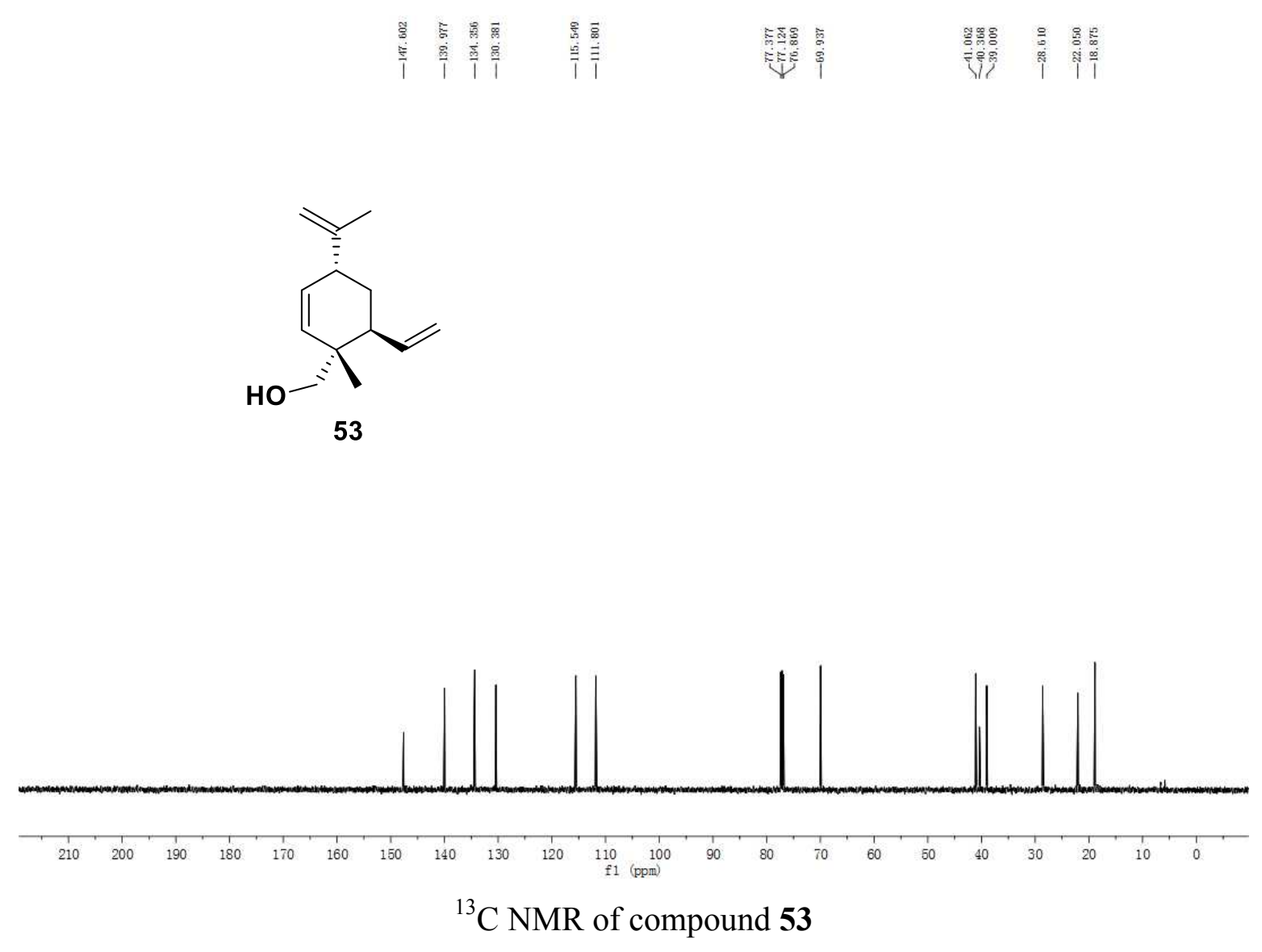


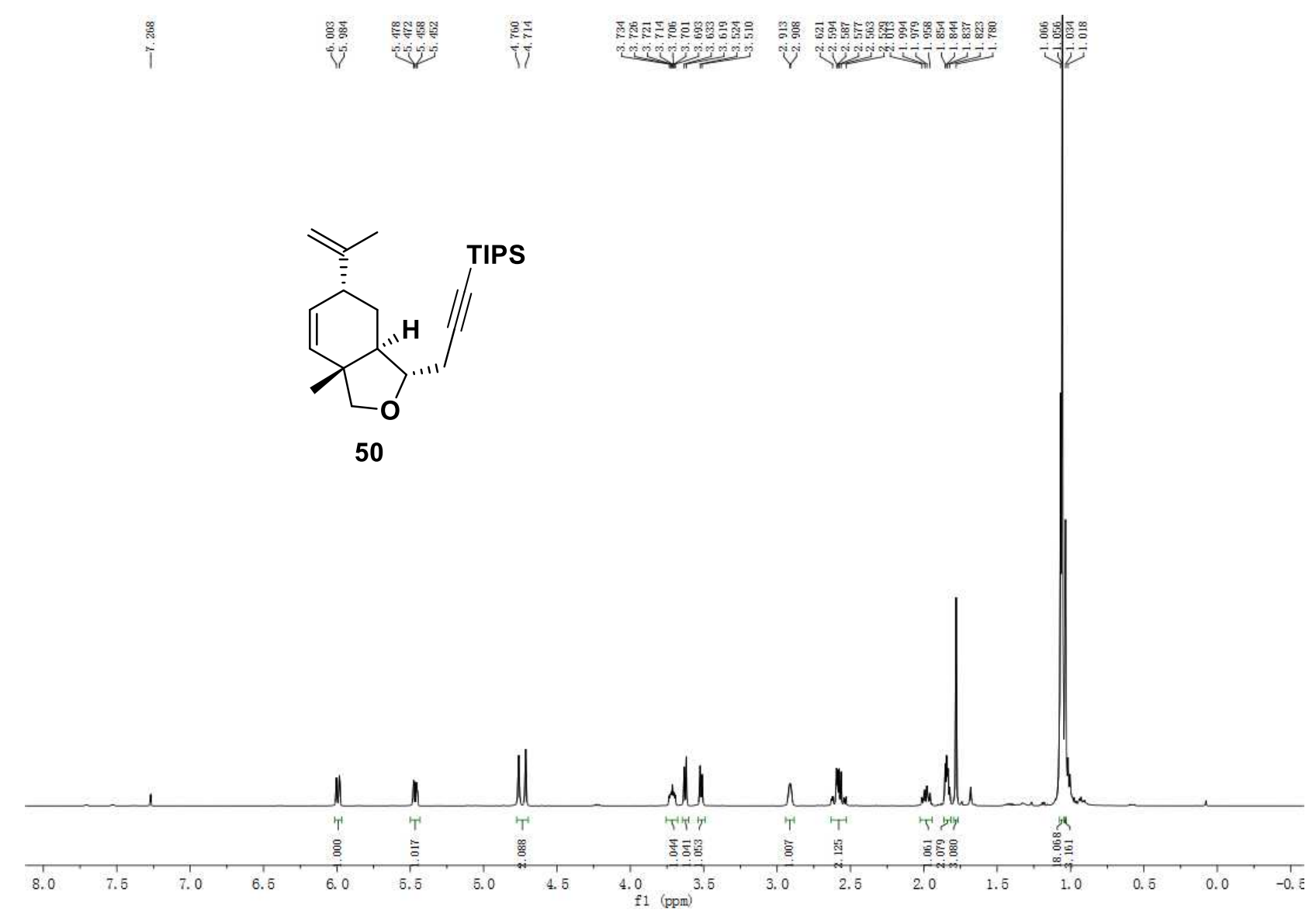

${ }^{1} \mathrm{H}$ NMR of compound $\mathbf{5 0}$

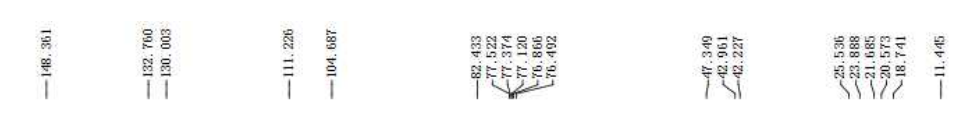

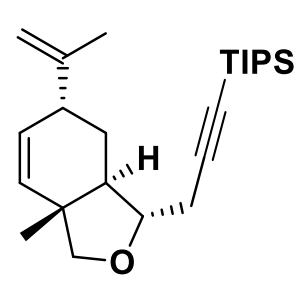

50 


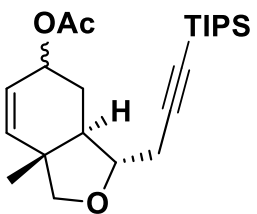

56 (马-OAc: - $-\mathrm{OAc} .=2.5: 1)$

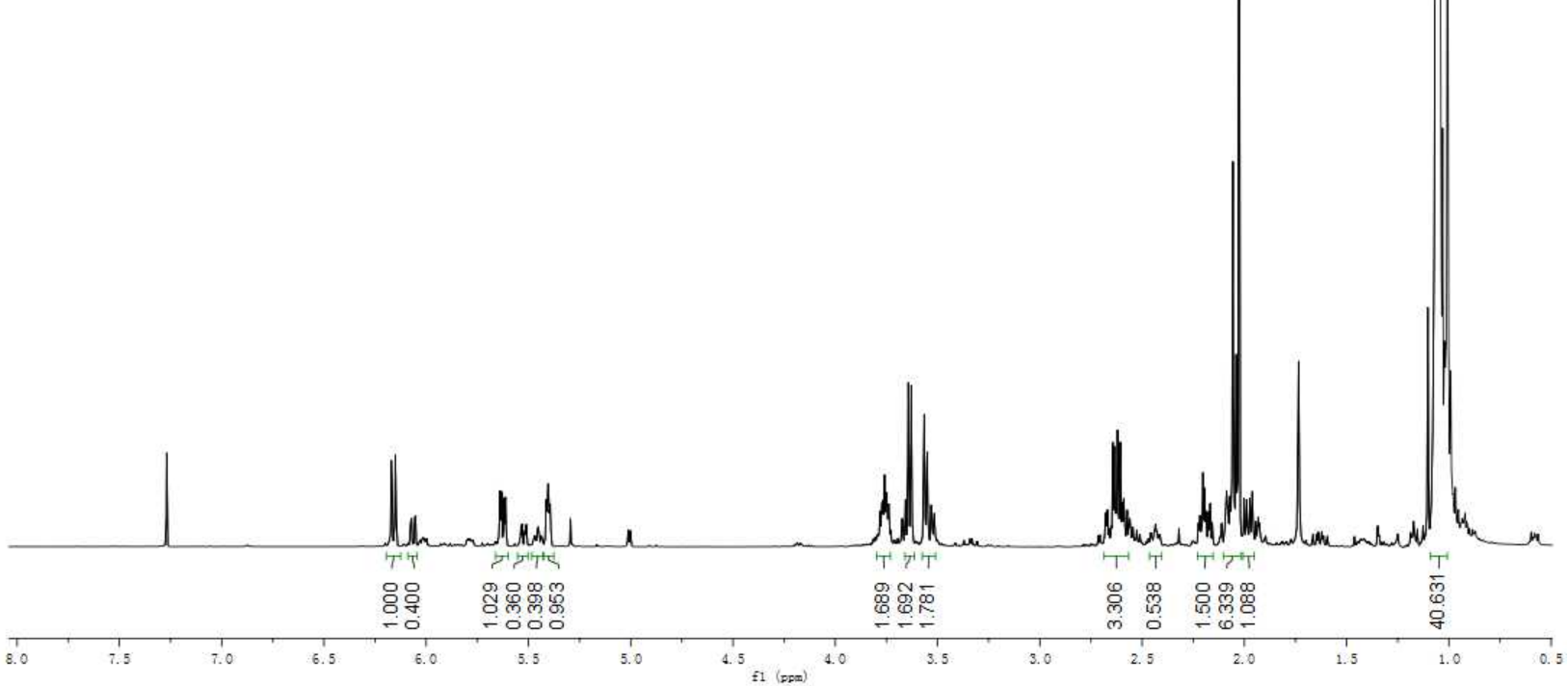

${ }^{1} \mathrm{H}$ NMR of compound $\mathbf{5 6}$
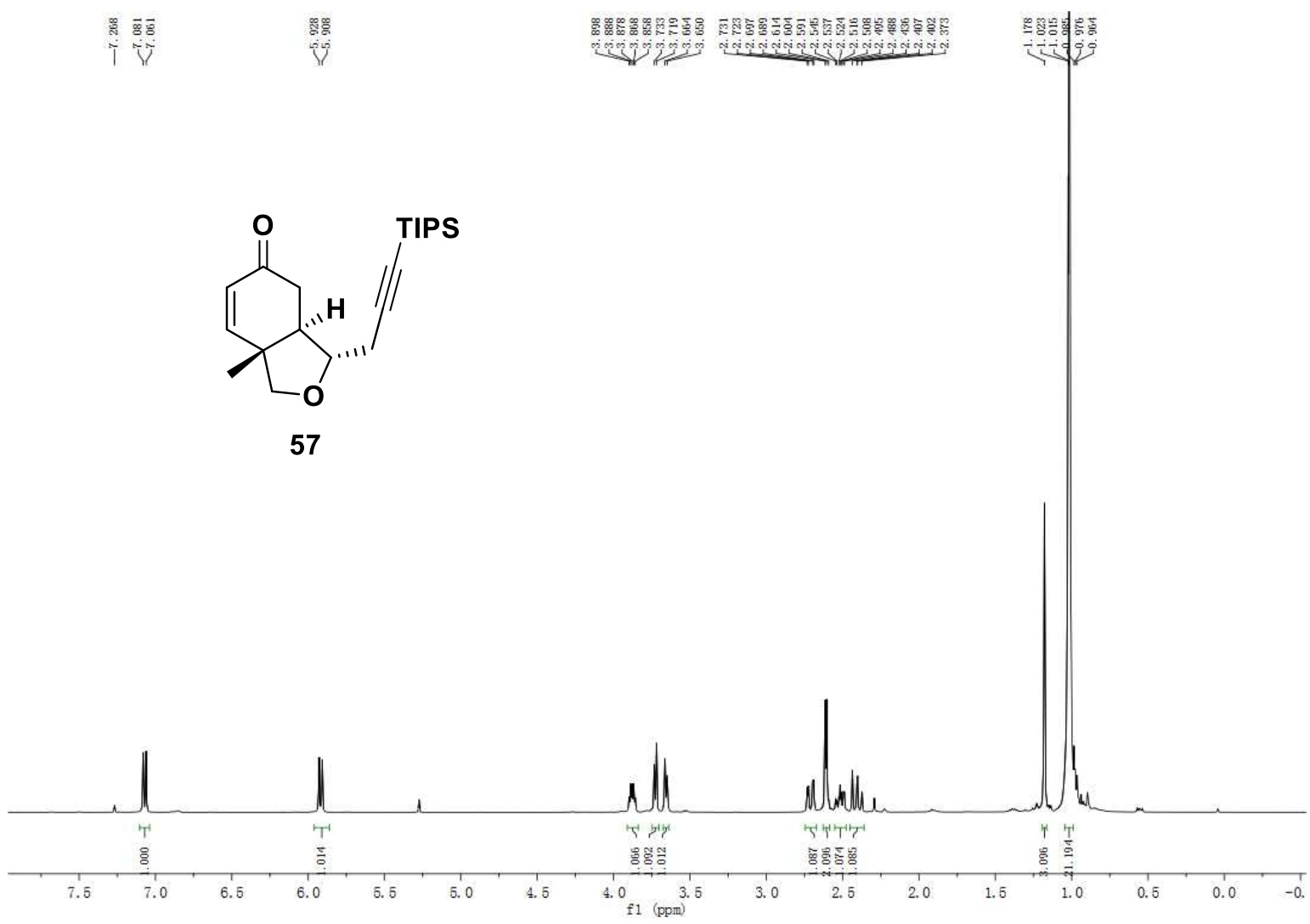

${ }^{1} \mathrm{H}$ NMR of compound $\mathbf{5 7}$ 


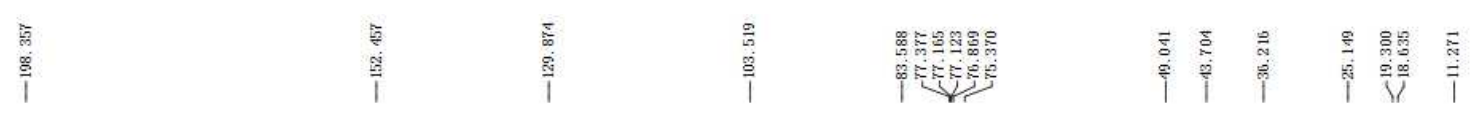<smiles>CC12C=CC(=O)C[C@H]1[C@H](CC#C[In])OC2</smiles>

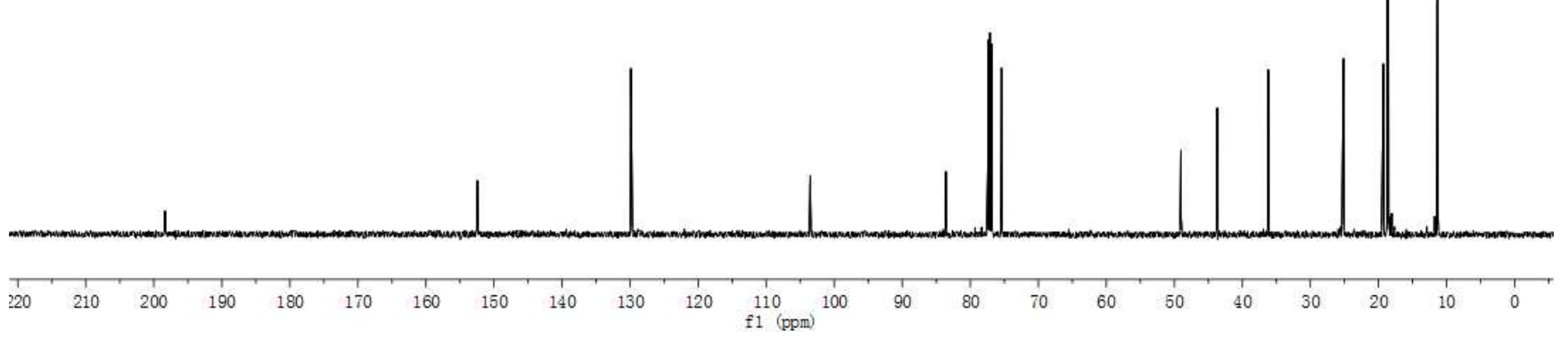

${ }^{13} \mathrm{C}$ NMR of compound $\mathbf{5 7}$

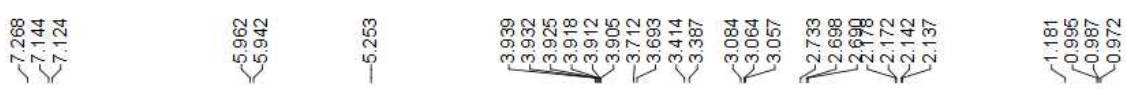<smiles>COC(=O)[C@H]1C(=O)C=C[C@]2(C)CO[C@H](CC#C[C@H](F)S)[C@H]12</smiles>

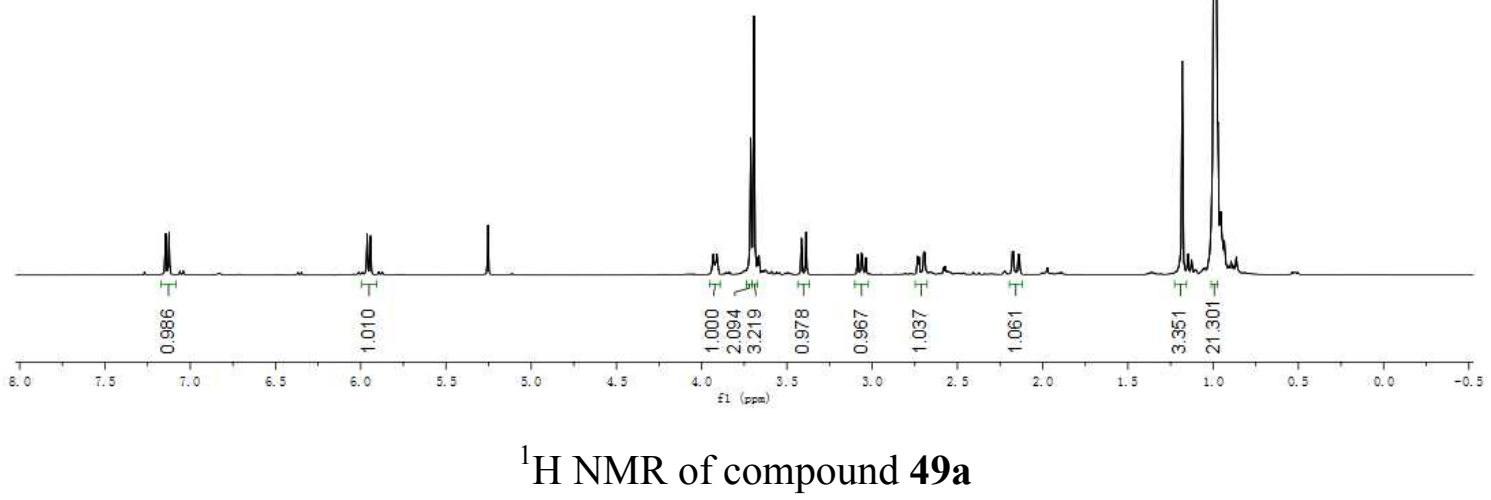




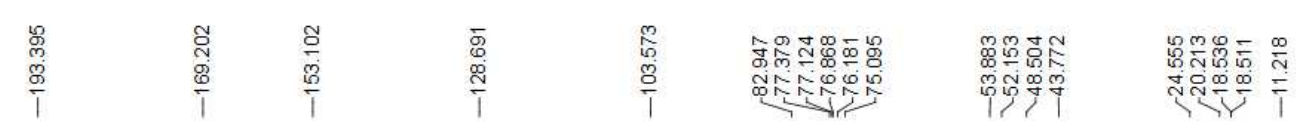
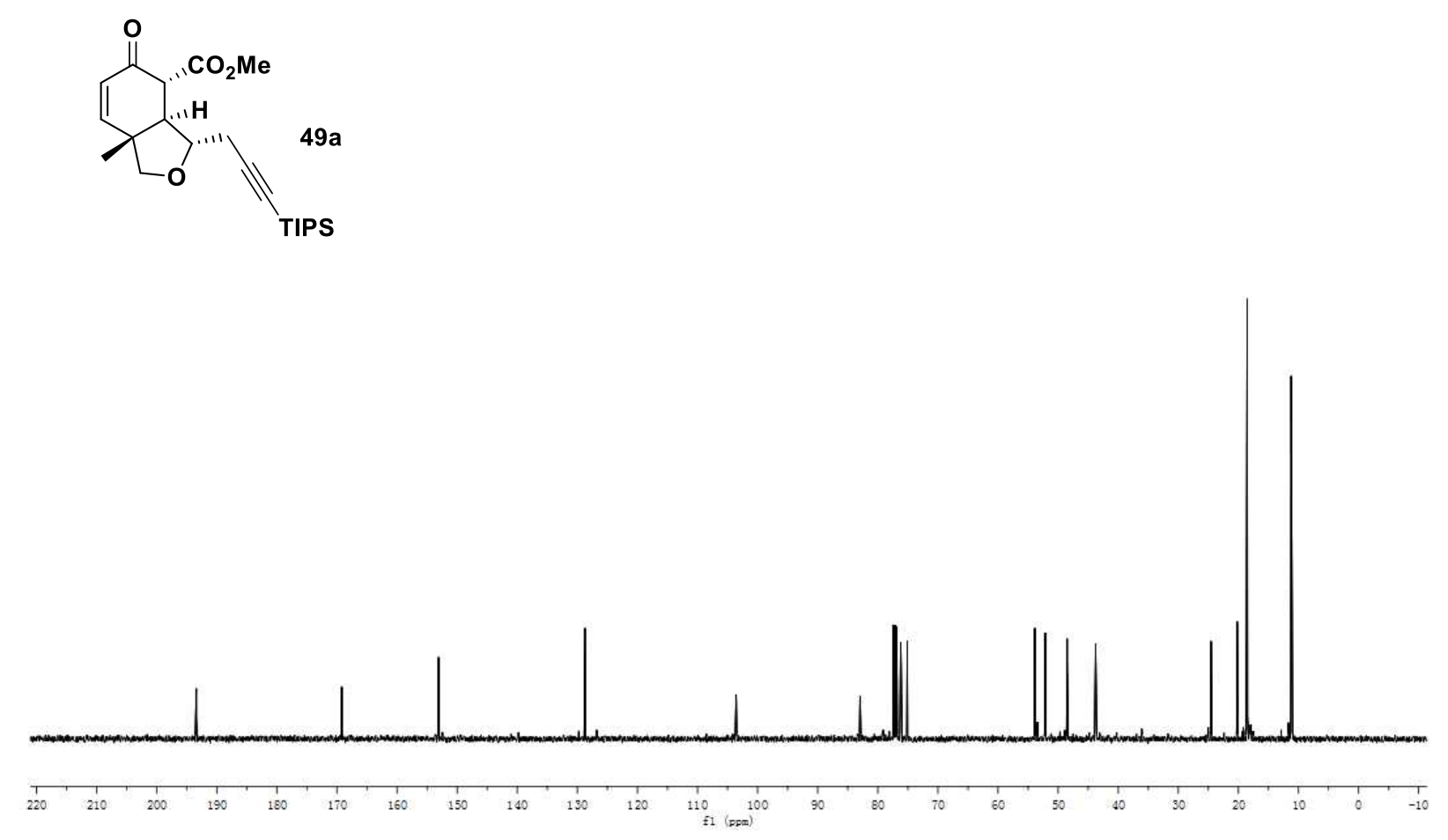

${ }^{13} \mathrm{C}$ NMR of compound 49a
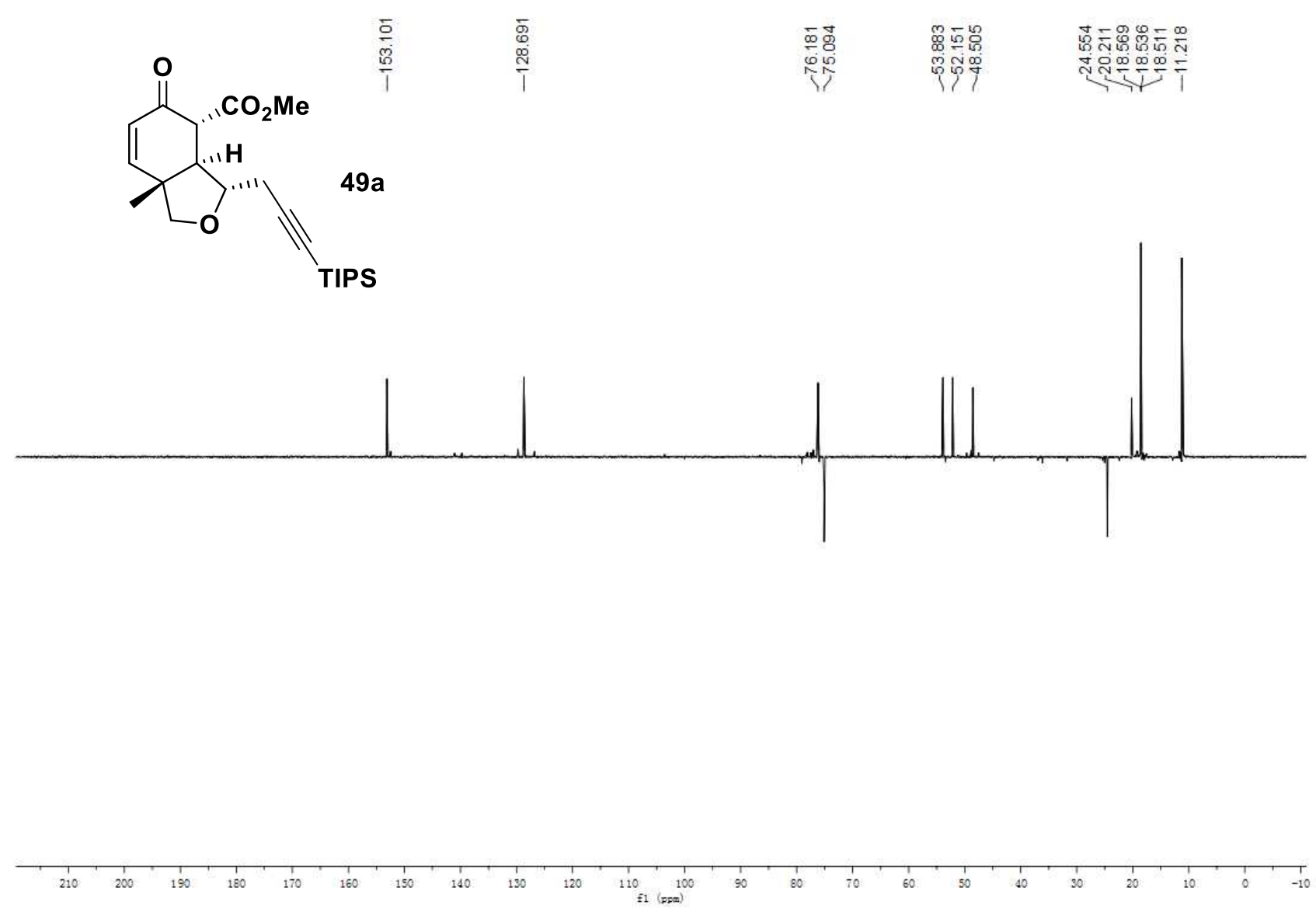

Dept135 NMR of compound 49a 


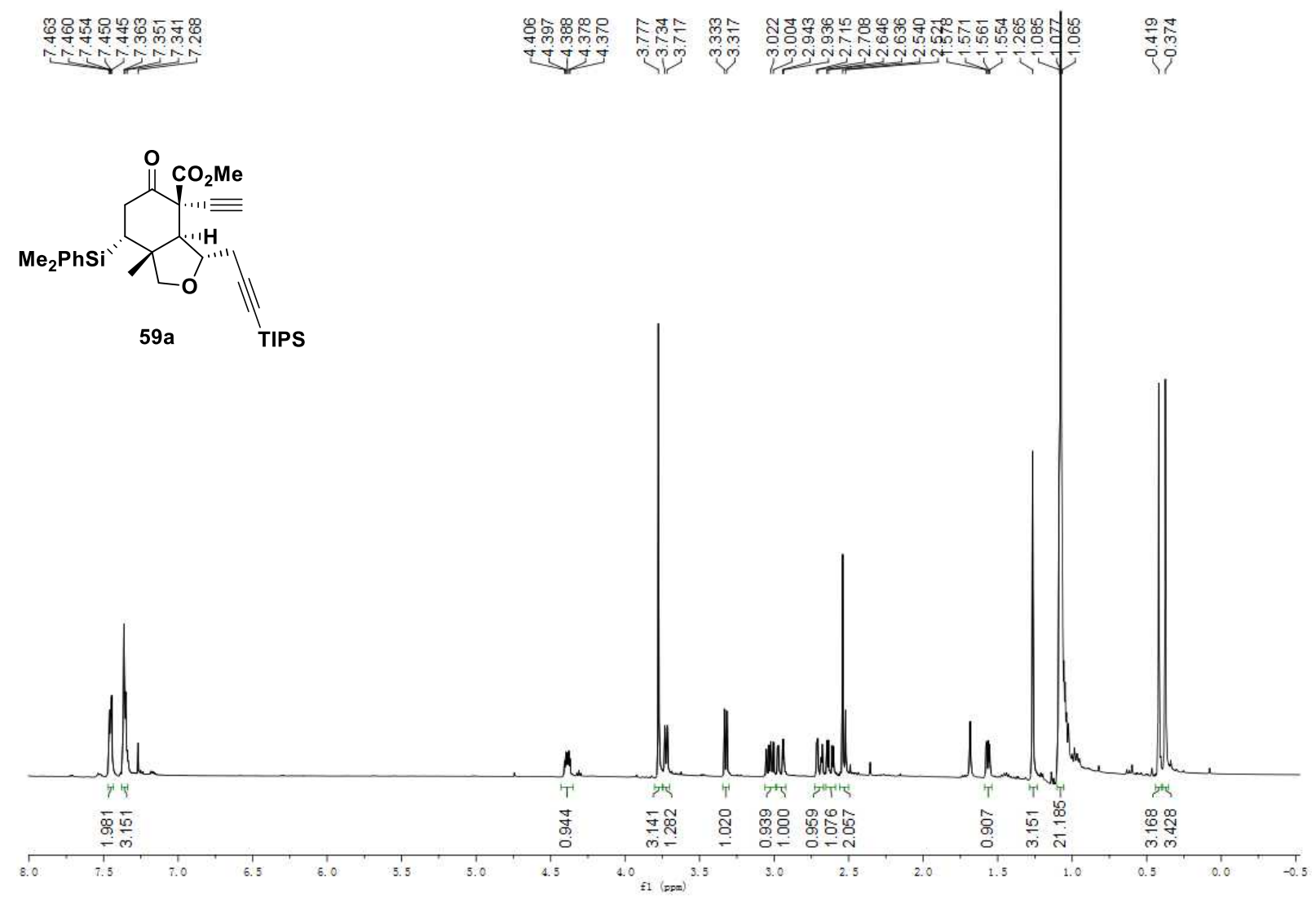

${ }^{1} \mathrm{H}$ NMR of compound 59a

\begin{tabular}{|c|c|c|c|c|c|c|}
\hline 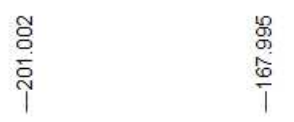 & 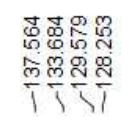 & 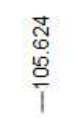 & 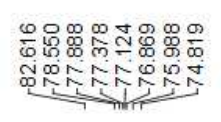 & 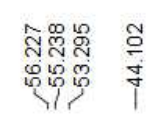 & $\frac{0}{j}$ & 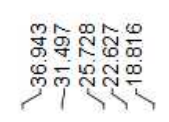 \\
\hline
\end{tabular}
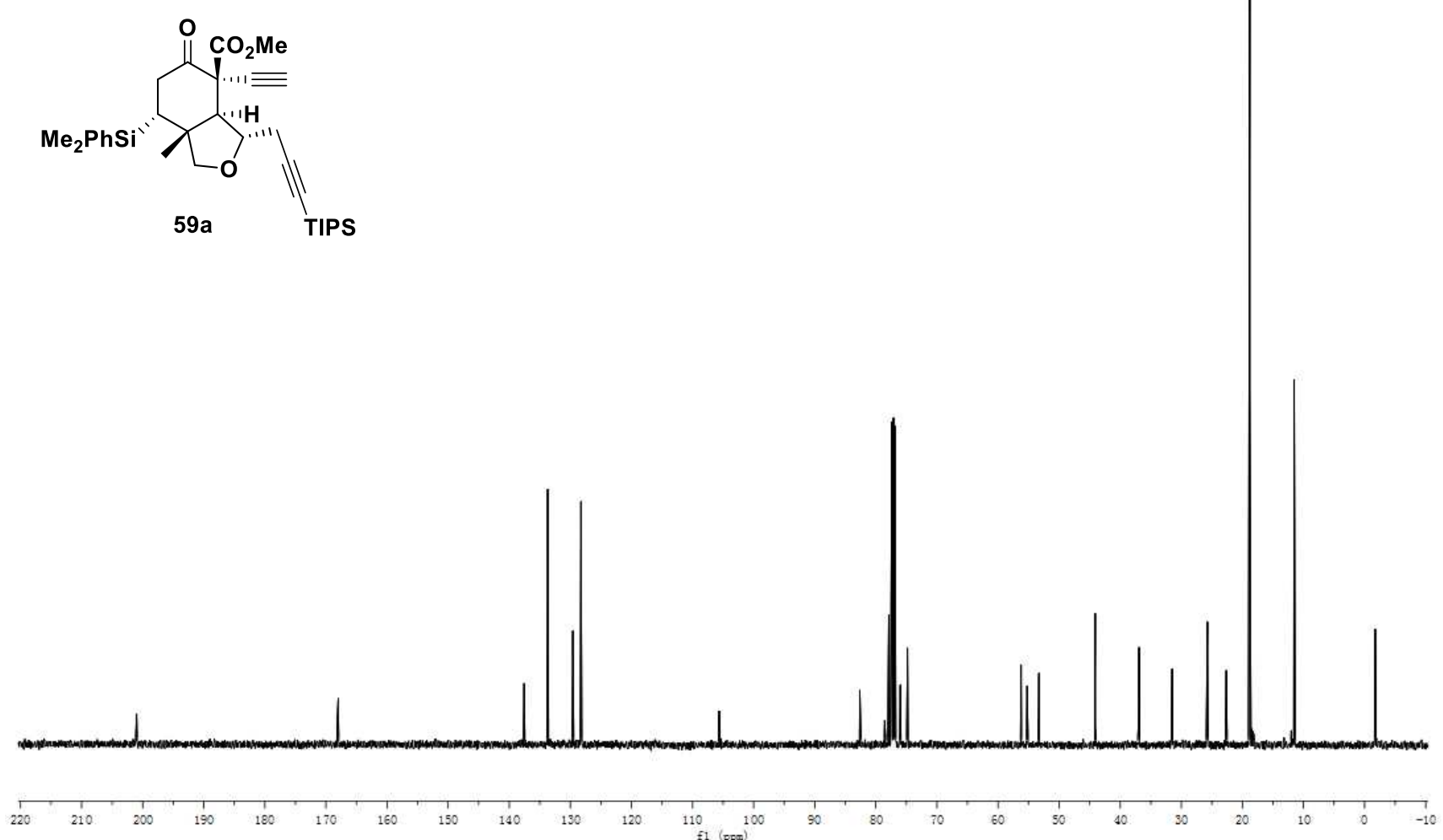

${ }^{13} \mathrm{C}$ NMR of compound 59a 

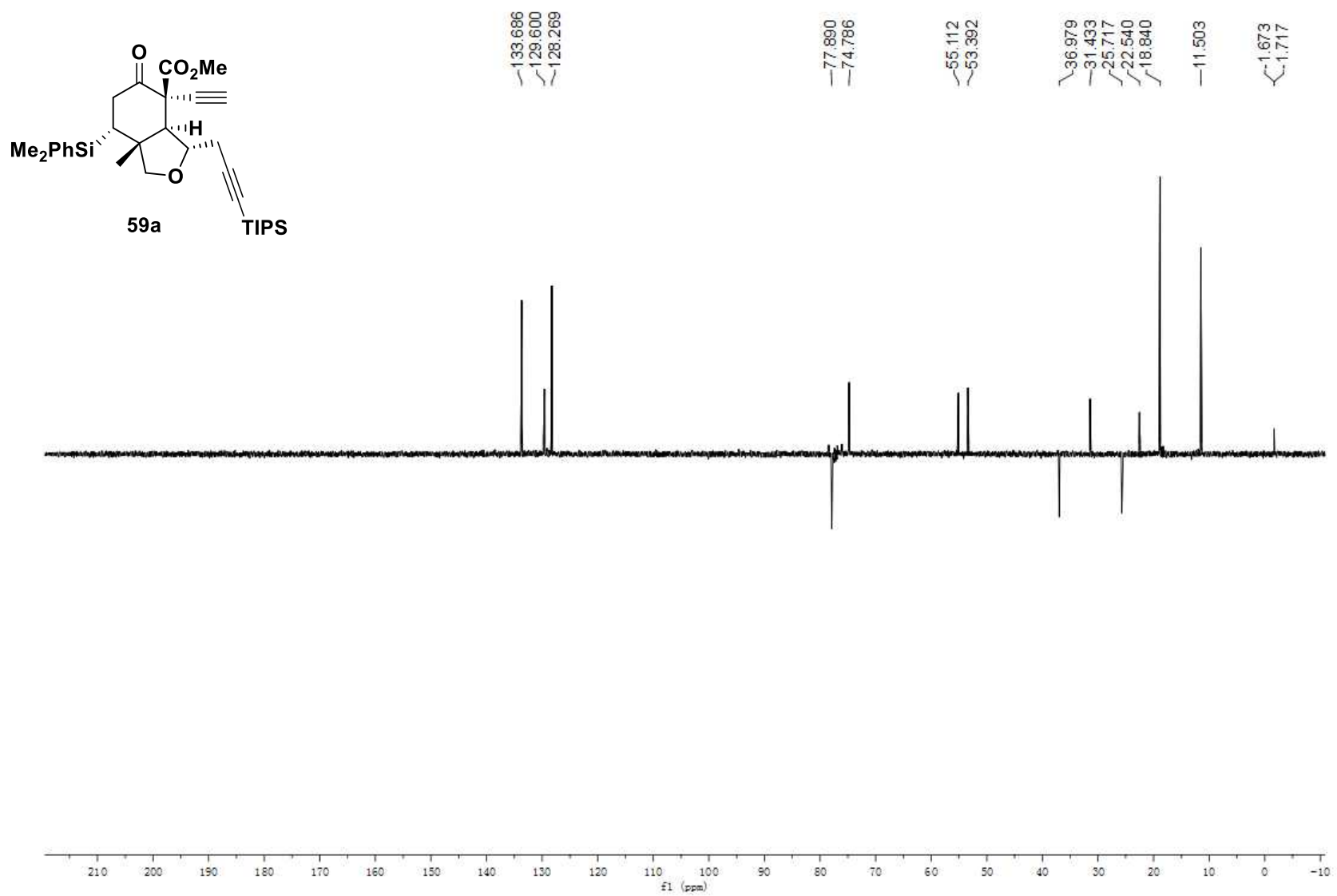

Dept135 NMR of compound 59a

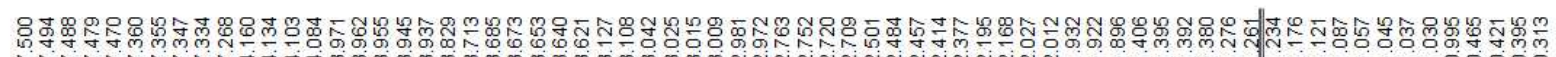
N
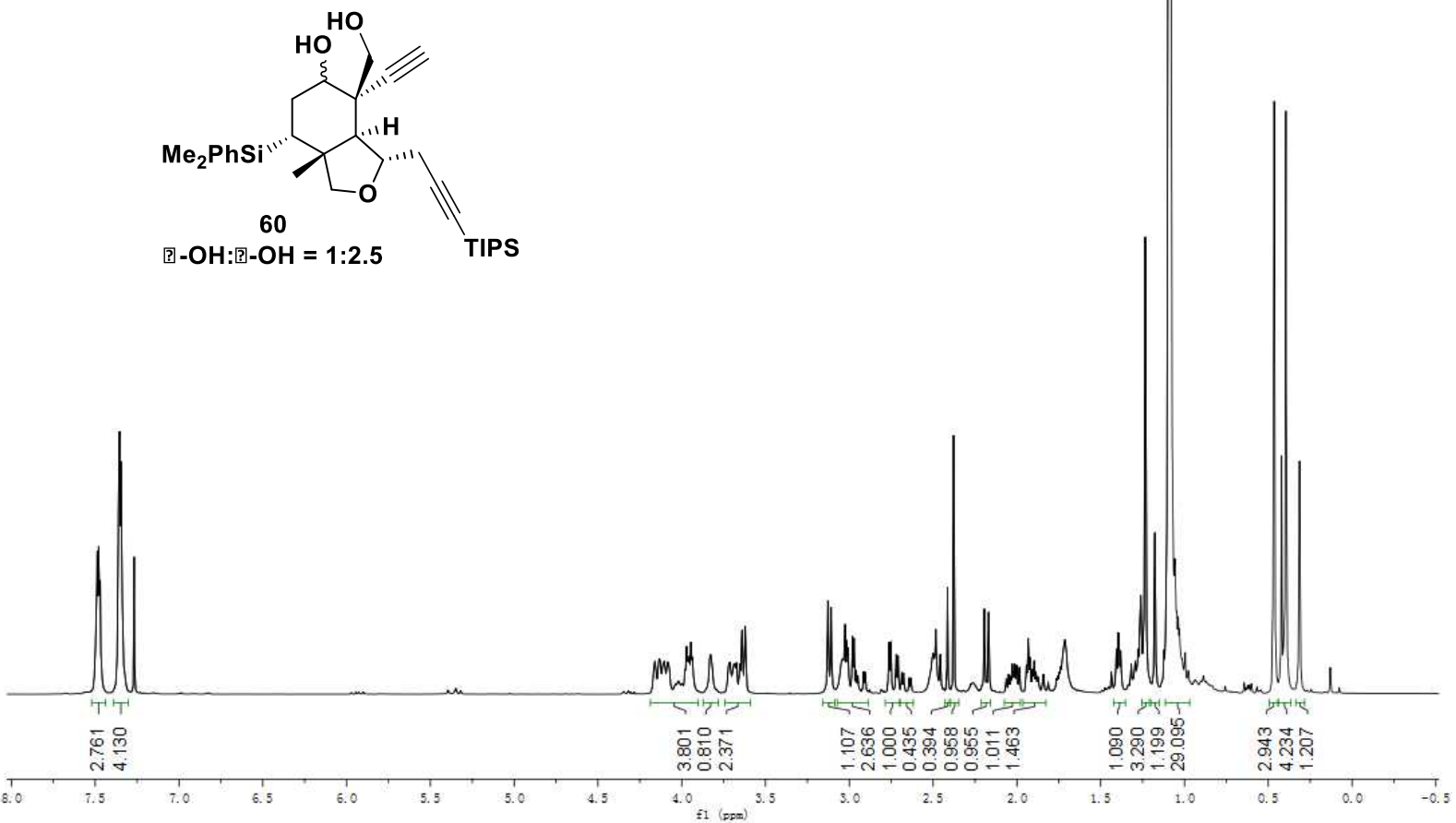

${ }^{1} \mathrm{H}$ NMR of compounds $\mathbf{6 0}(\alpha-\mathrm{OH}: \beta-\mathrm{OH}=1: 2.5)$ 

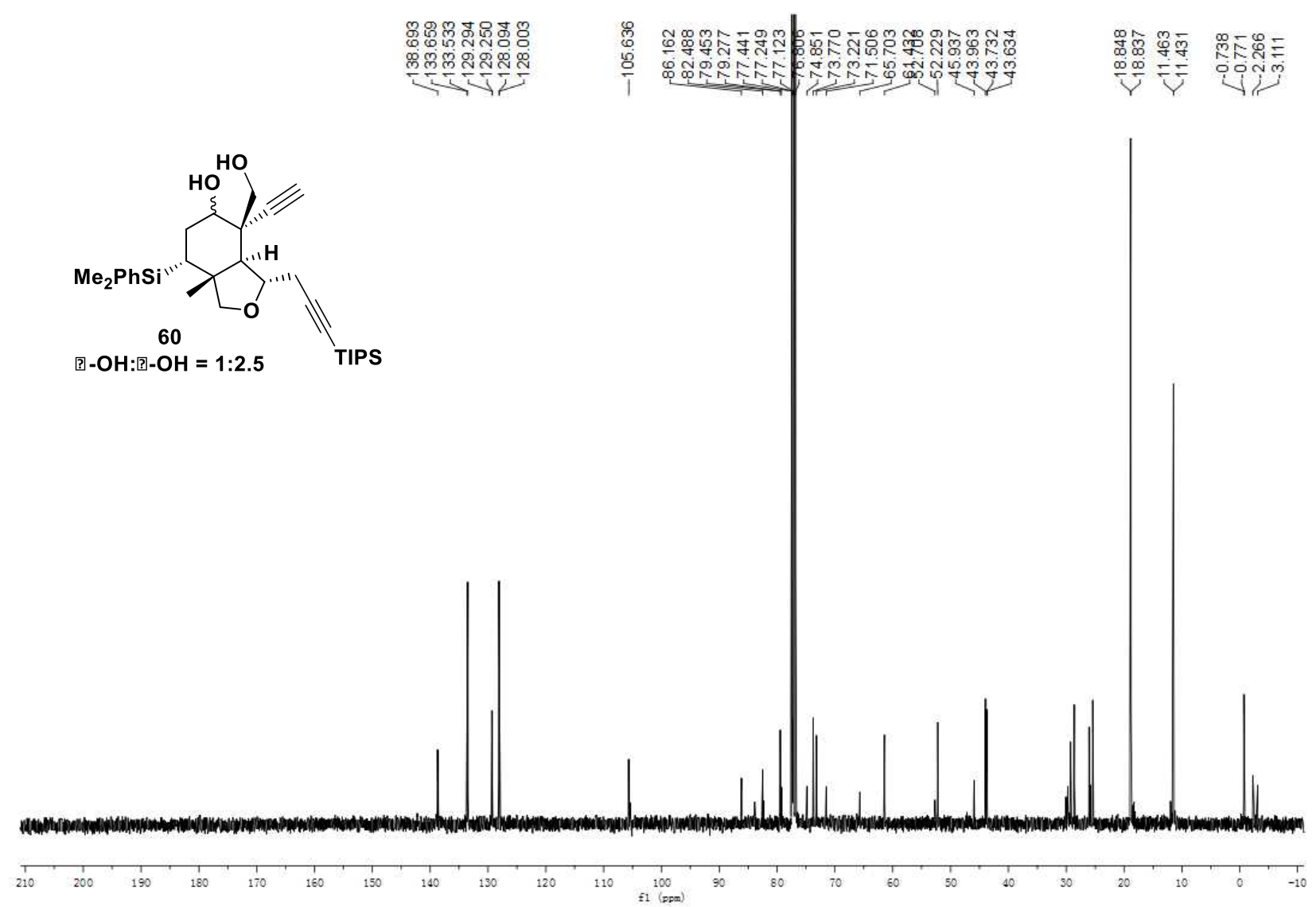

${ }^{13} \mathrm{C}$ NMR of compounds $60(\alpha-\mathrm{OH}: \beta-\mathrm{OH}=1: 2.5)$

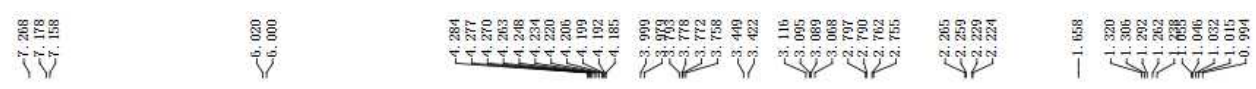

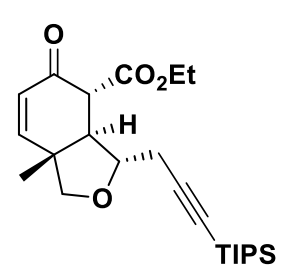

$49 b$

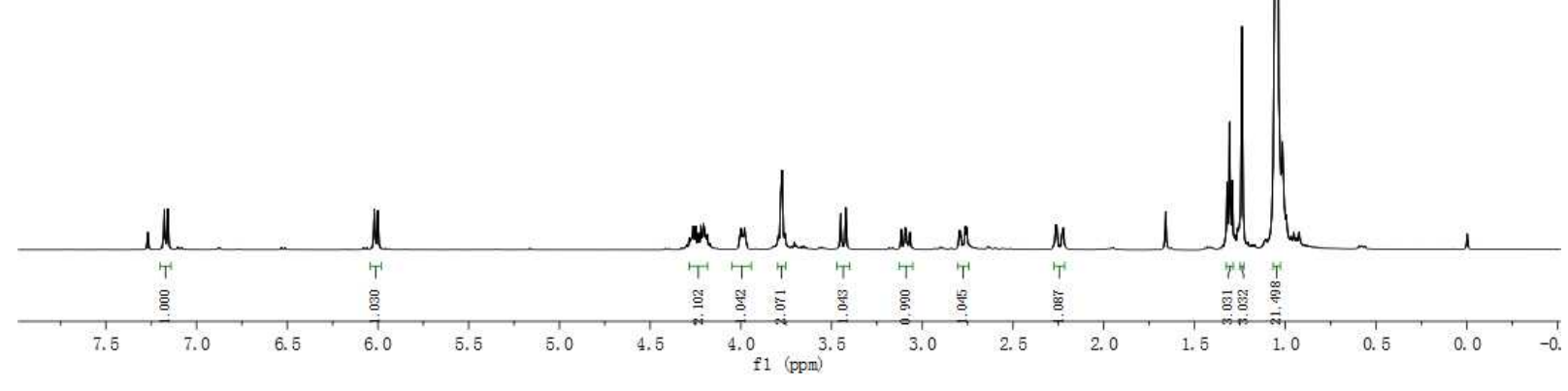

${ }^{1} \mathrm{H}$ NMR of compound 49b 


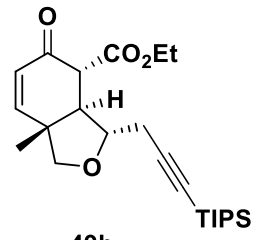

$49 b$

TIPS

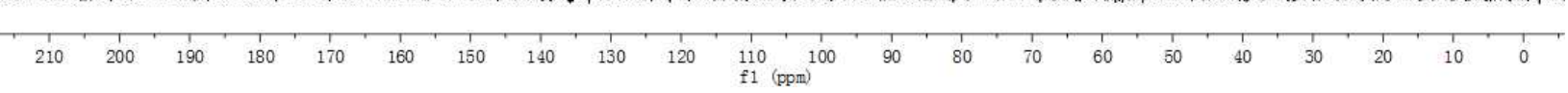

${ }^{13} \mathrm{C}$ NMR of compound 49b

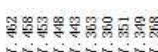

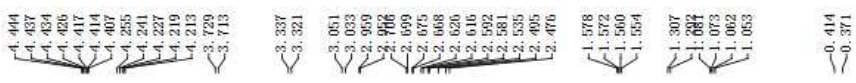

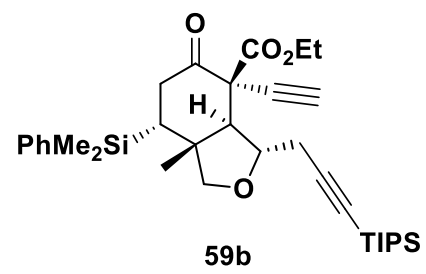

59b

TIPS

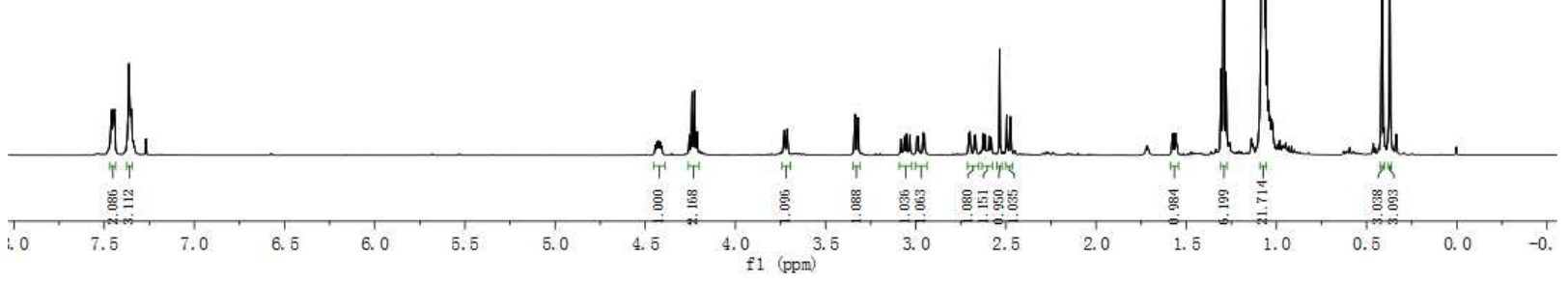

${ }^{1} \mathrm{H}$ NMR of compound 59b 


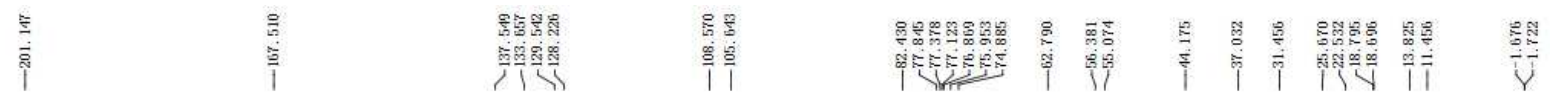
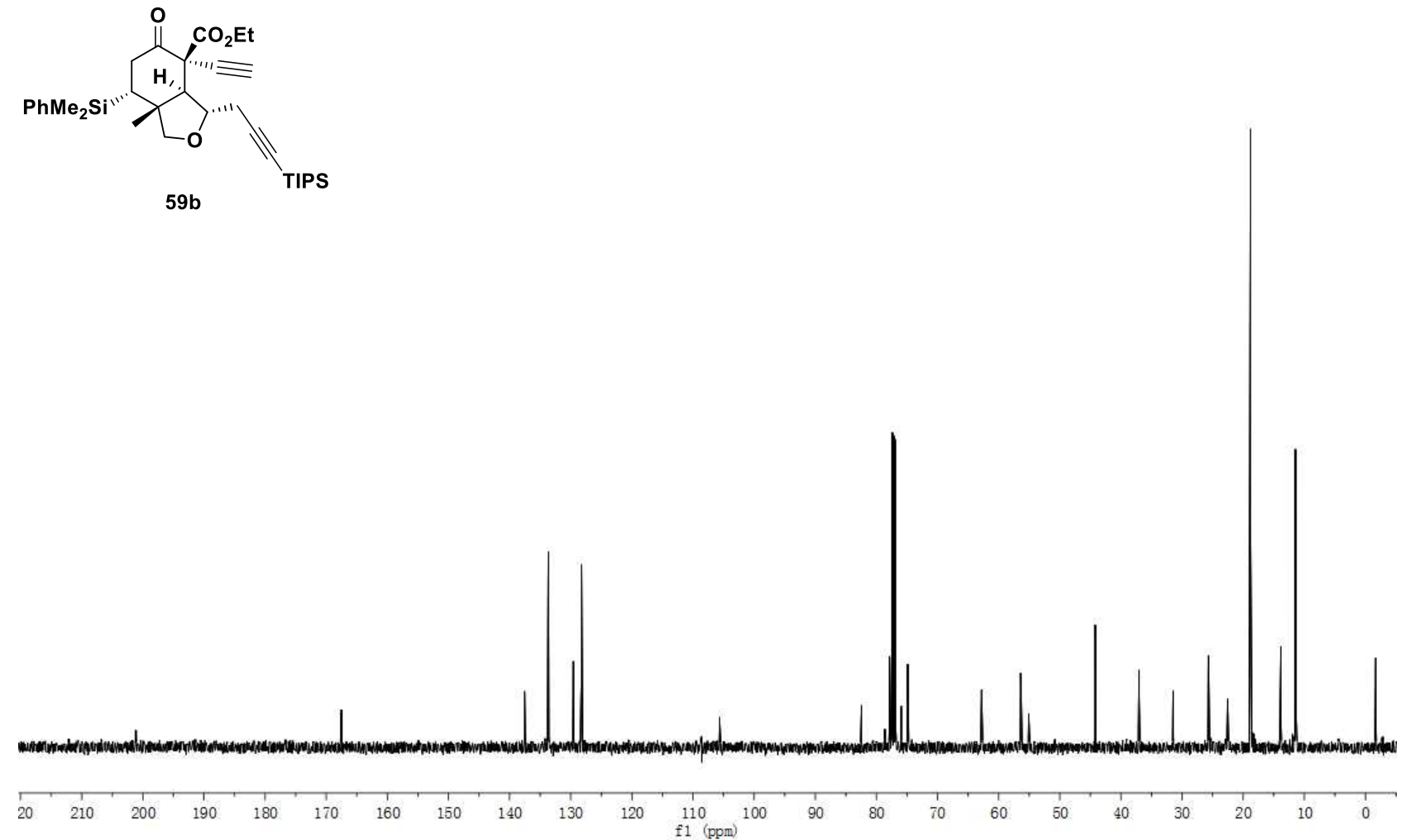

${ }^{13} \mathrm{C}$ NMR of compound 59b

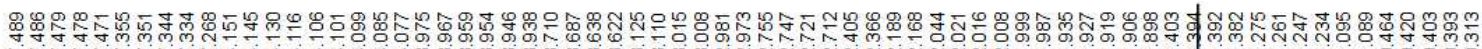

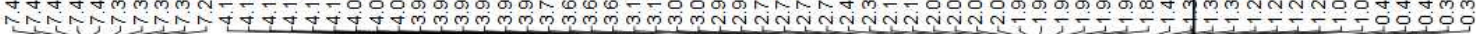

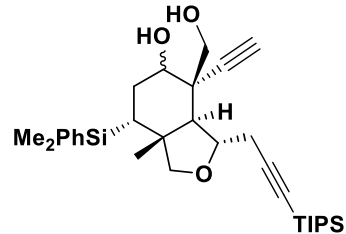

60 (回-OH:-OH $=1: 9)$

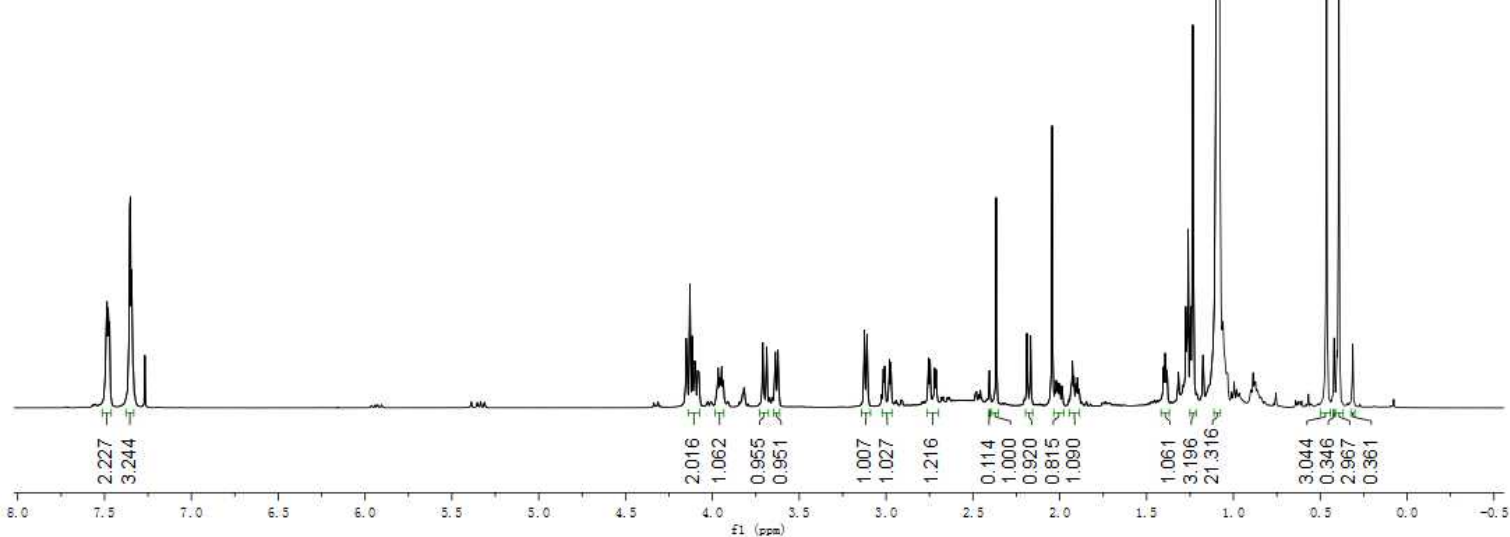

${ }^{1} \mathrm{H}$ NMR of compound 60 


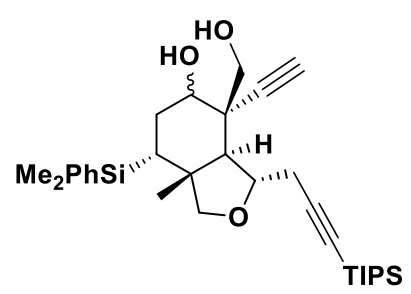

$60($ [? $-\mathrm{OH}:$ [? $-\mathrm{OH}=1: 9)$

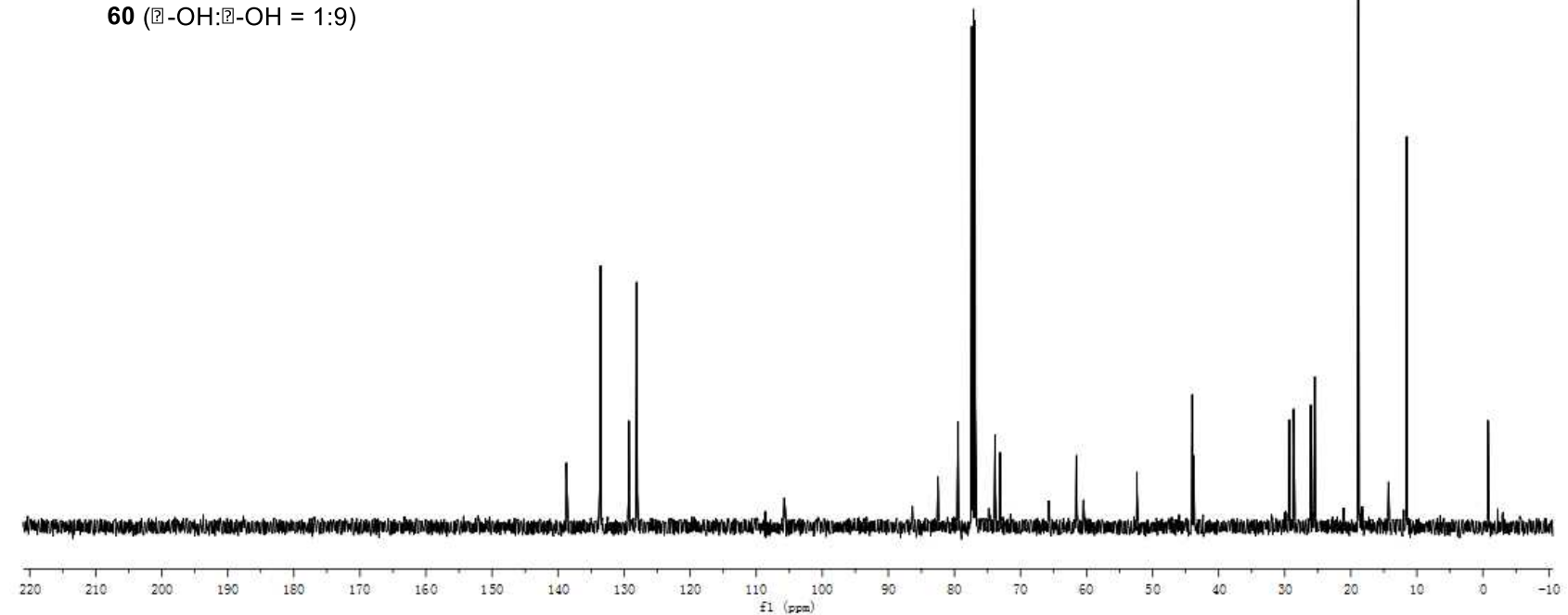

${ }^{13} \mathrm{C}$ NMR of compound $\mathbf{6 0}$

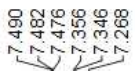

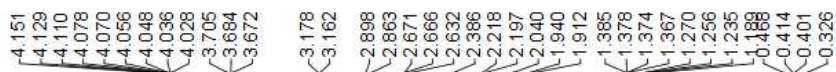

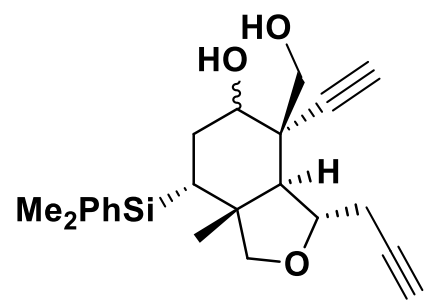

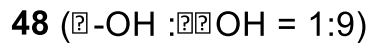

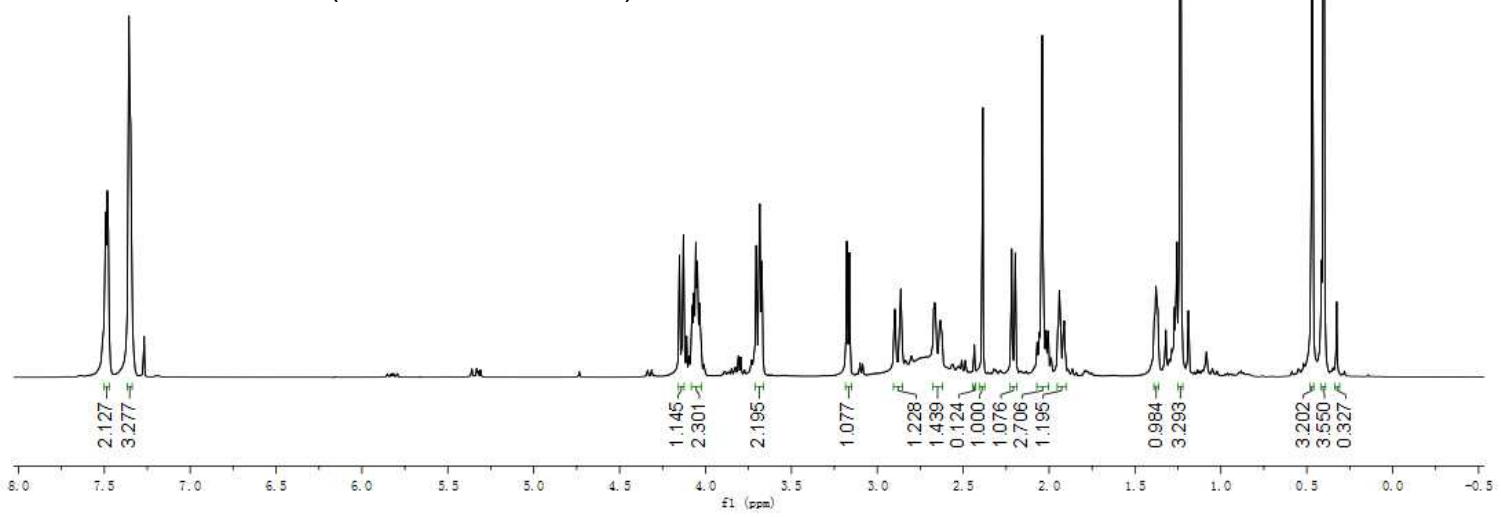

${ }^{1} \mathrm{H}$ NMR of compound $\mathbf{4 8}$ 

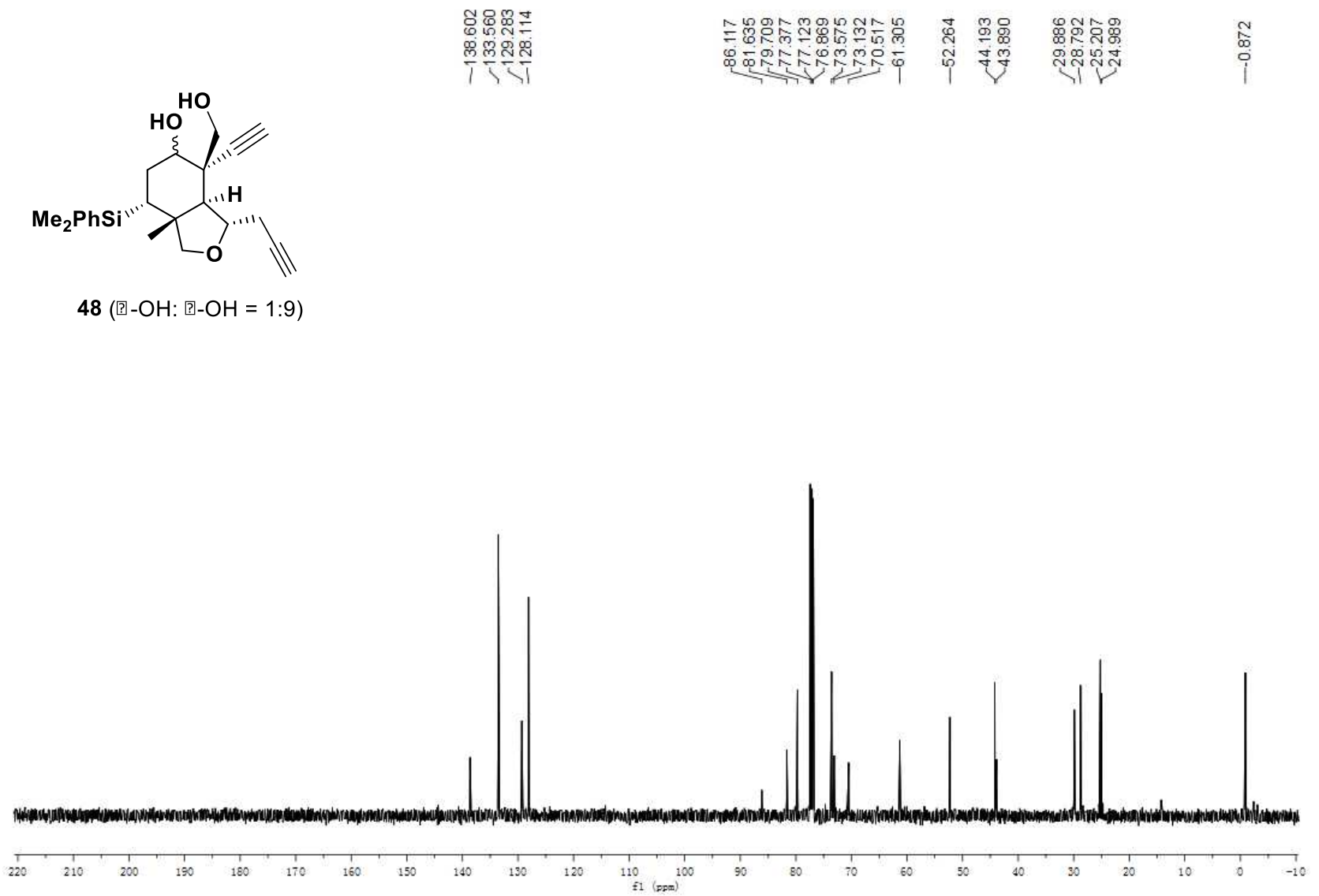

${ }^{13} \mathrm{C}$ NMR of compound 48

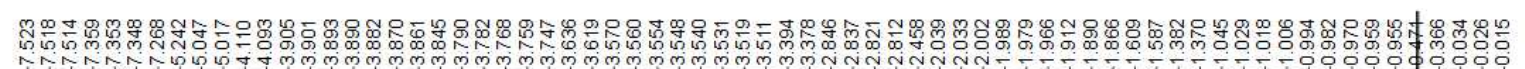

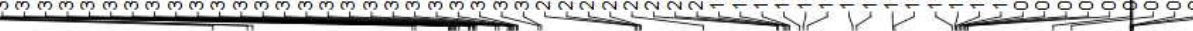

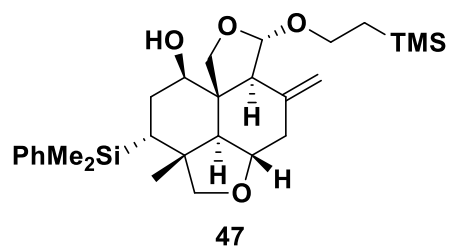

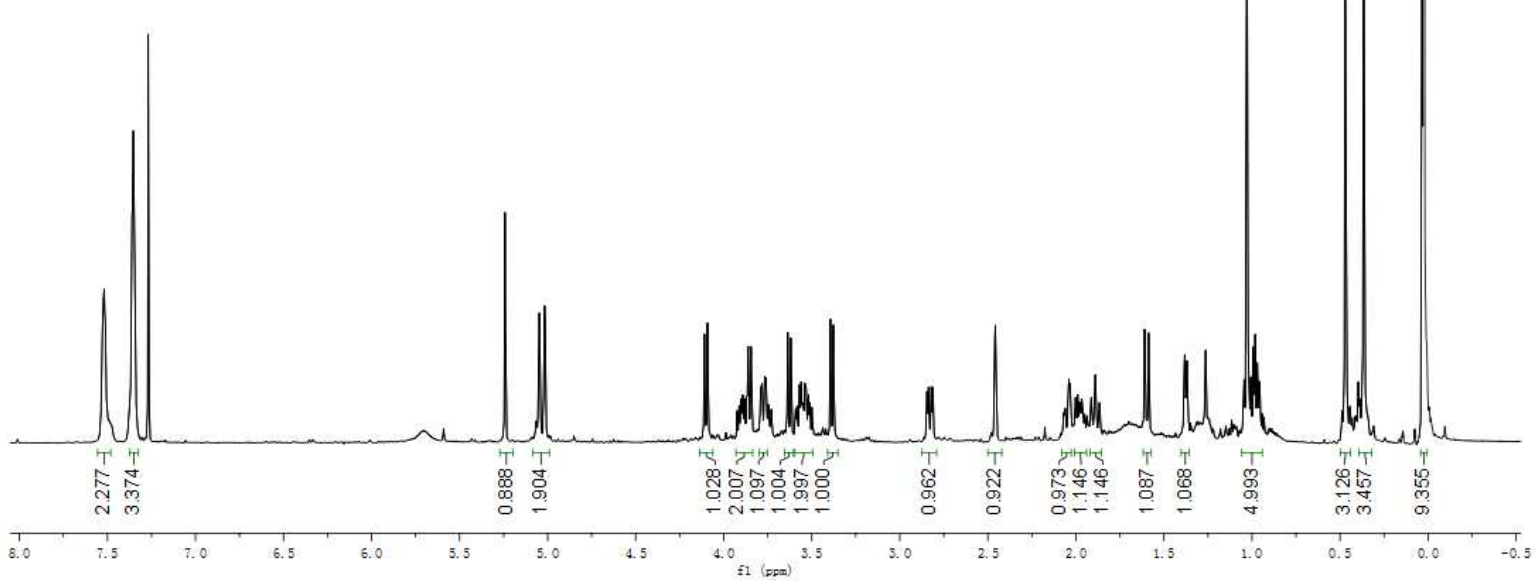

${ }^{1} \mathrm{H}$ NMR of compound $\mathbf{4 7}$ 


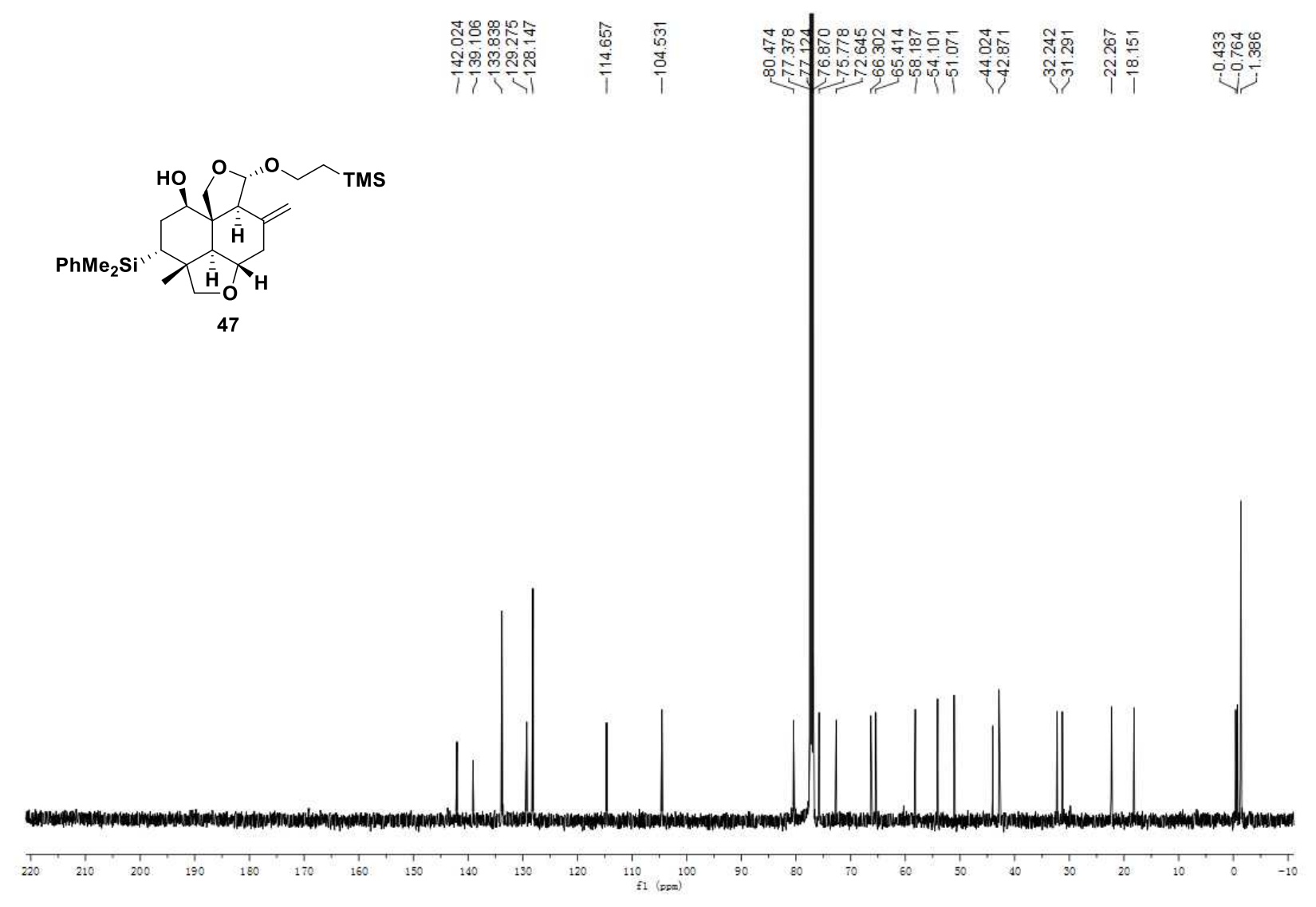

${ }^{13} \mathrm{C}$ NMR of compound 47

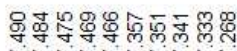

viñNiñ

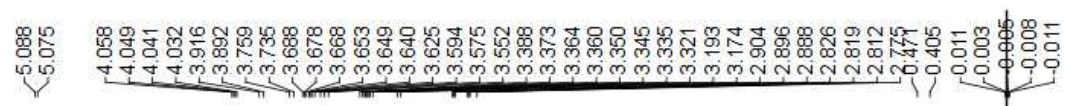

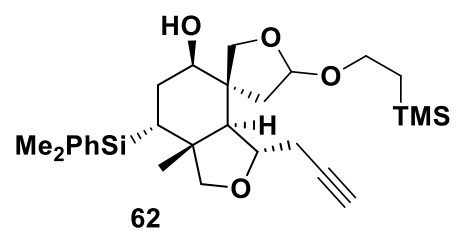

62

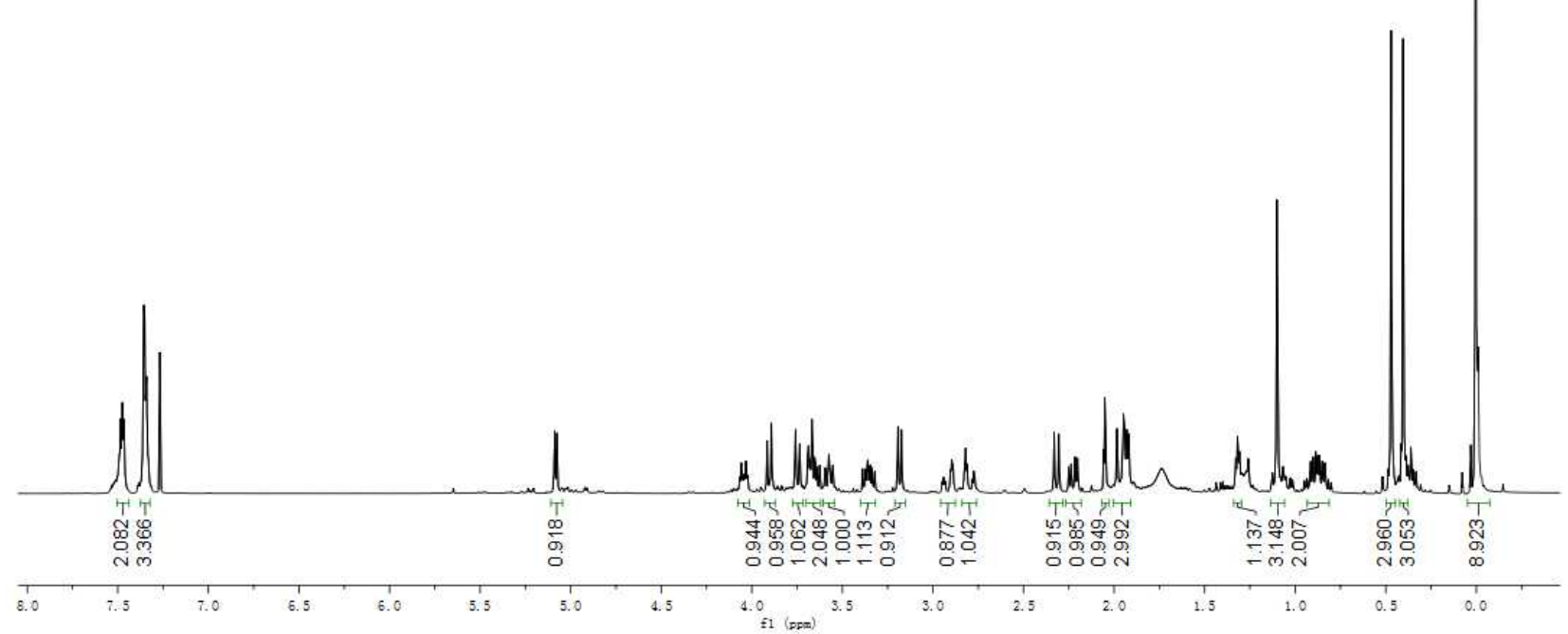

${ }^{1} \mathrm{H}$ NMR of compound $\mathbf{6 2}$ 


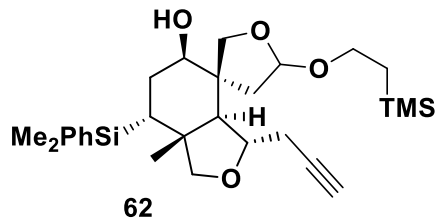

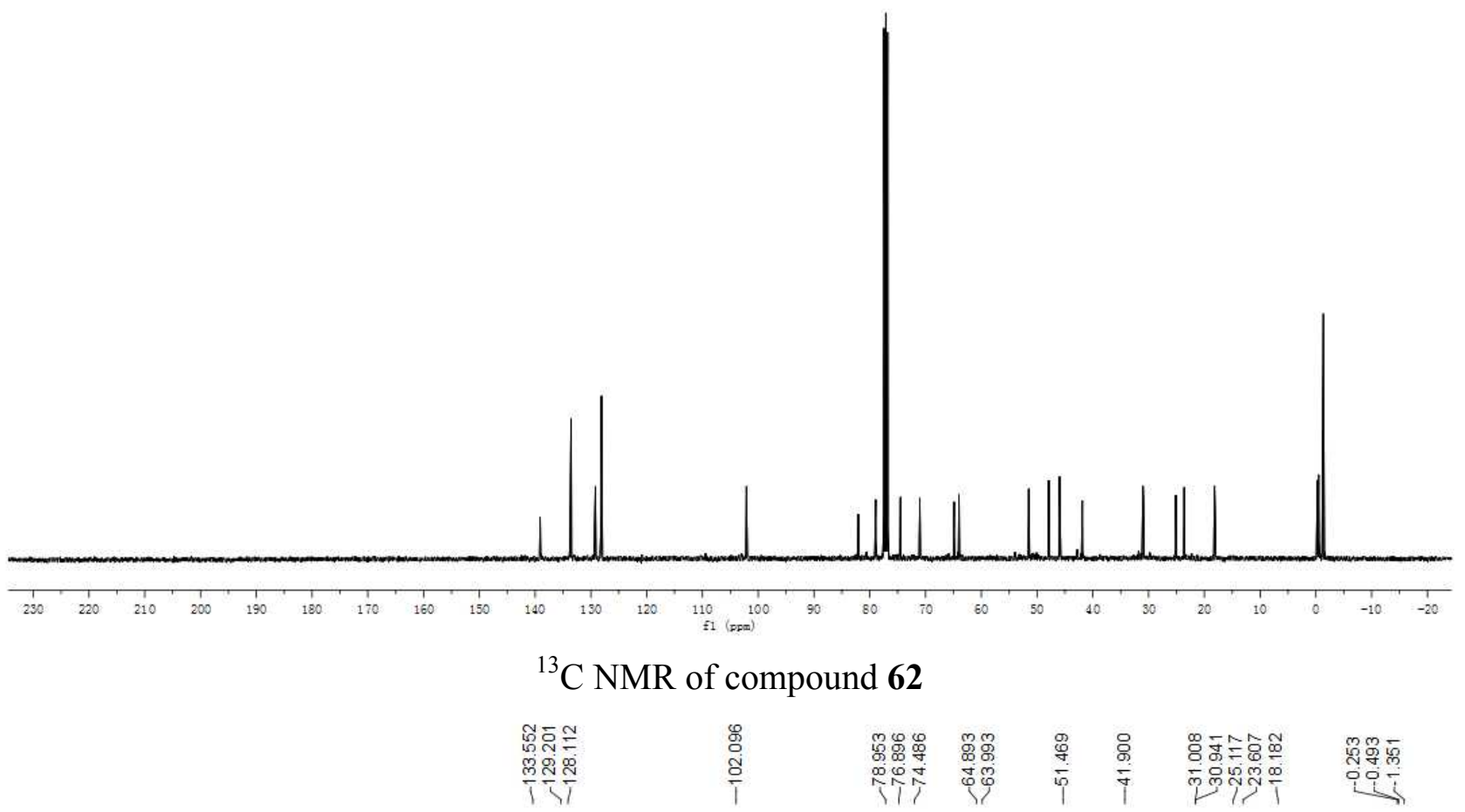

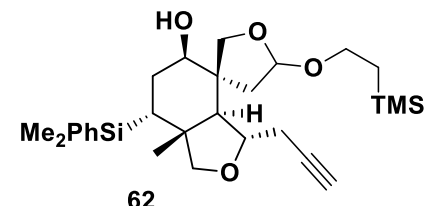
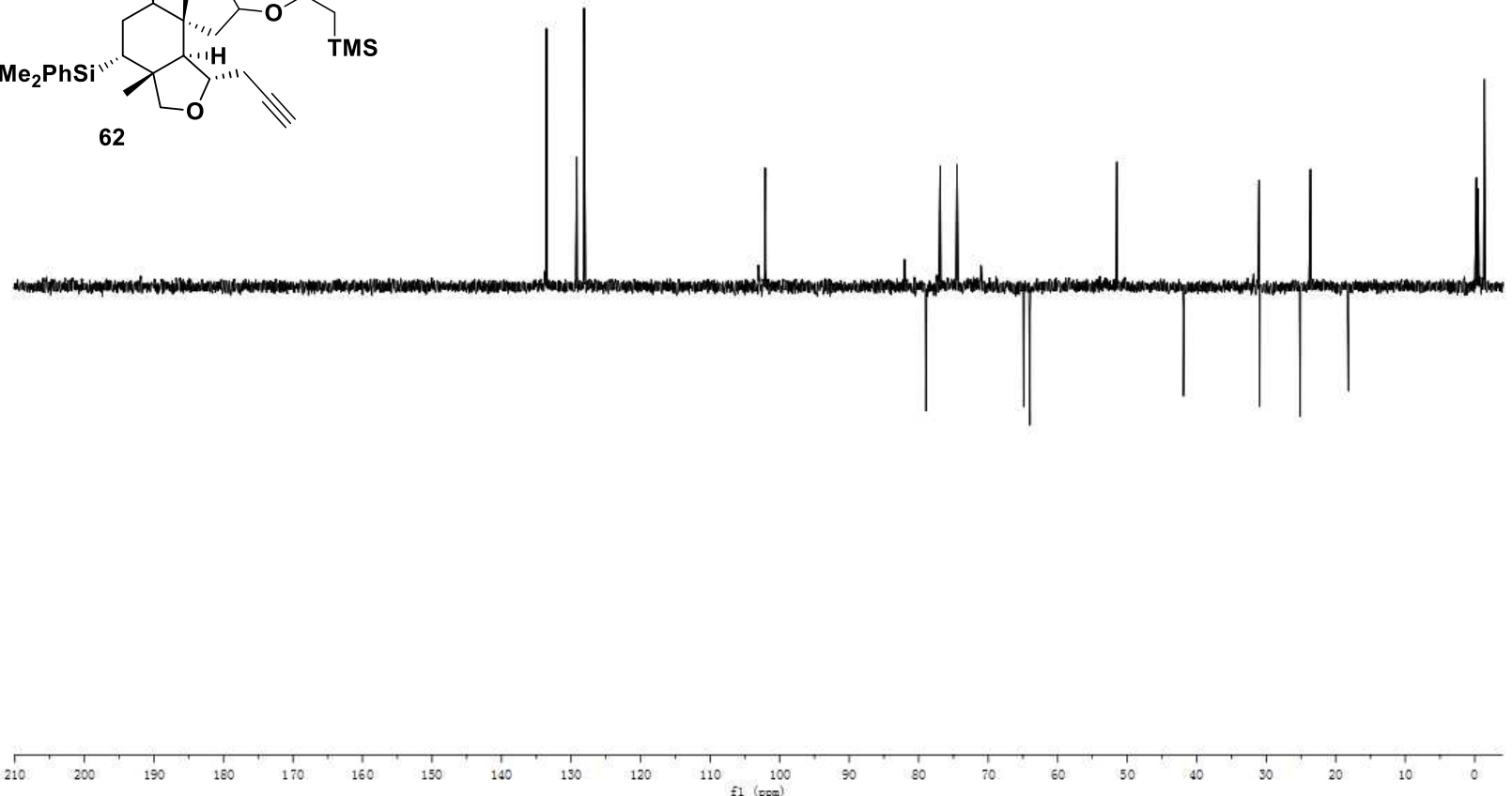

Dept135 NMR of compound 62 


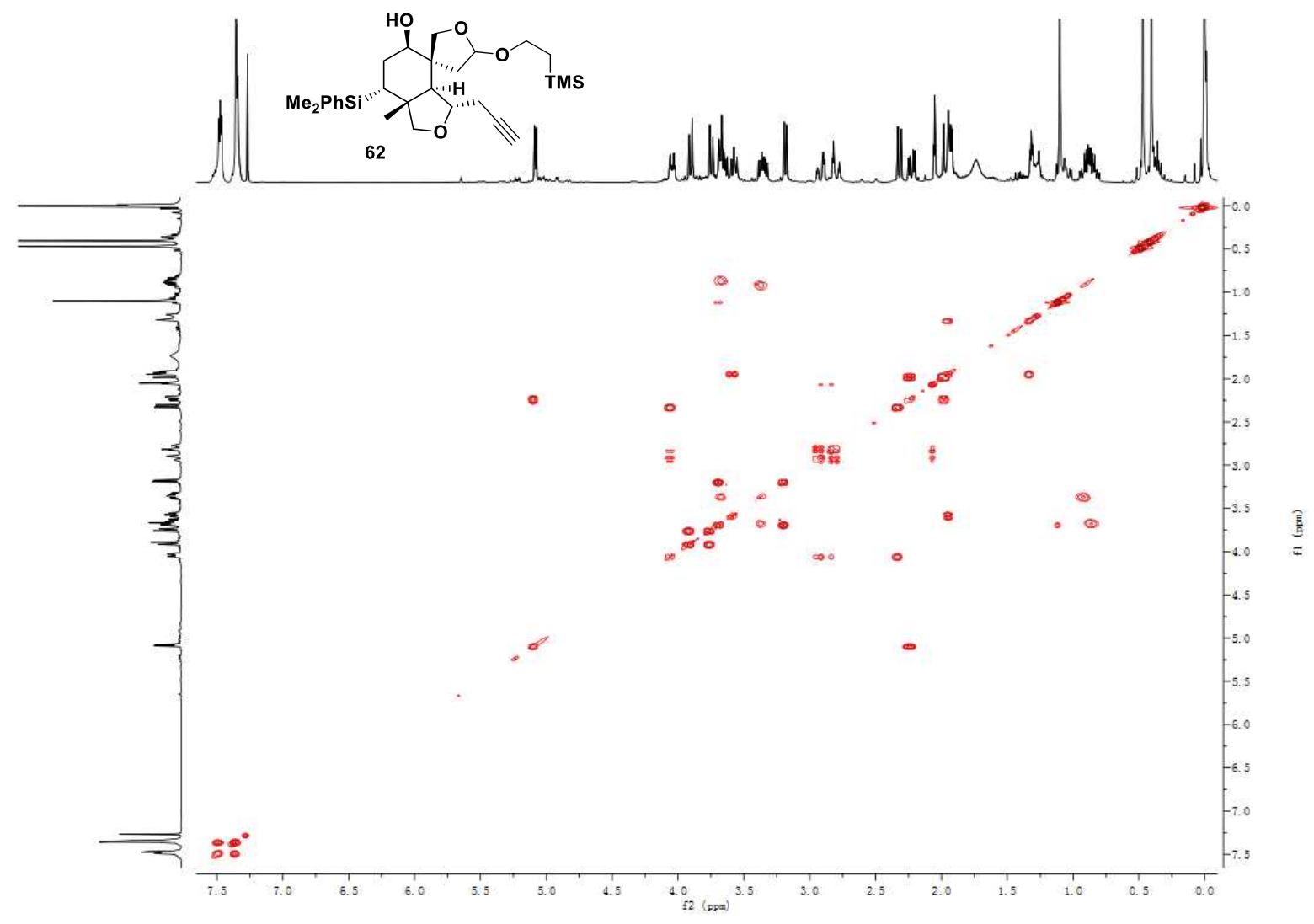

COSY NMR of compound 62

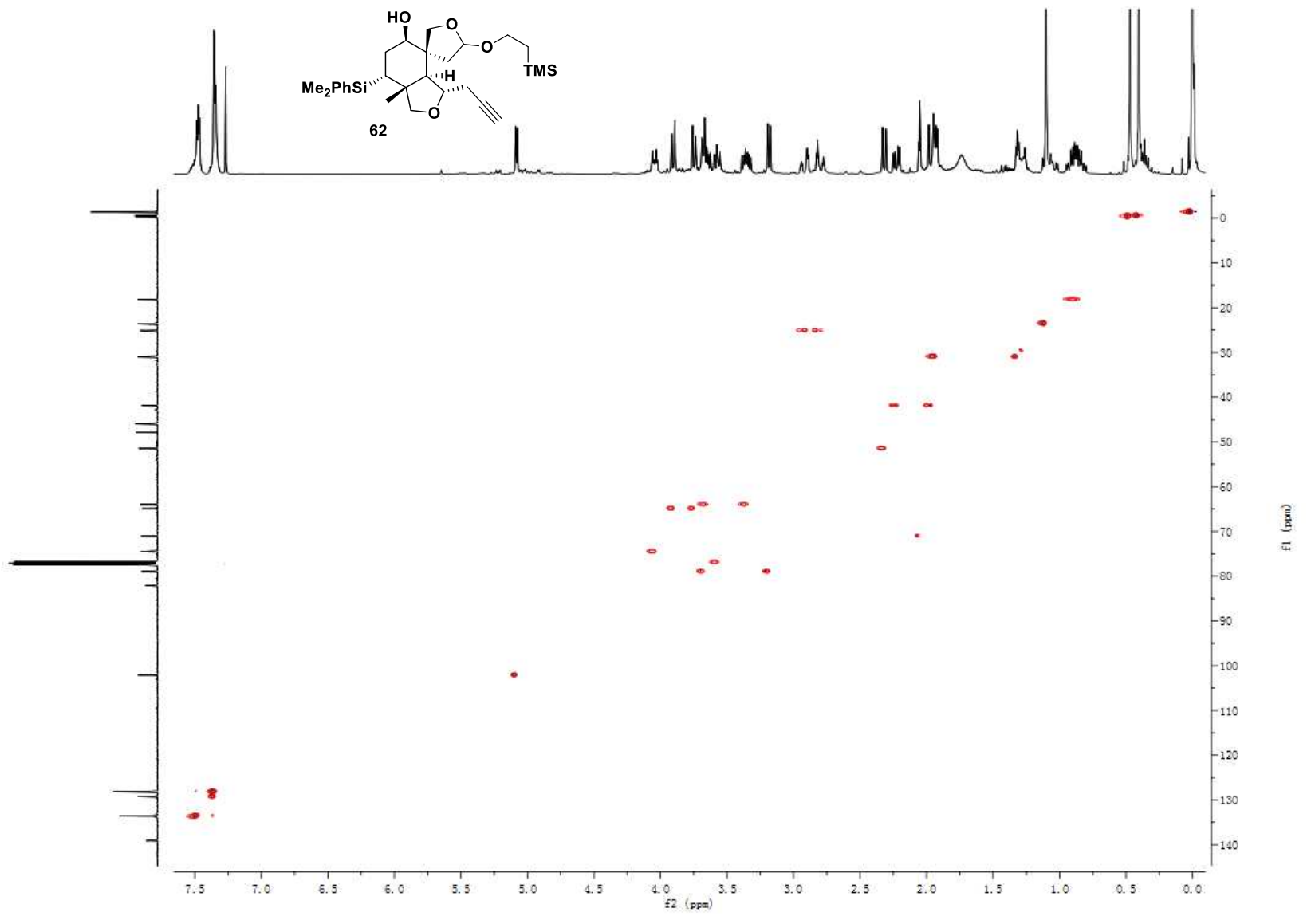

HSQC NMR of compound $\mathbf{6 2}$ 


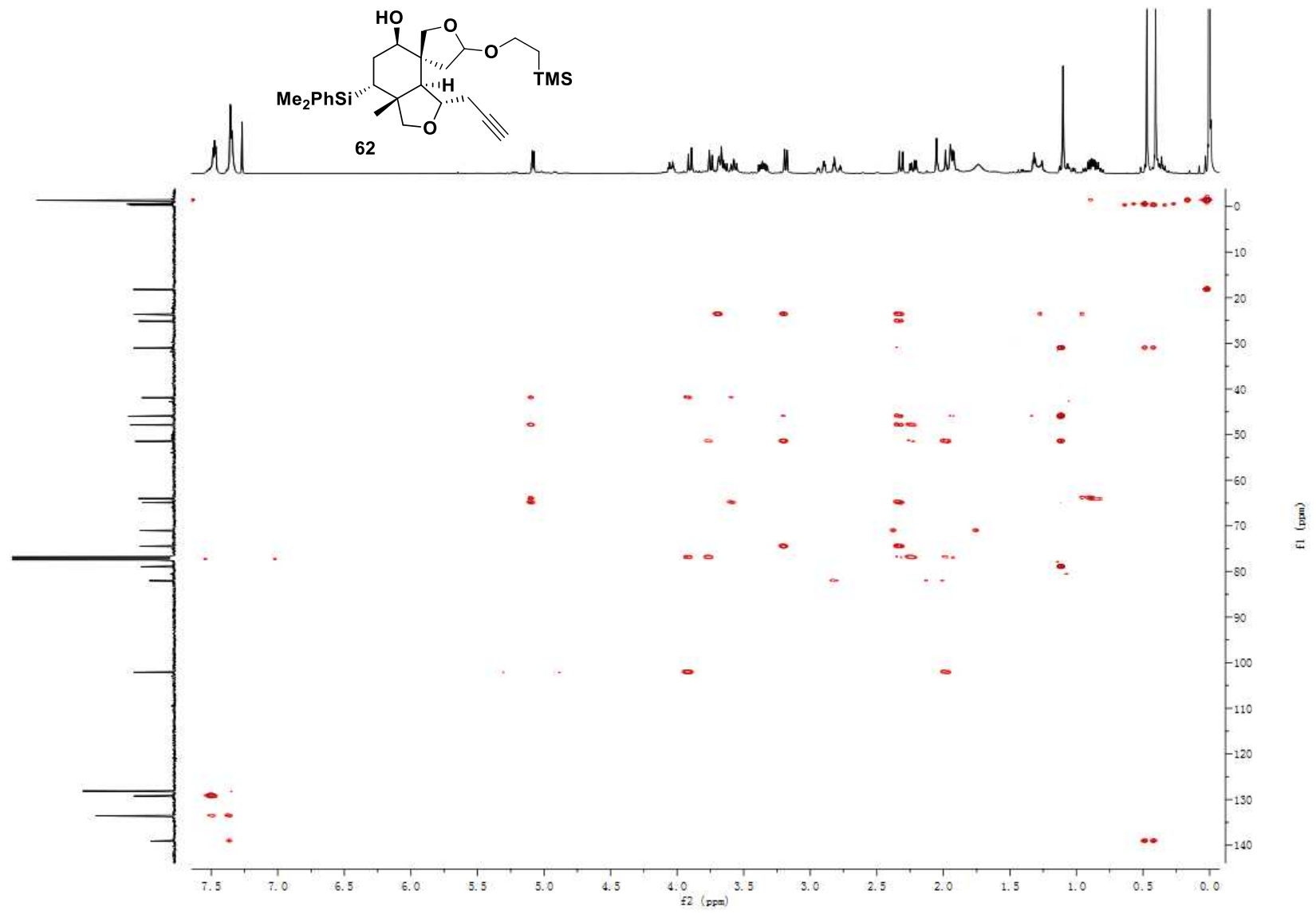

HMBC NMR of compound 62

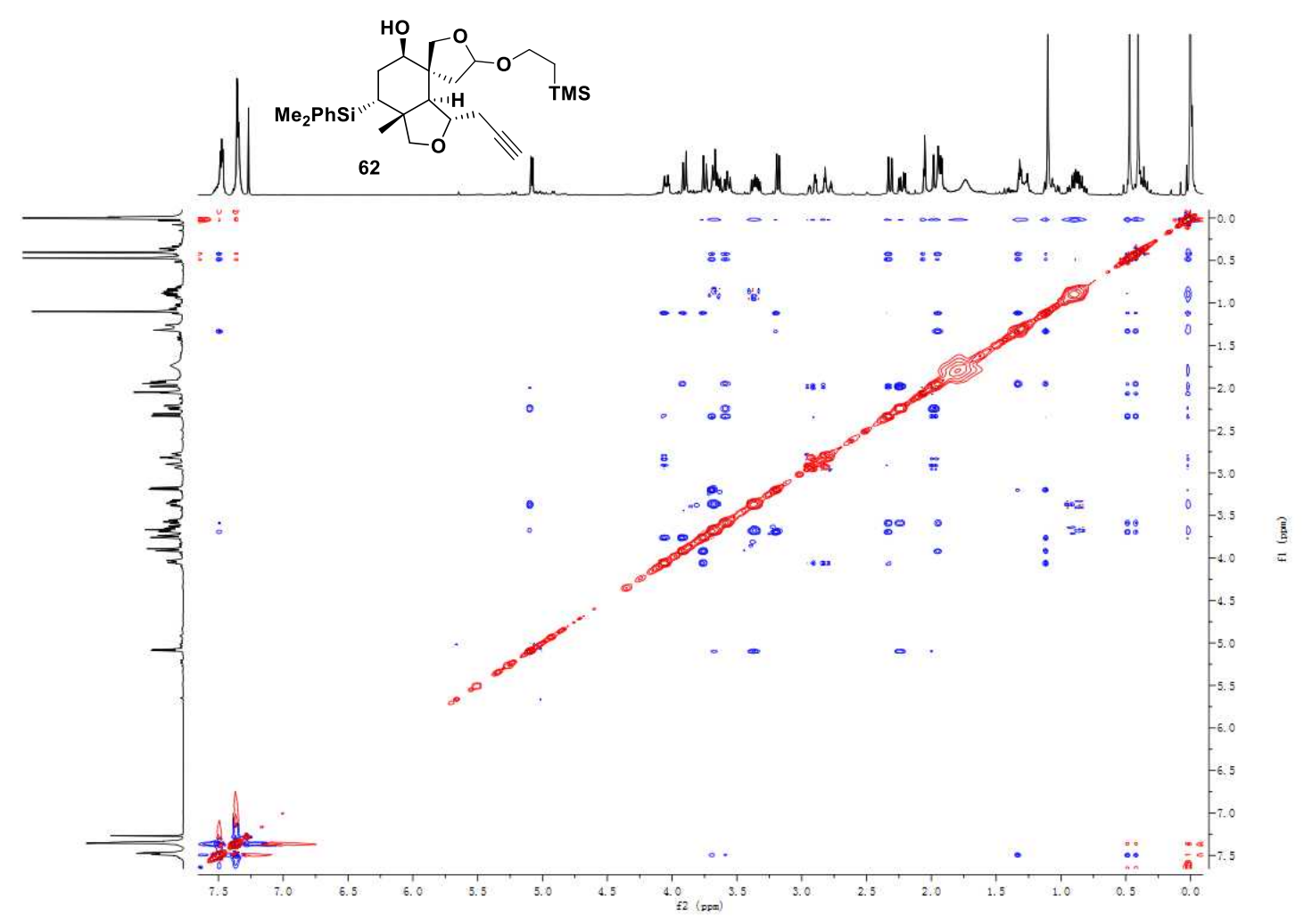

NOESY NMR of compound $\mathbf{6 2}$ 


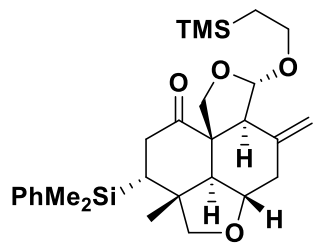

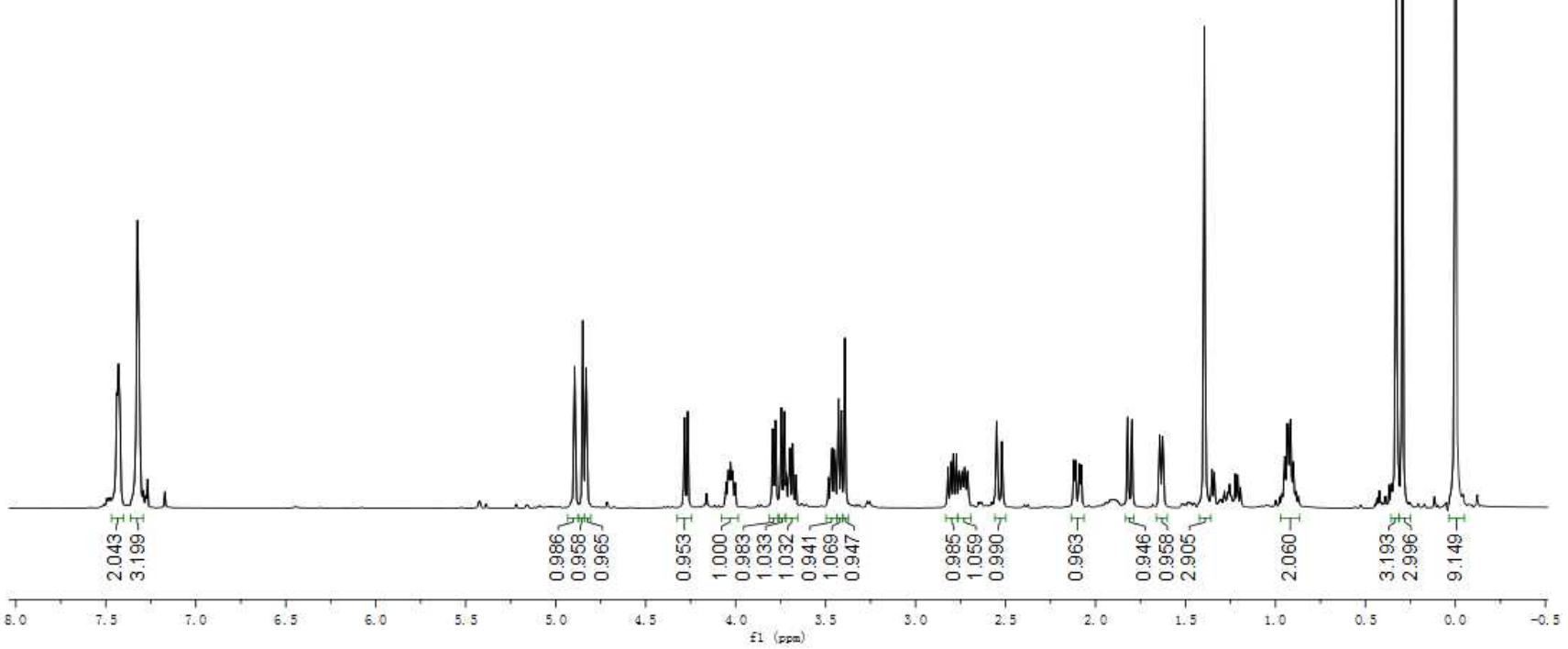

${ }^{1} \mathrm{H}$ NMR of compound $\mathbf{6 3}$
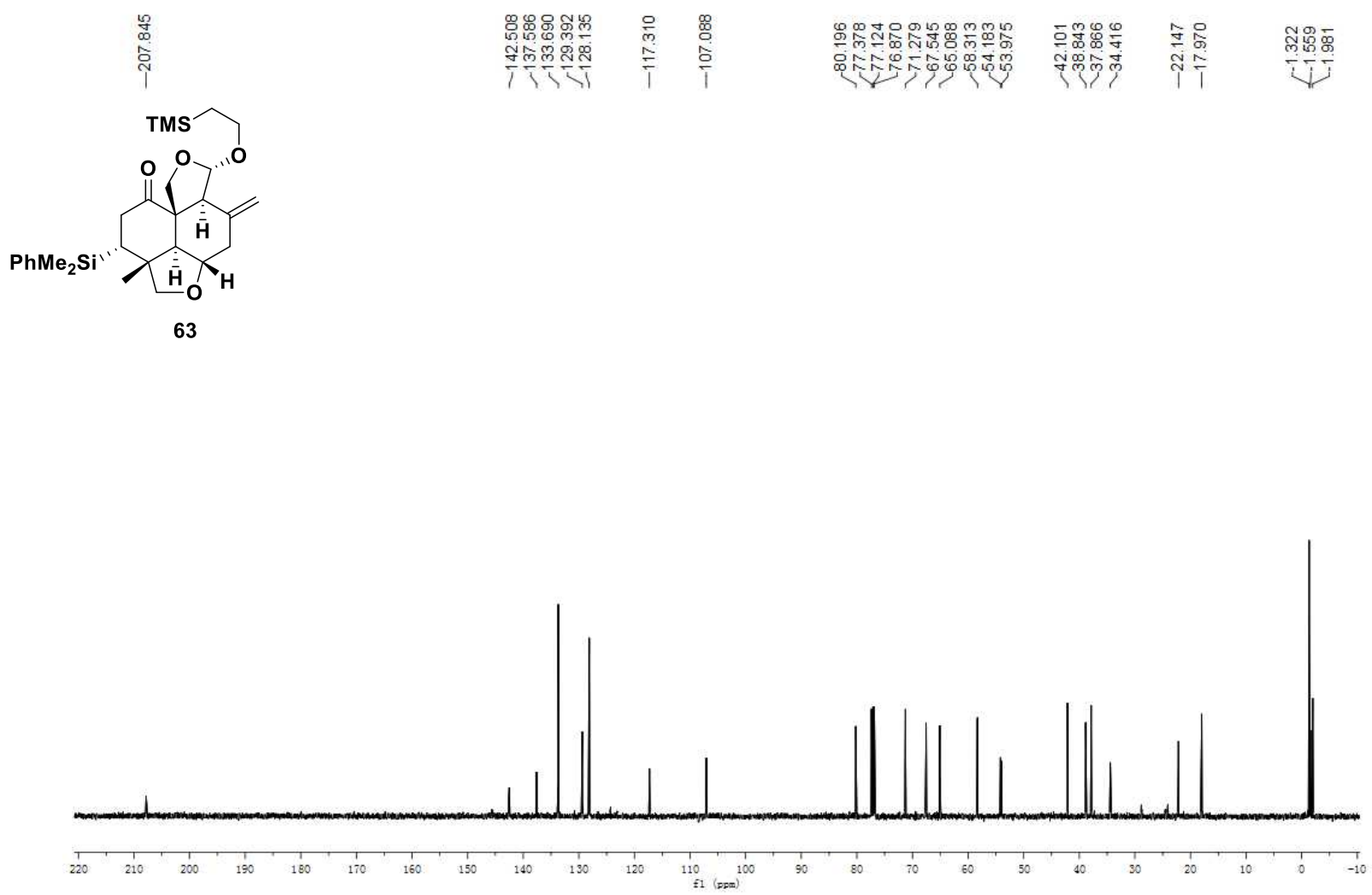

${ }^{13} \mathrm{C}$ NMR of compound 63 

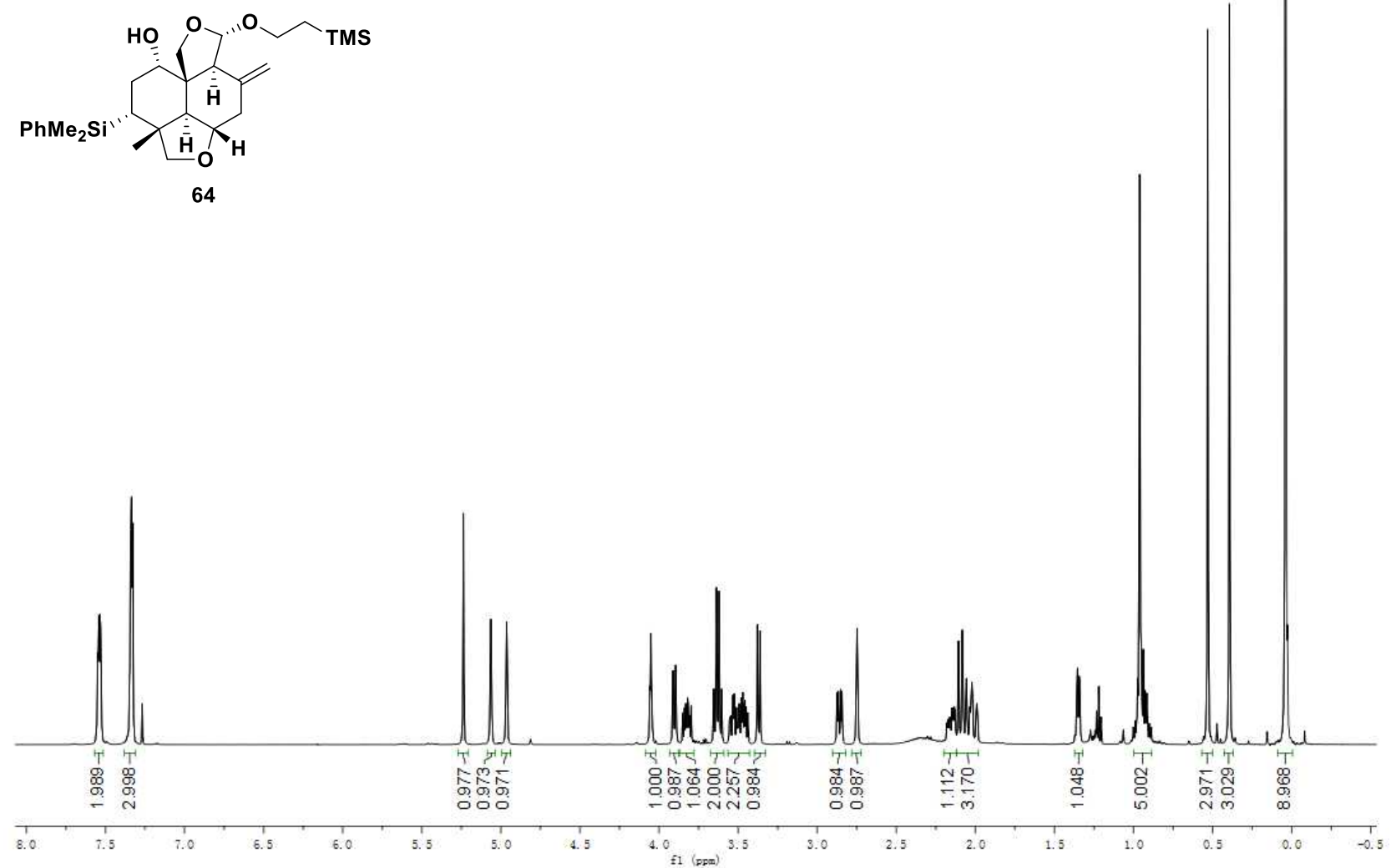

${ }^{1} \mathrm{H}$ NMR of compound 64

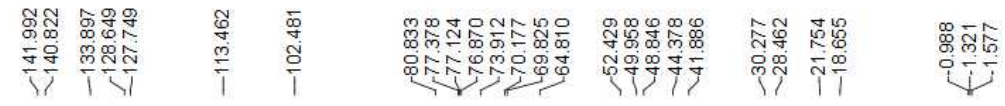

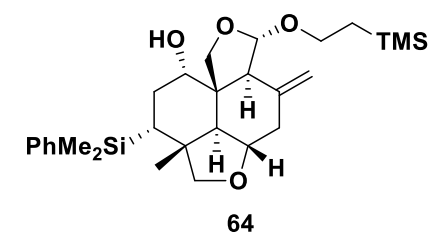

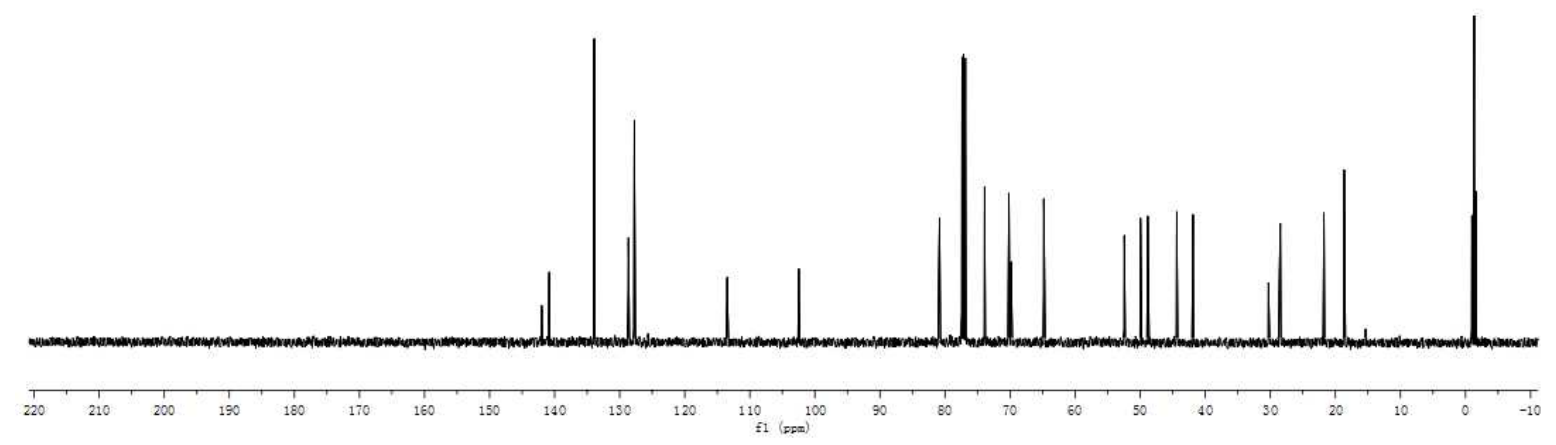

${ }^{13} \mathrm{C}$ NMR of compound 64 


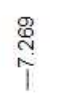

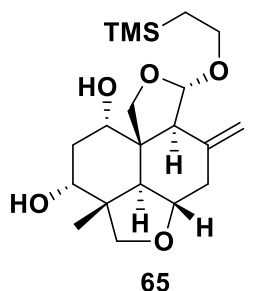

65

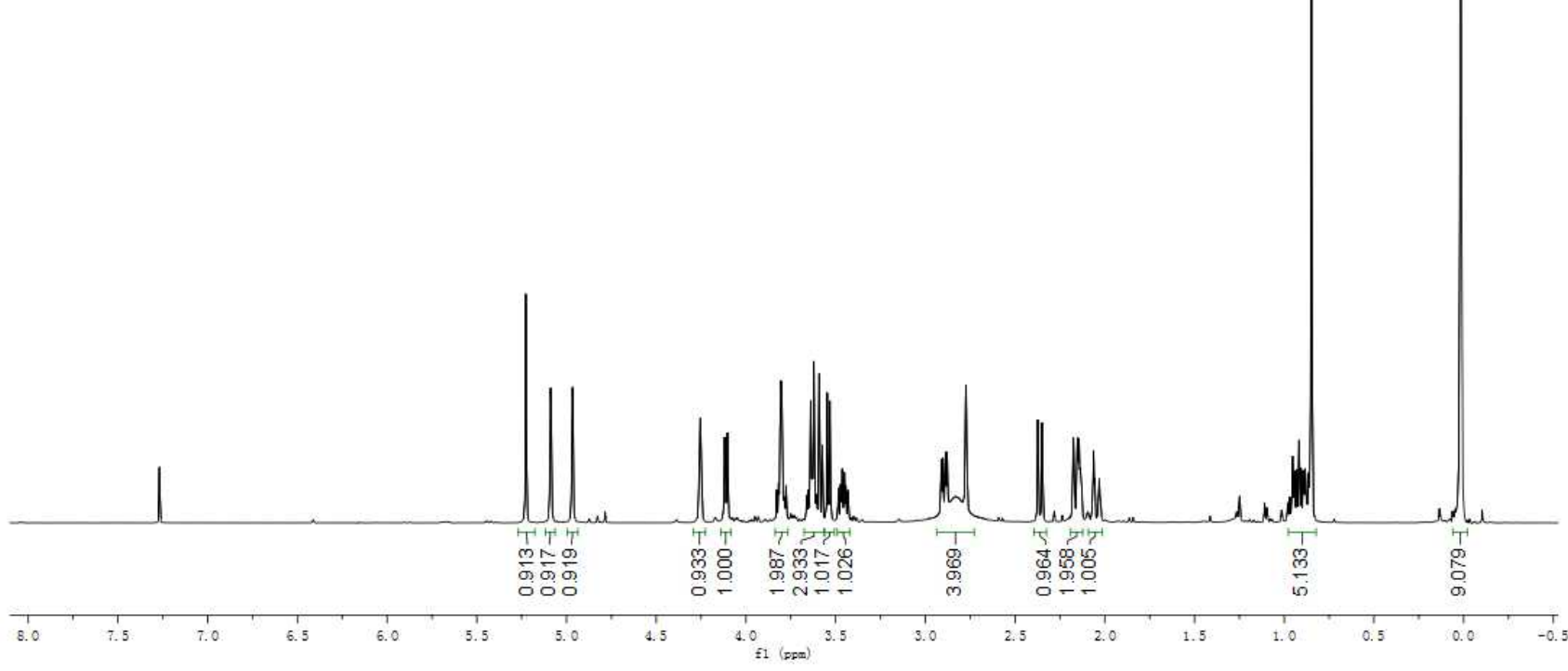

${ }^{1} \mathrm{H}$ NMR of compound $\mathbf{6 5}$

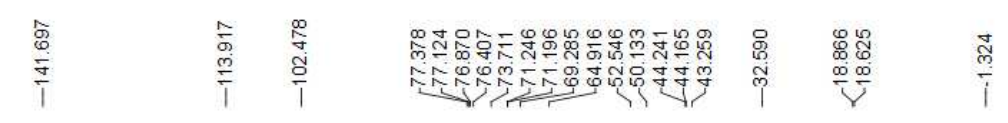
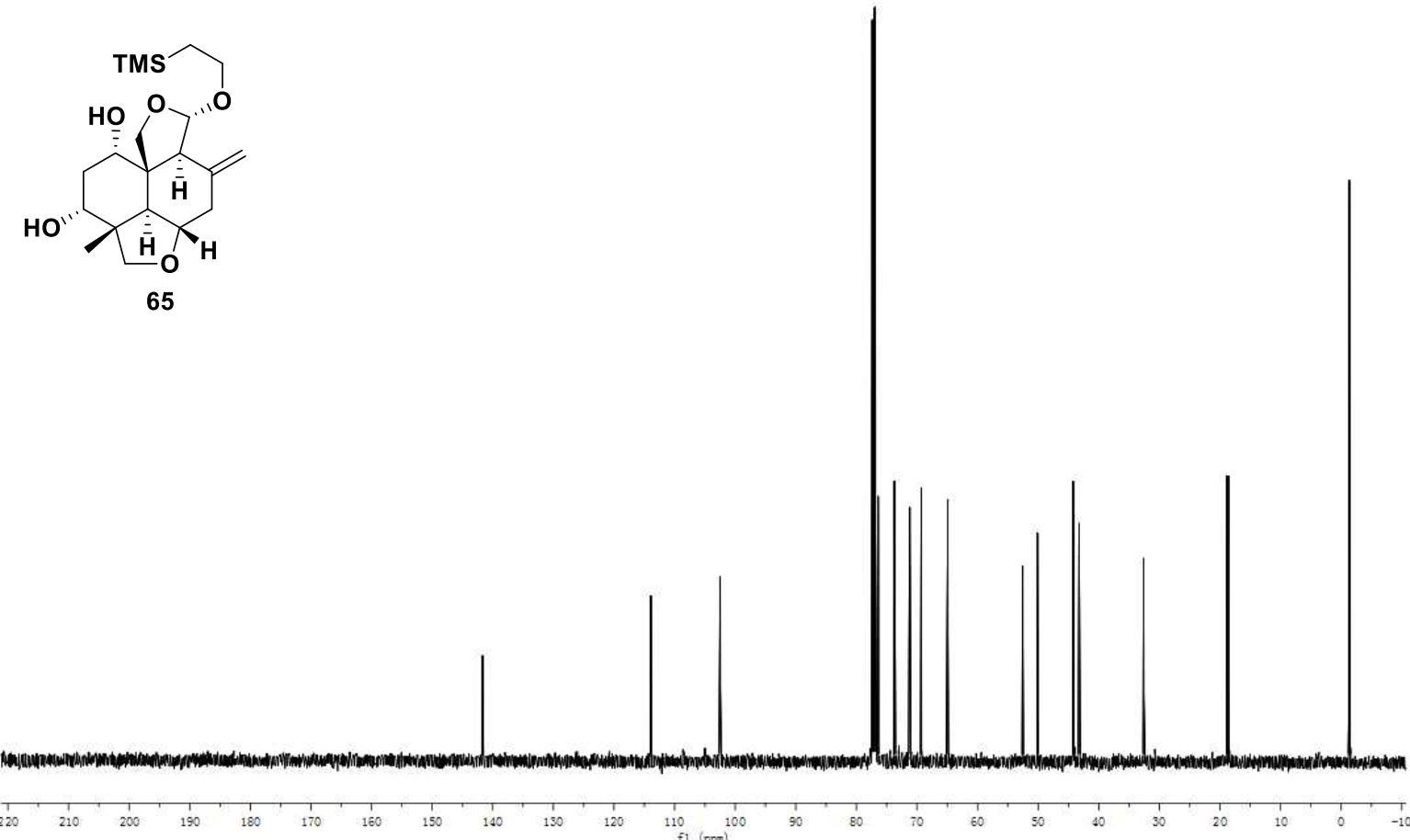

${ }^{13} \mathrm{C}$ NMR of compound 65 


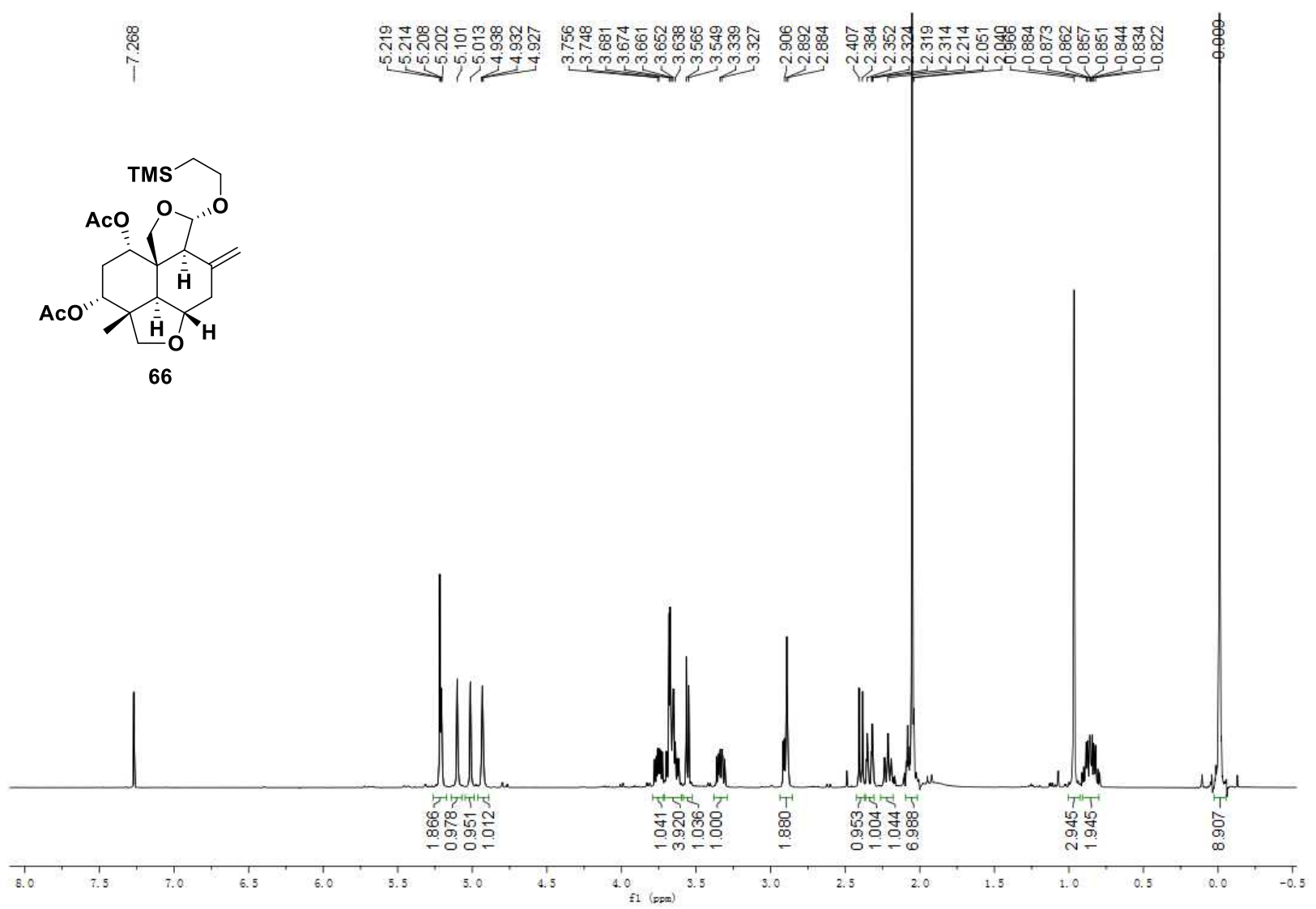

${ }^{1} \mathrm{H}$ NMR of compound $\mathbf{6 6}$

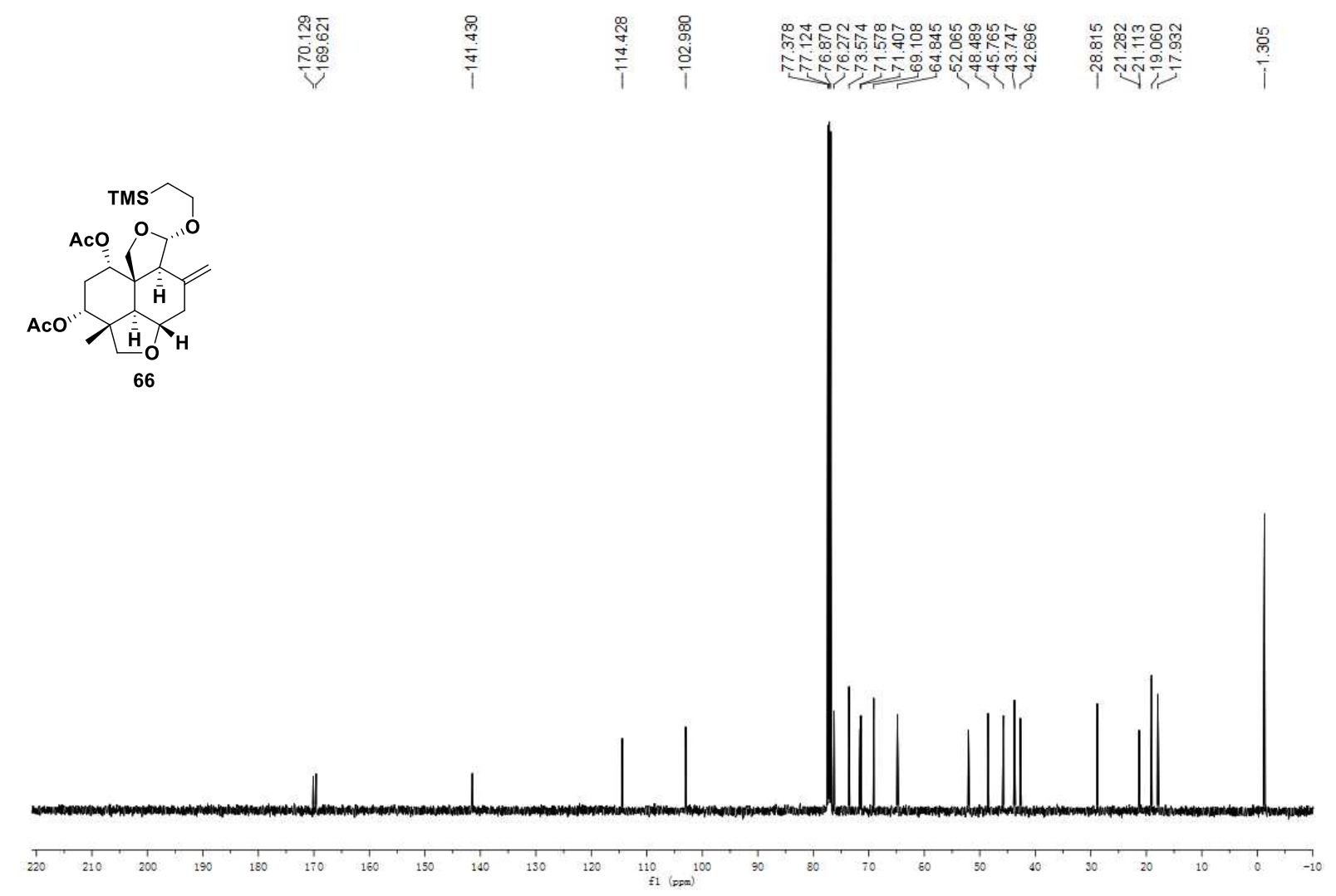

${ }^{13} \mathrm{C}$ NMR of compound 66 


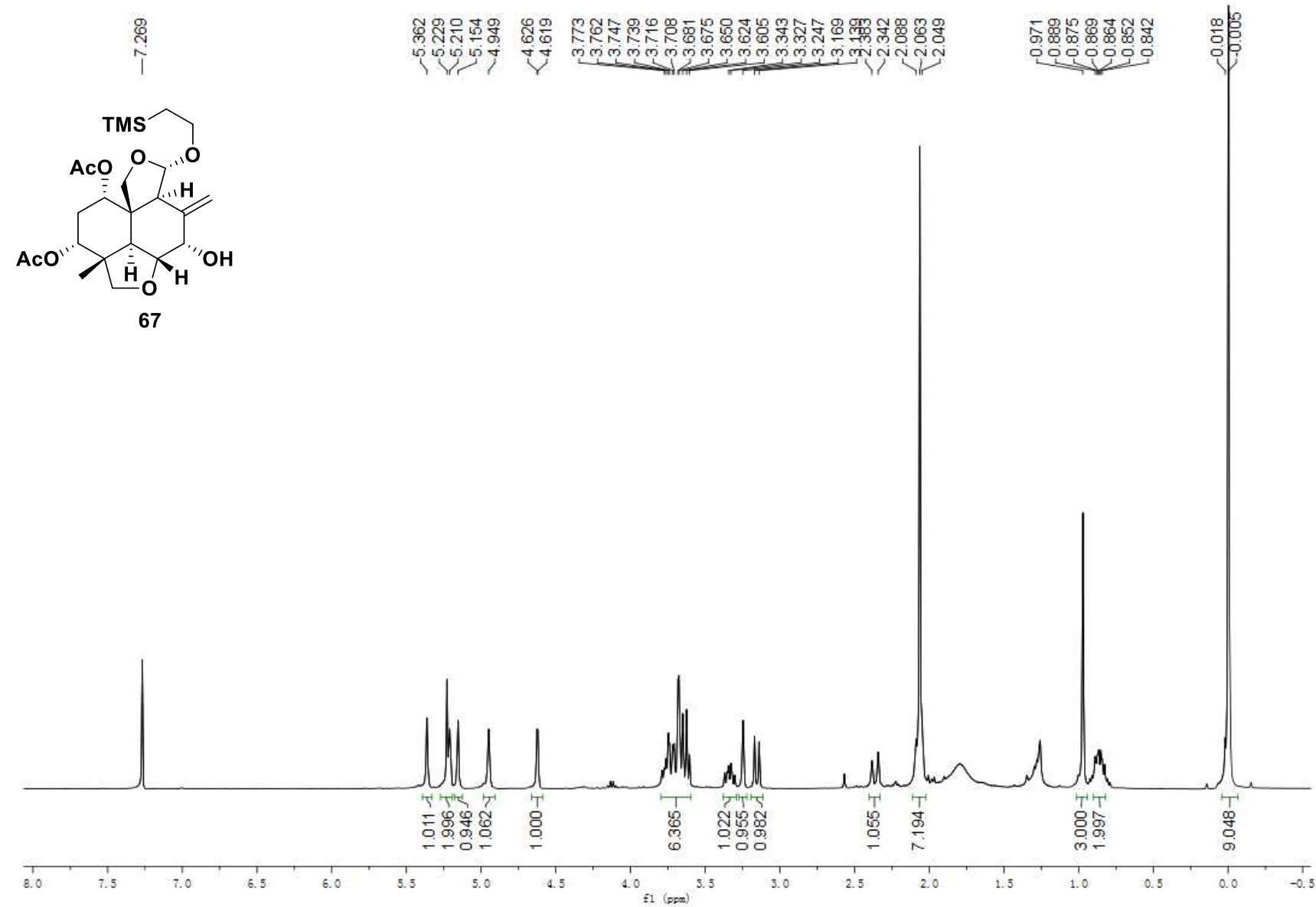

${ }^{1} \mathrm{H}$ NMR of compound $\mathbf{6 7}$

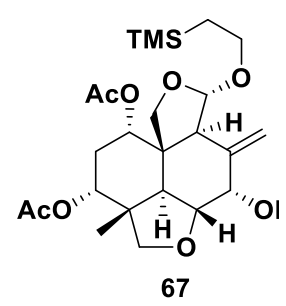

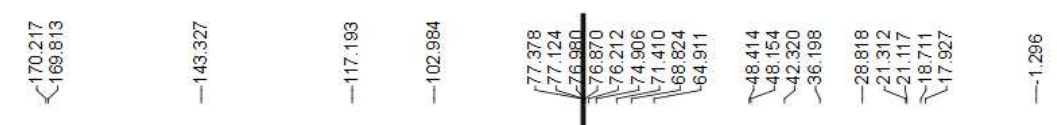
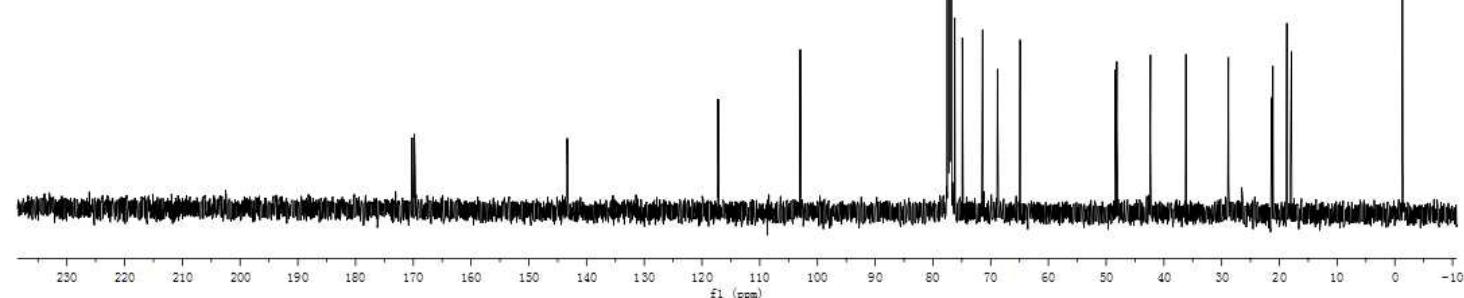

${ }^{13} \mathrm{C}$ NMR of compound 67 


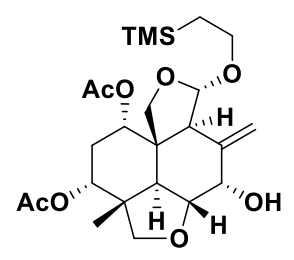

67
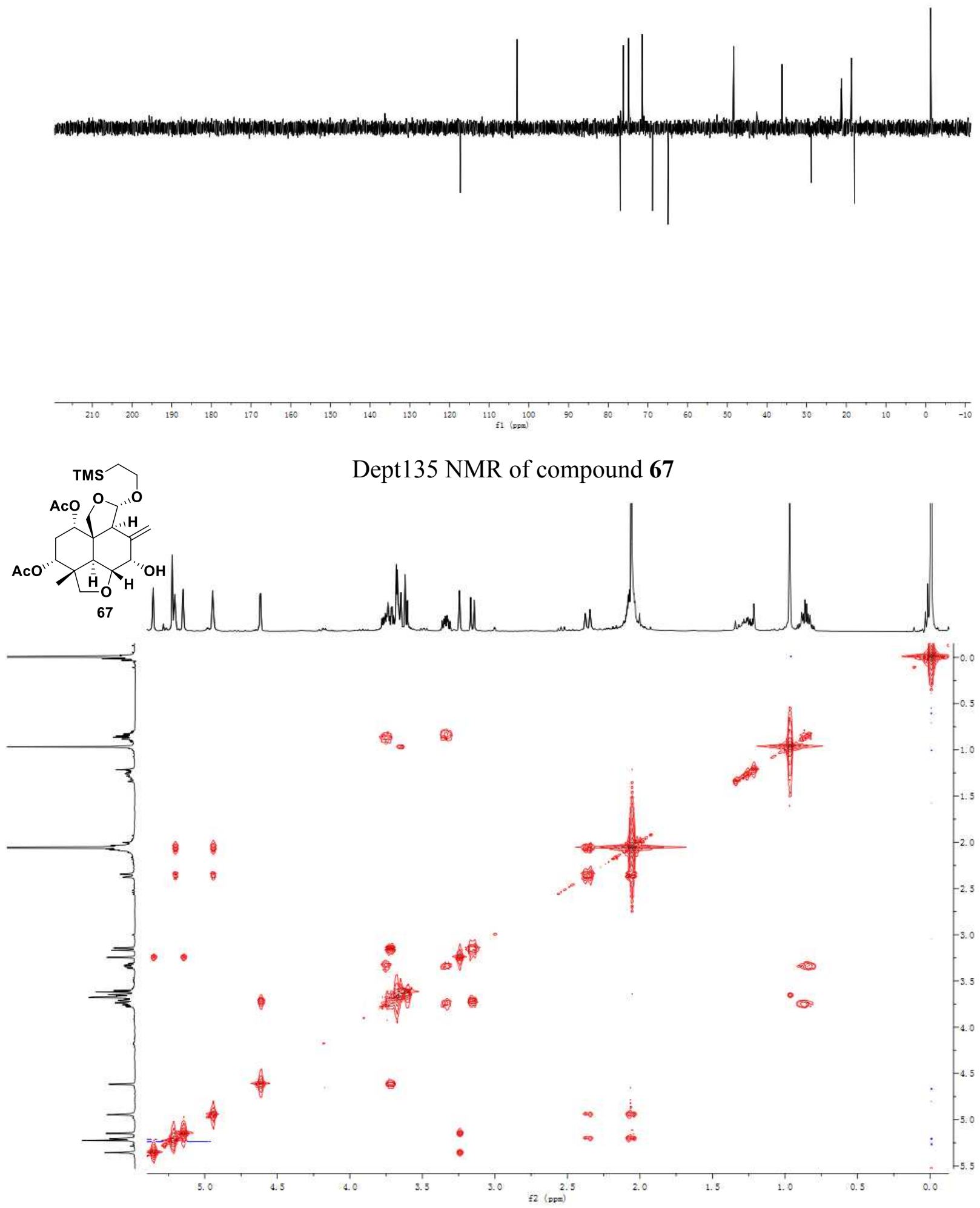

COSY NMR of compound $\mathbf{6 7}$ 

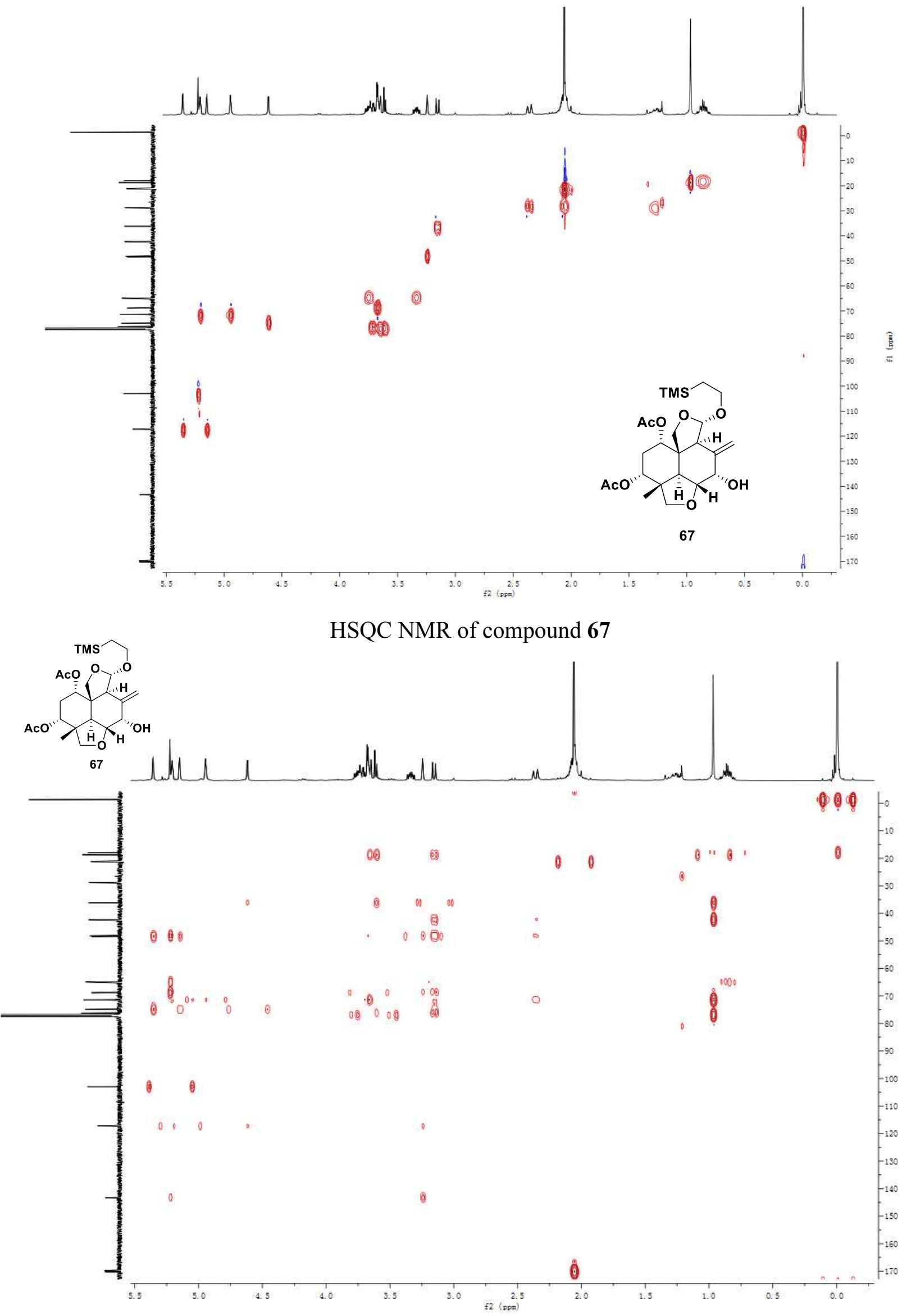

HMBC NMR of compound $\mathbf{6 7}$ 


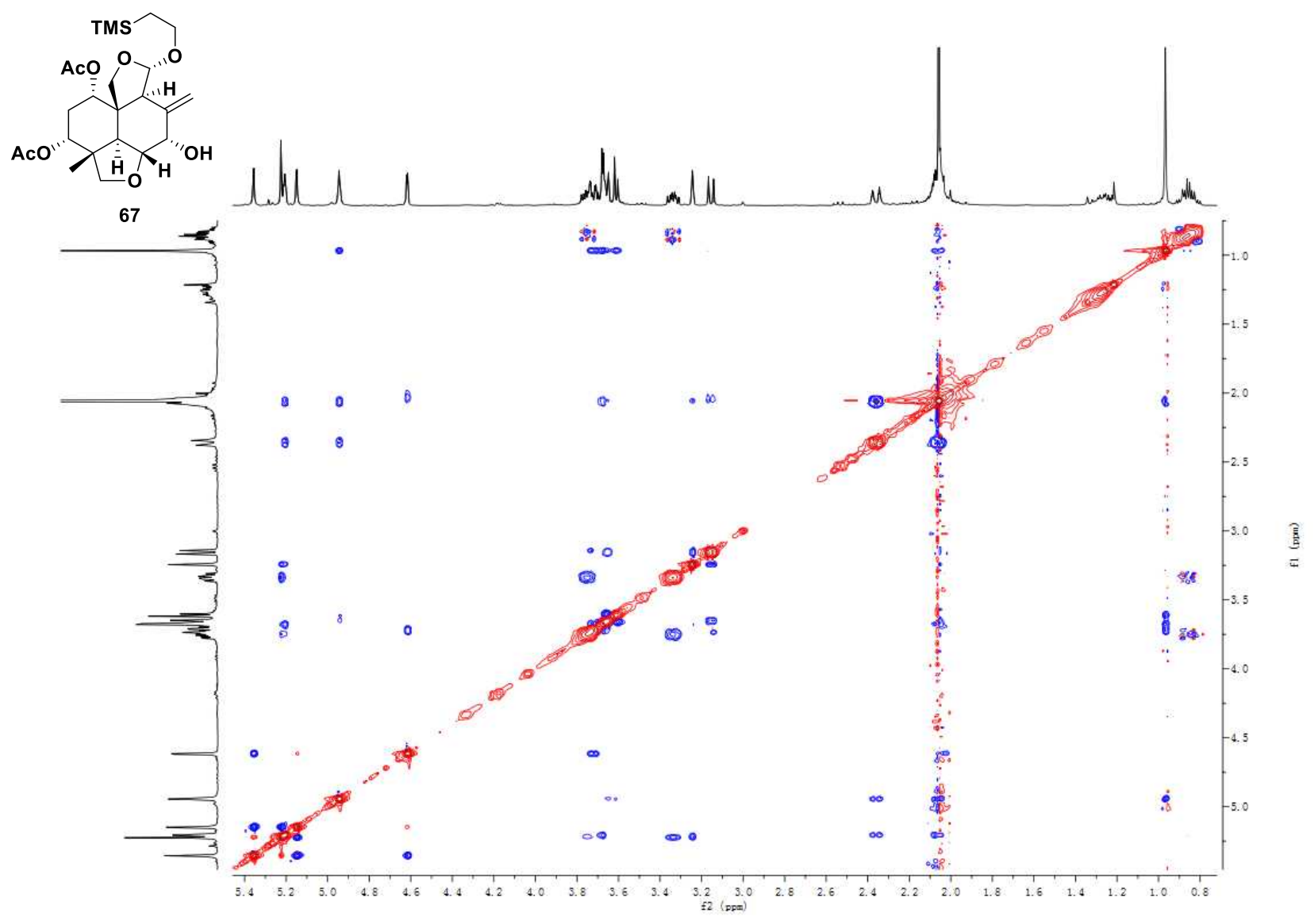

NOESY NMR of compound $\mathbf{6 7}$

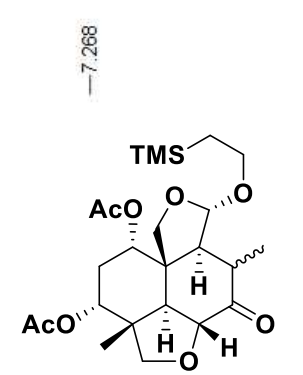

15 (घ-Me:团-Me $=10: 3$ )

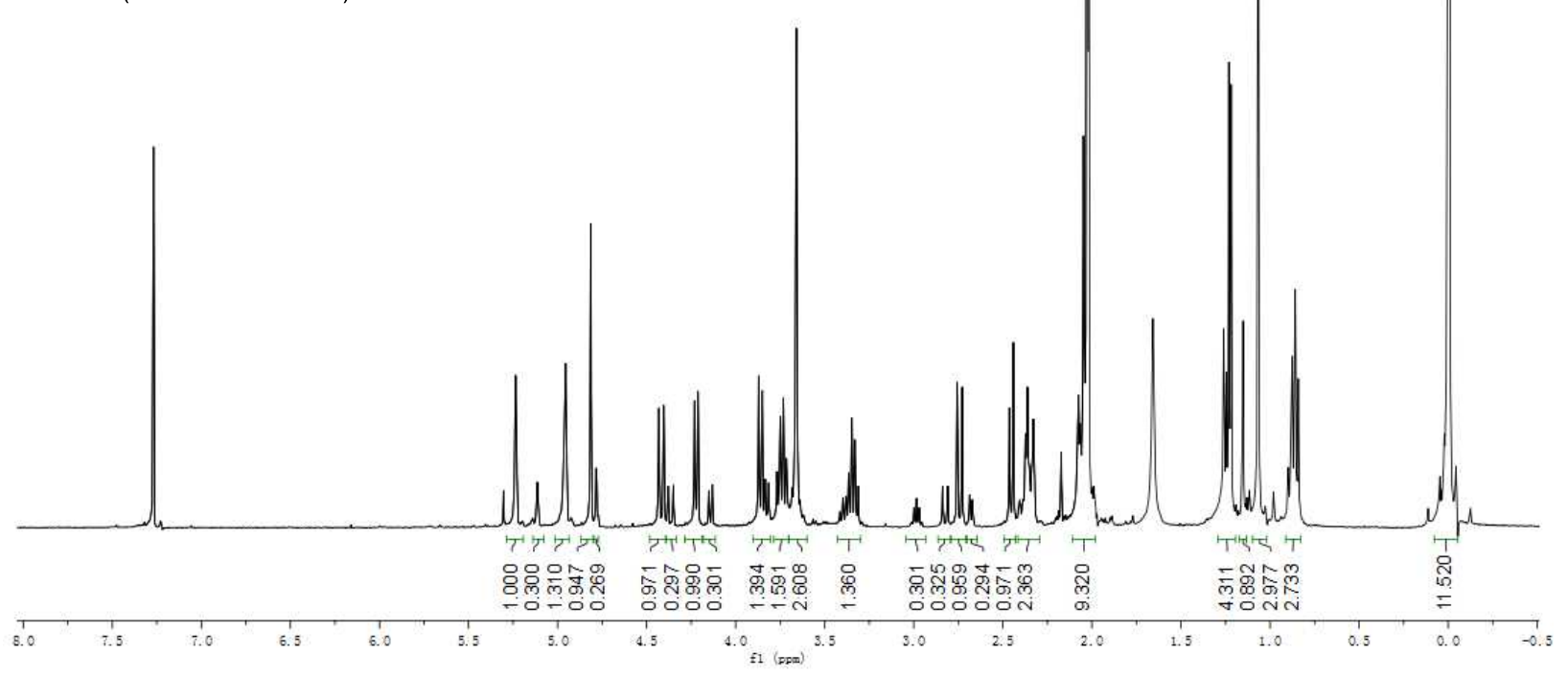

${ }^{1} \mathrm{H}$ NMR of compound $\mathbf{1 5}$ 


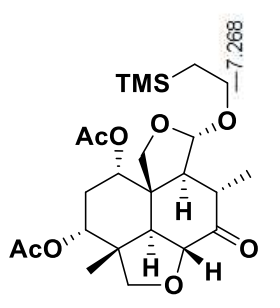

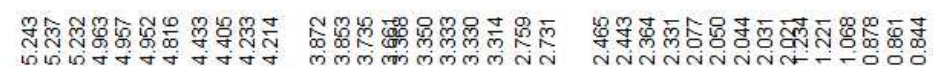

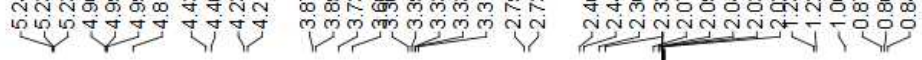

15 (回-Me)

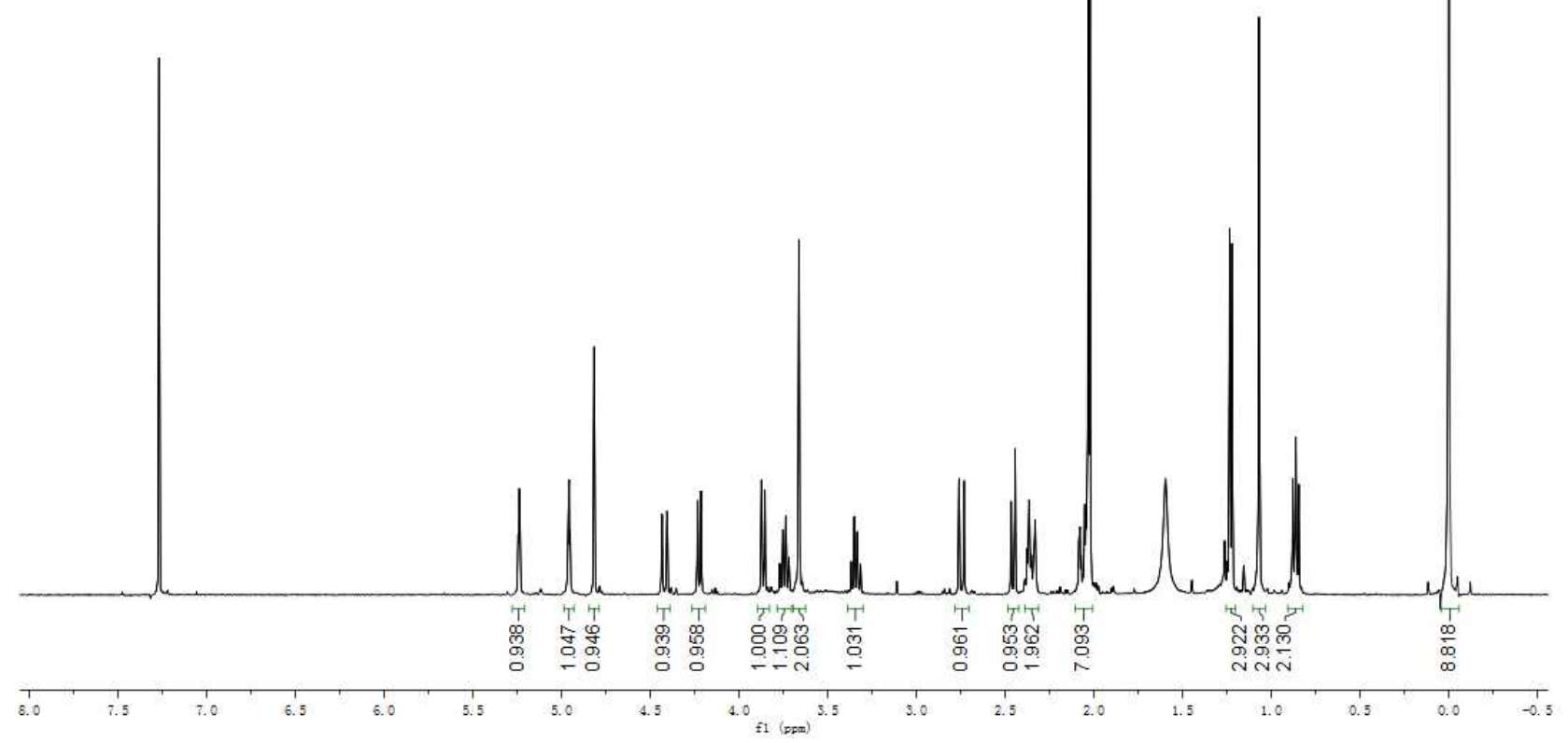

${ }^{1} \mathrm{H}$ NMR of compound $\mathbf{1 5}$

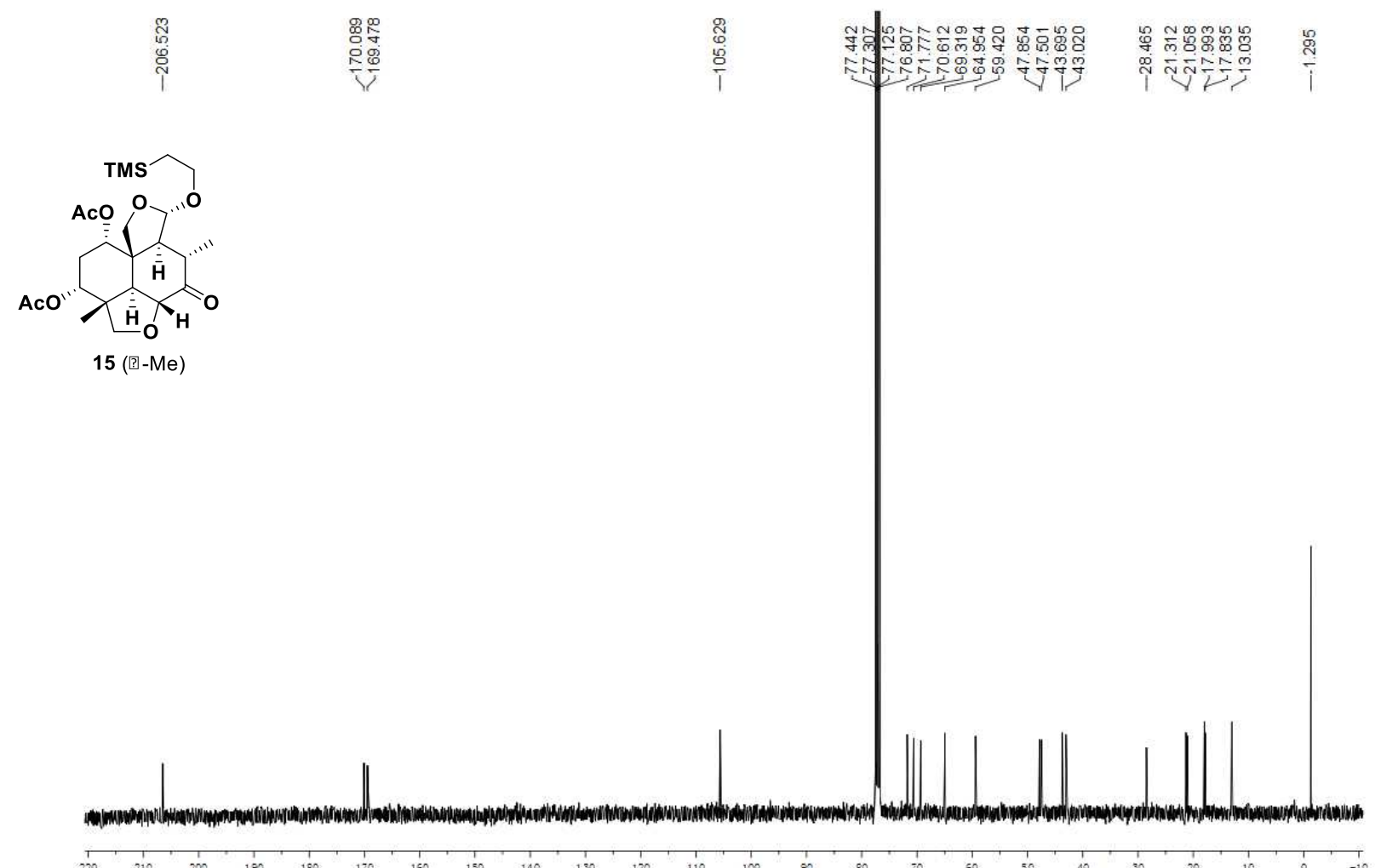

${ }^{13} \mathrm{C}$ NMR of compound $\mathbf{1 5}$ 


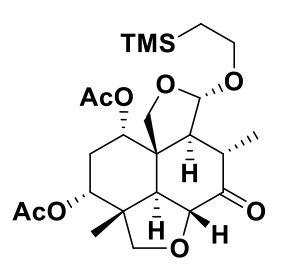

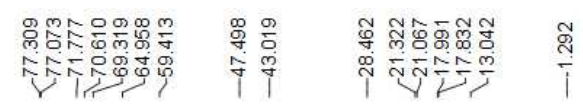

15 (미-Me)
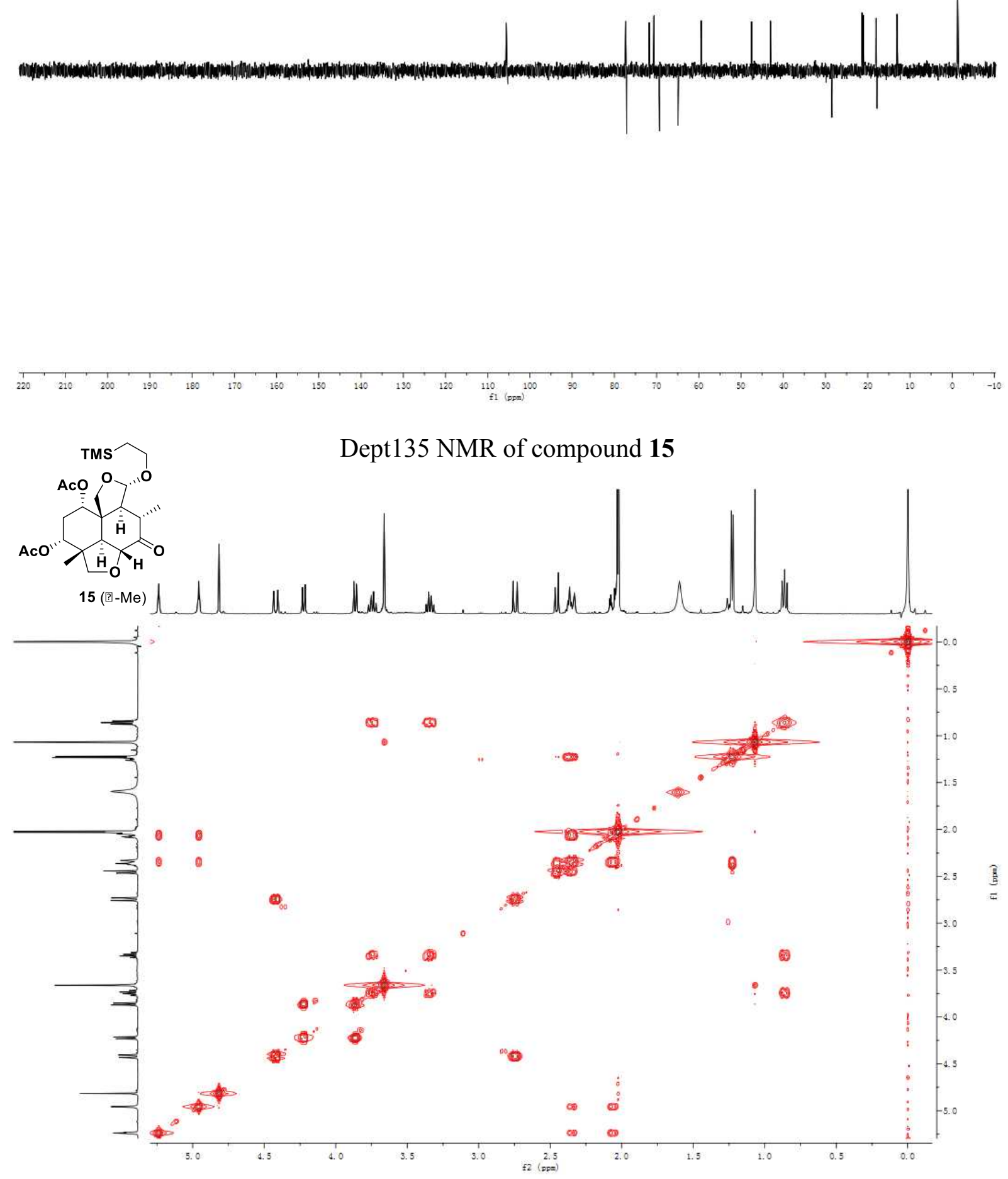

COSY NMR of compound $\mathbf{1 5}$ 

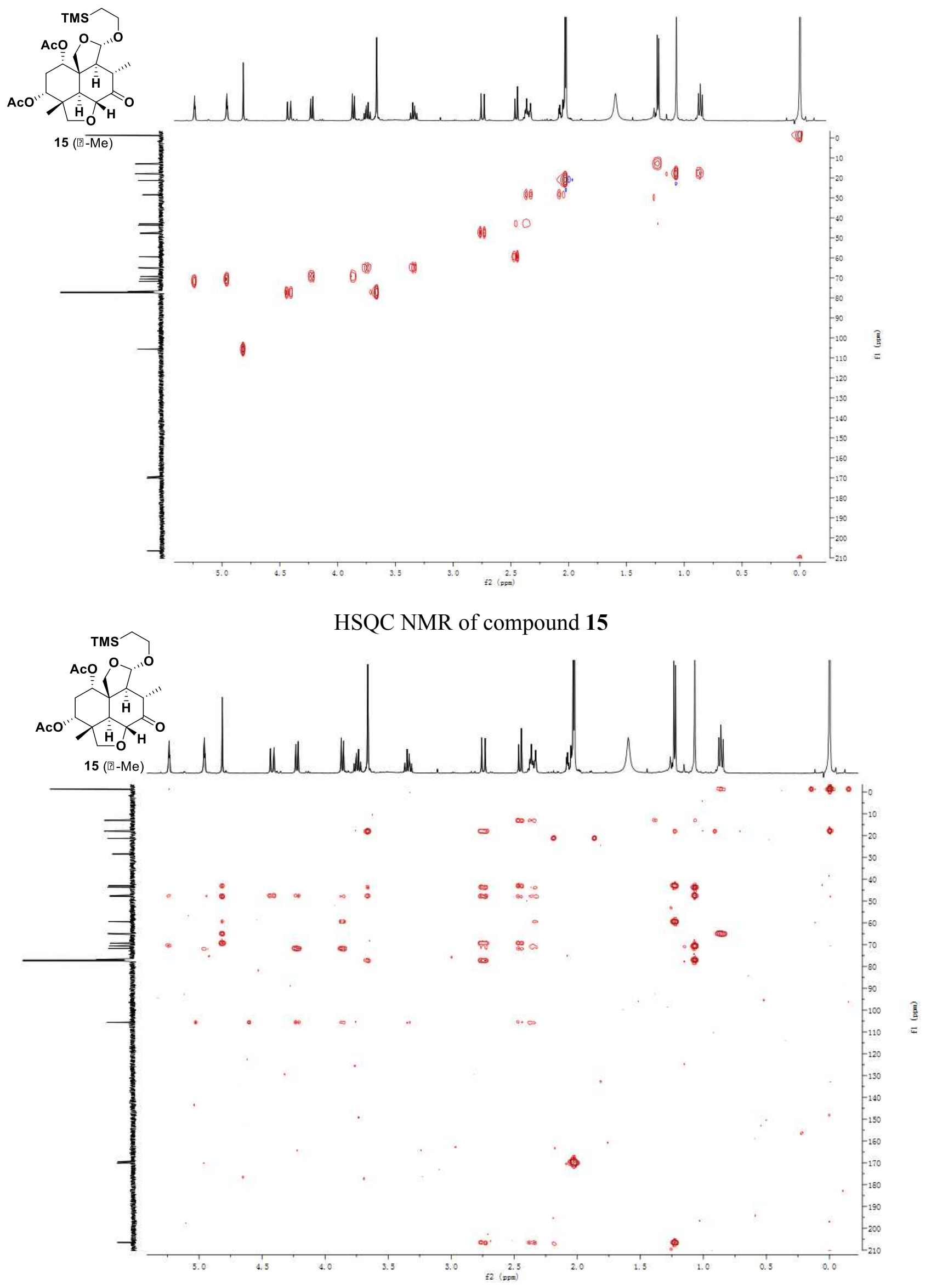

HMBC NMR of compound 15 


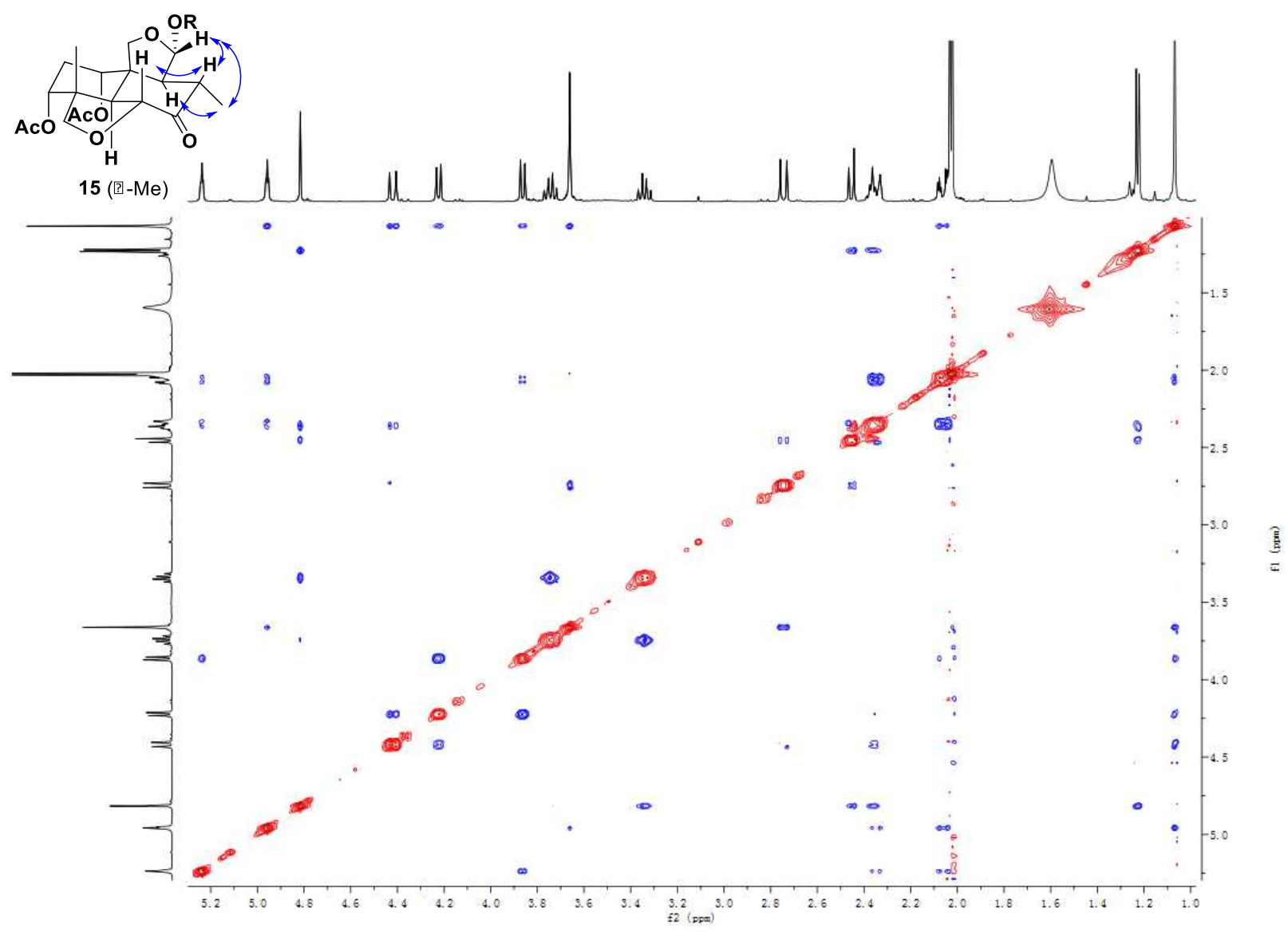

NOESY NMR of compound $\mathbf{1 5}$

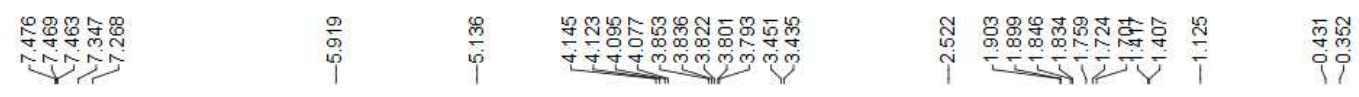

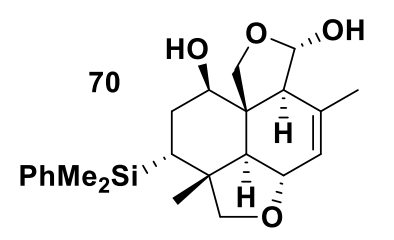

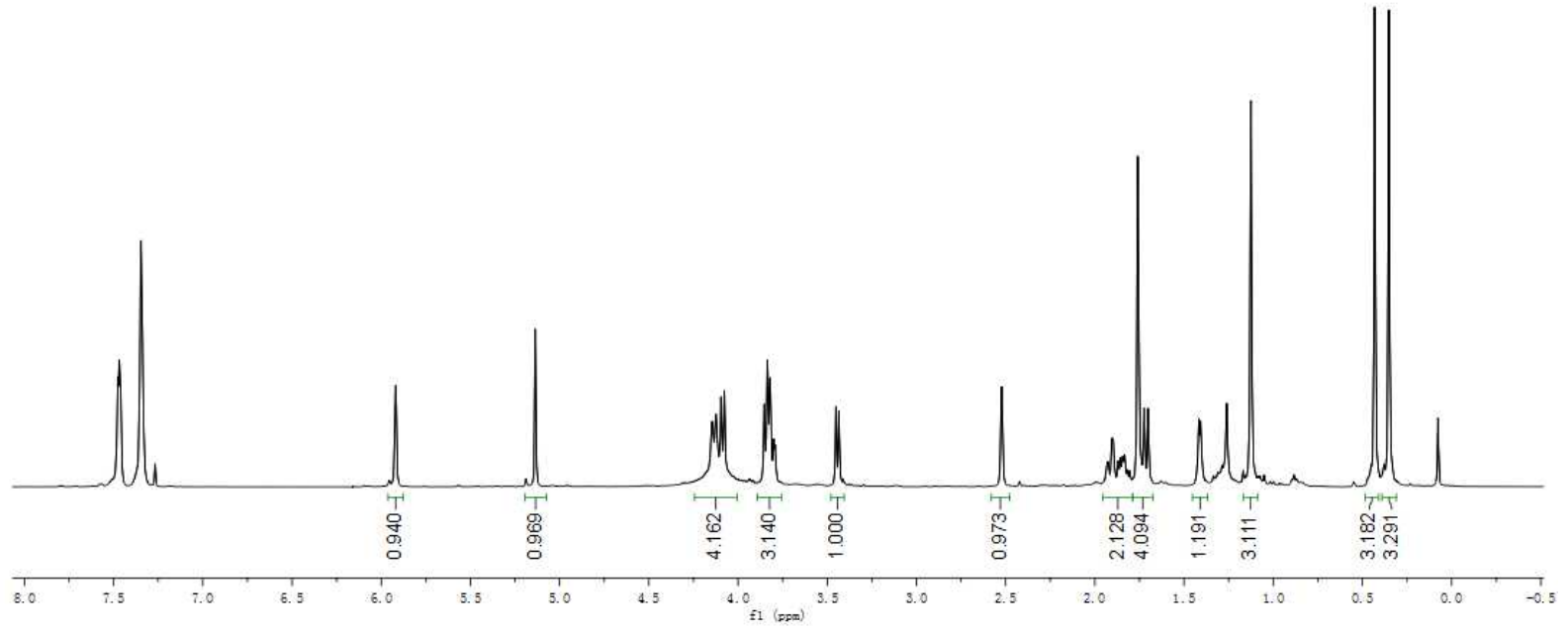

${ }^{1} \mathrm{H}$ NMR of compound $\mathbf{7 0}$ 


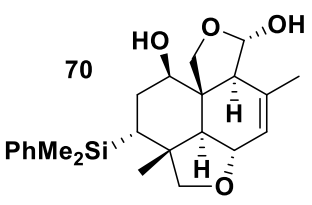

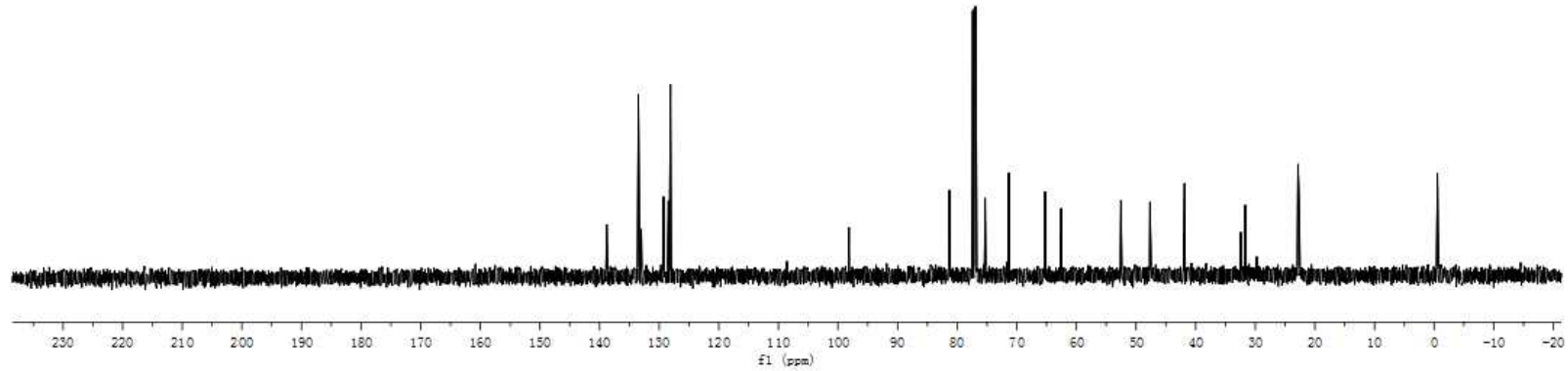

${ }^{13} \mathrm{C}$ NMR of compound 70
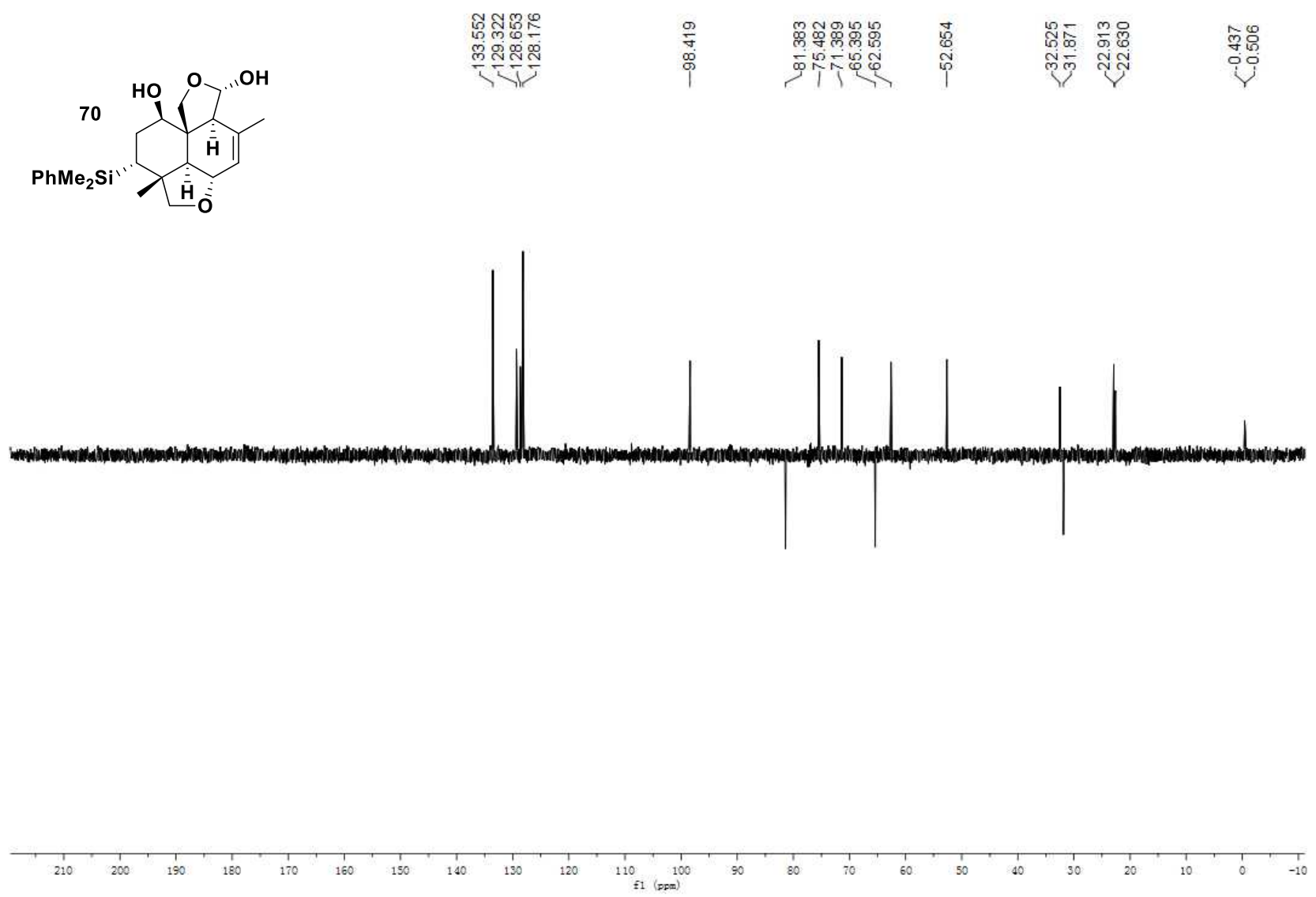

Dept135 NMR of compound 70 


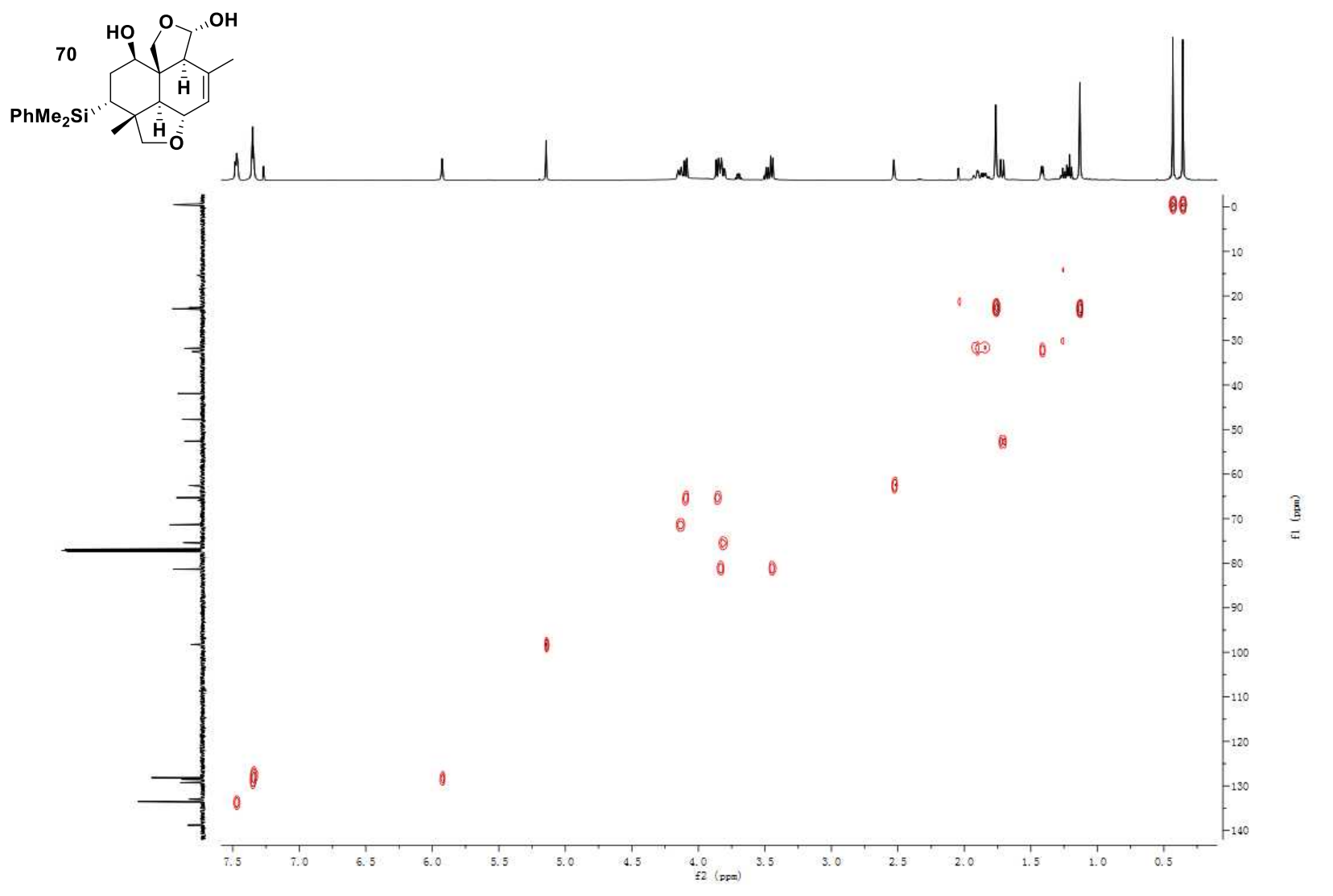

HSQC NMR of compound 70
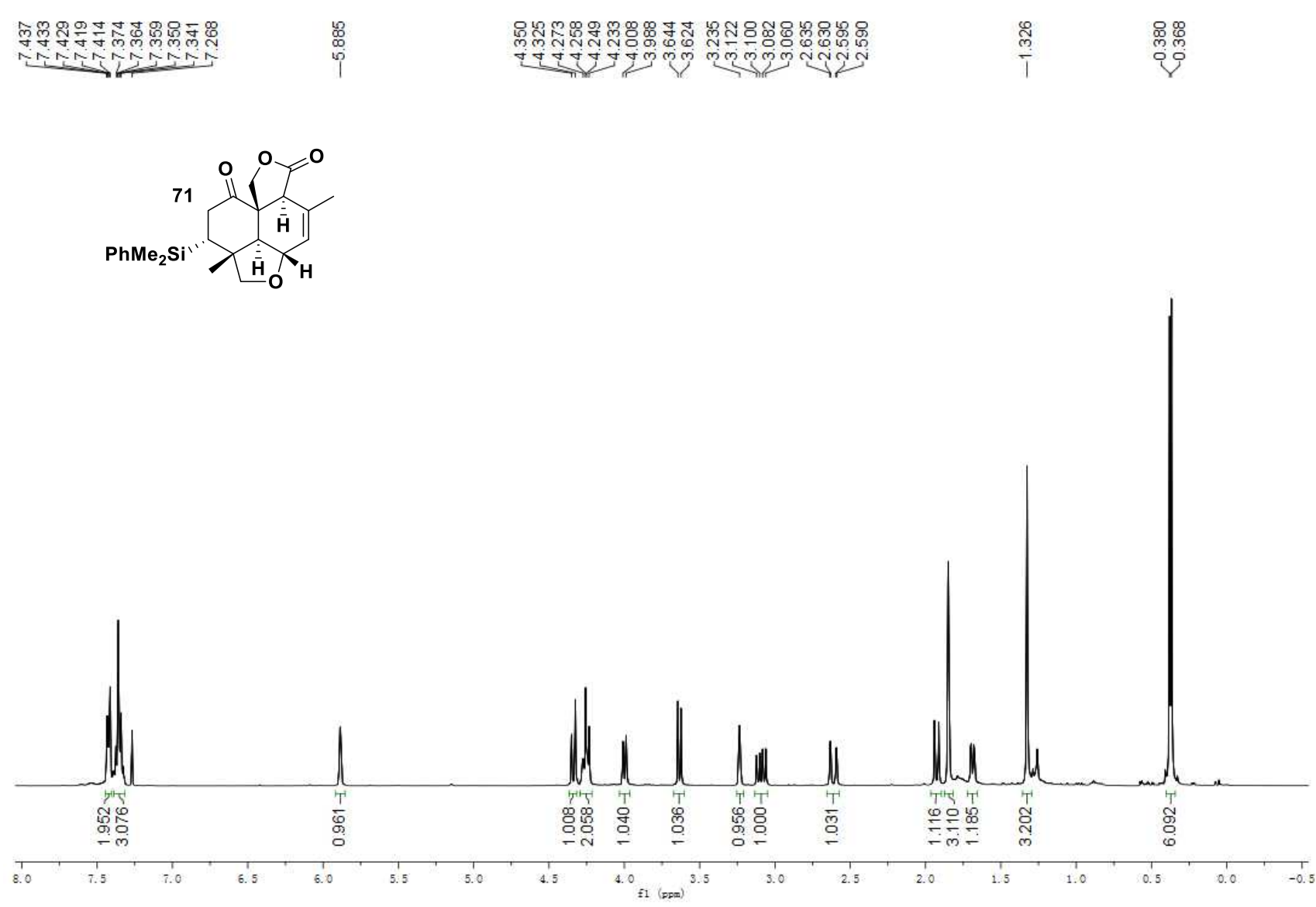

${ }^{1} \mathrm{H}$ NMR of compound $\mathbf{7 1}$ 


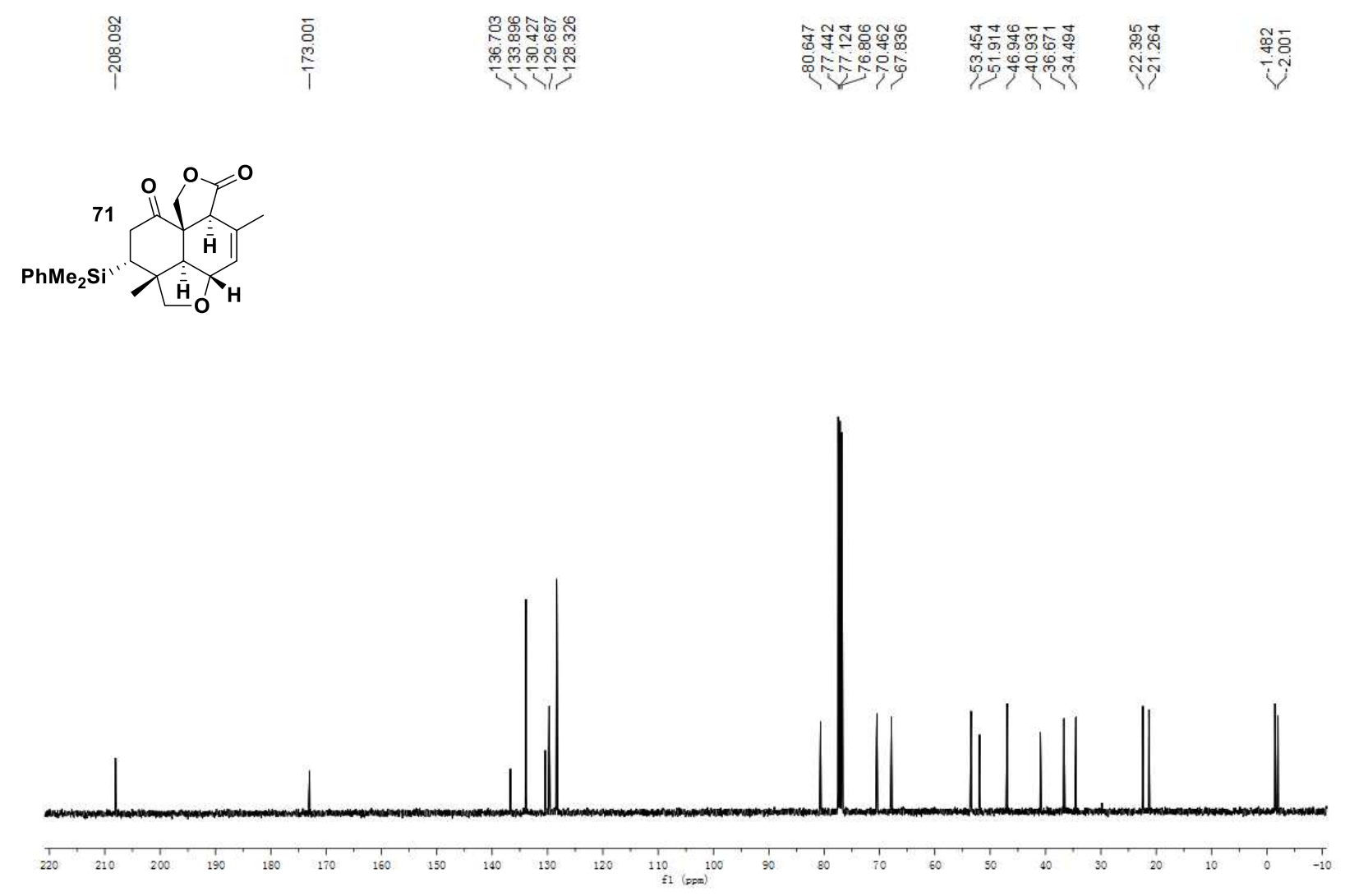

${ }^{13} \mathrm{C}$ NMR of compound 71
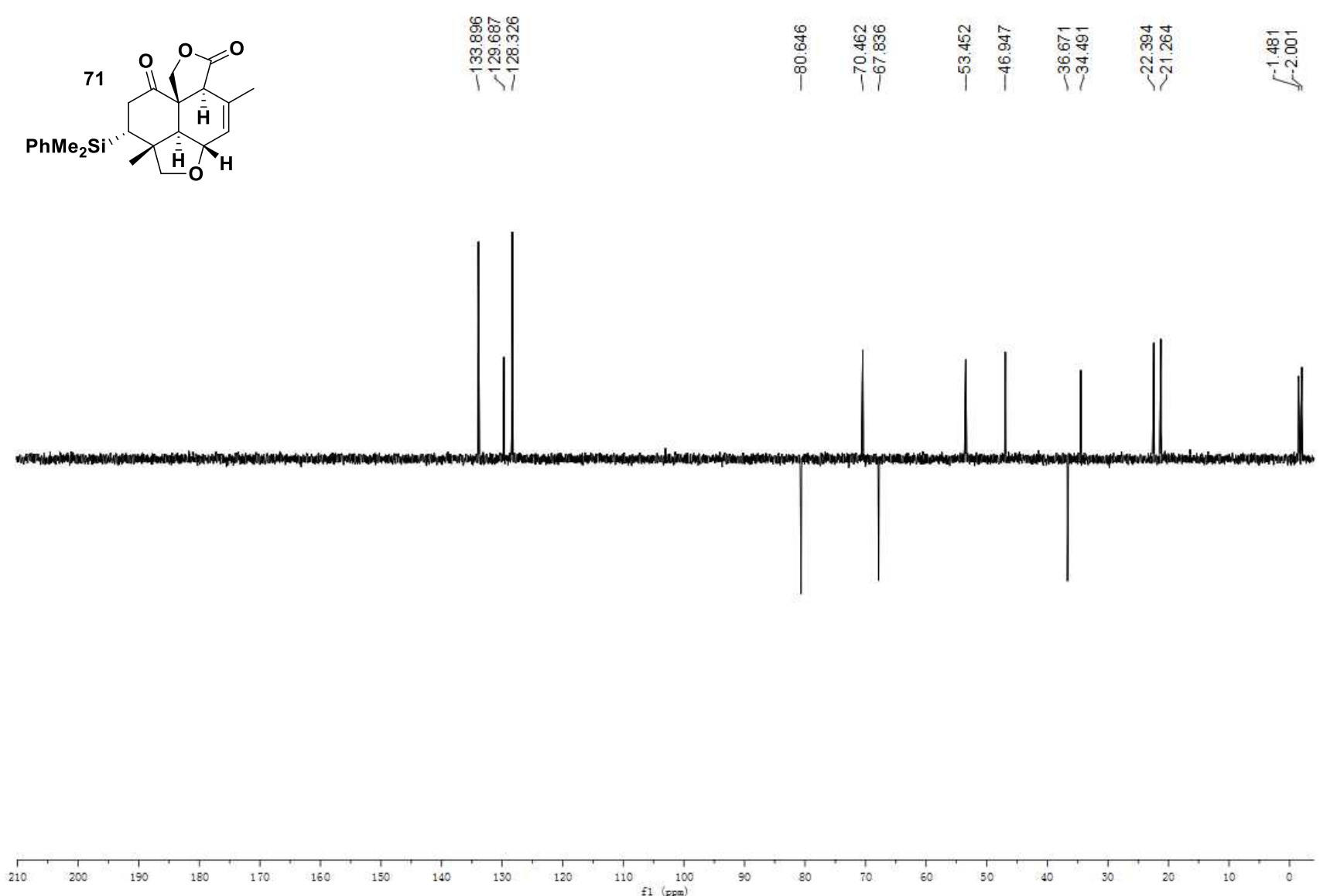

Dept135 NMR of compound 71 


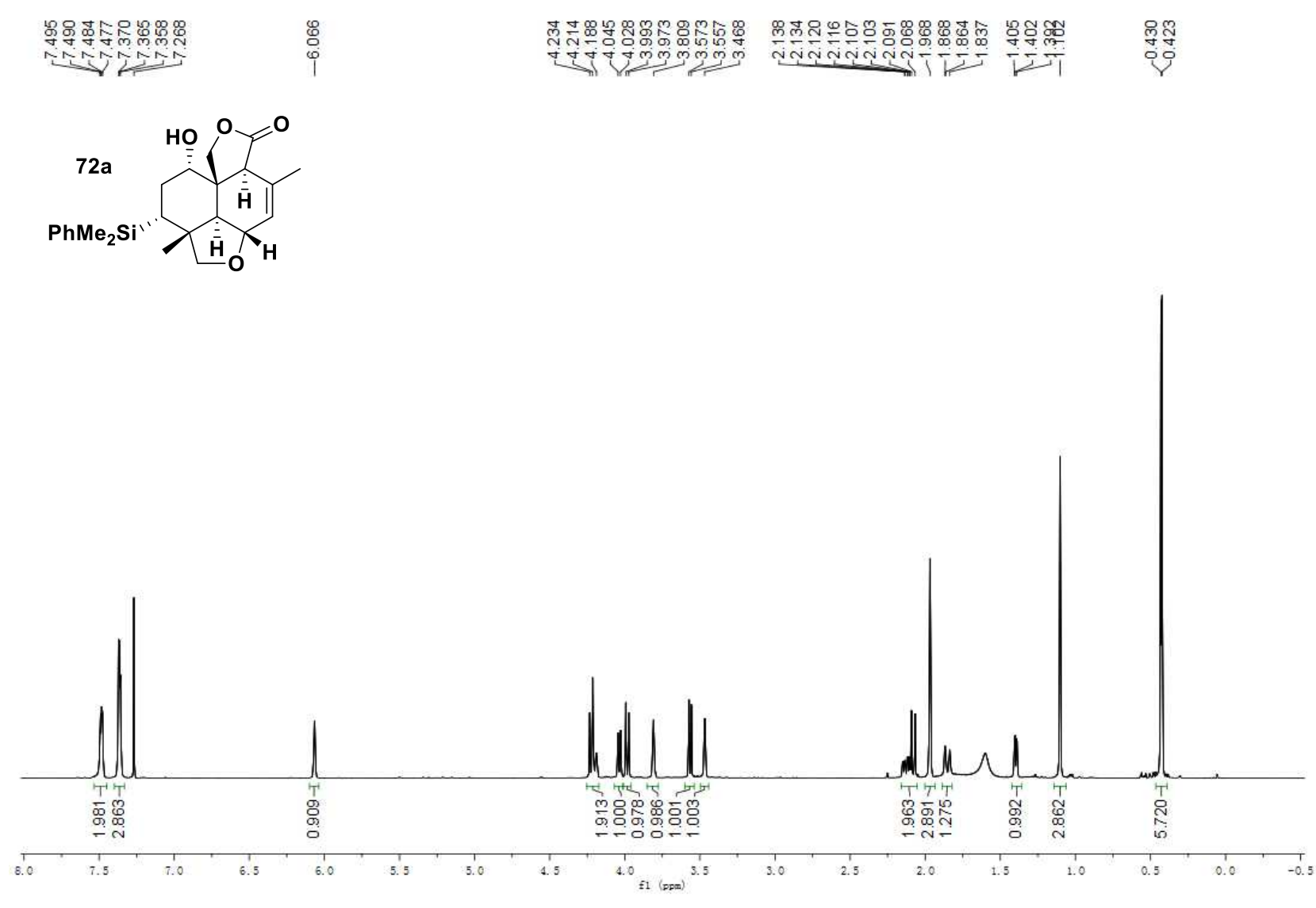

${ }^{1} \mathrm{H}$ NMR of compound 72a

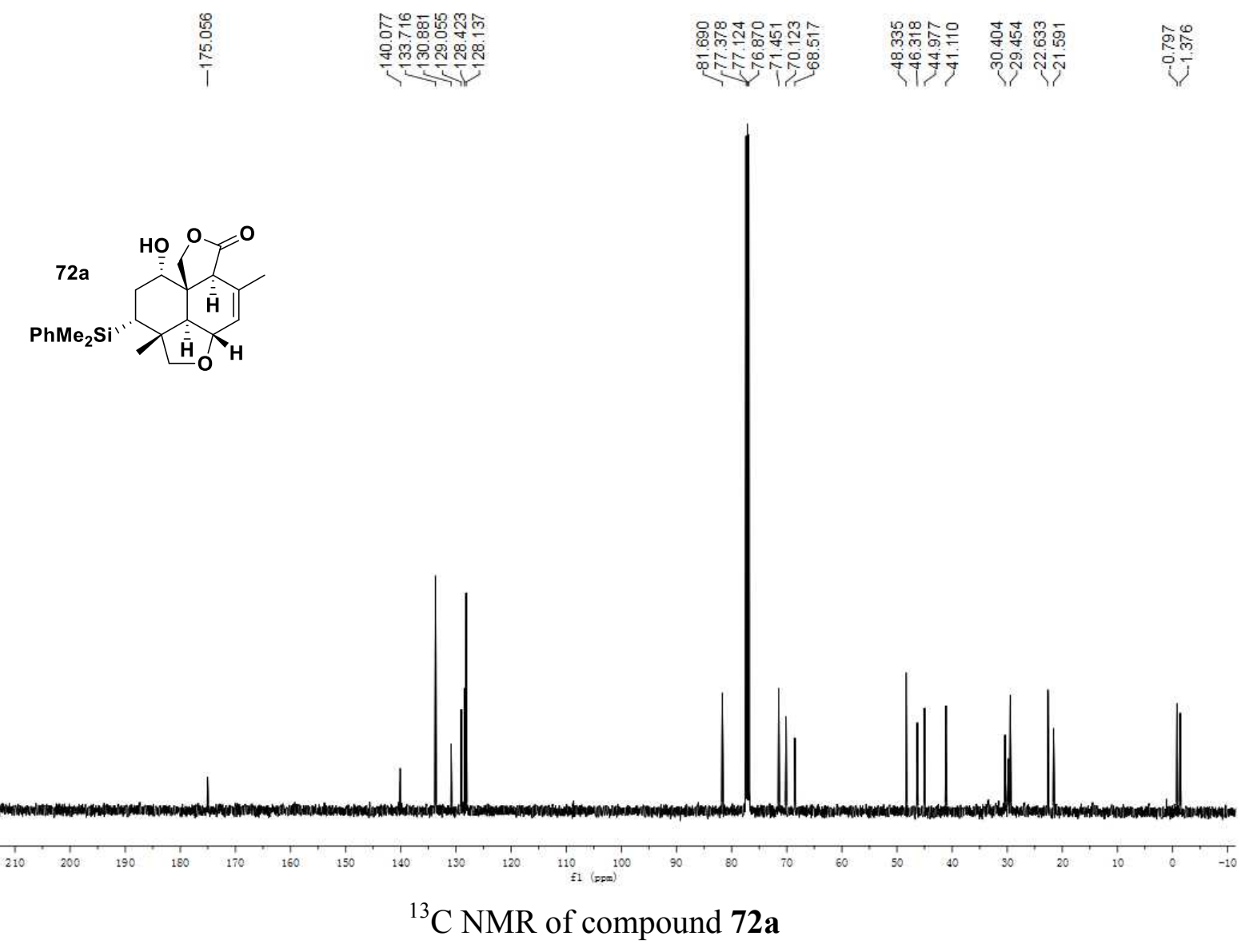



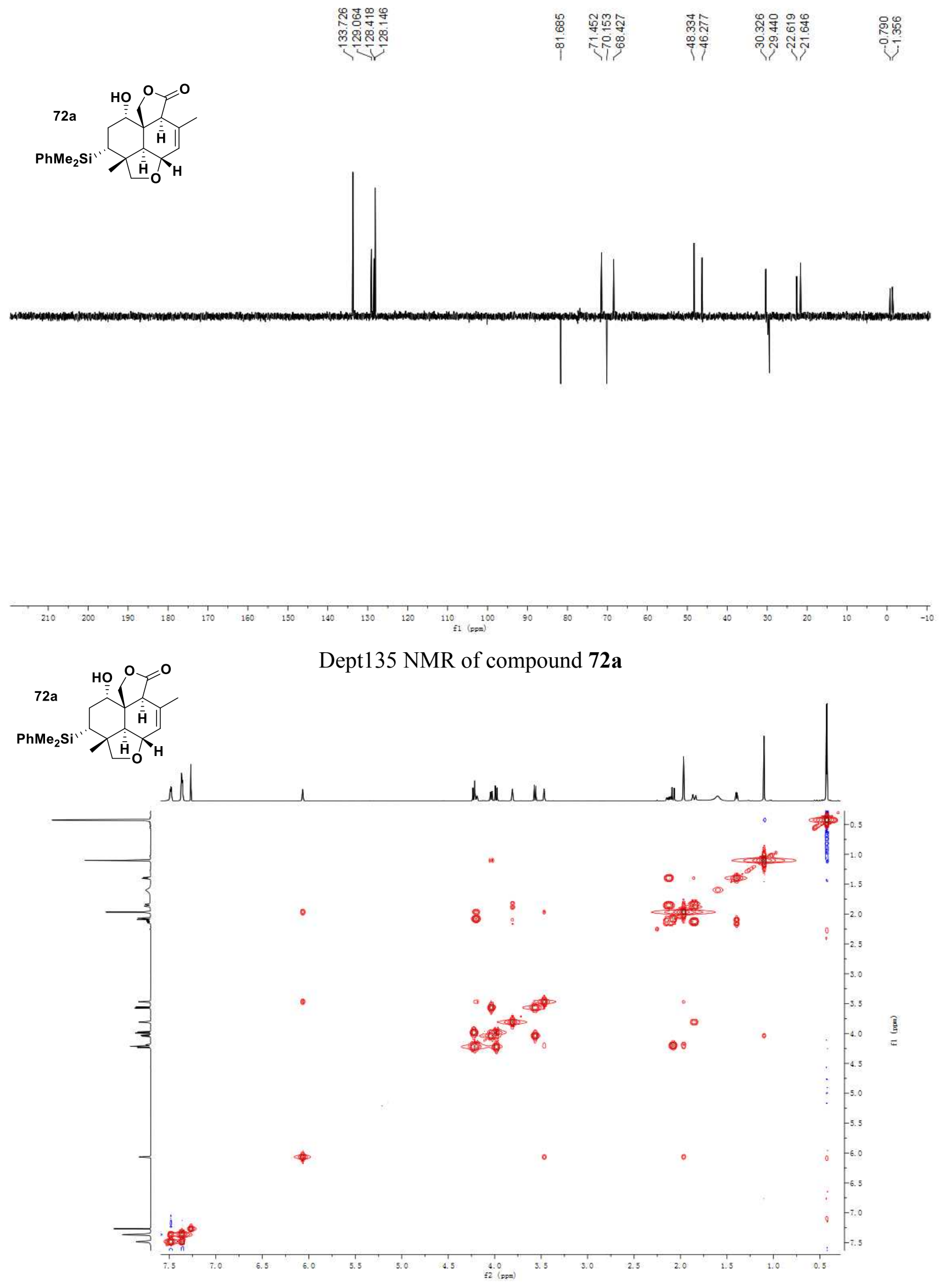

COSY NMR of compound 72a 


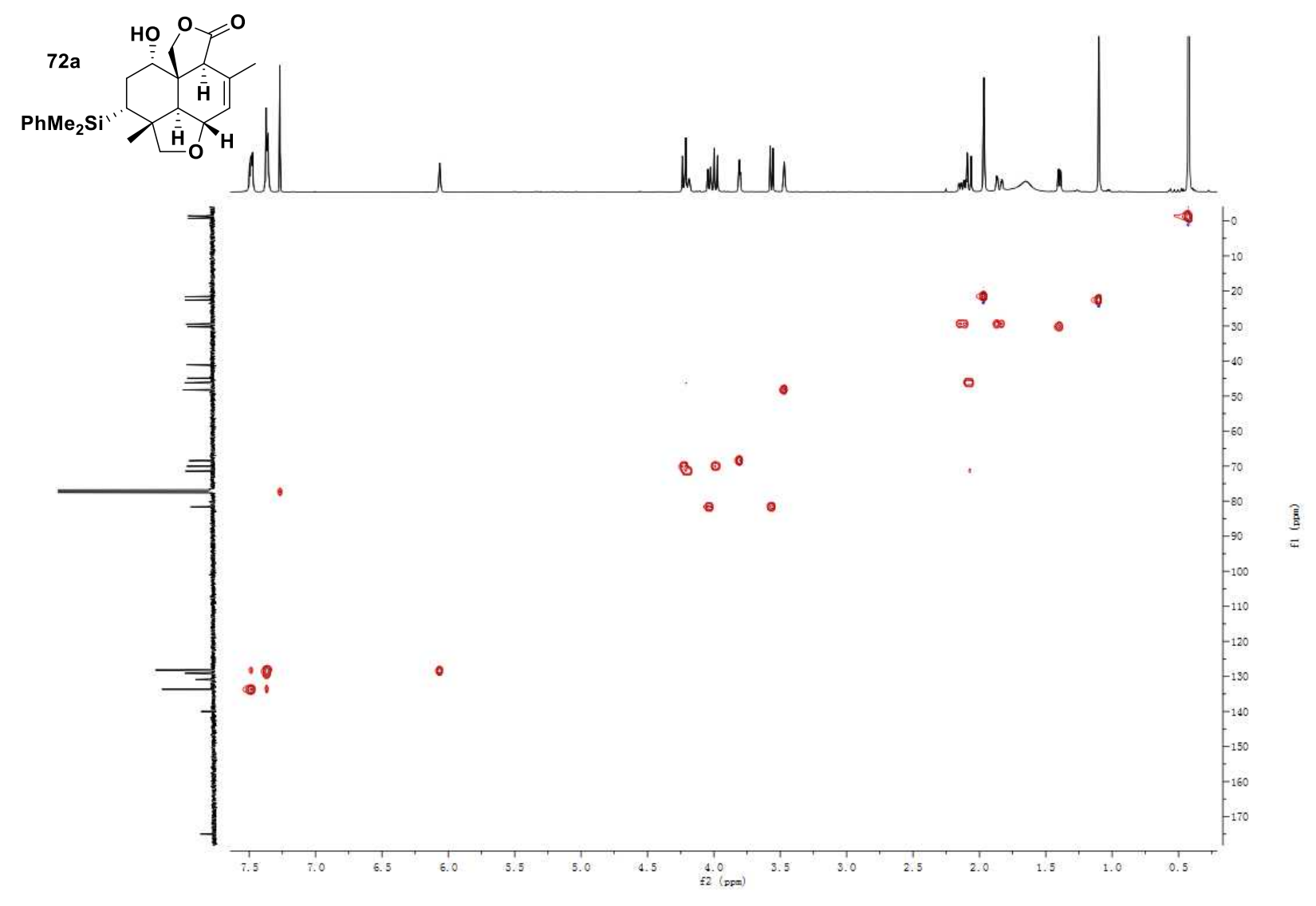

HSQC NMR of compound 72a

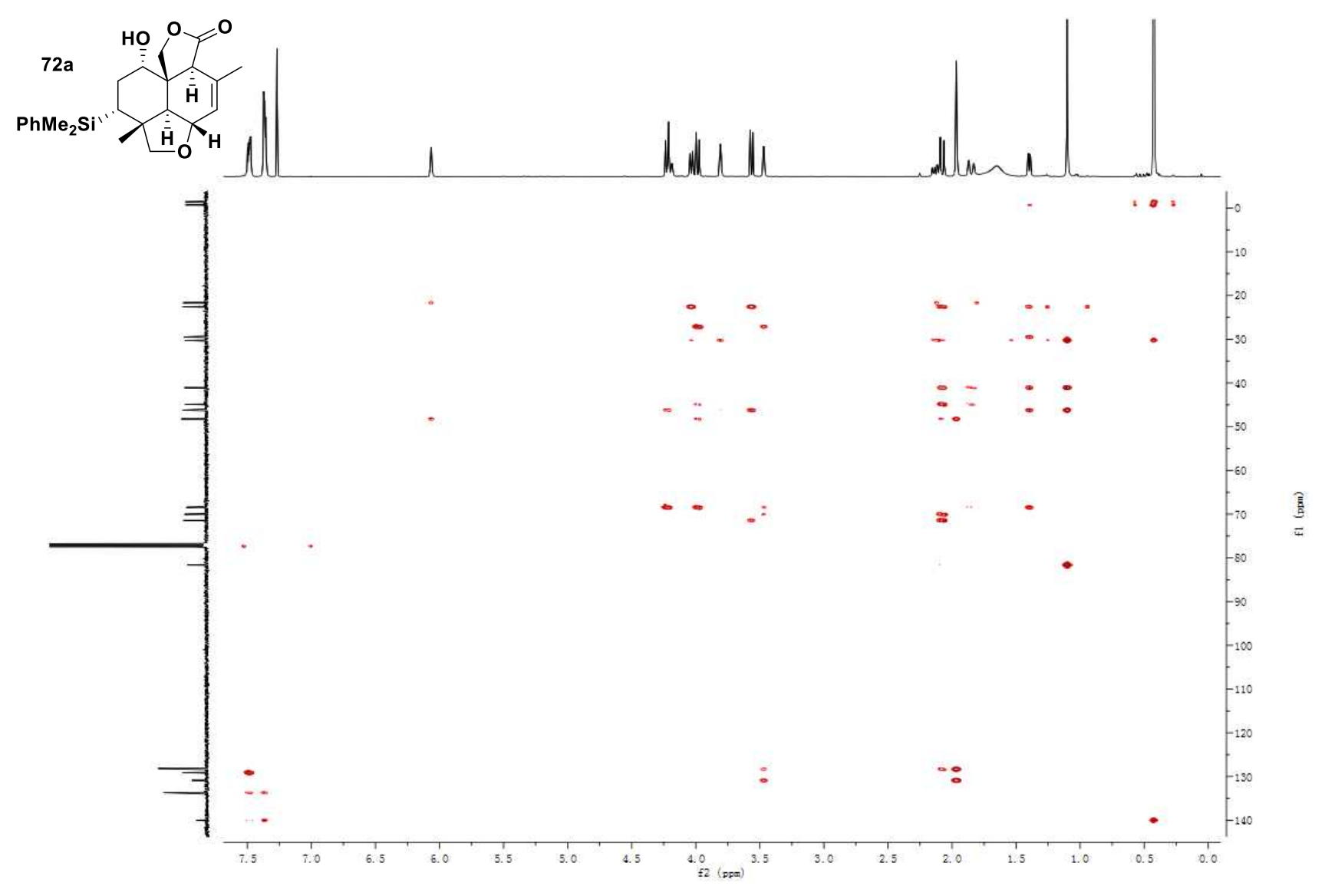

HMBC NMR of compound 72a 

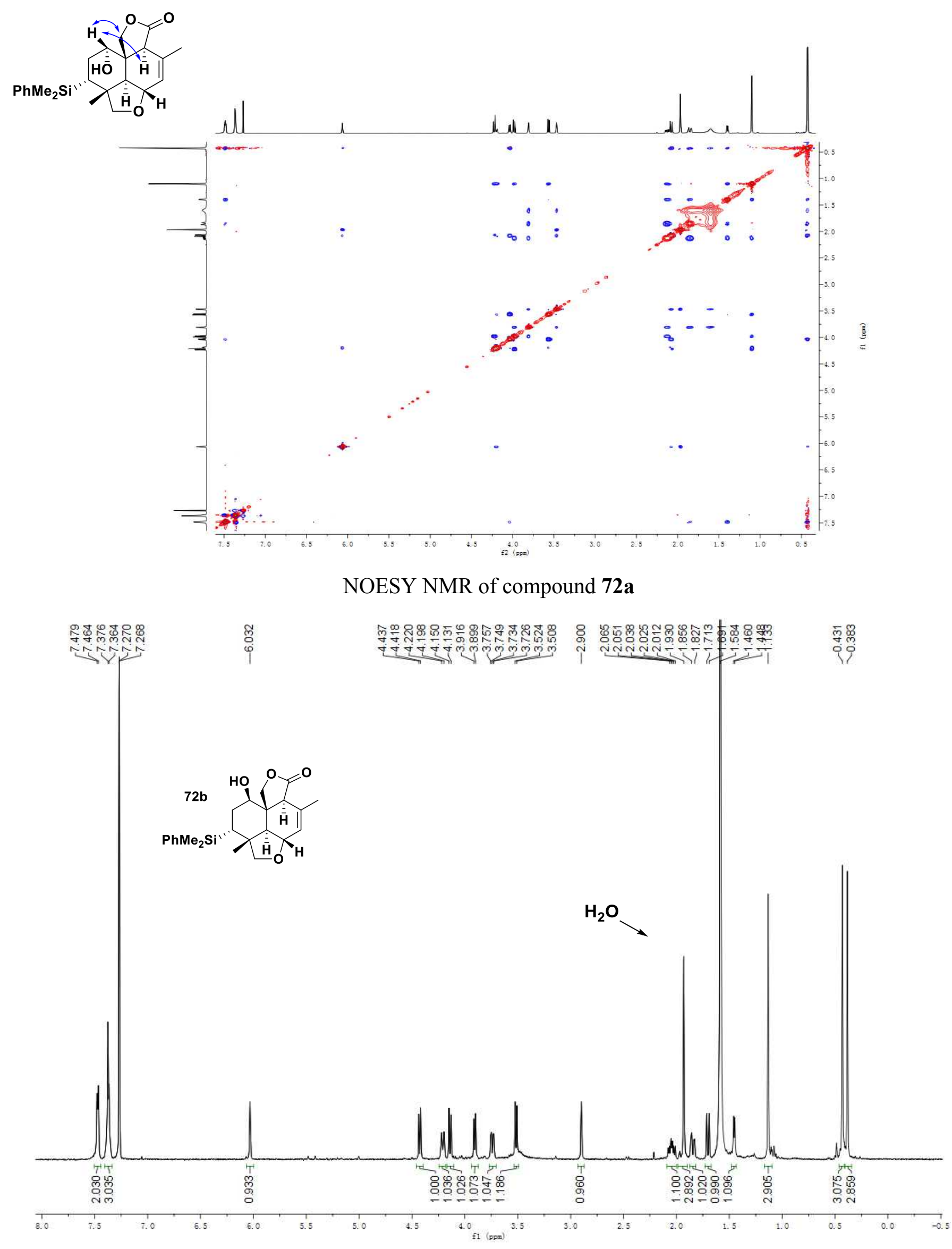

${ }^{1} \mathrm{H}$ NMR of compound $\mathbf{7 2 b}$ 


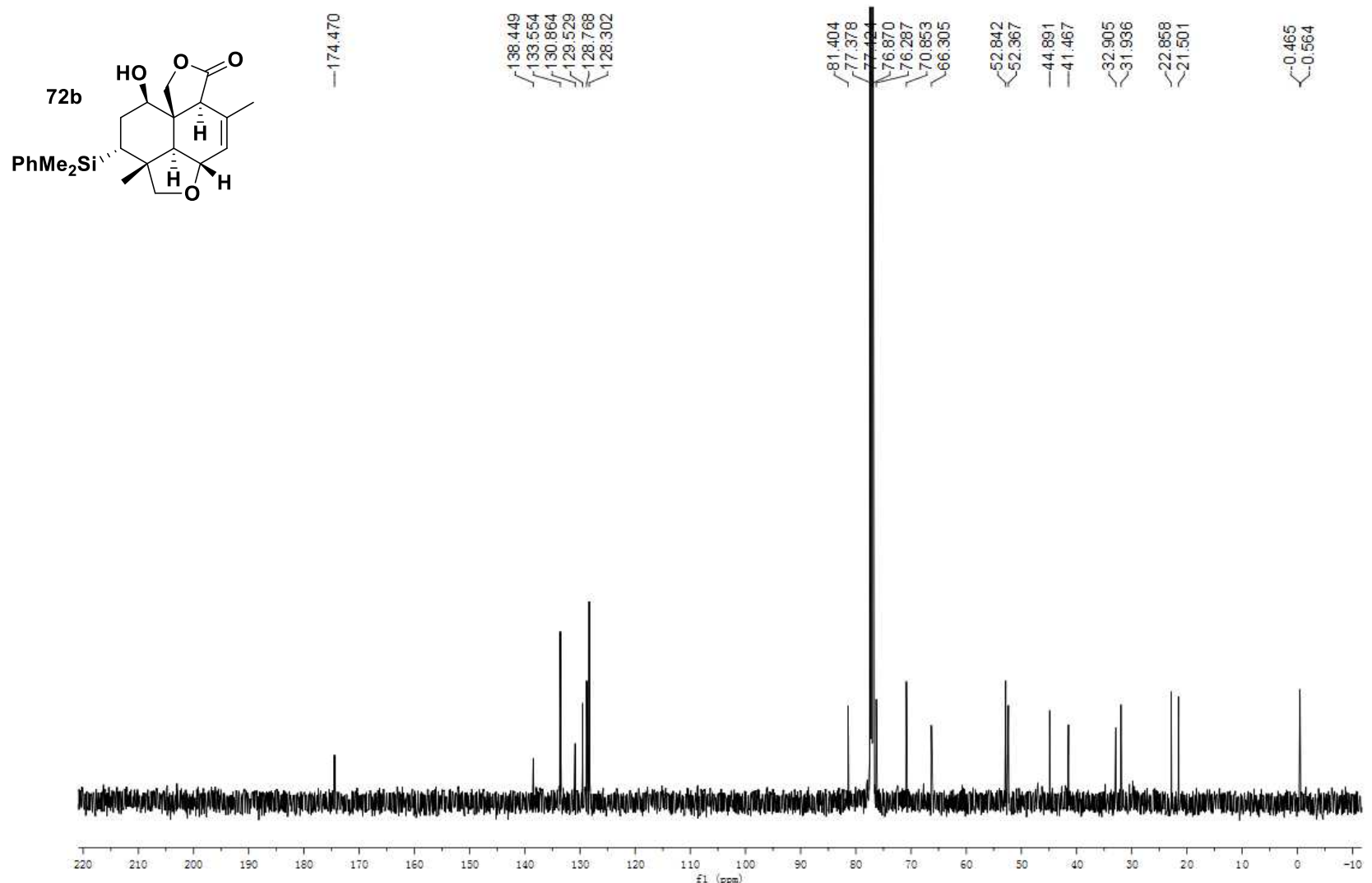

${ }^{13} \mathrm{C}$ NMR of compound $\mathbf{7 2 b}$

\begin{tabular}{|c|c|c|c|}
\hline 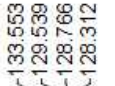 & 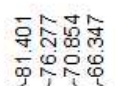 & 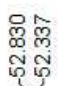 & 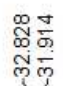 \\
\hline
\end{tabular}
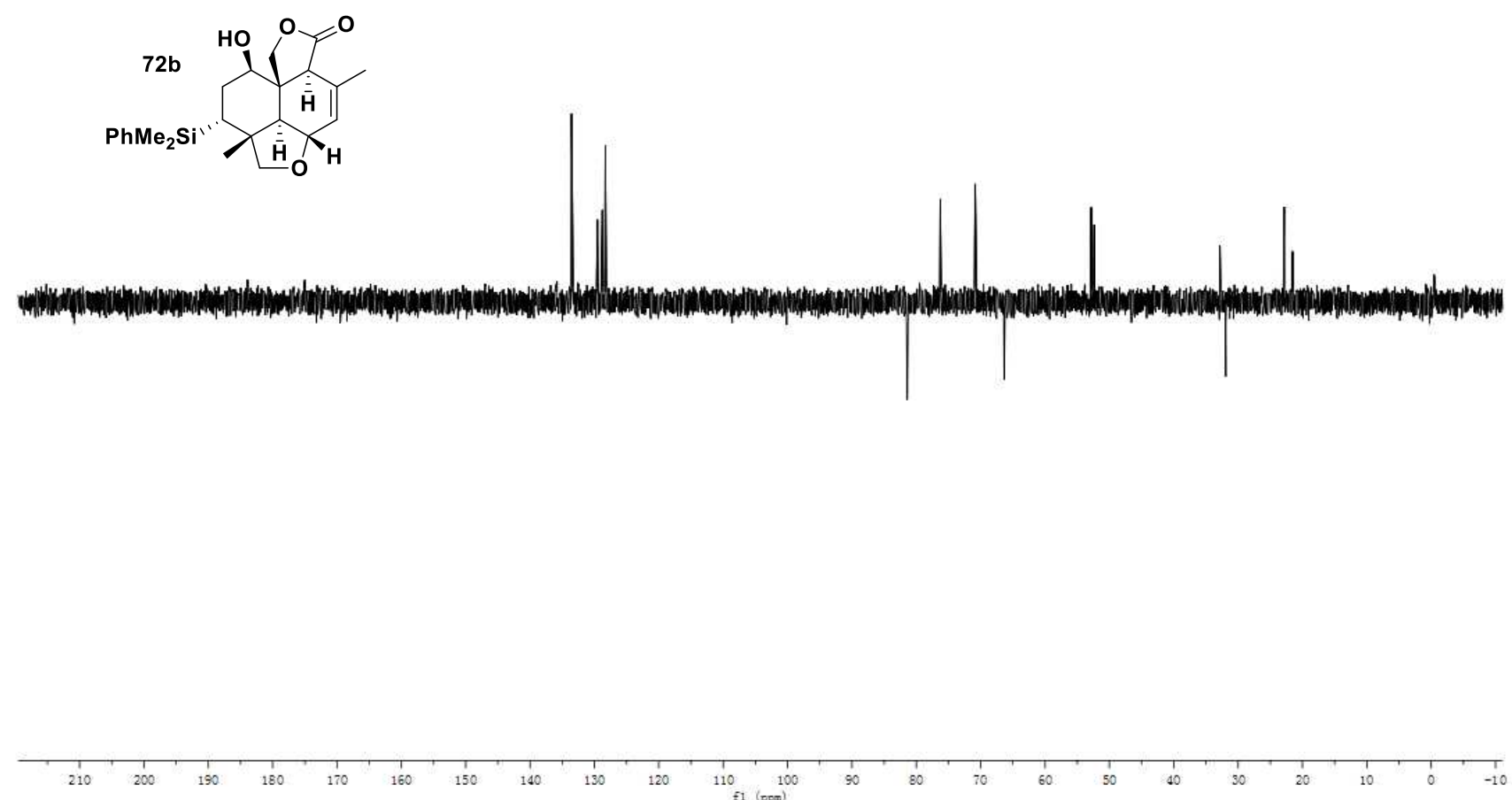

Dept135 NMR of compound 72b 


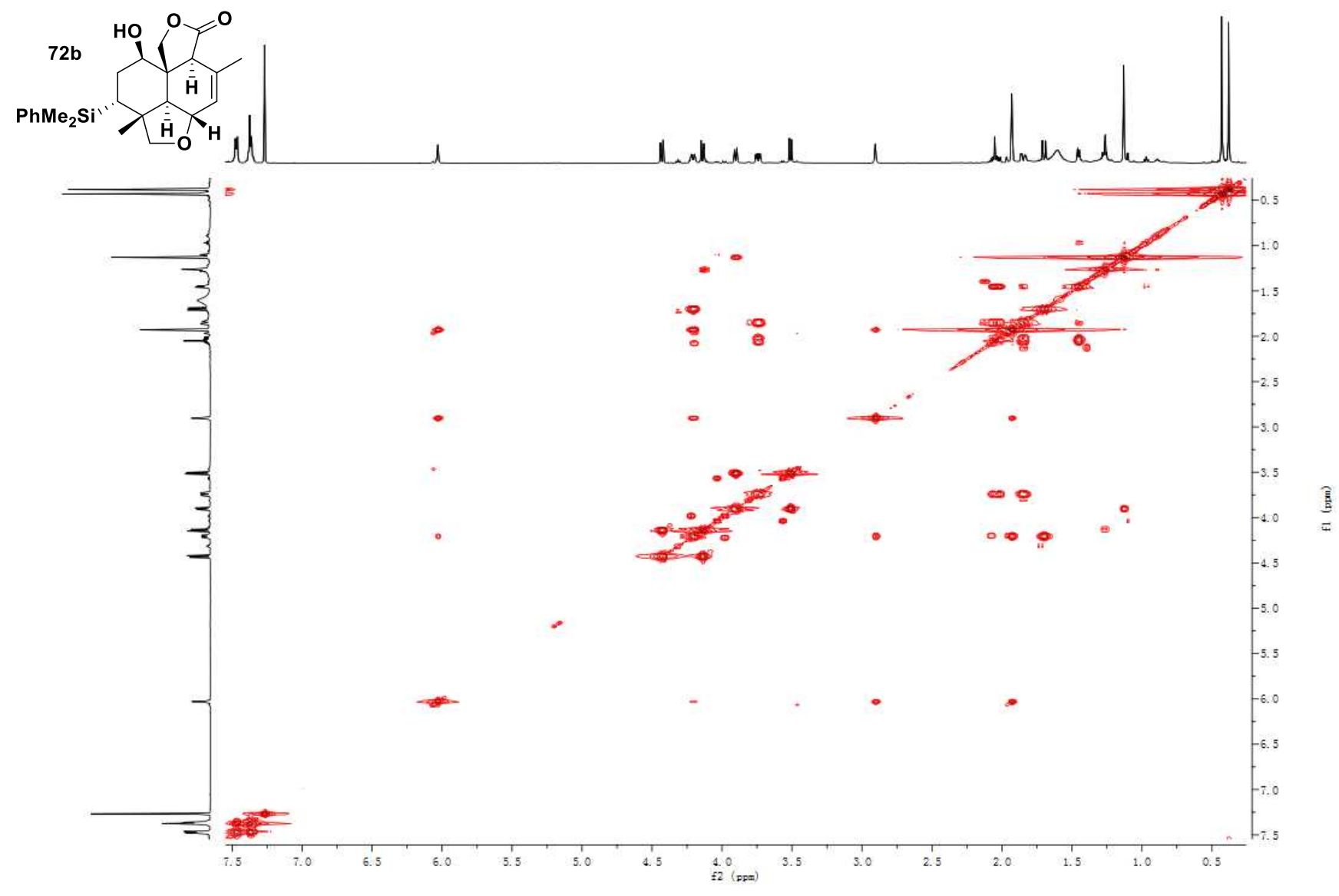

COSY NMR of compound $\mathbf{7 2 b}$

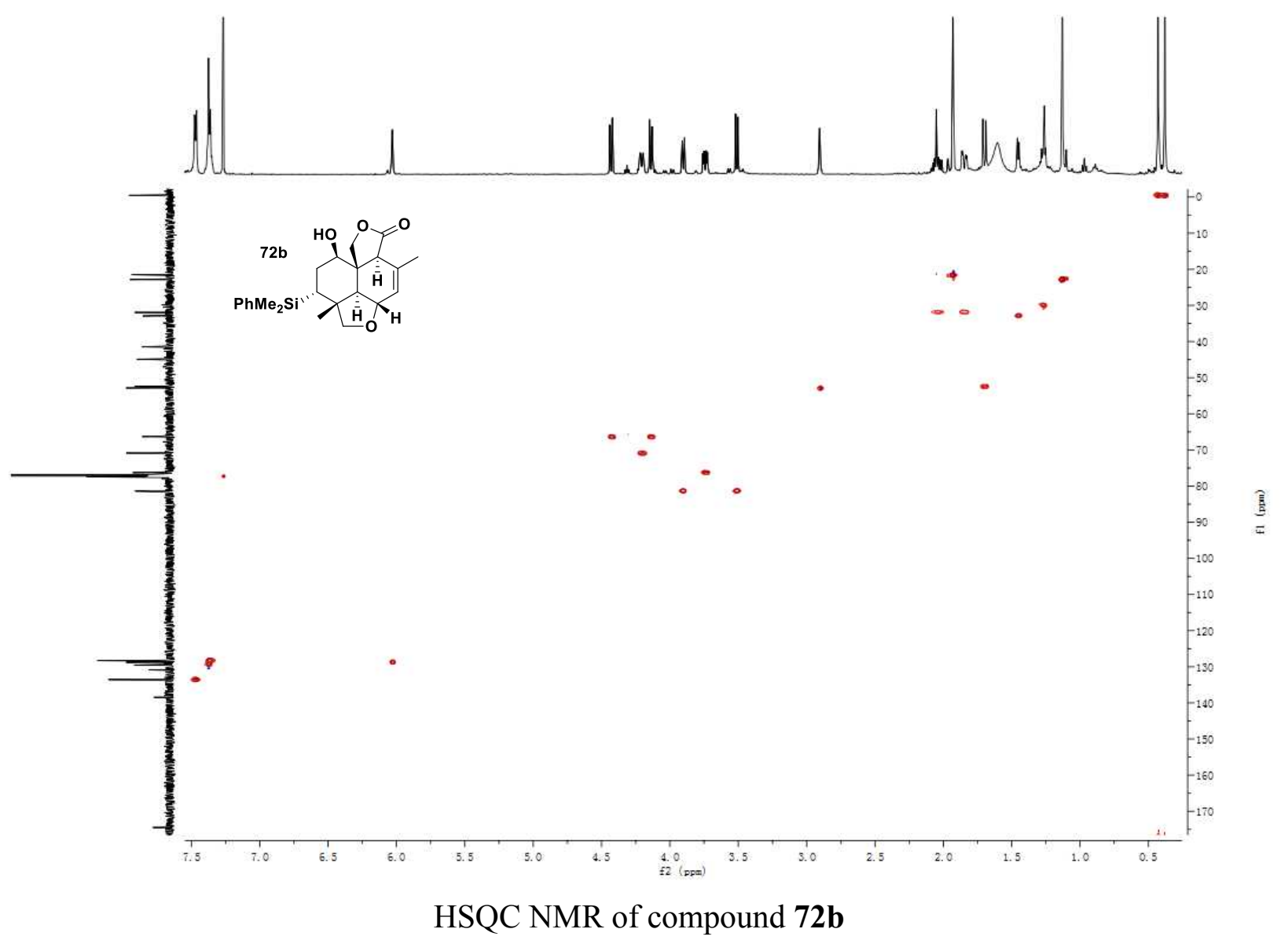




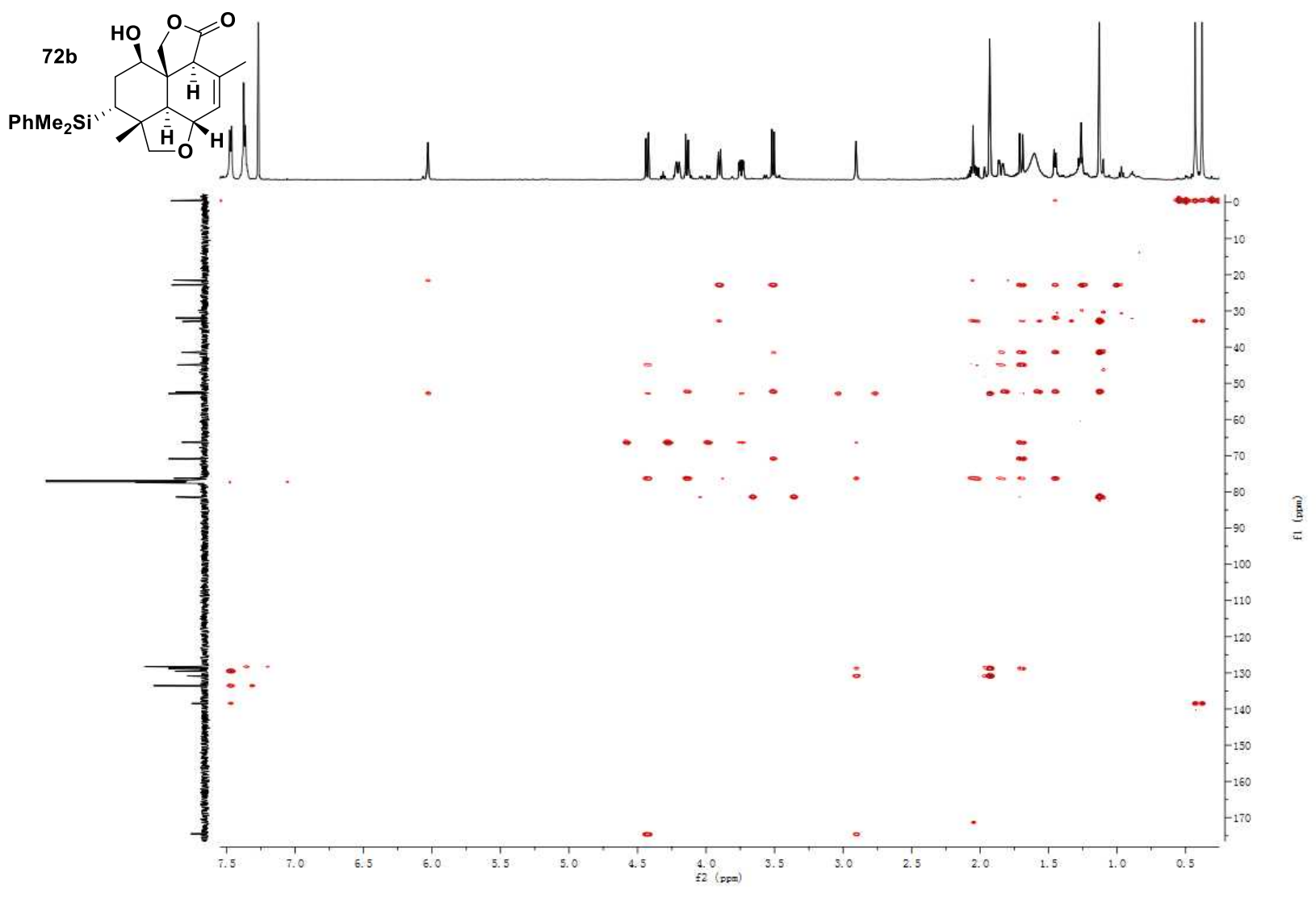

HMBC NMR of compound 72b
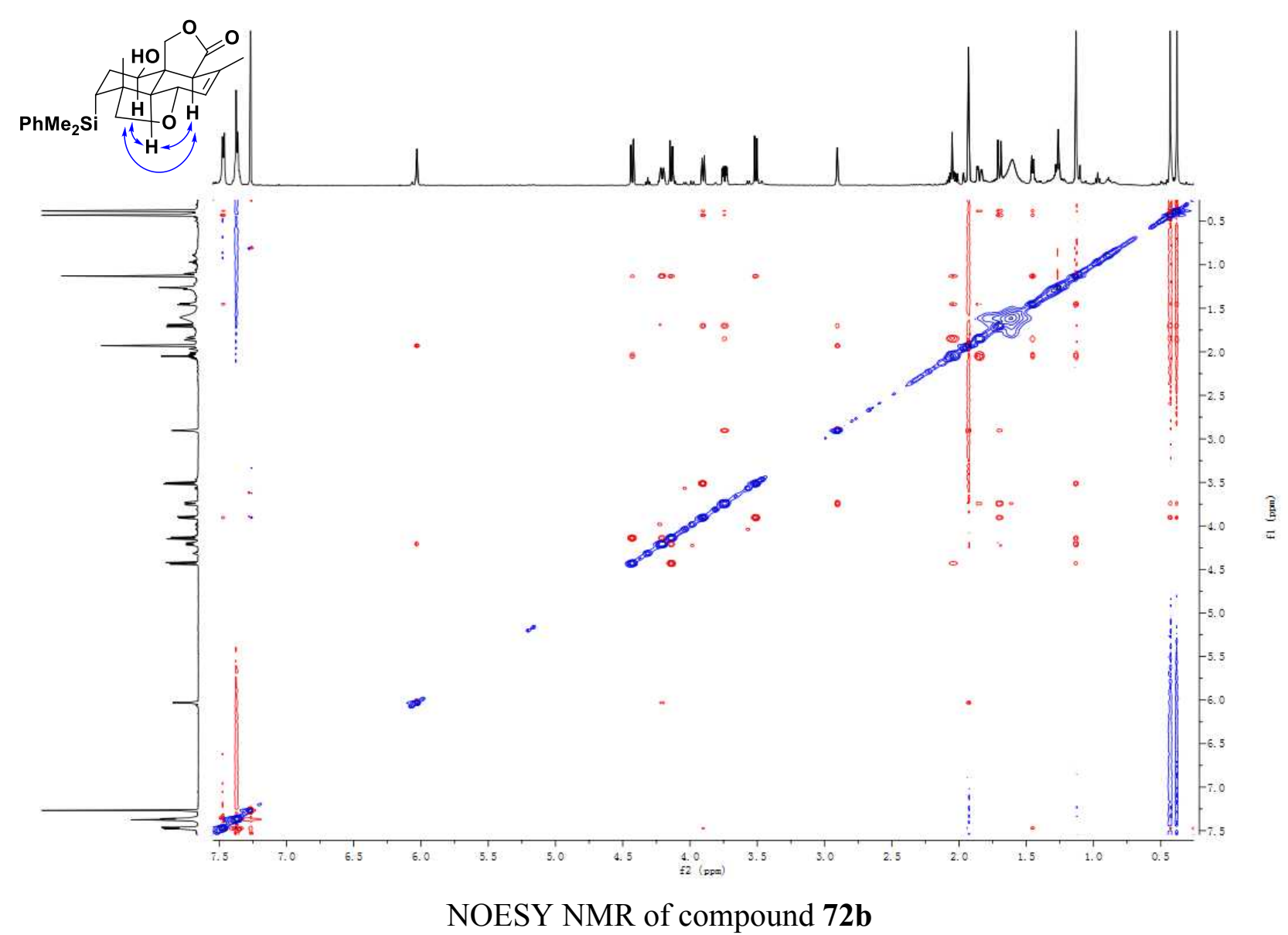


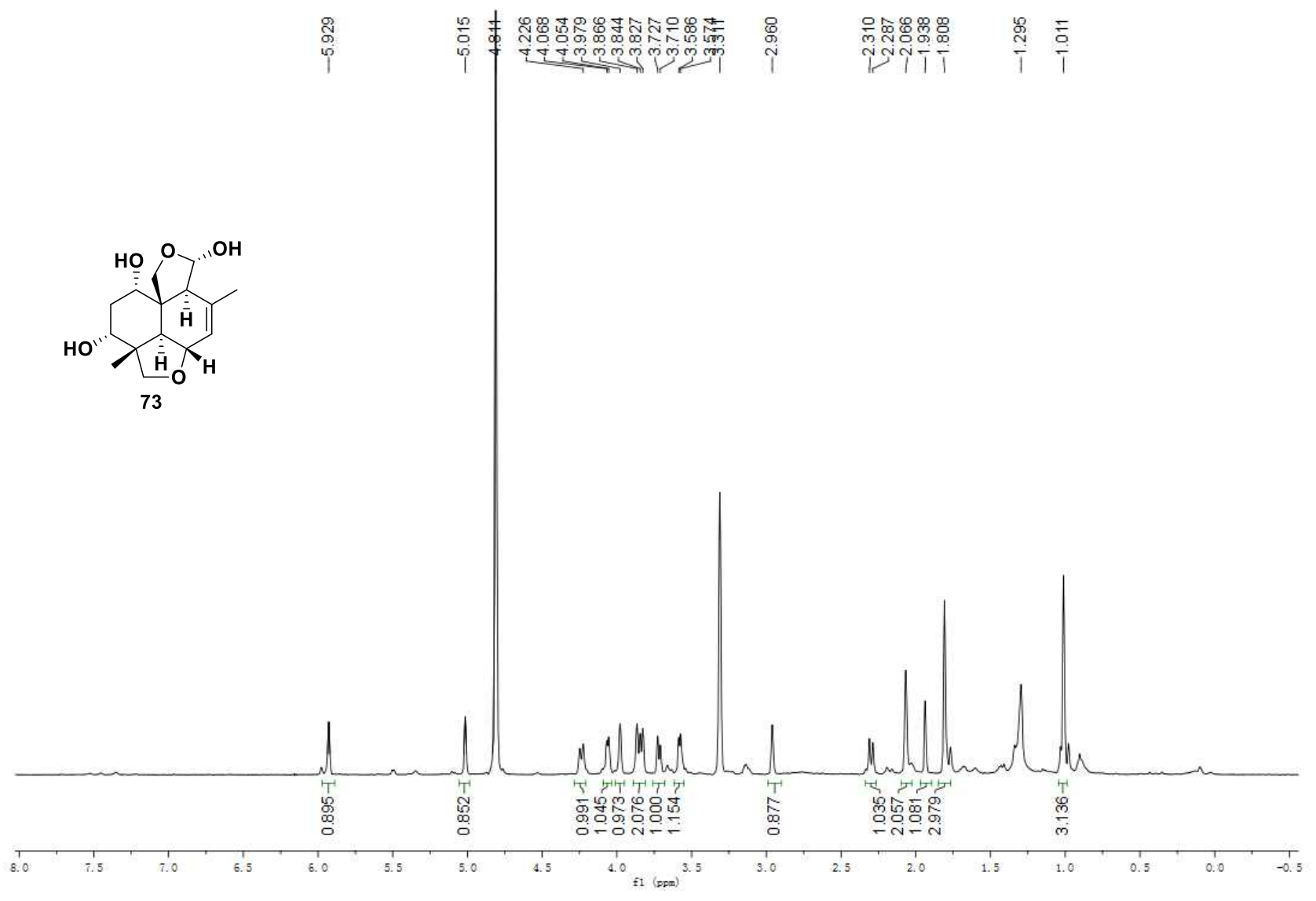

${ }^{1} \mathrm{H}$ NMR of compound $\mathbf{7 3}$

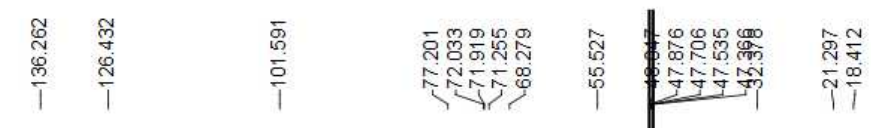

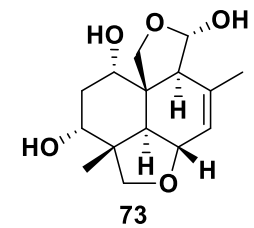




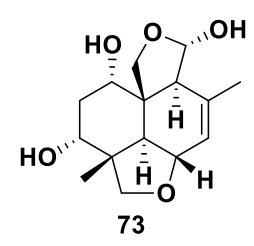
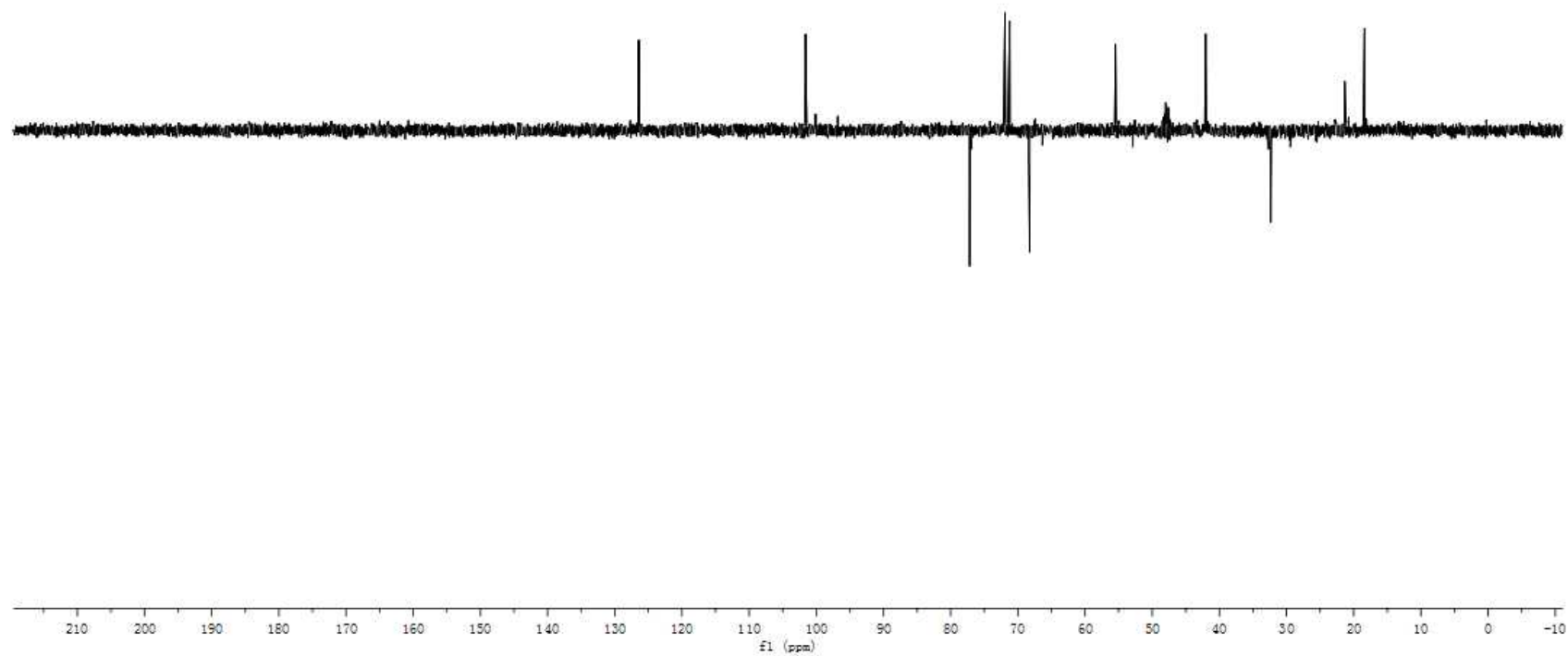

Dept135 NMR of compound $\mathbf{7 3}$

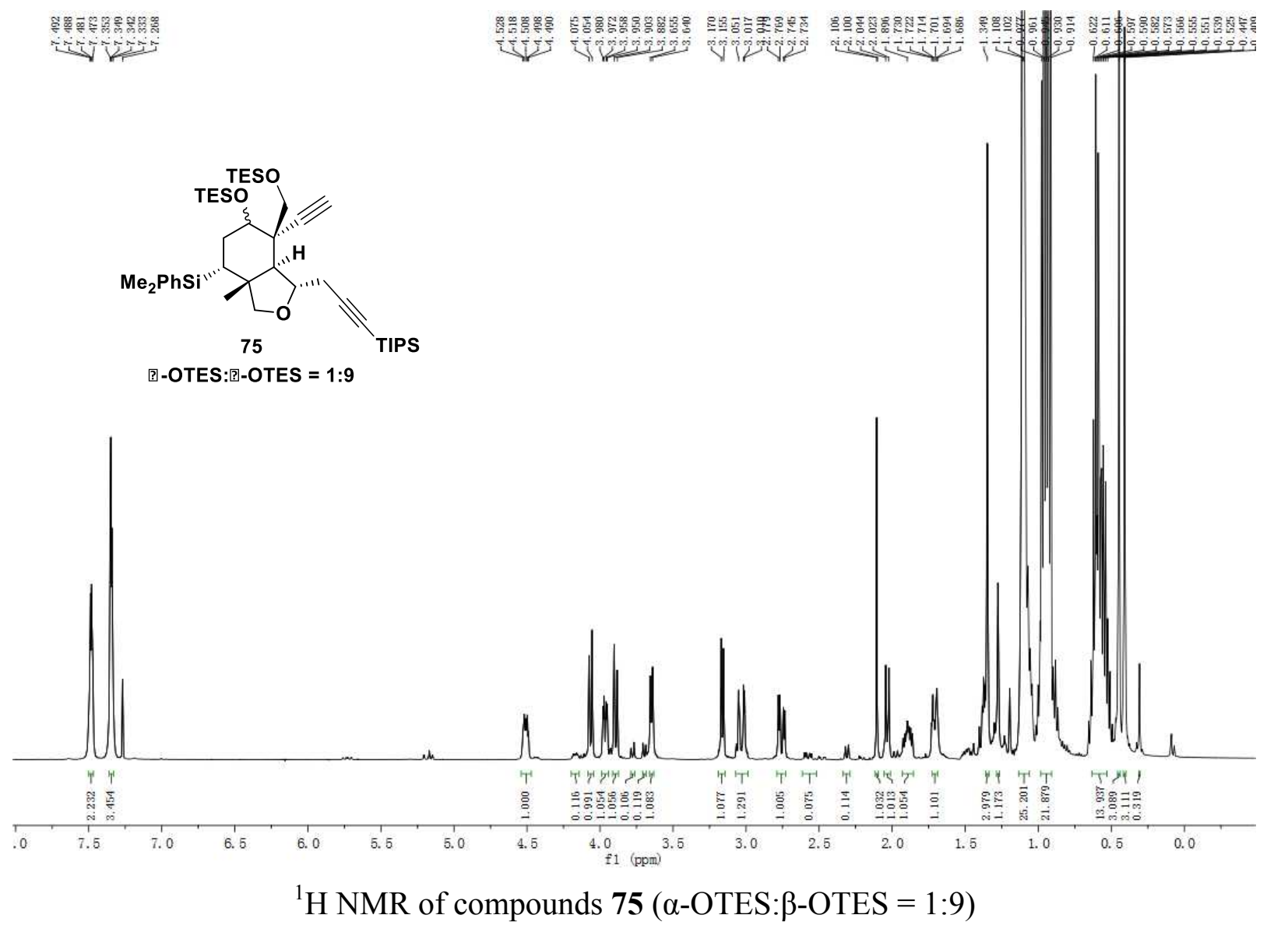



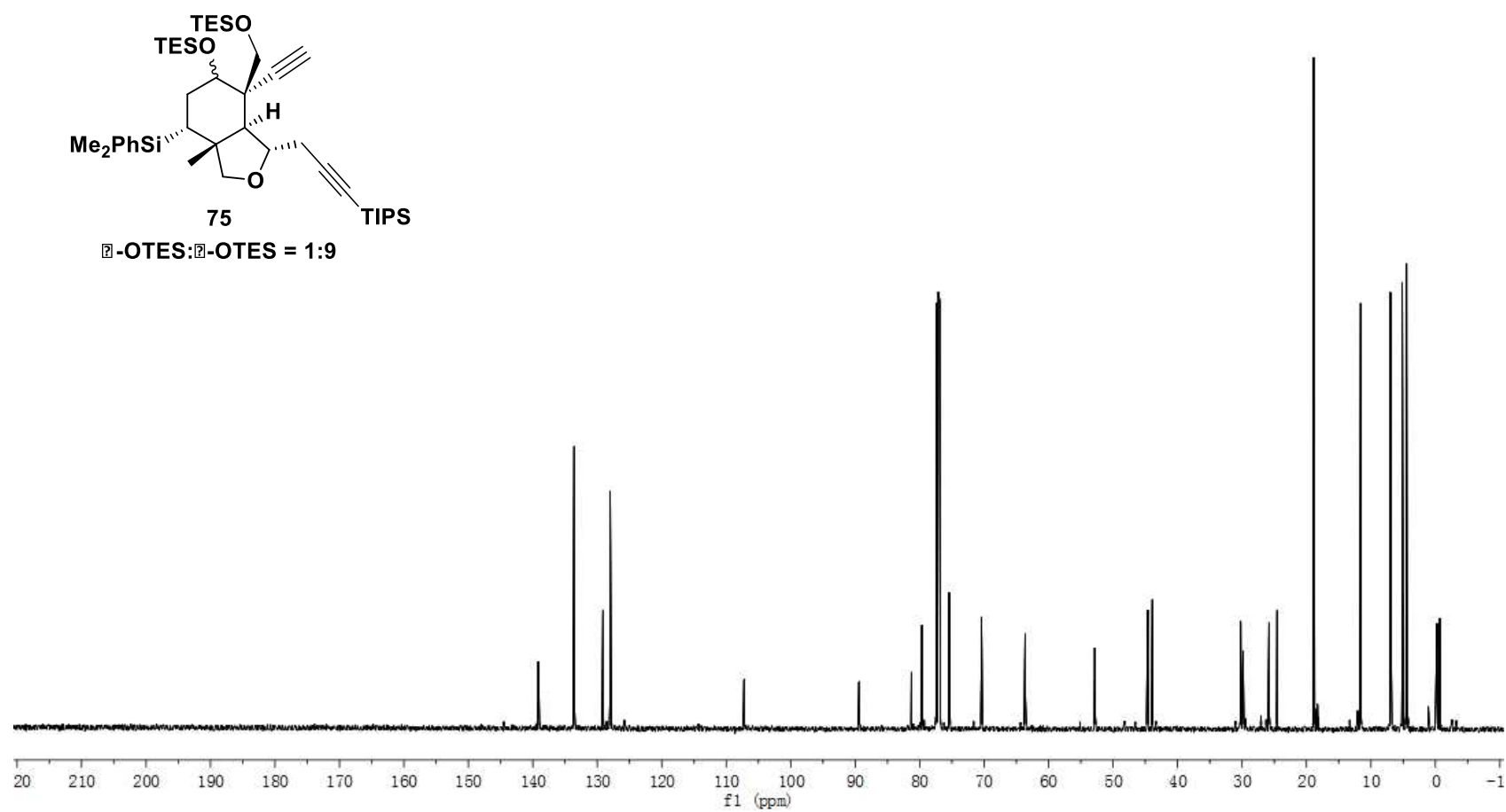

${ }^{13} \mathrm{C}$ NMR of compounds 75 ( $\alpha$-OTES: $\beta$-OTES $=1: 9$ )

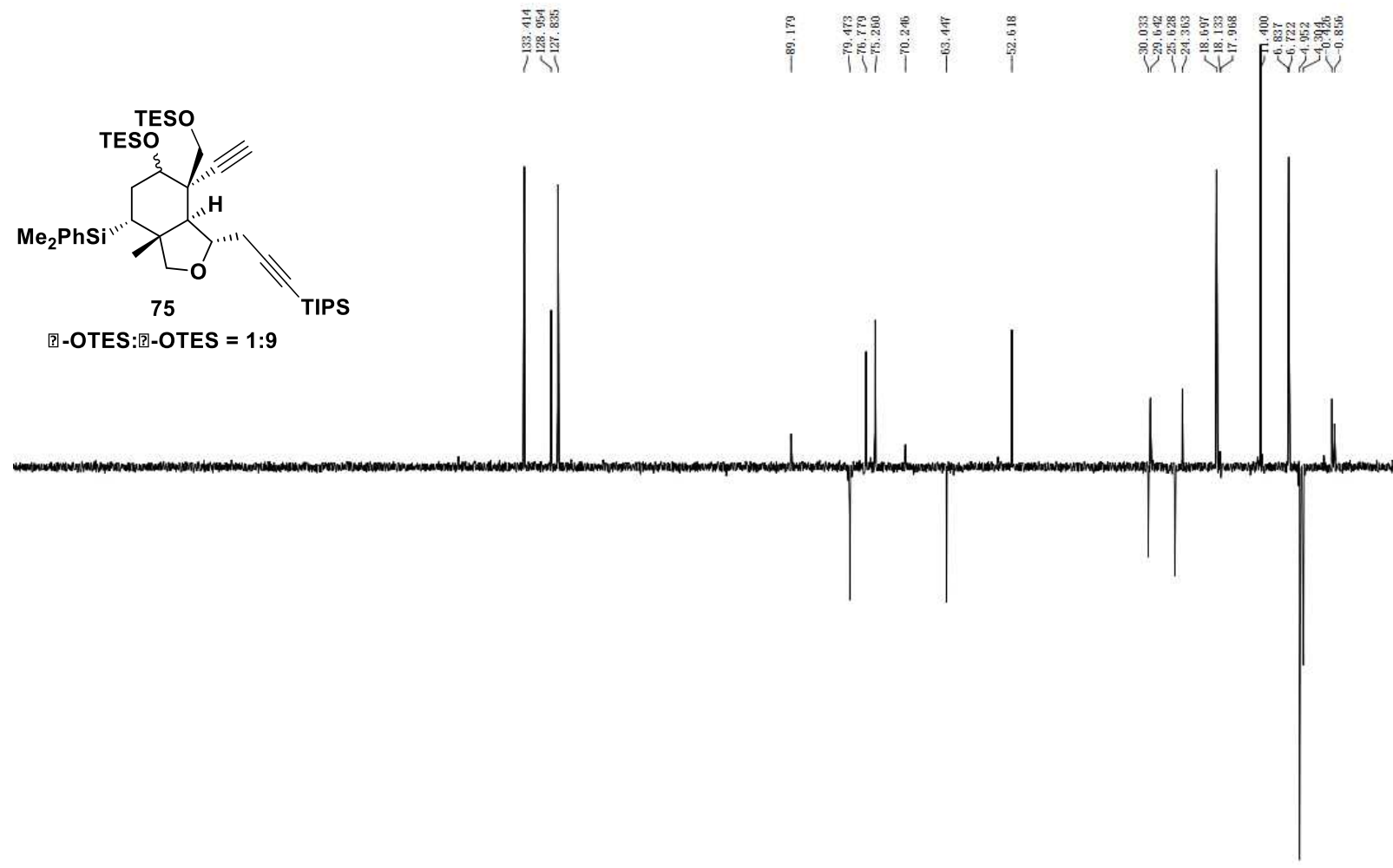

$\begin{array}{lllllllllllllllllllllllllll}210 & 200 & 190 & 180 & 170 & 160 & 150 & 140 & 130 & 120 & 110 & 100 & 90 & 80 & 70 & 60 & 50 & 40 & 30 & 20 & 10 & 0 & -1\end{array}$

Dept135 NMR of compounds 75 ( $\alpha$-OTES: $\beta$-OTES $=1: 9)$ 


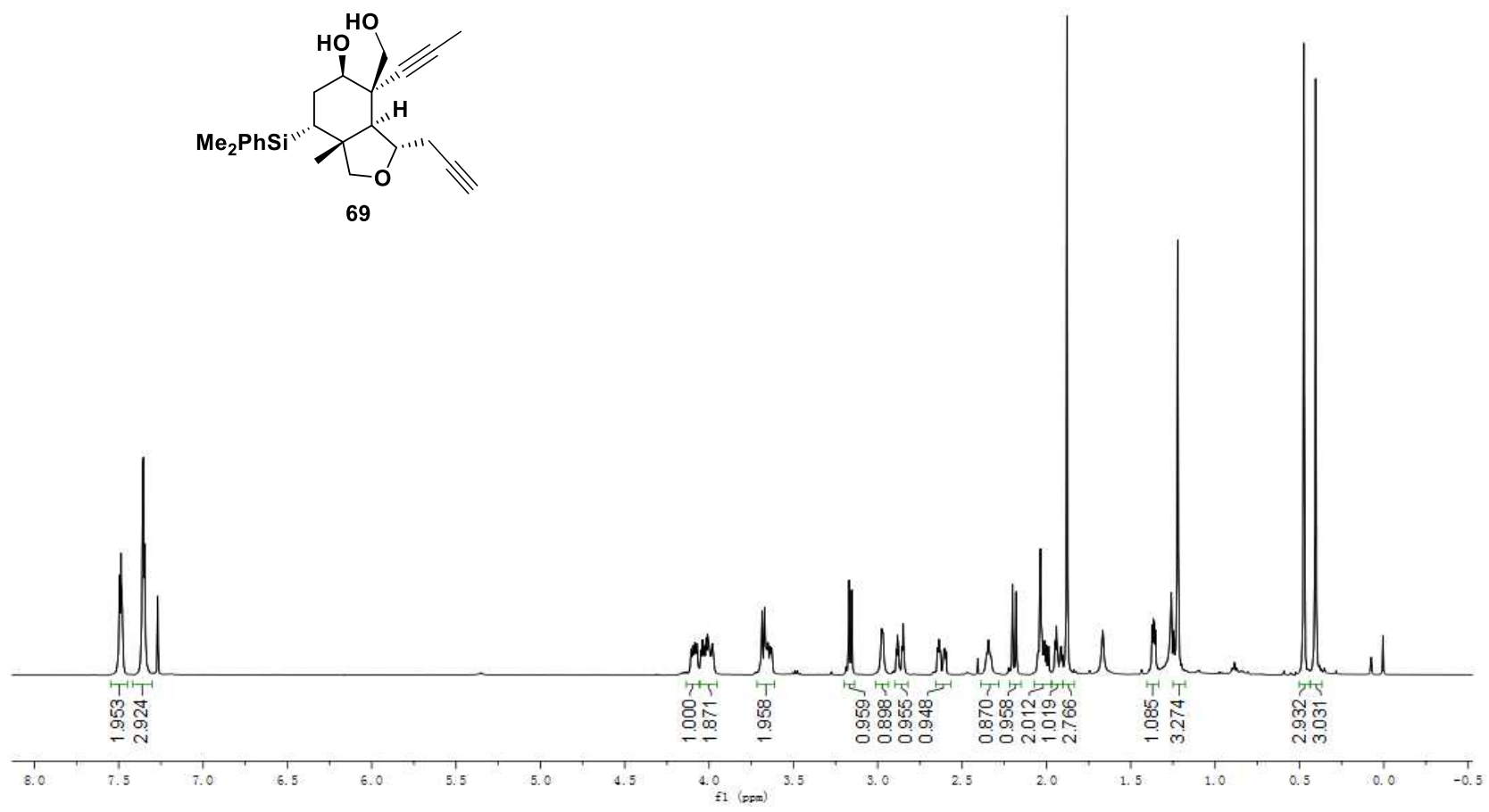

69

${ }^{1} \mathrm{H}$ NMR of compound 69
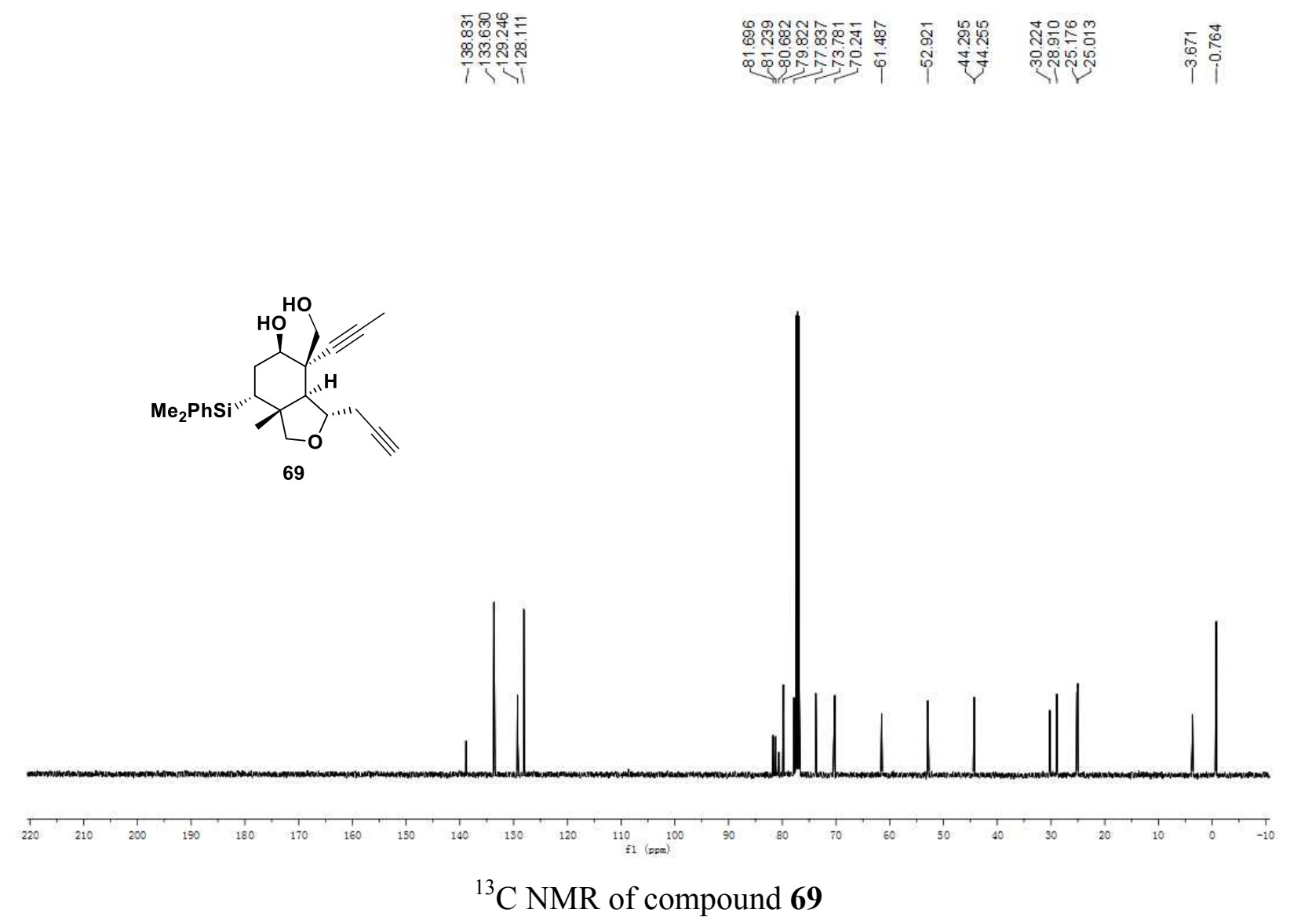

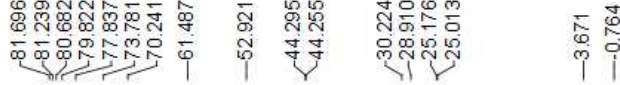



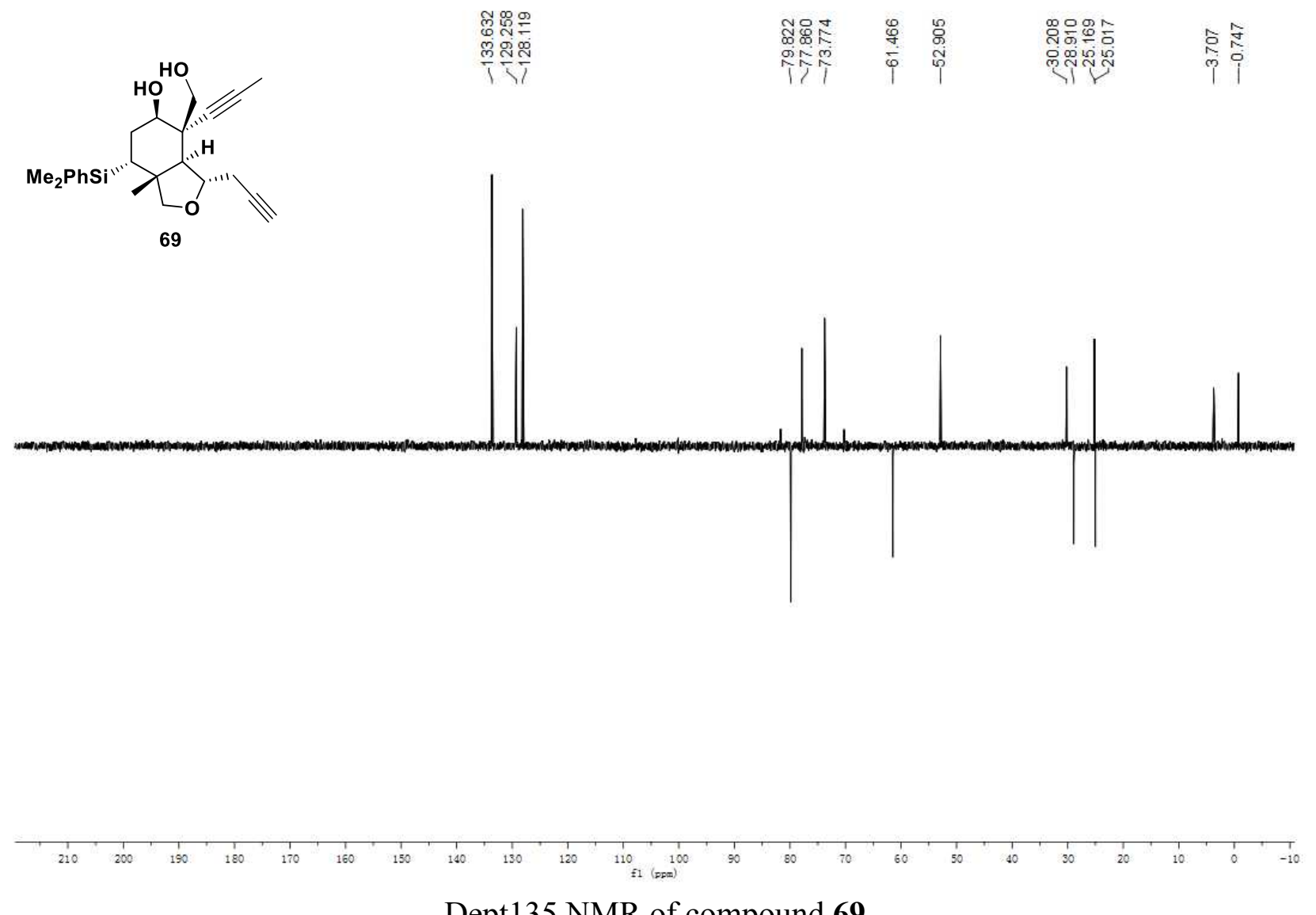

Dept135 NMR of compound 69

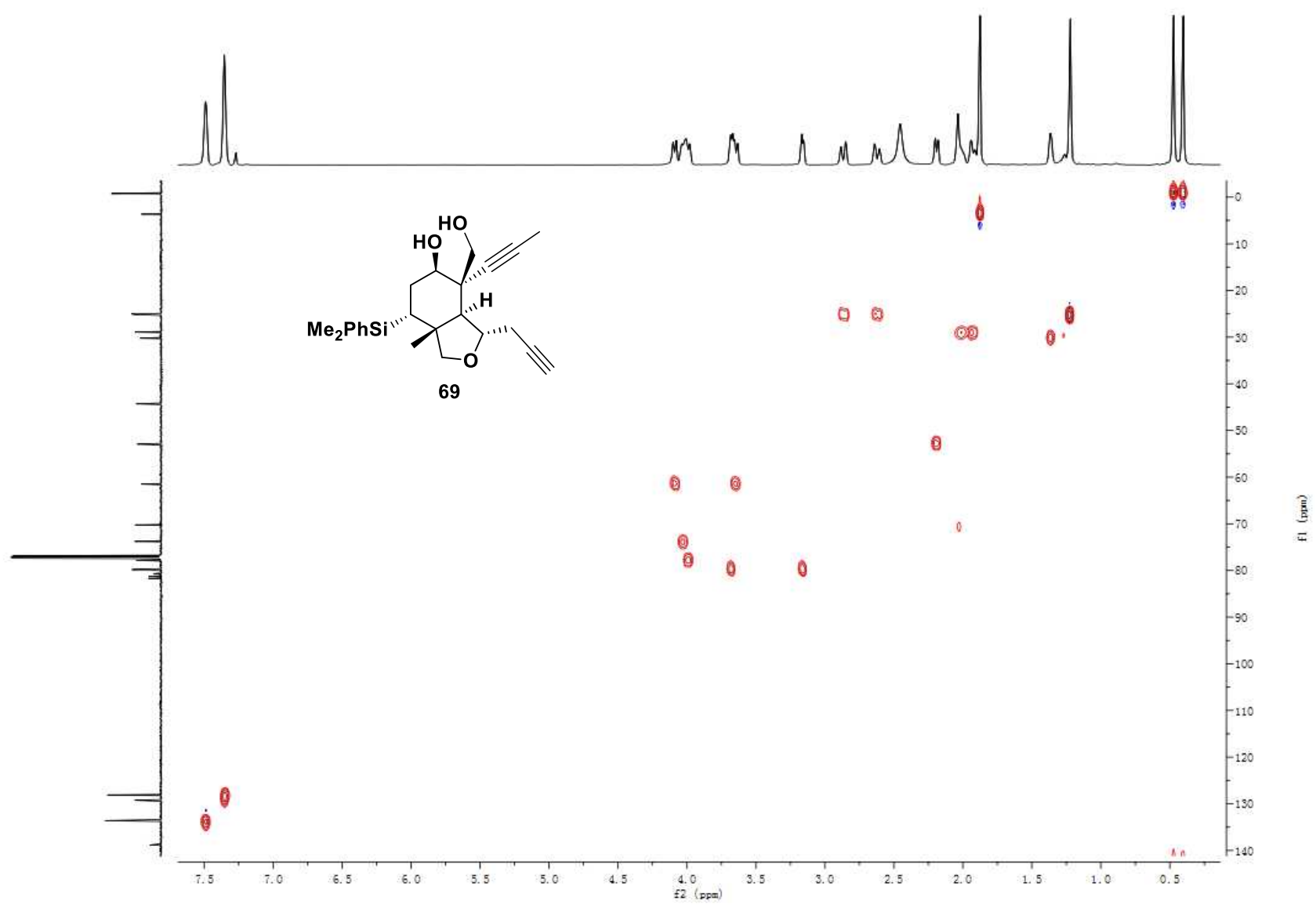

HSQC NMR of compound $\mathbf{6 9}$ 


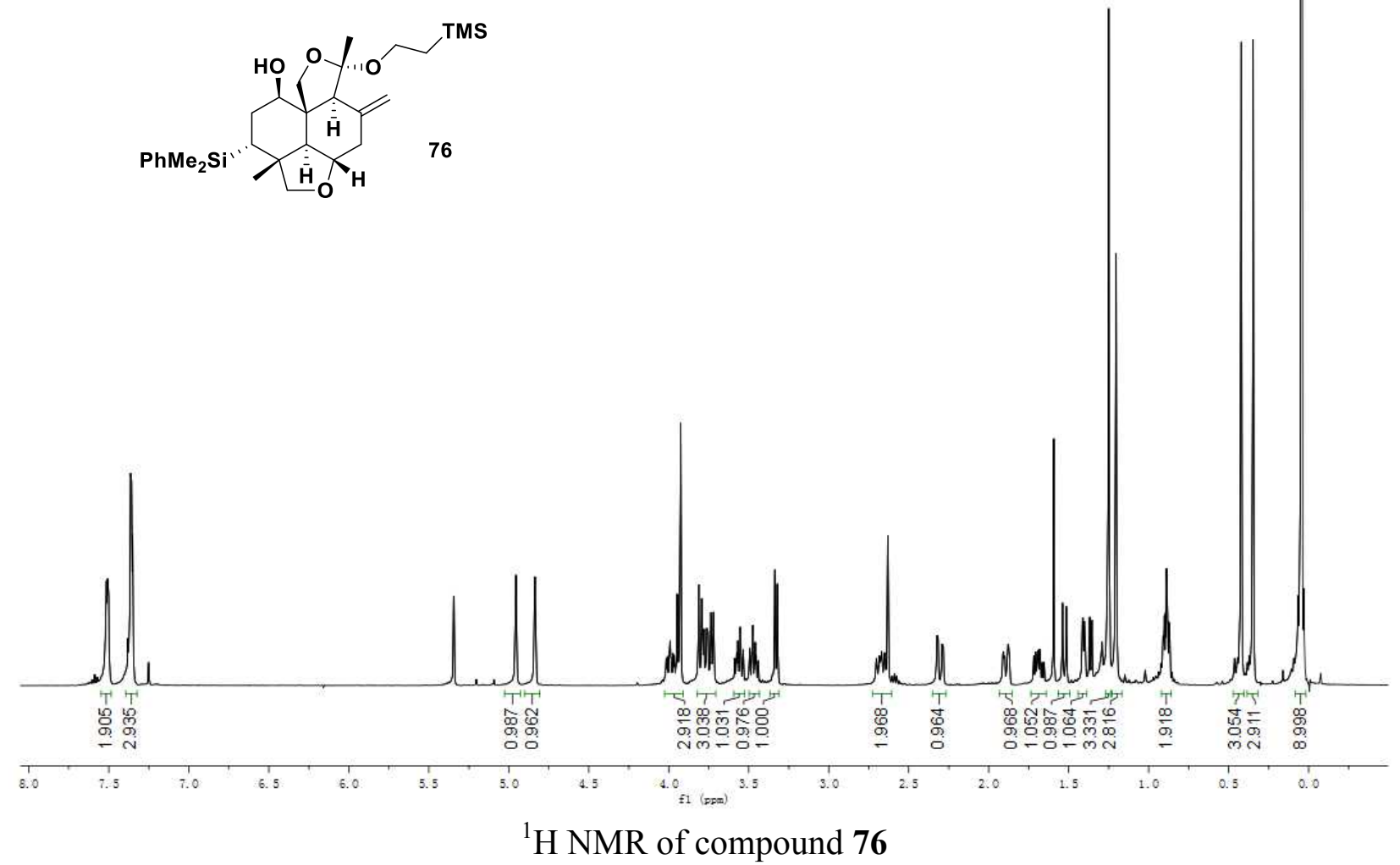

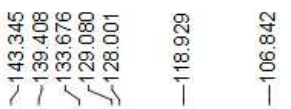

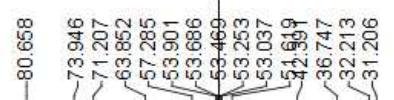

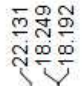

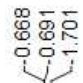
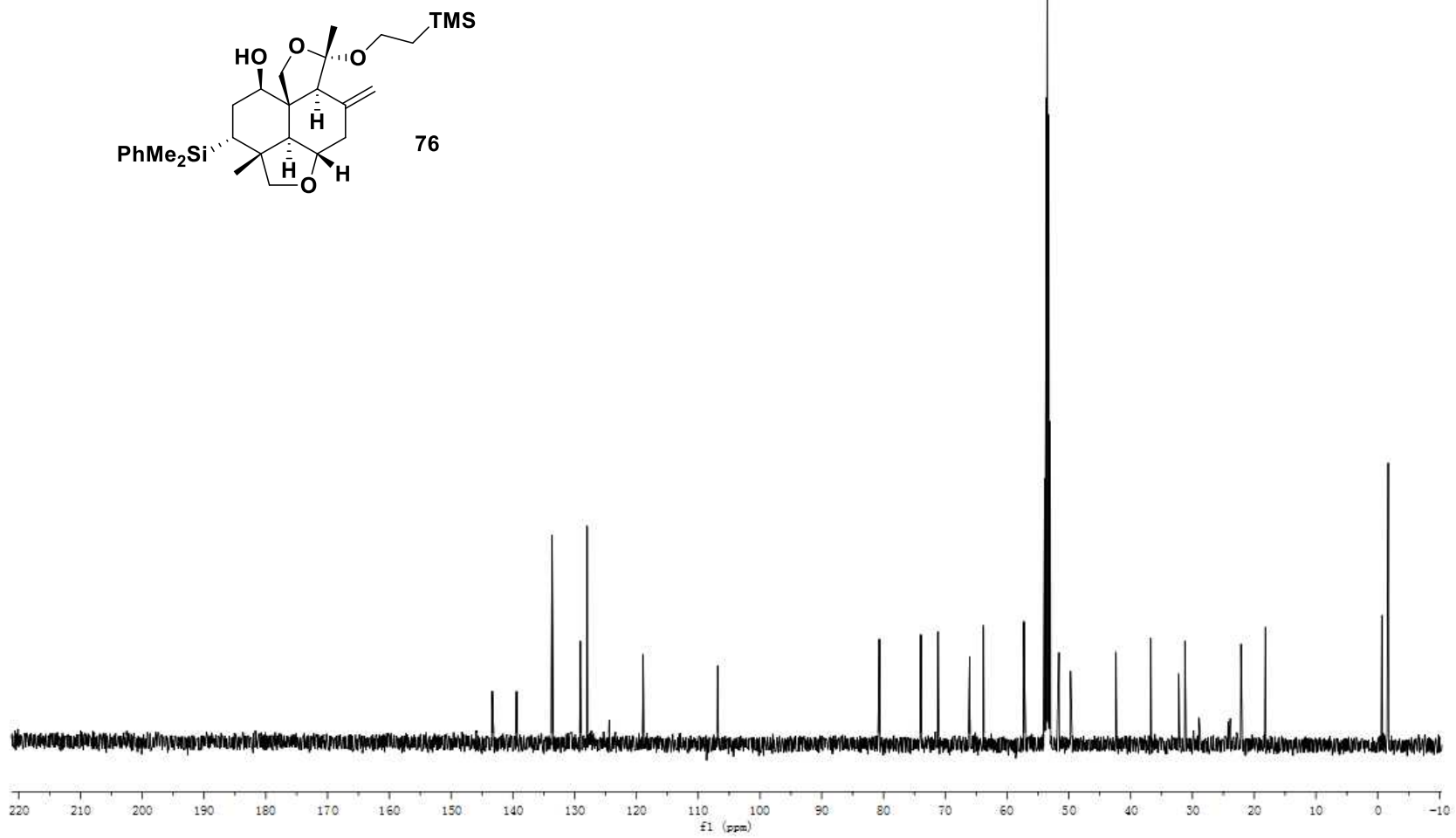

${ }^{13} \mathrm{C}$ NMR of compound 76 

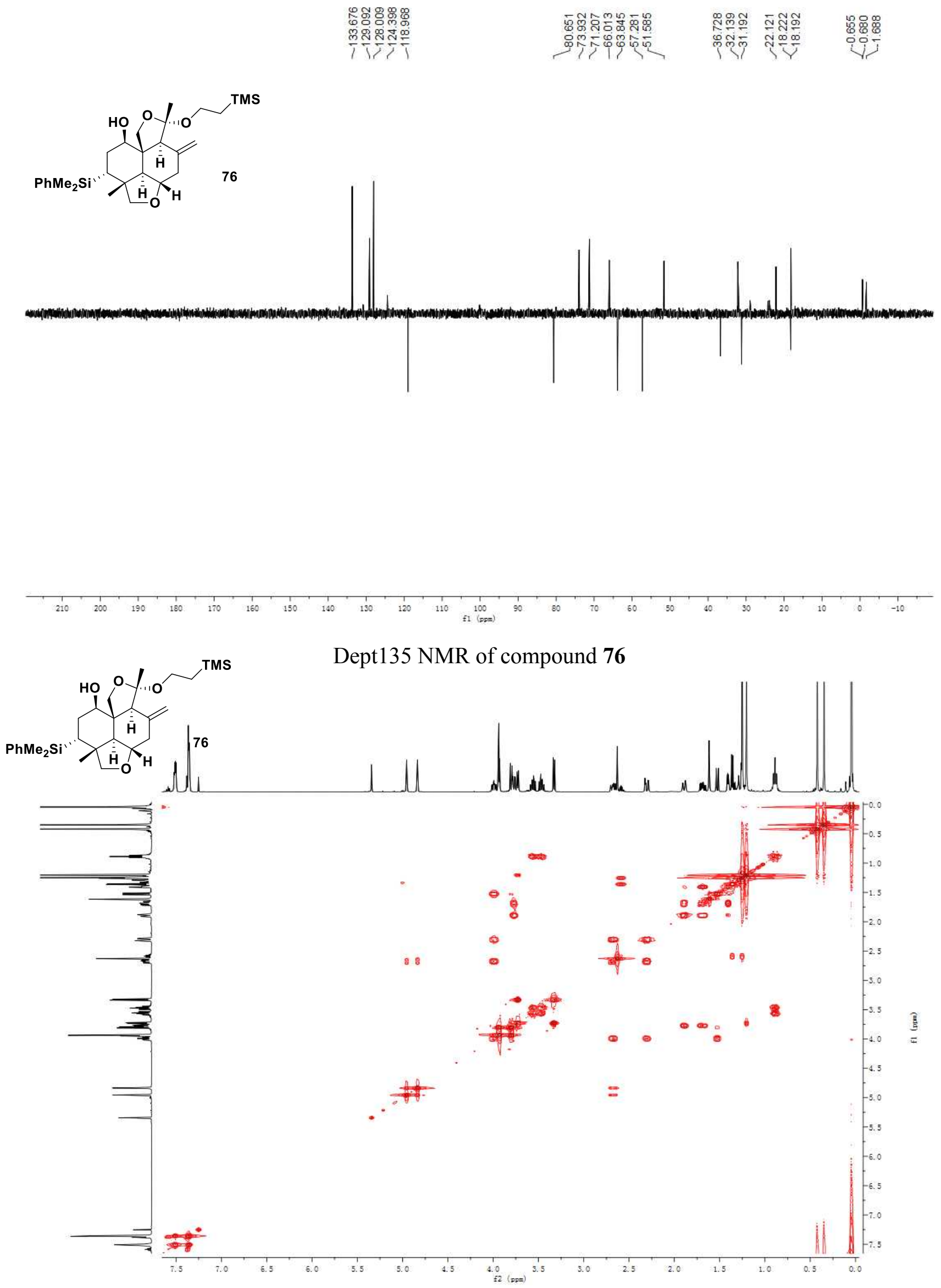

COSY NMR of compound $\mathbf{7 6}$ 


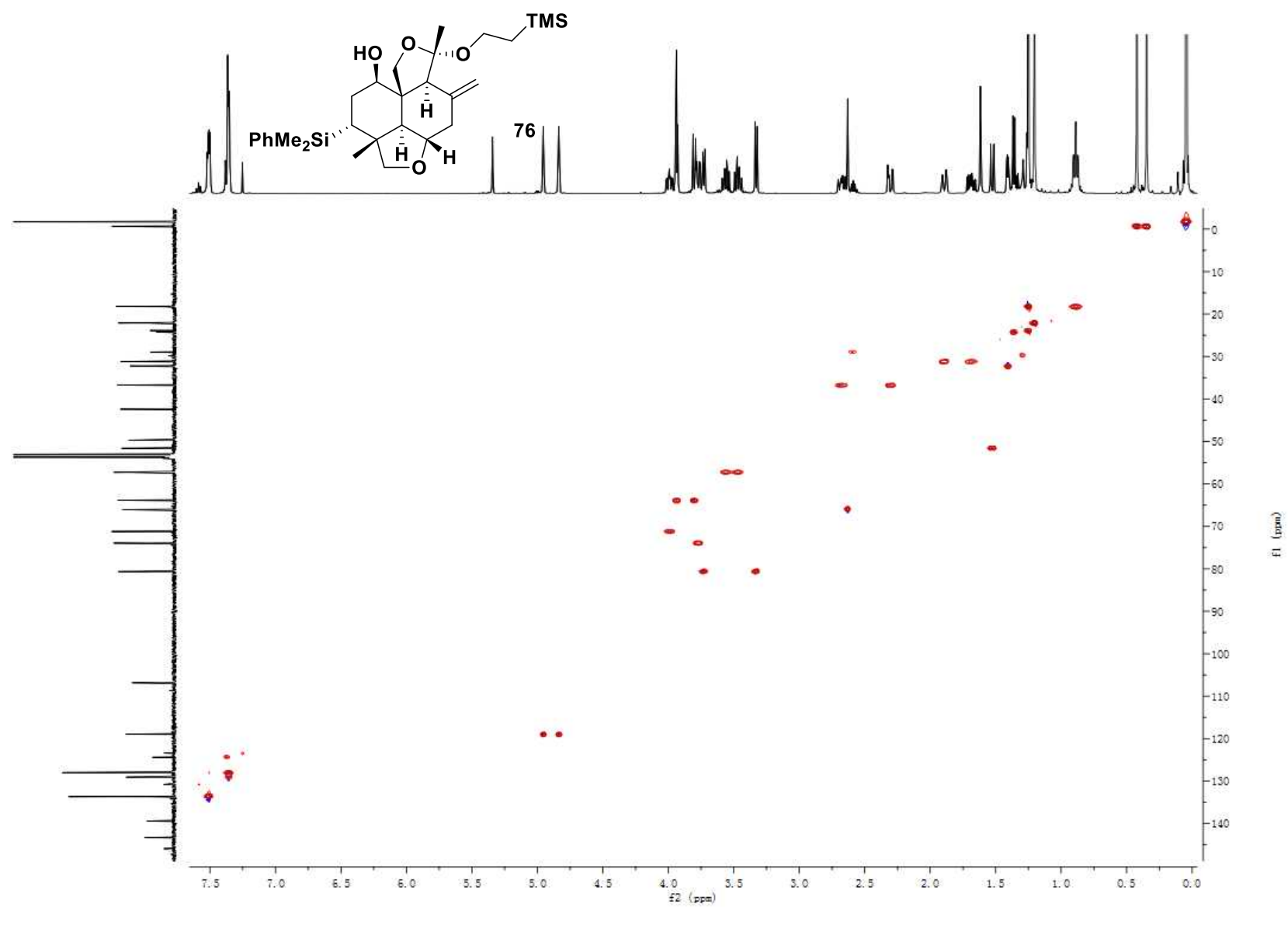

COSY NMR of compound 76

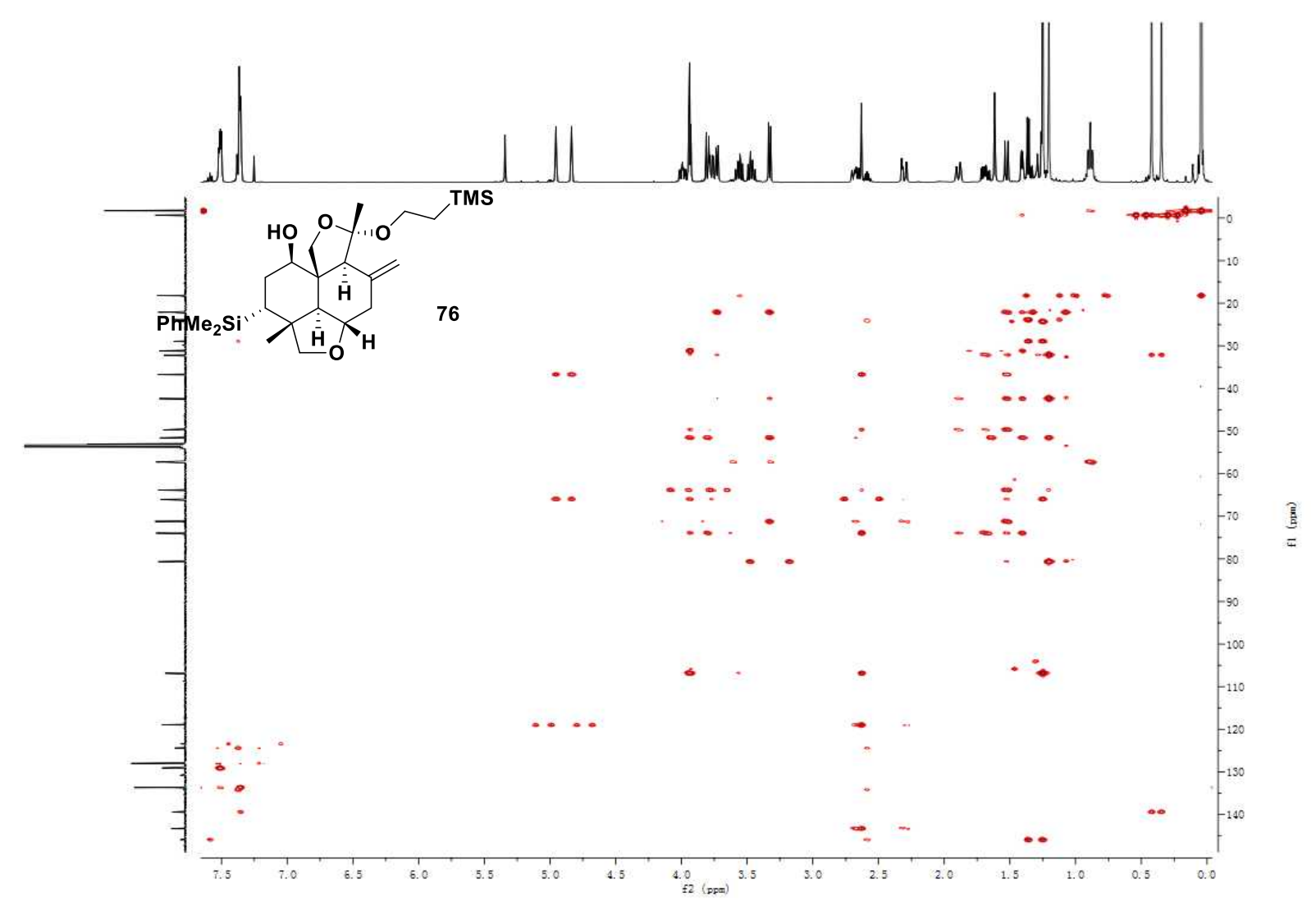

HMBC NMR of compound 76 


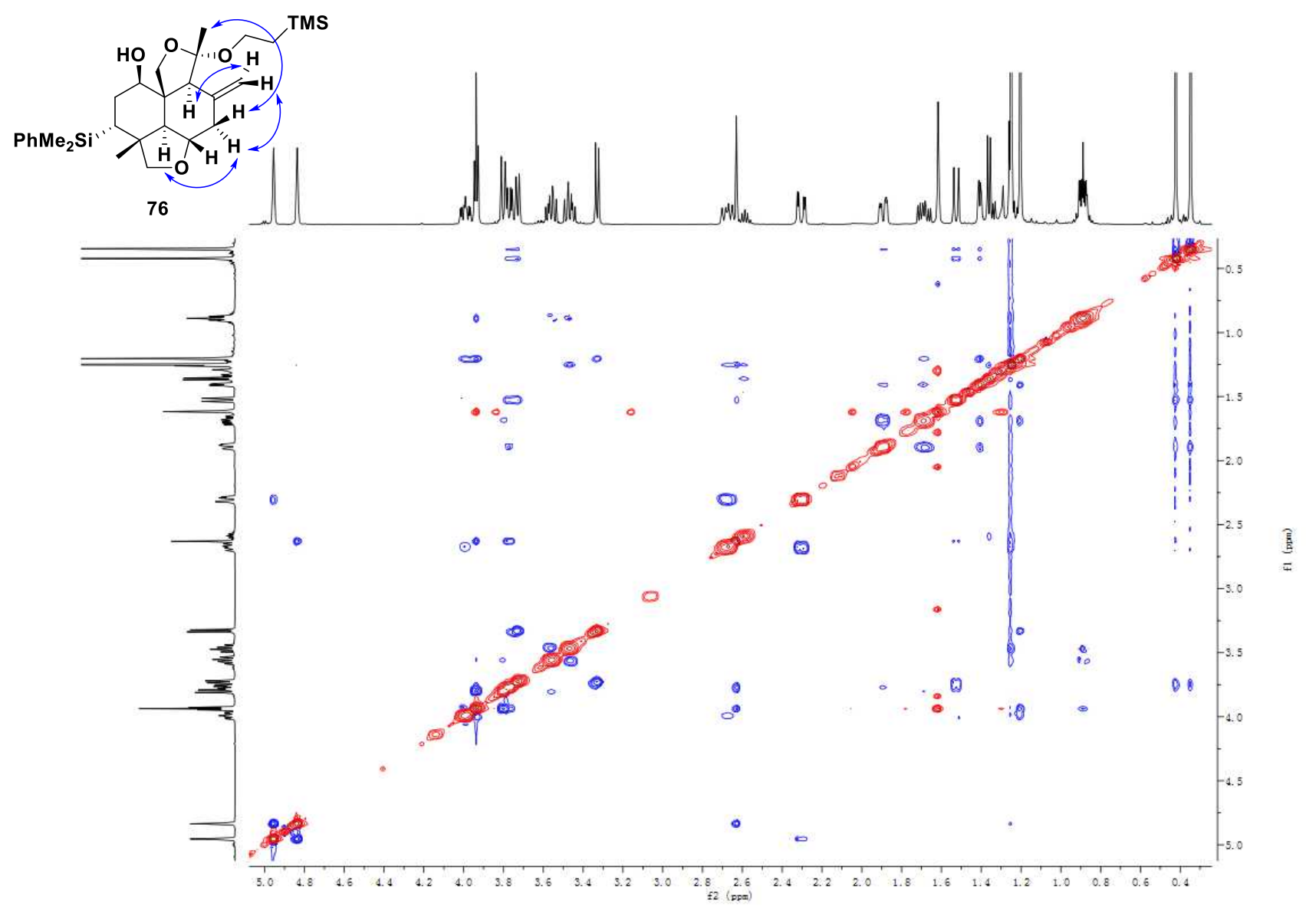

NOESY NMR of compound $\mathbf{7 6}$

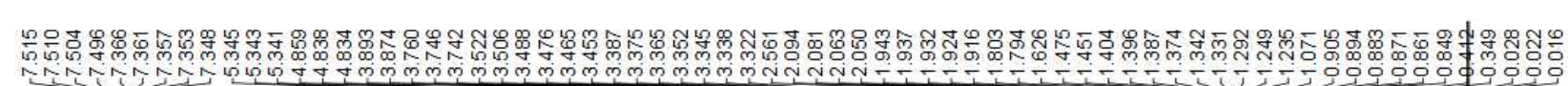

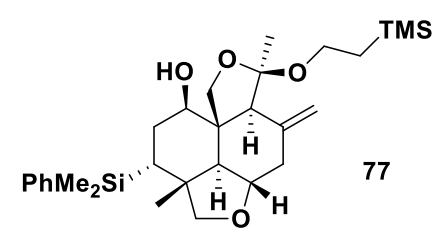

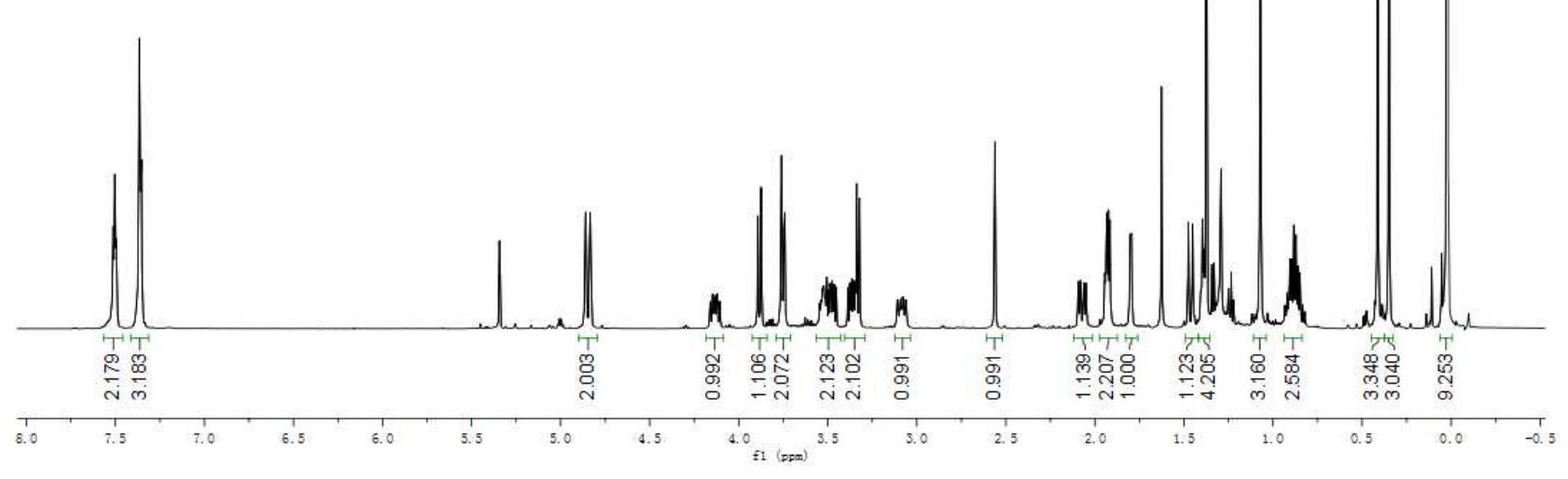

${ }^{1} \mathrm{H}$ NMR of compound 77 


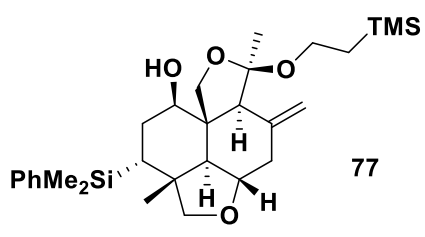
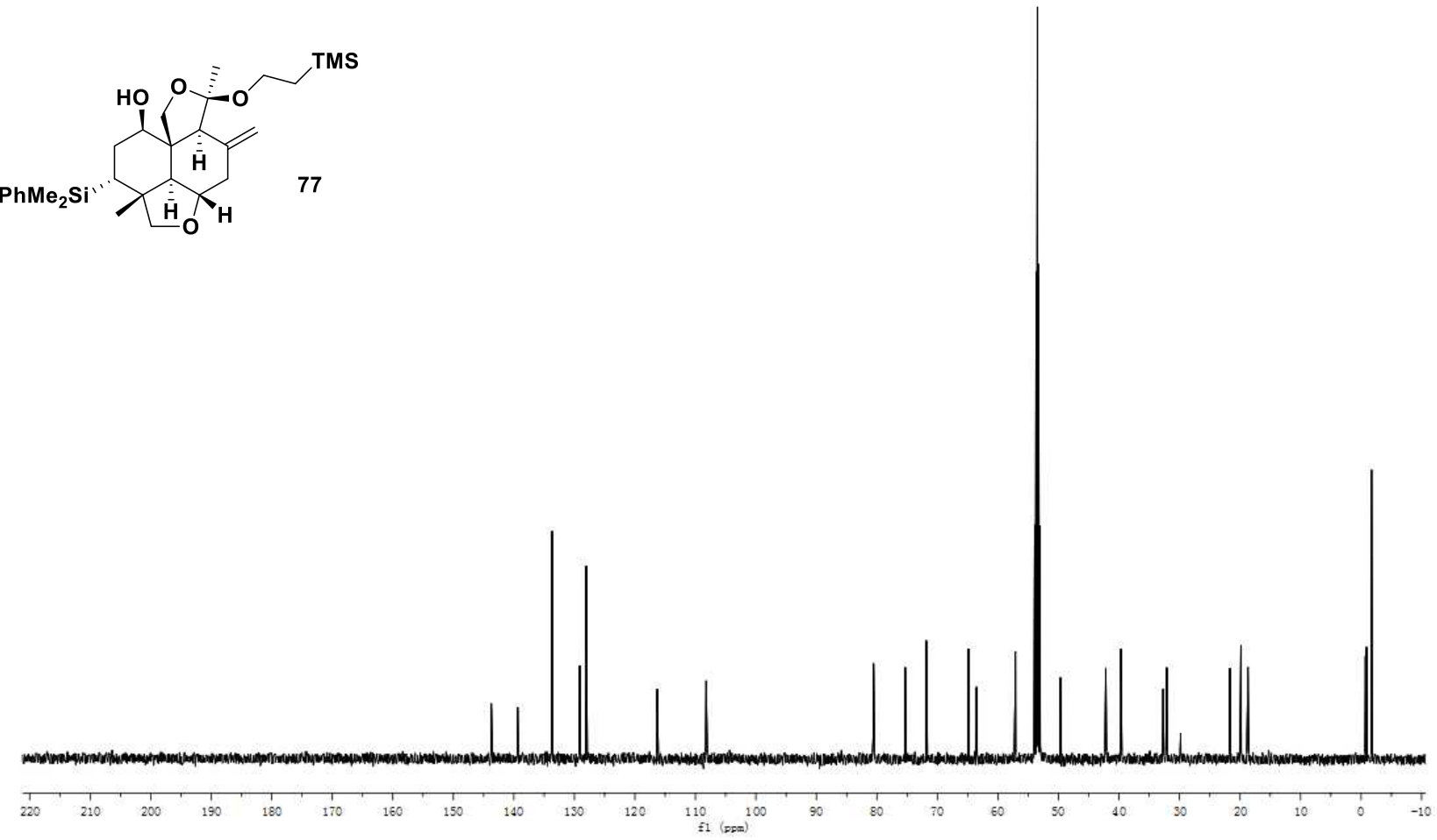

${ }^{13} \mathrm{C}$ NMR of compound 77
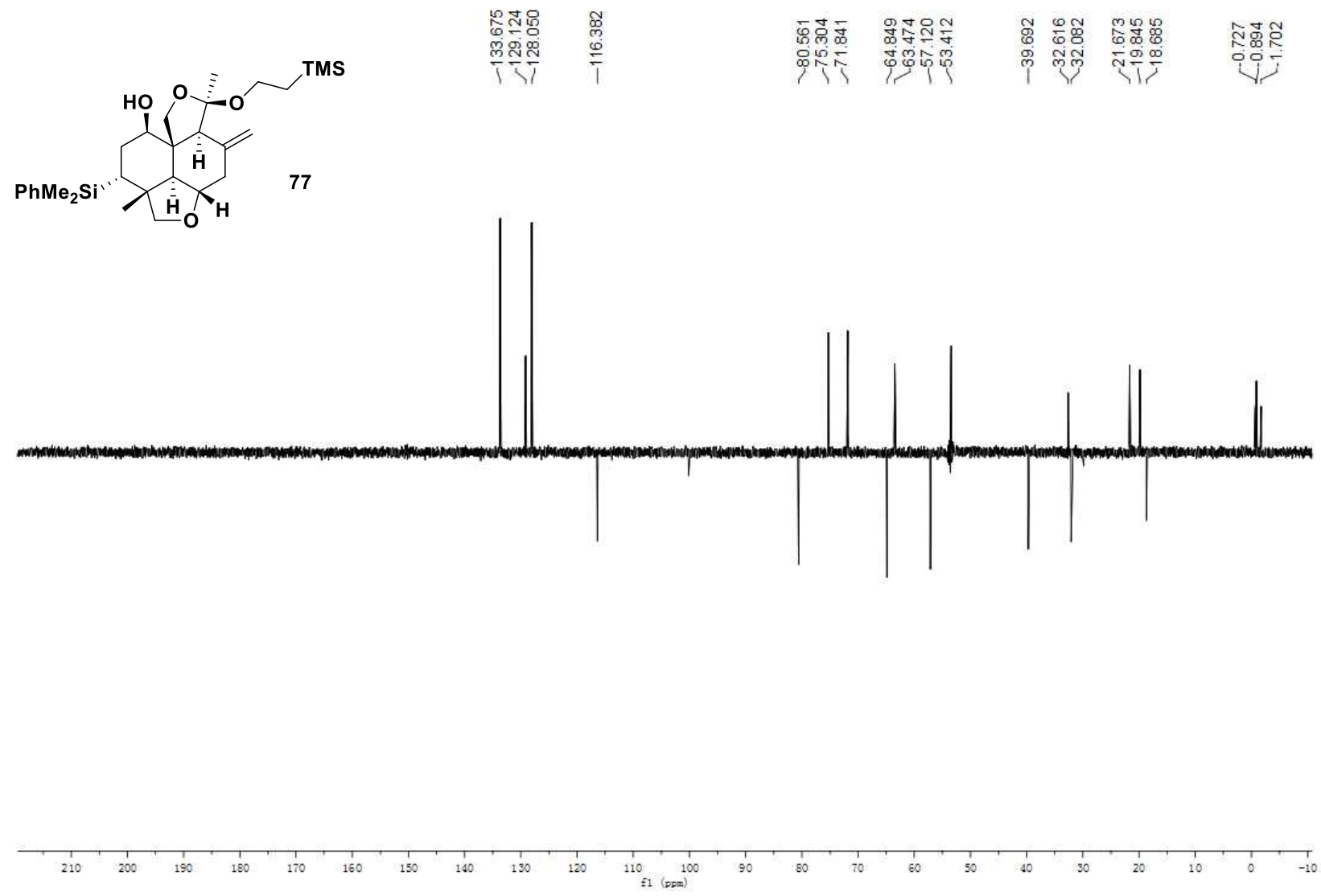

Dept135 NMR of compound 77 

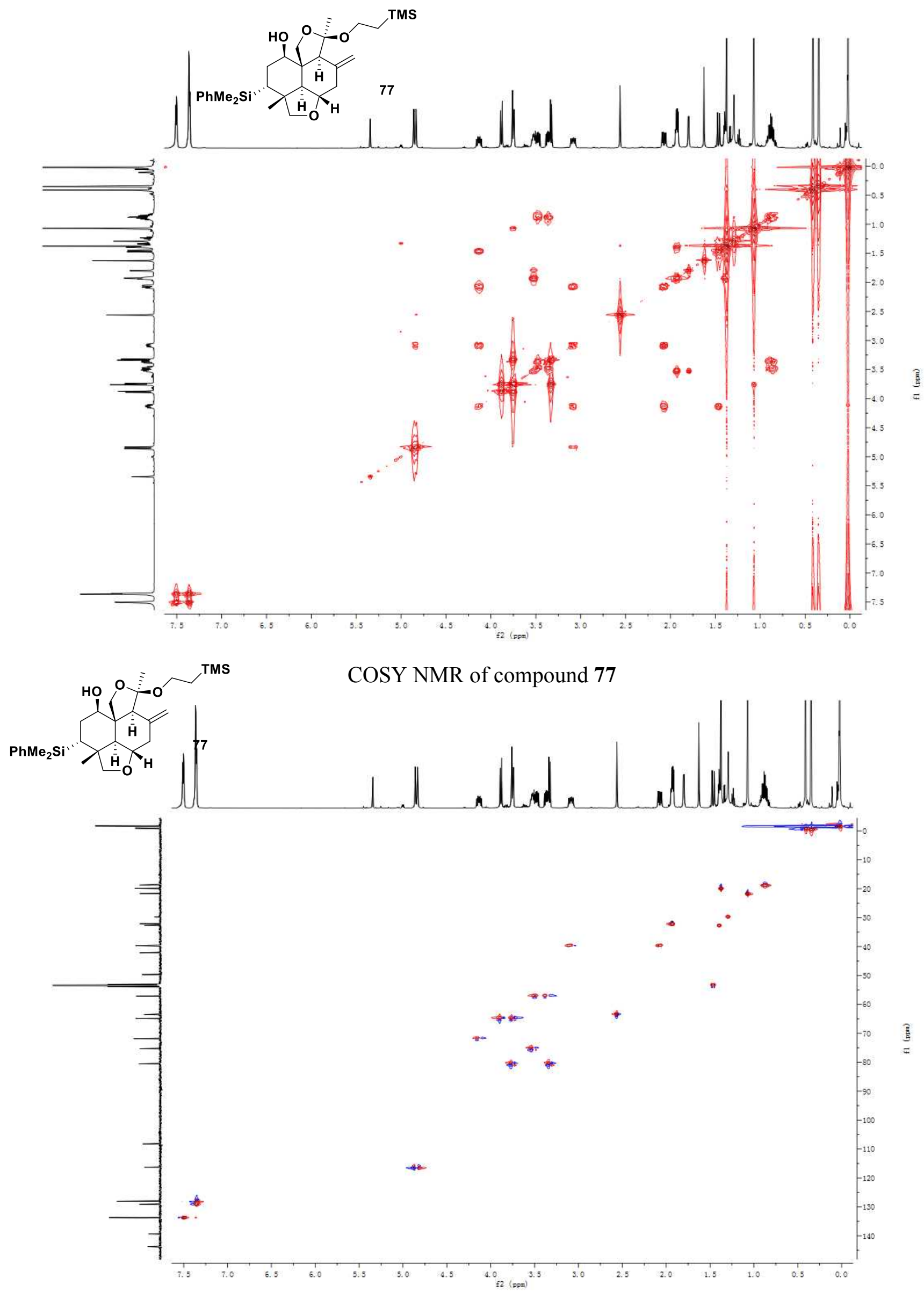

HSQC NMR of compound 77 

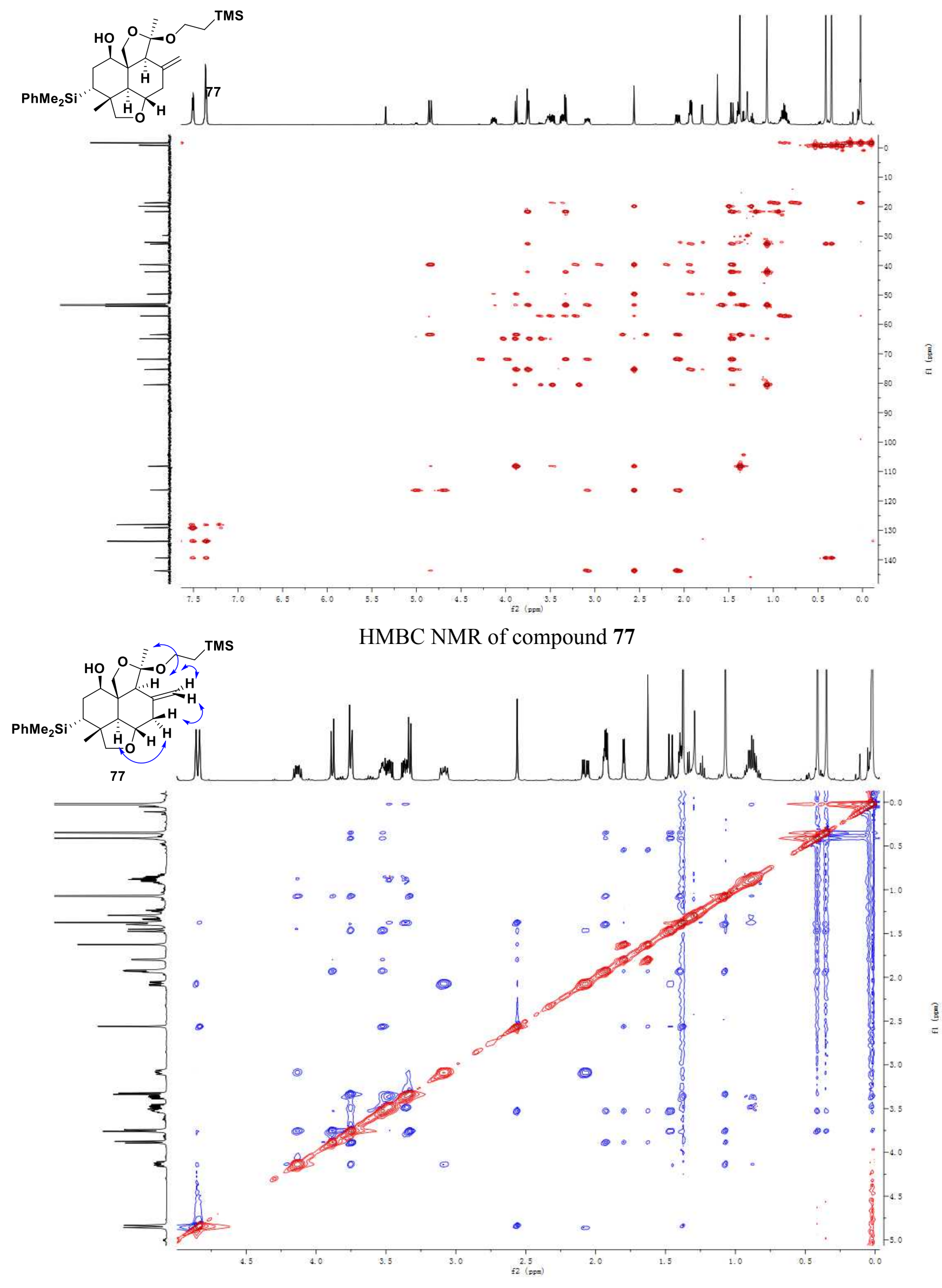

NOESY NMR of compound 77 


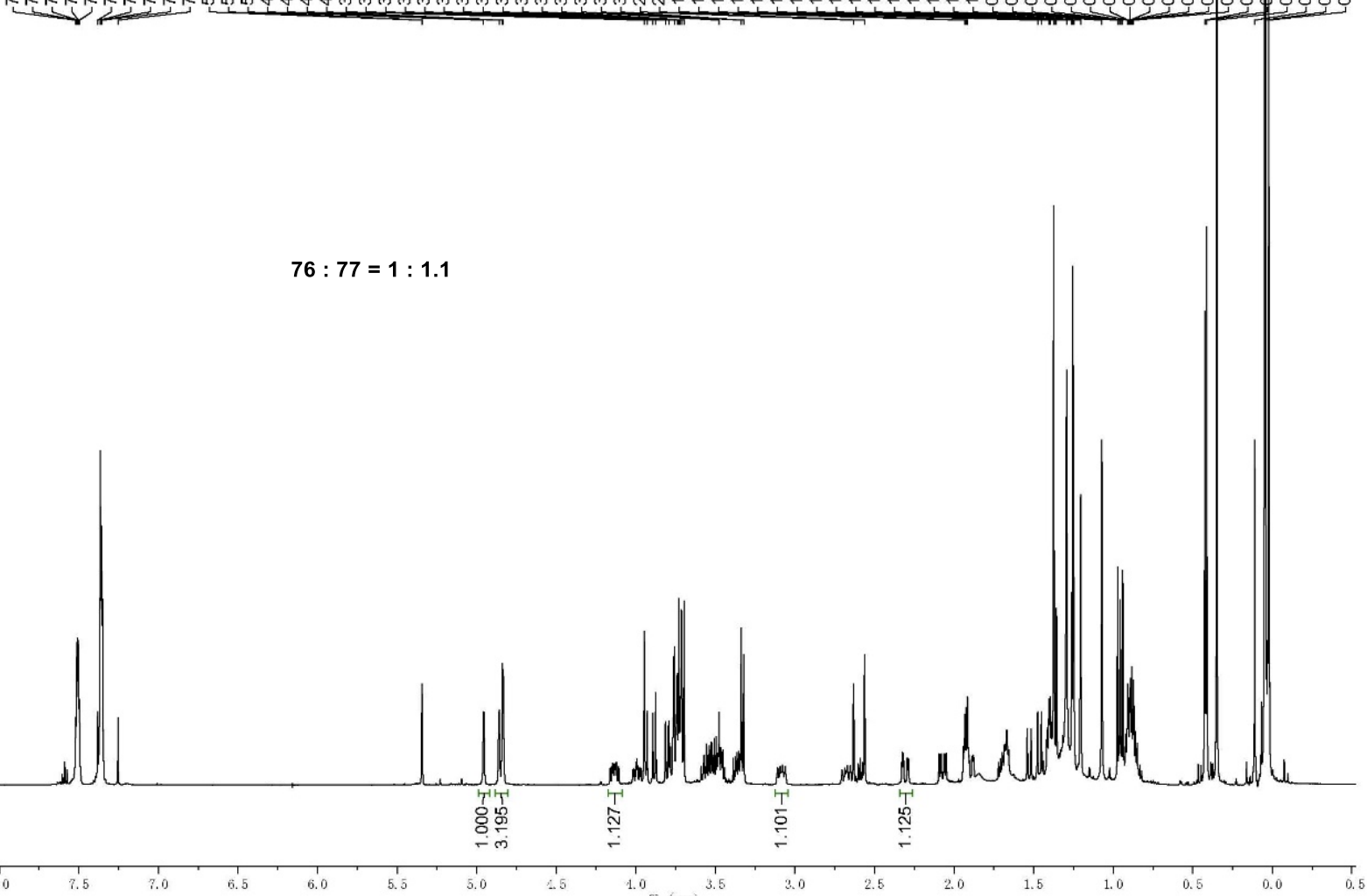

${ }^{1} \mathrm{H}$ NMR of compounds $\mathbf{7 6}$ and $\mathbf{7 7}$

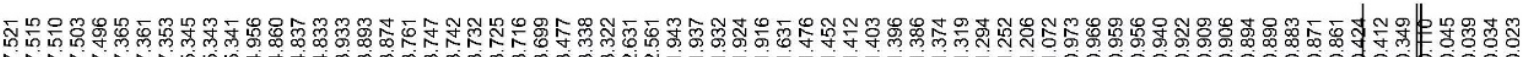

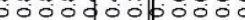

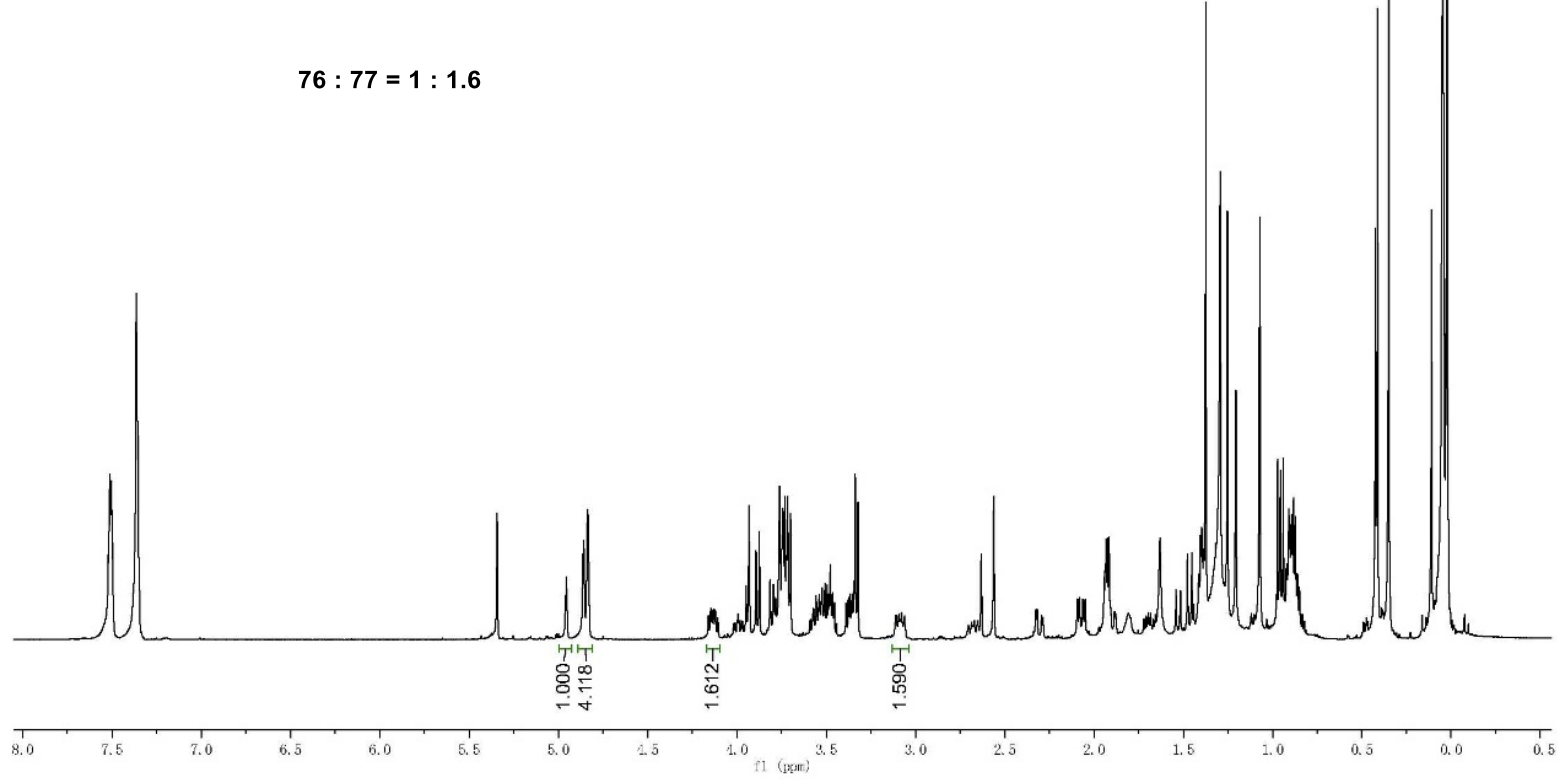

${ }^{1} \mathrm{H}$ NMR of compounds $\mathbf{7 6}$ and 77 


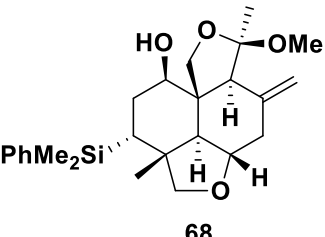

68

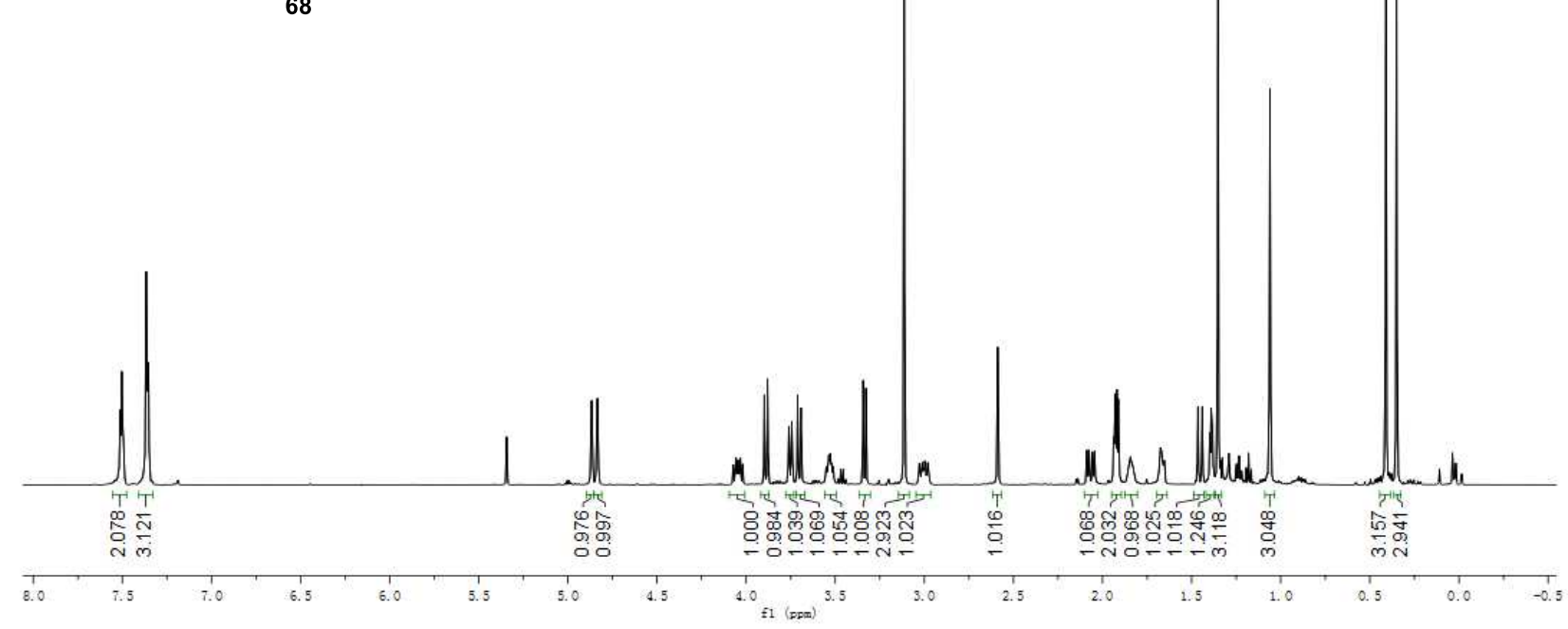

${ }^{1} \mathrm{H}$ NMR of compound 68

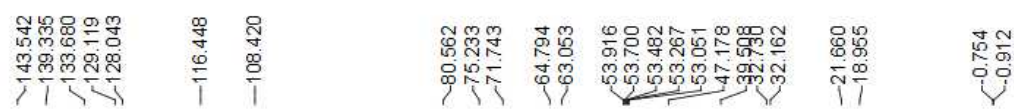

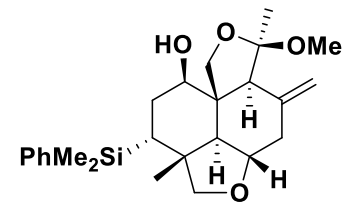

68

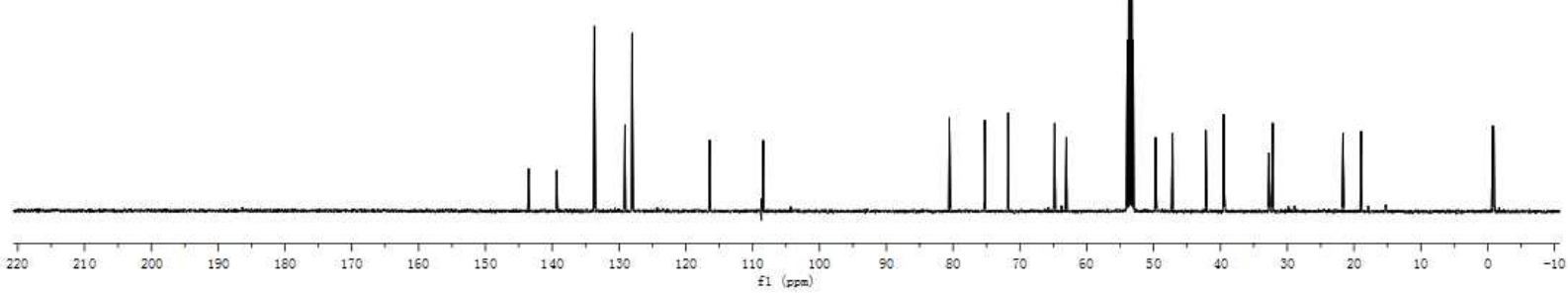

${ }^{13} \mathrm{C}$ NMR of compound 68 


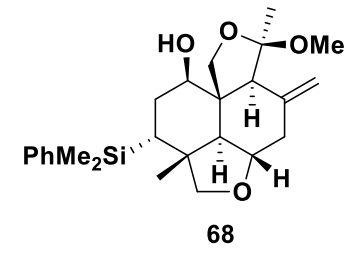
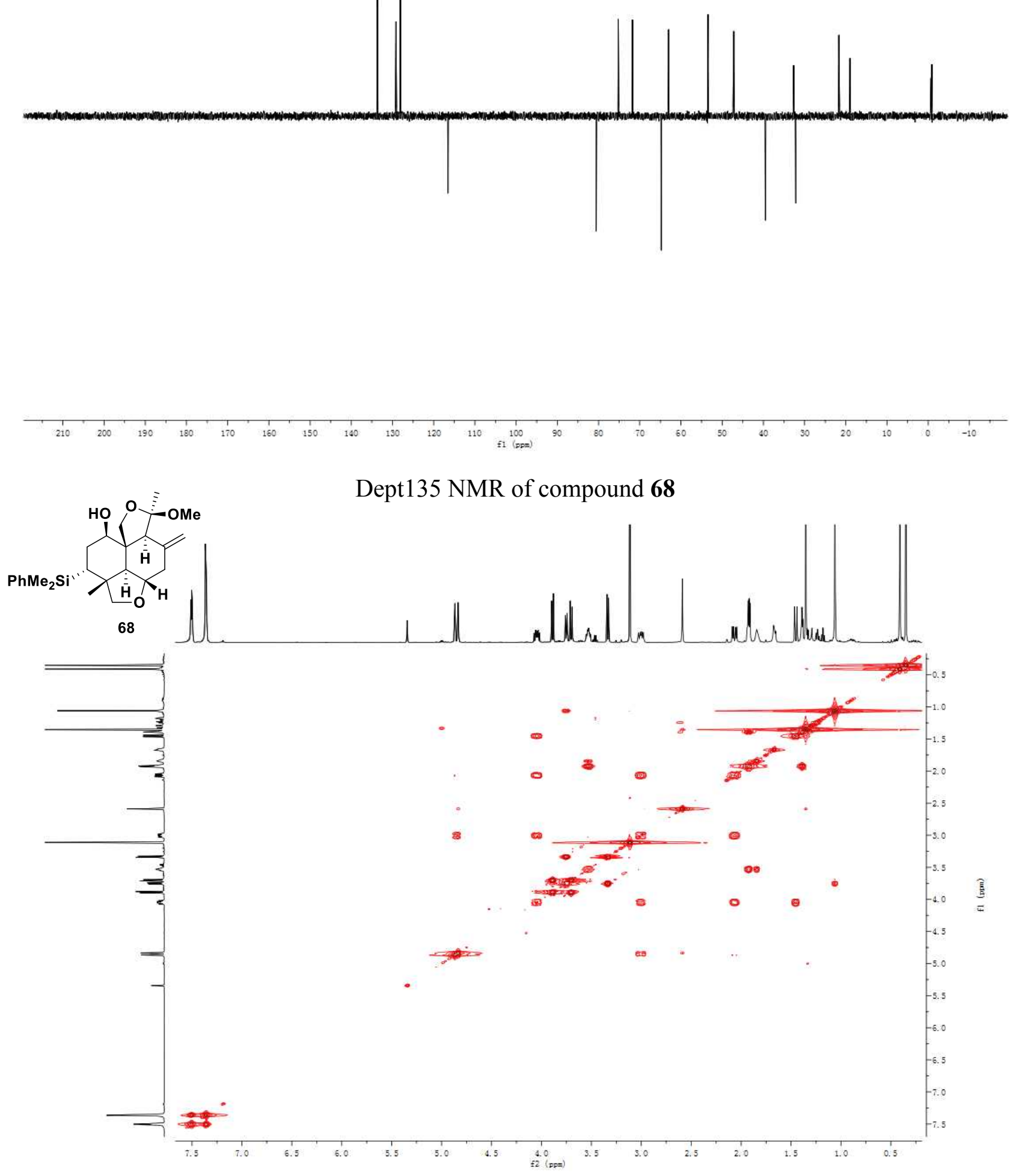

COSY NMR of compound $\mathbf{6 8}$ 


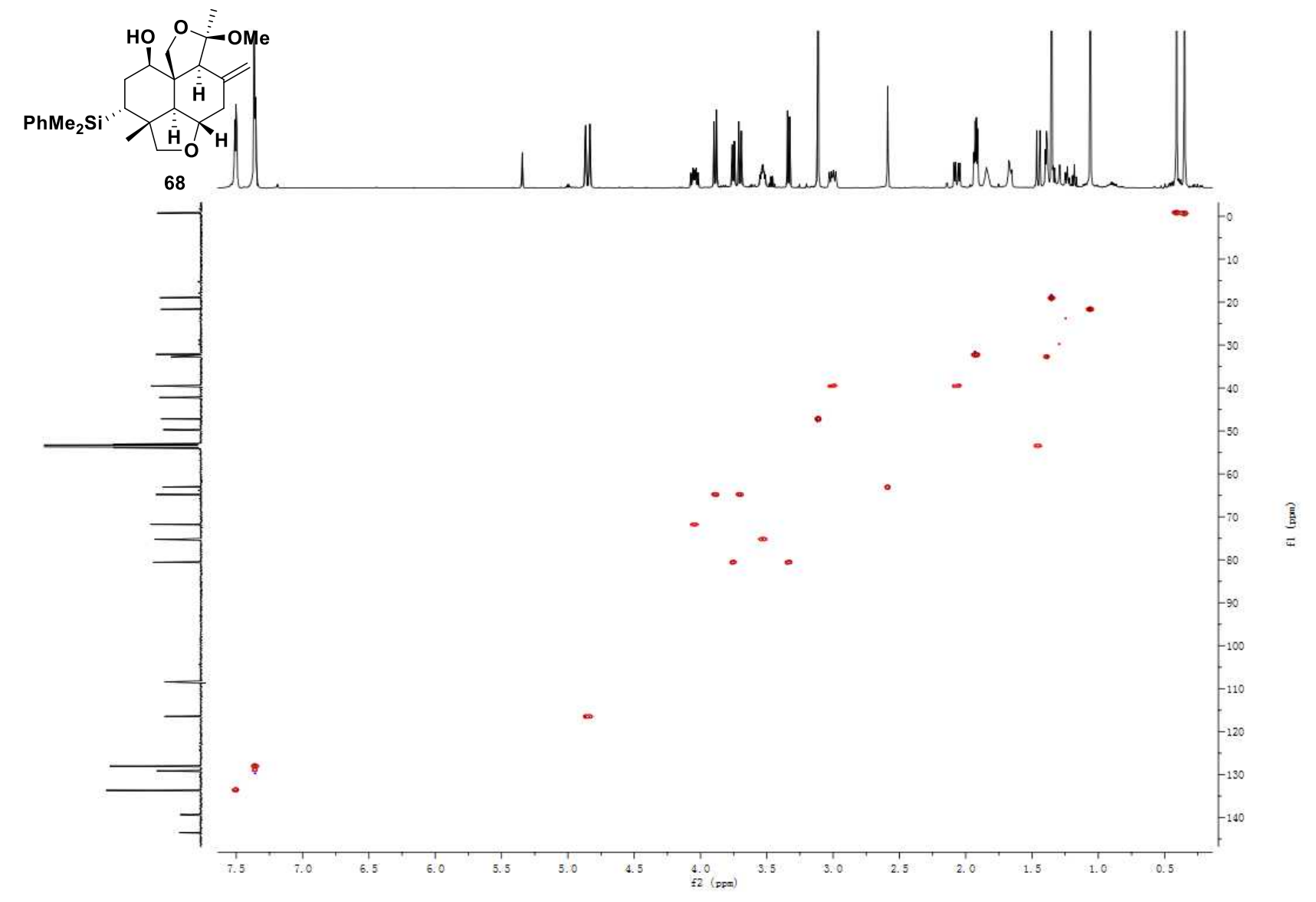

HSQC NMR of compound $\mathbf{6 8}$

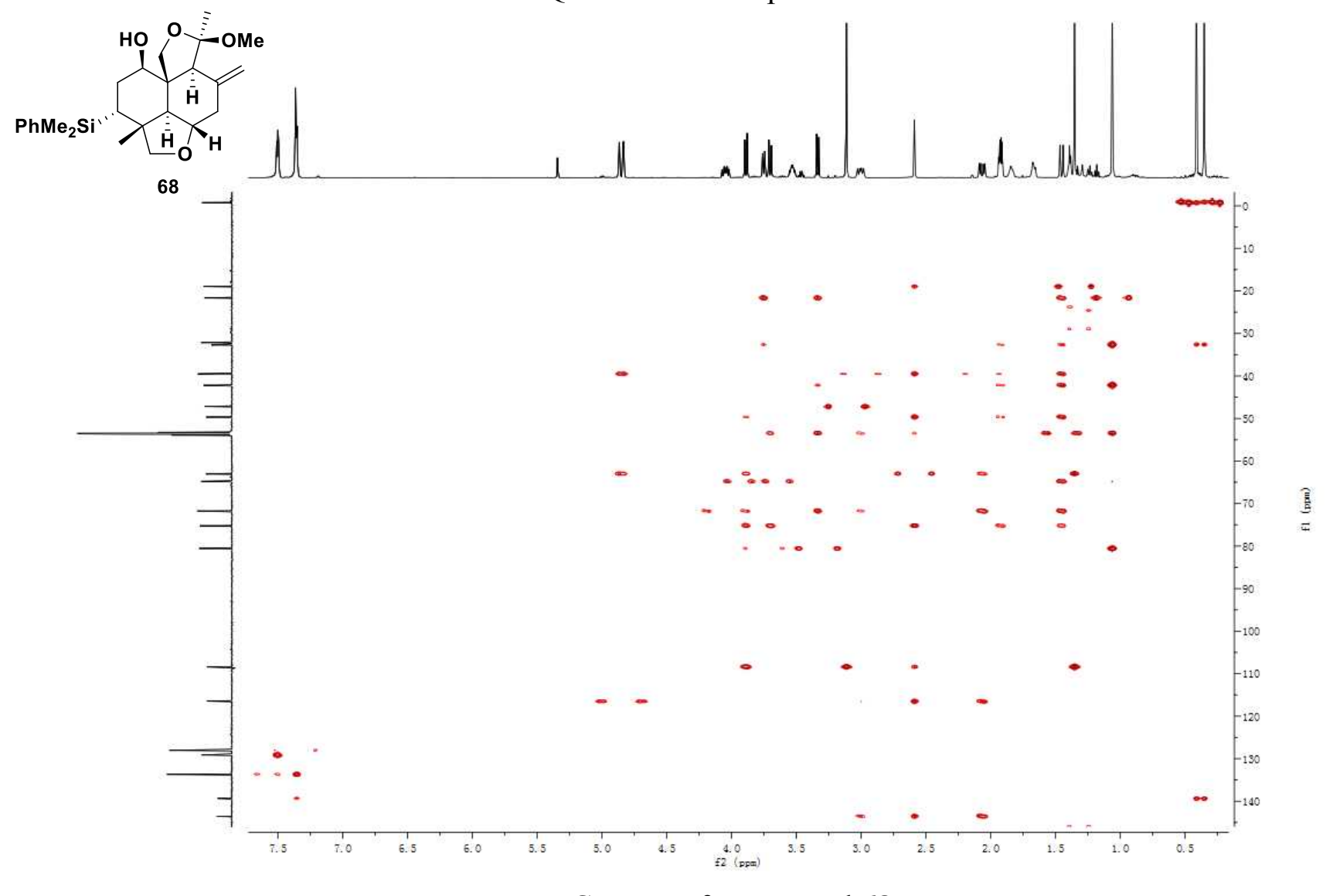

HMBC NMR of compound $\mathbf{6 8}$ 


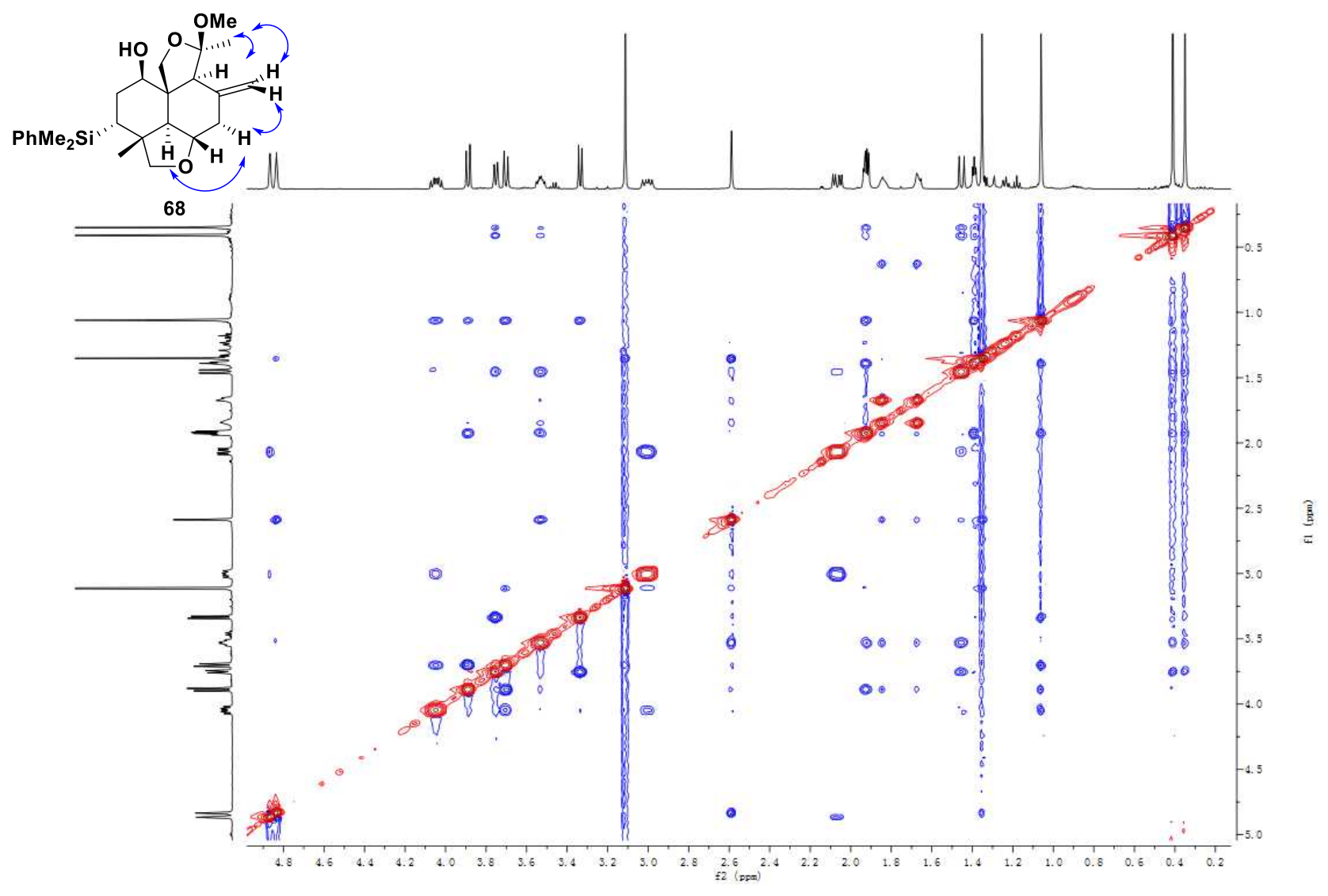

NOESY NMR of compound $\mathbf{6 8}$

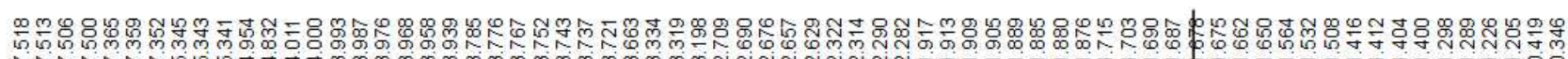

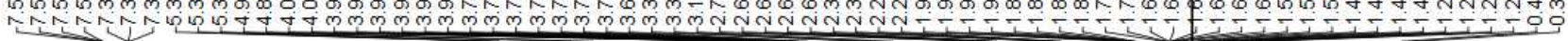

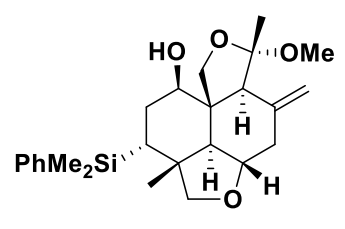

78

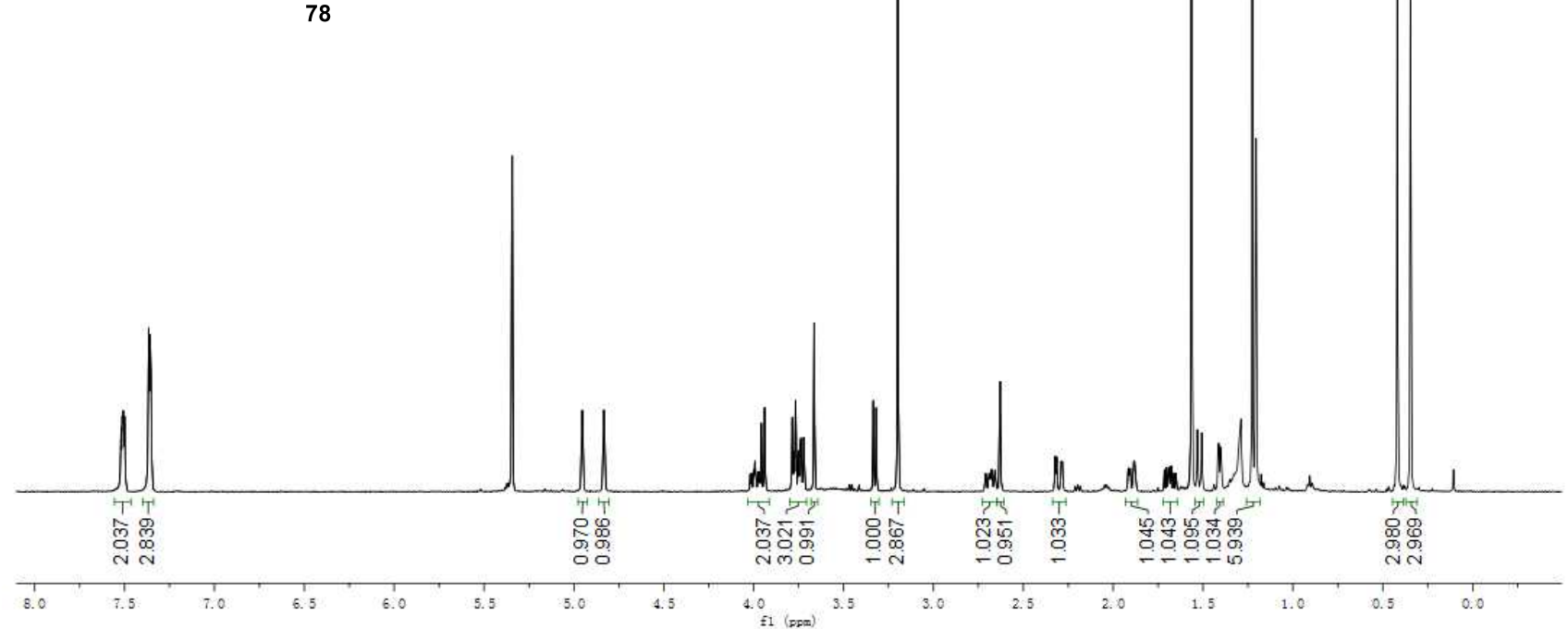

${ }^{1}$ H NMR of compound 78 


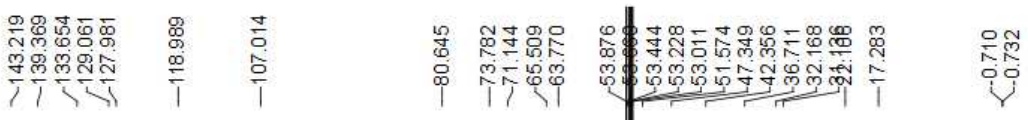

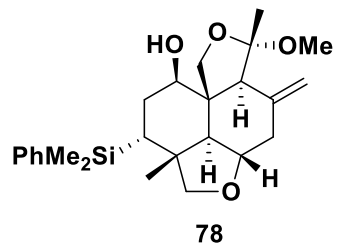

78
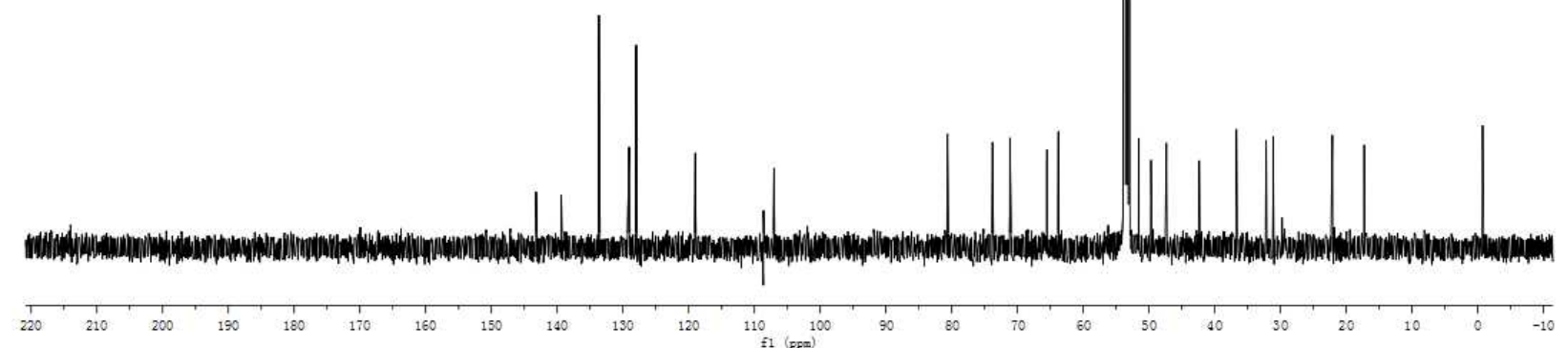

${ }^{13} \mathrm{C}$ NMR of compound 78
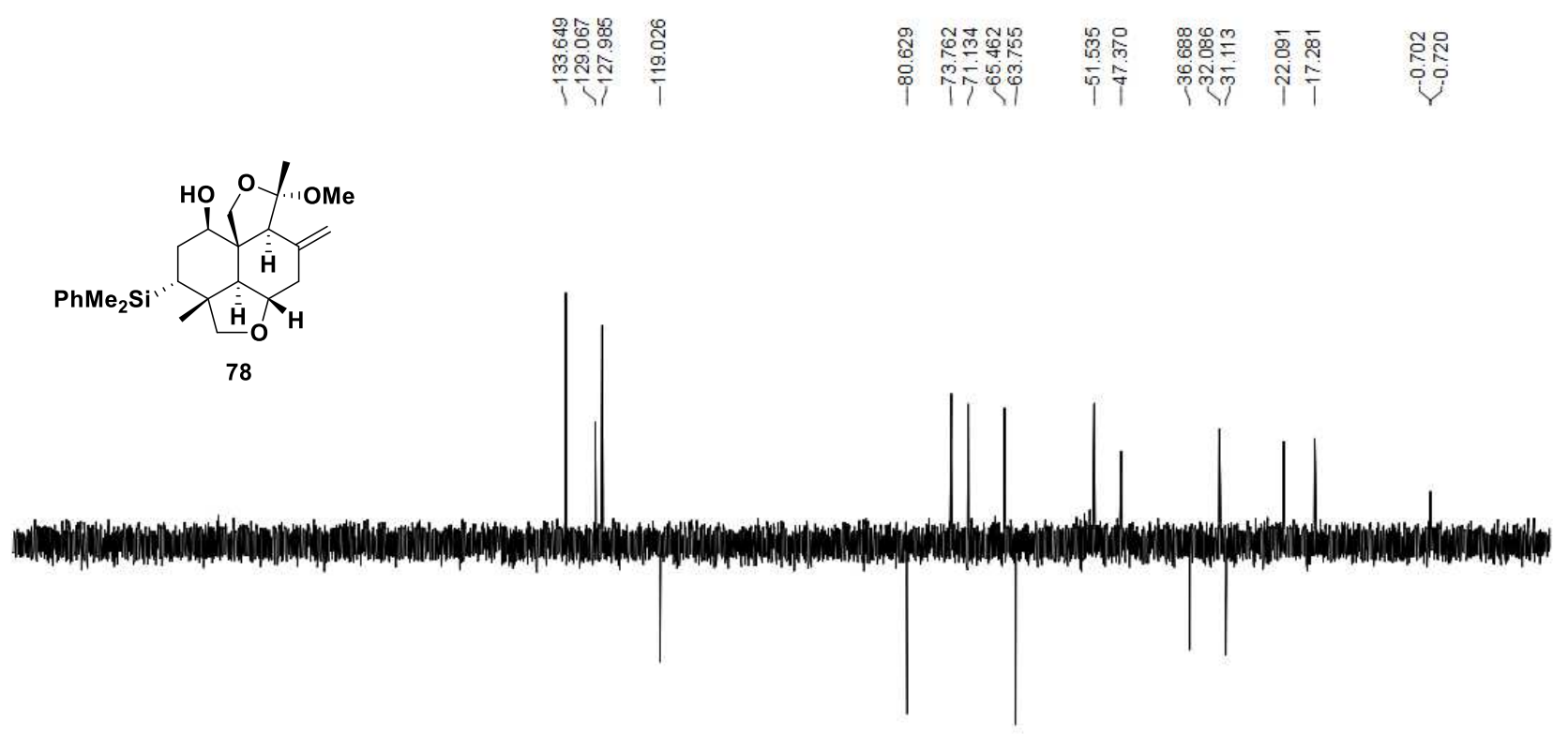

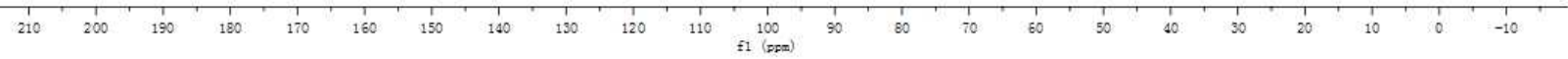

Dept135 NMR of compound 78 

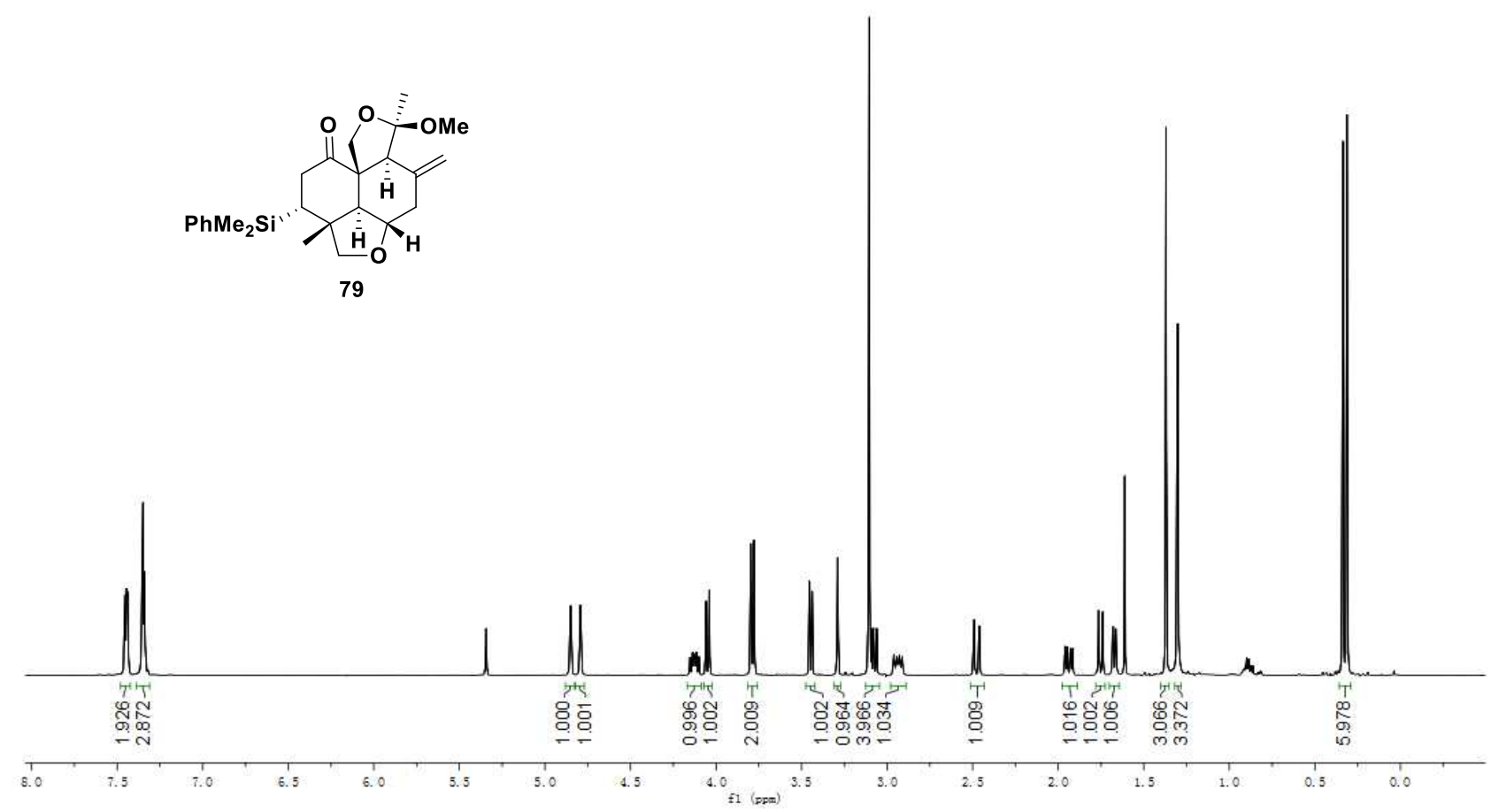

${ }^{1} \mathrm{H}$ NMR of compound 79
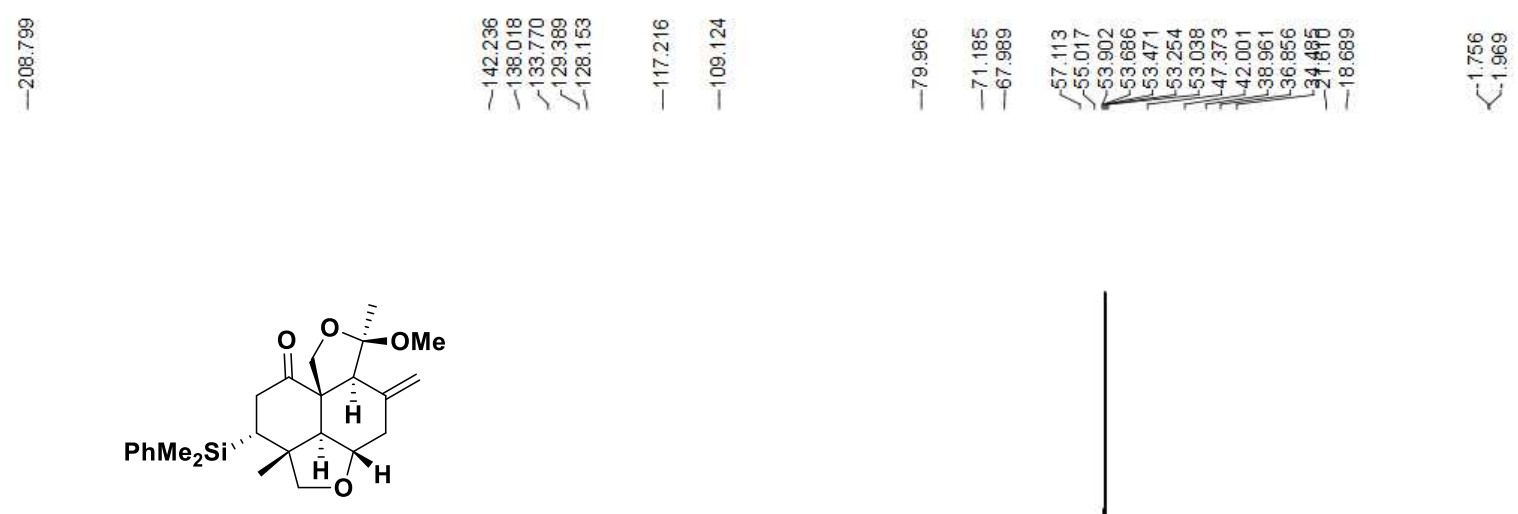

79
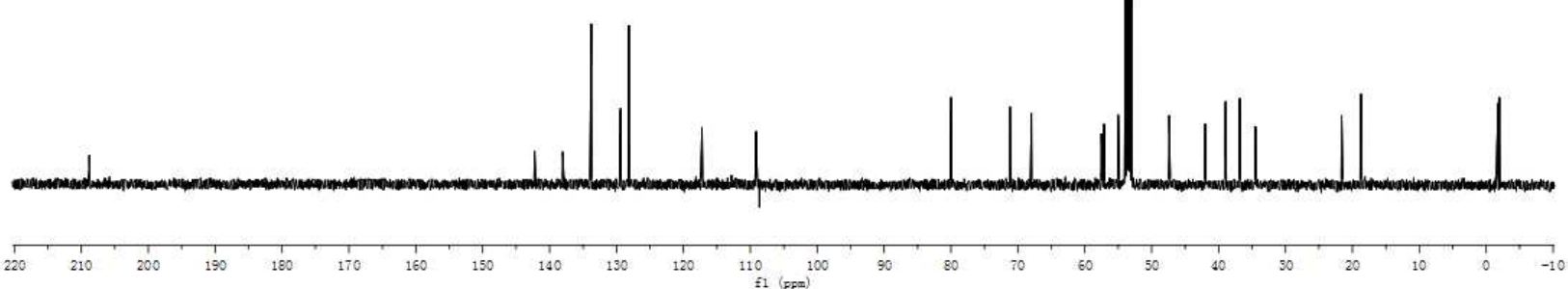

${ }^{13} \mathrm{C}$ NMR of compound 79 

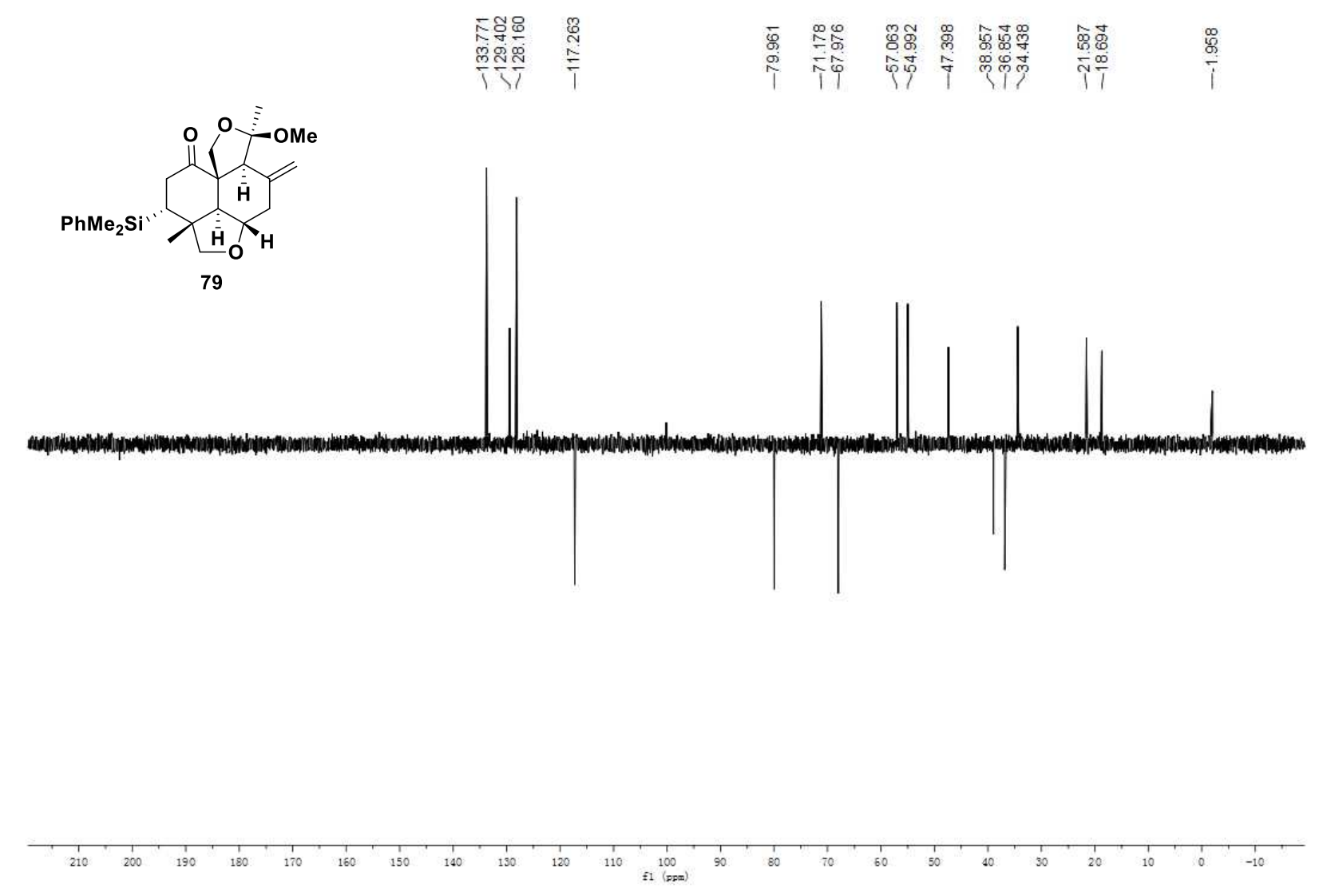

Dept135 NMR of compound 79

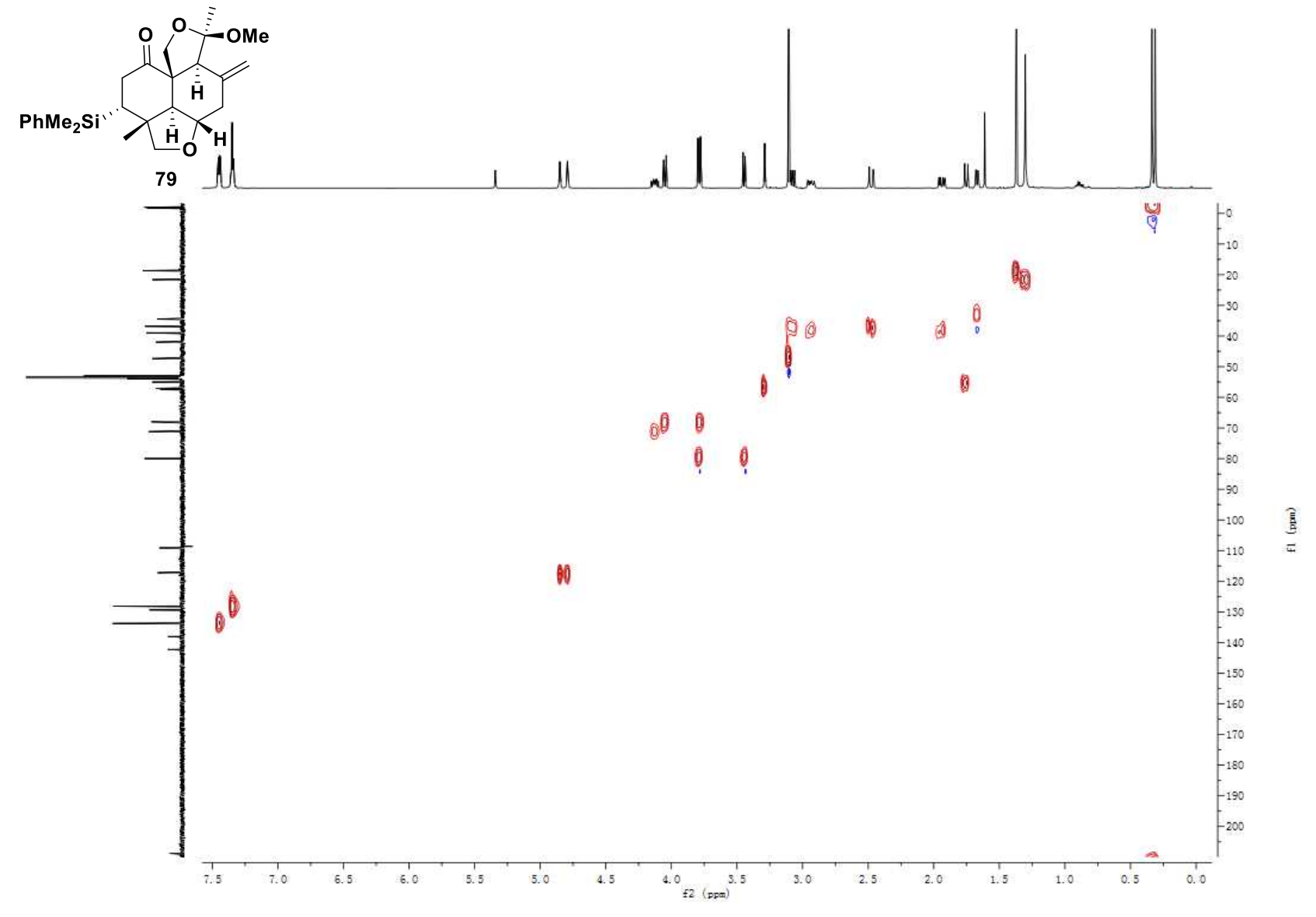

HSQC NMR of compound 79 


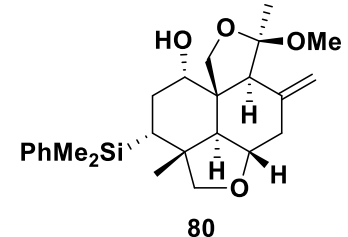

80

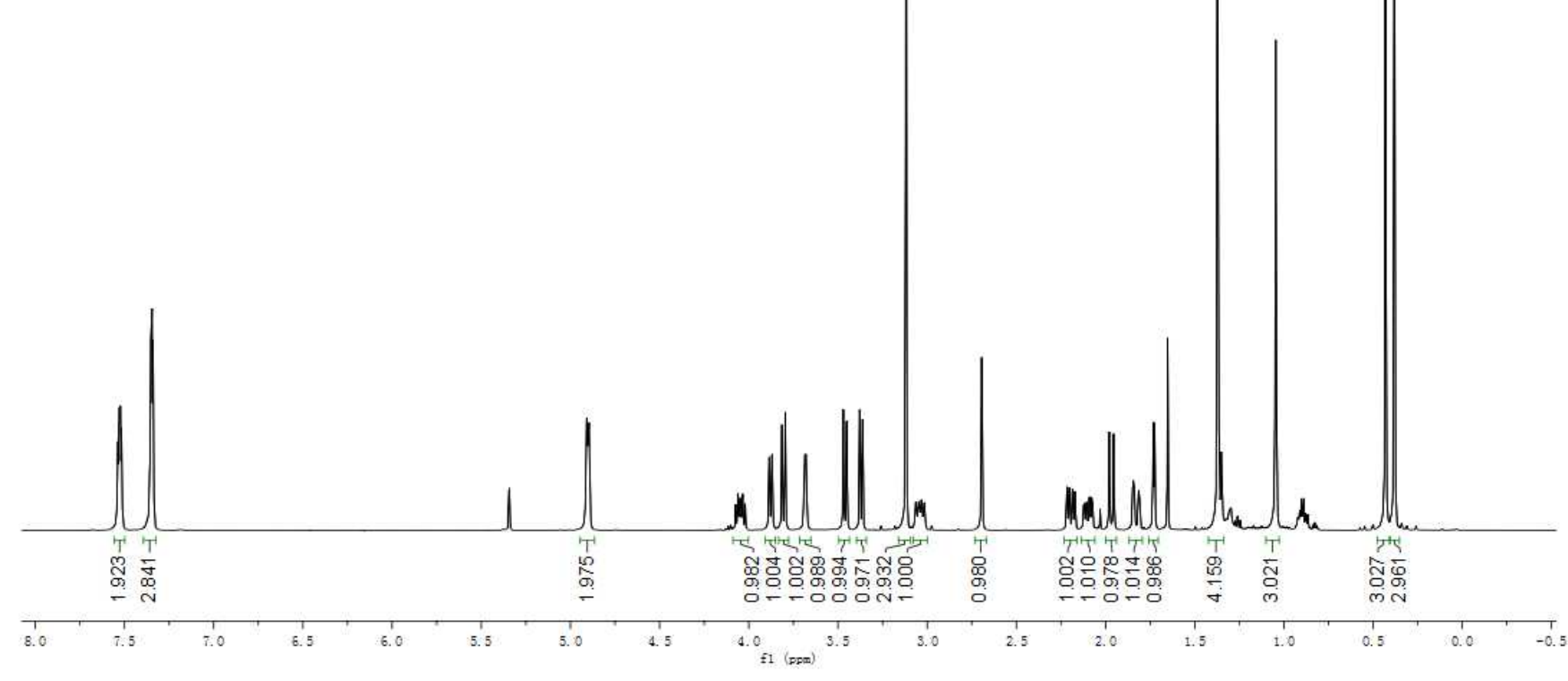

${ }^{1} \mathrm{H}$ NMR of compound 80
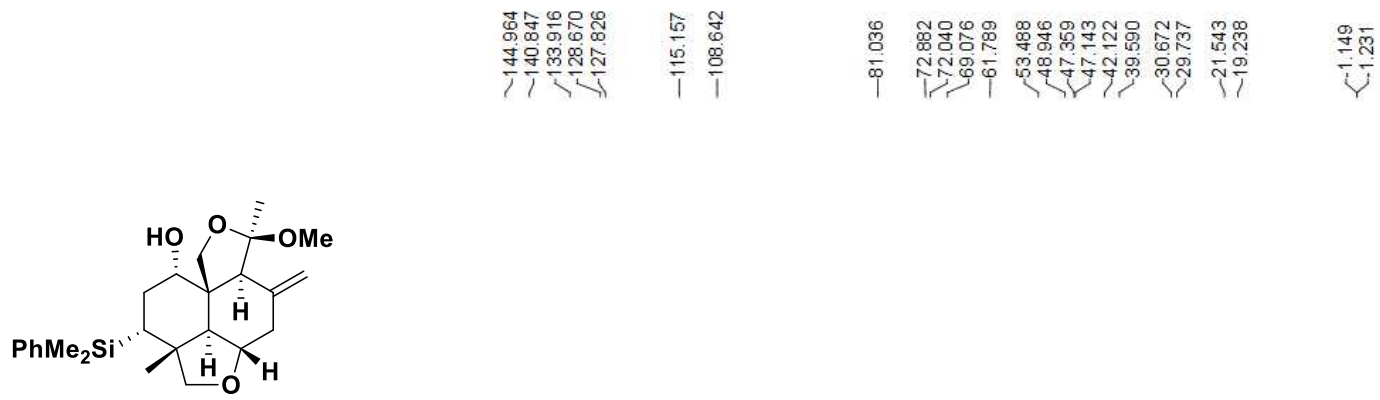

80

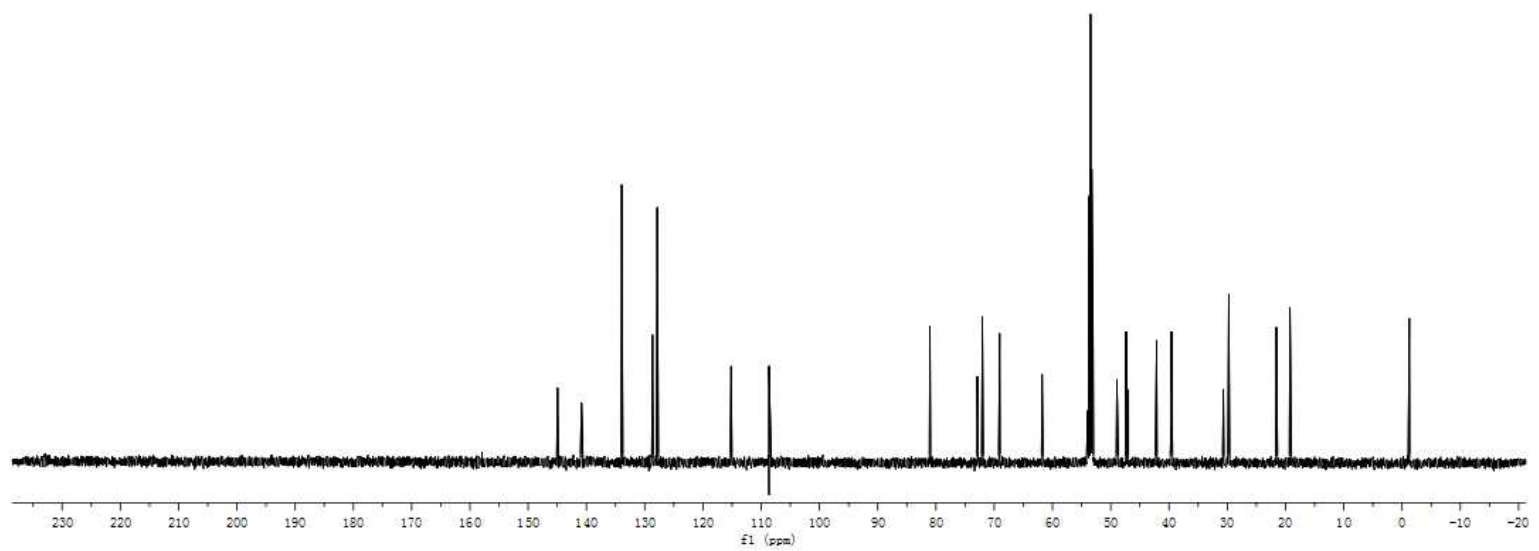

${ }^{13} \mathrm{C}$ NMR of compound $\mathbf{8 0}$ 

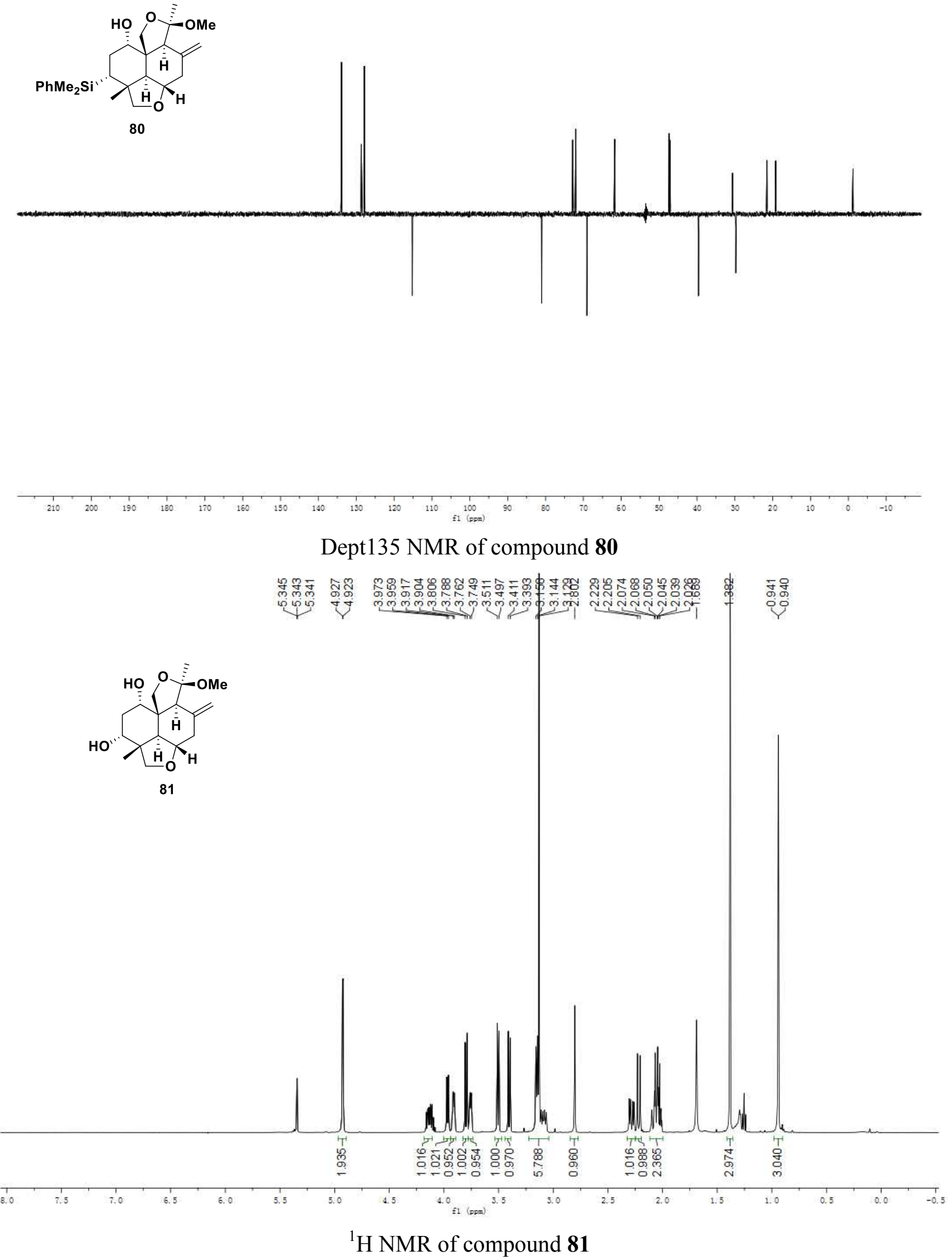

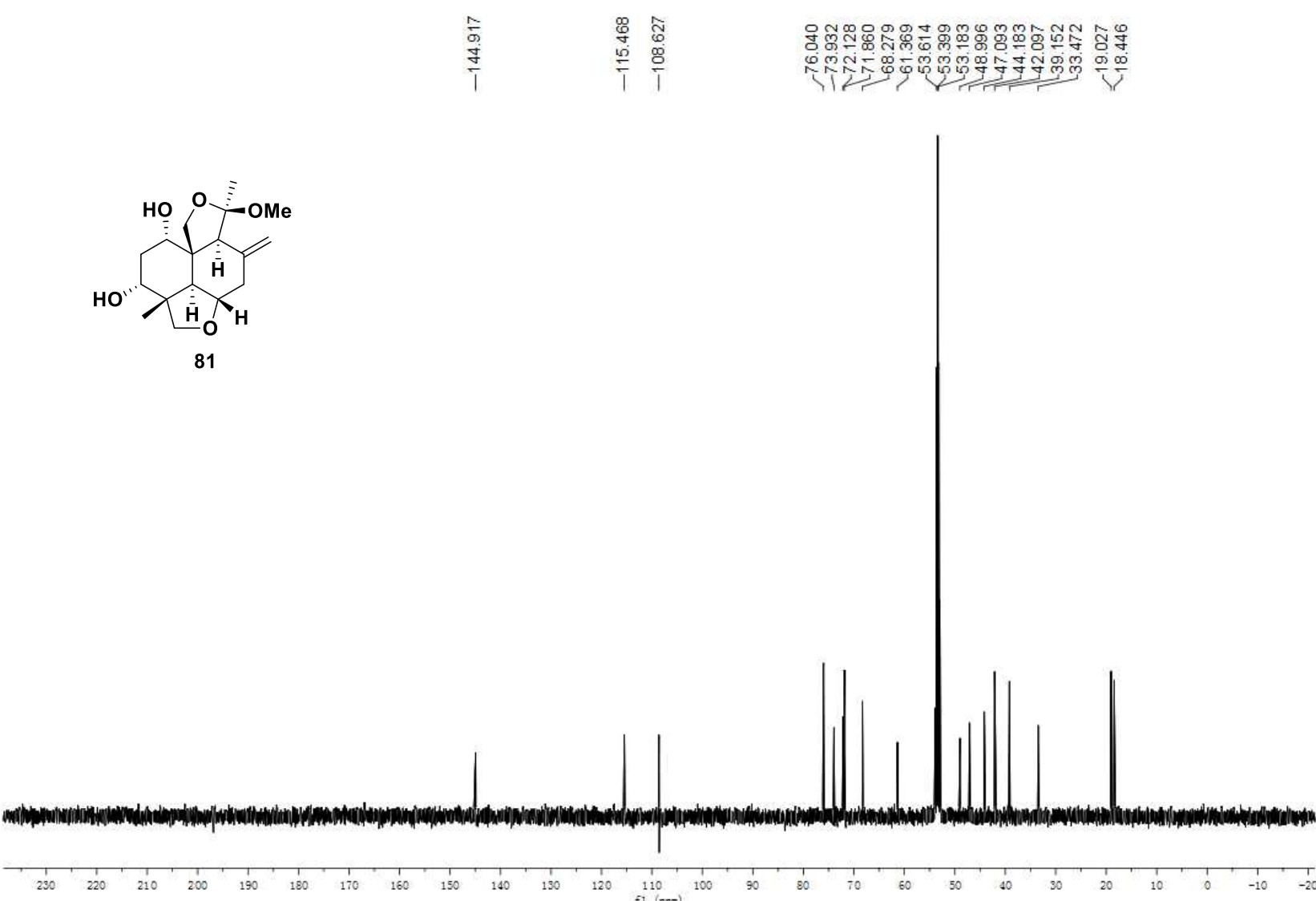

${ }^{13} \mathrm{C}$ NMR of compound $\mathbf{8 1}$

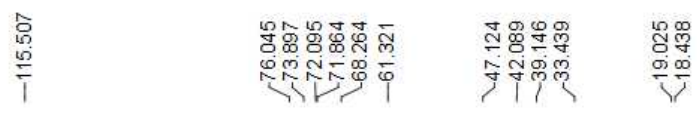

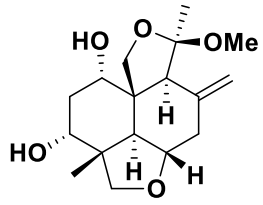

81
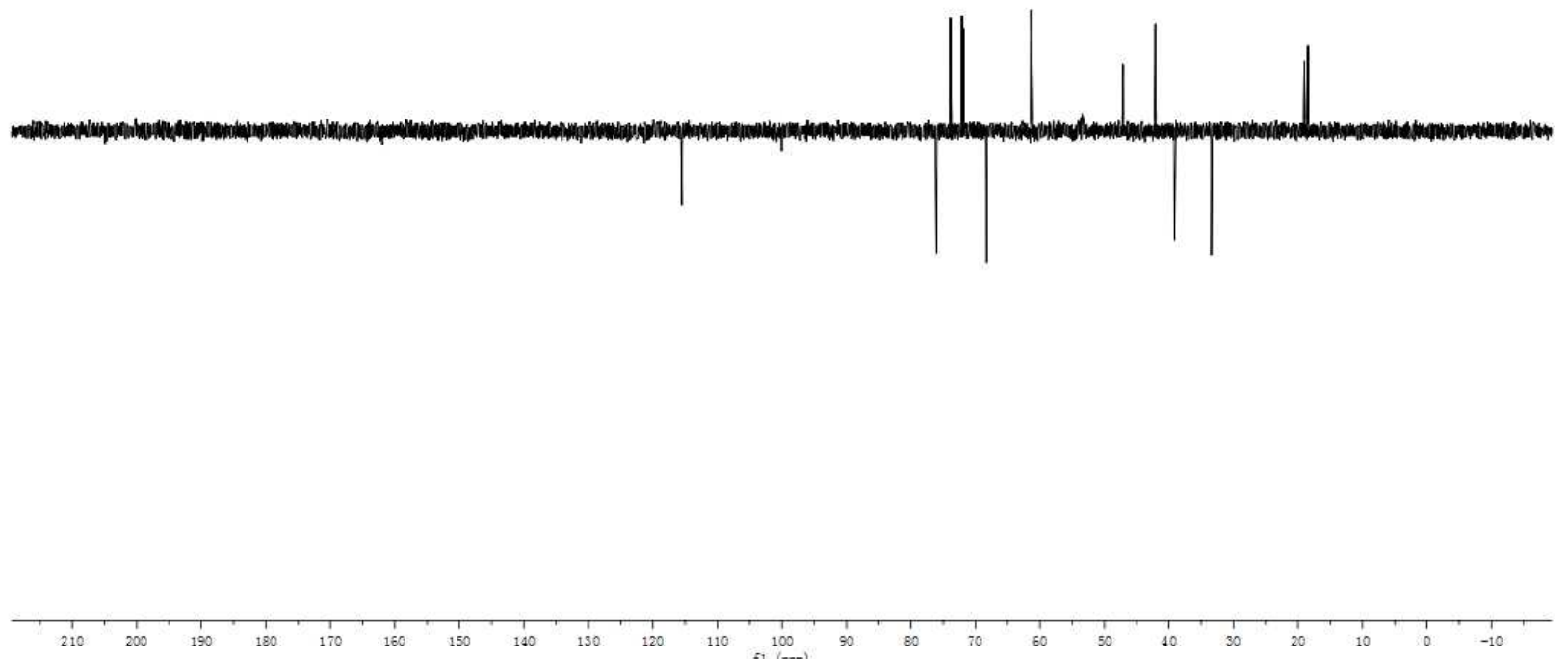

Dept135 NMR of compound $\mathbf{8 1}$ 


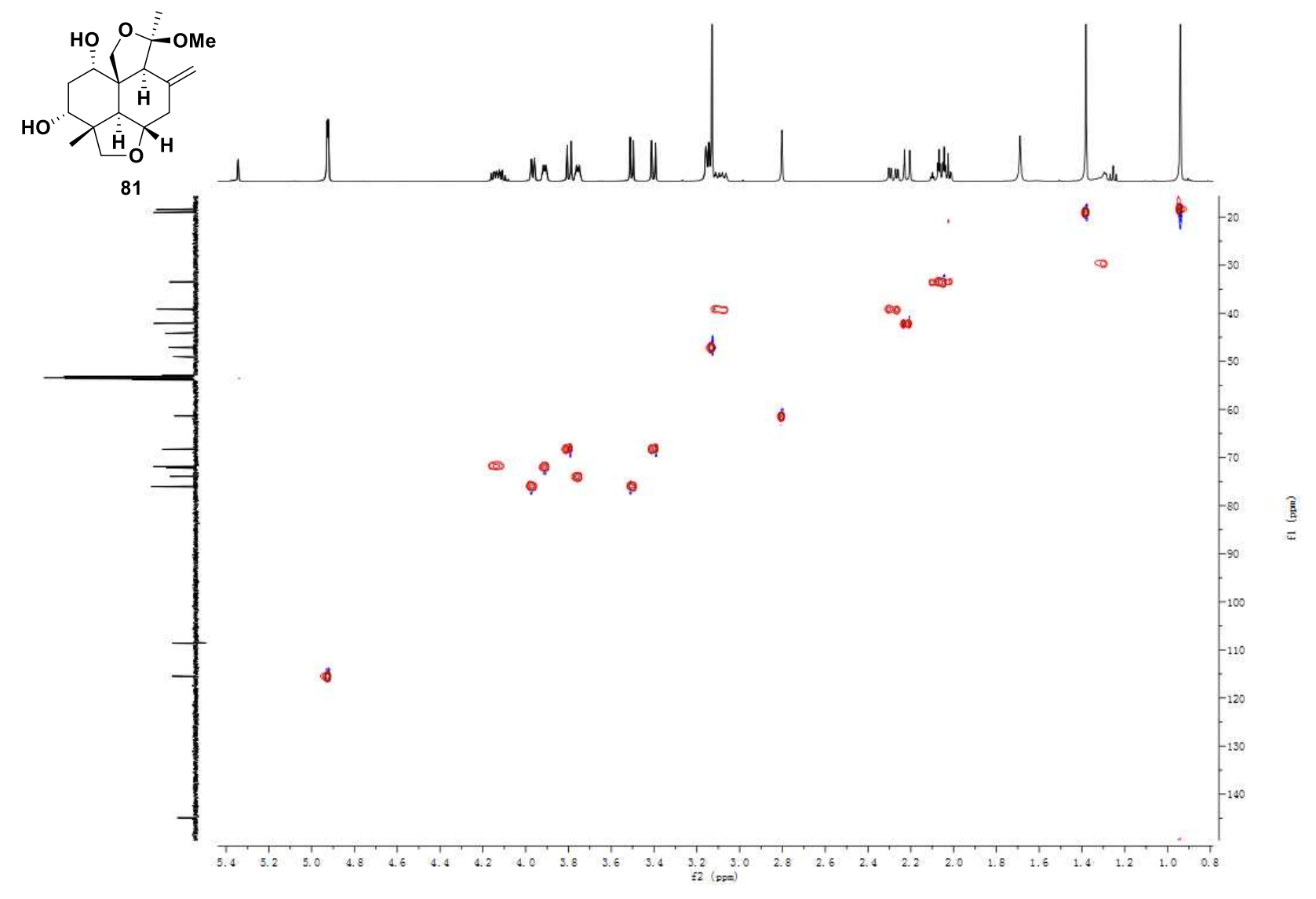

HSQC NMR of compound $\mathbf{8 1}$

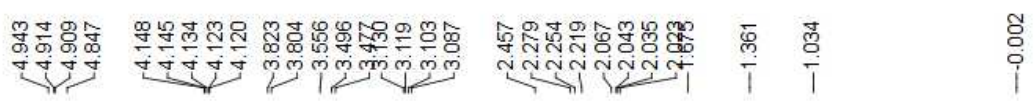

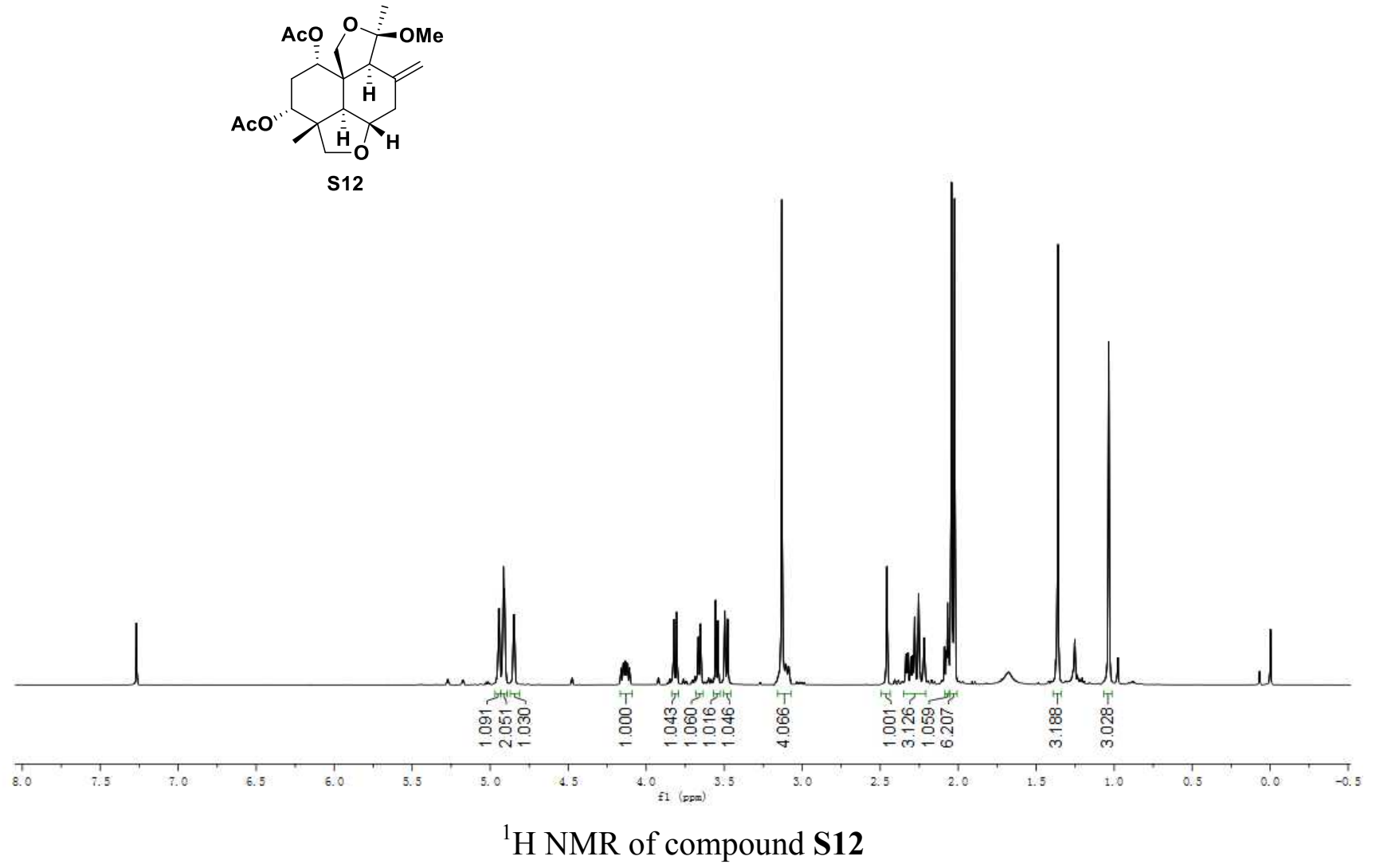



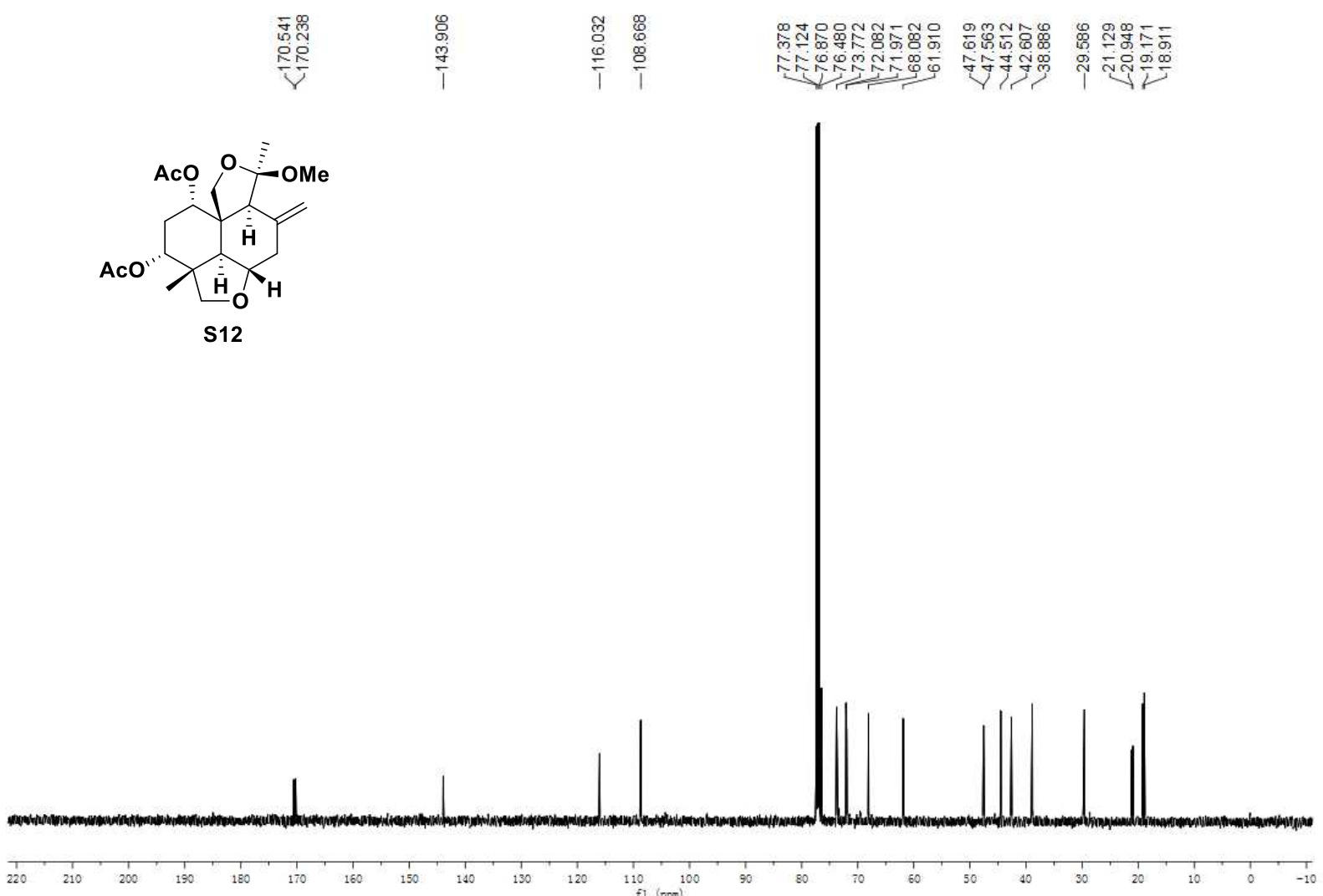

${ }^{13} \mathrm{C}$ NMR of compound $\mathbf{S 1 2}$
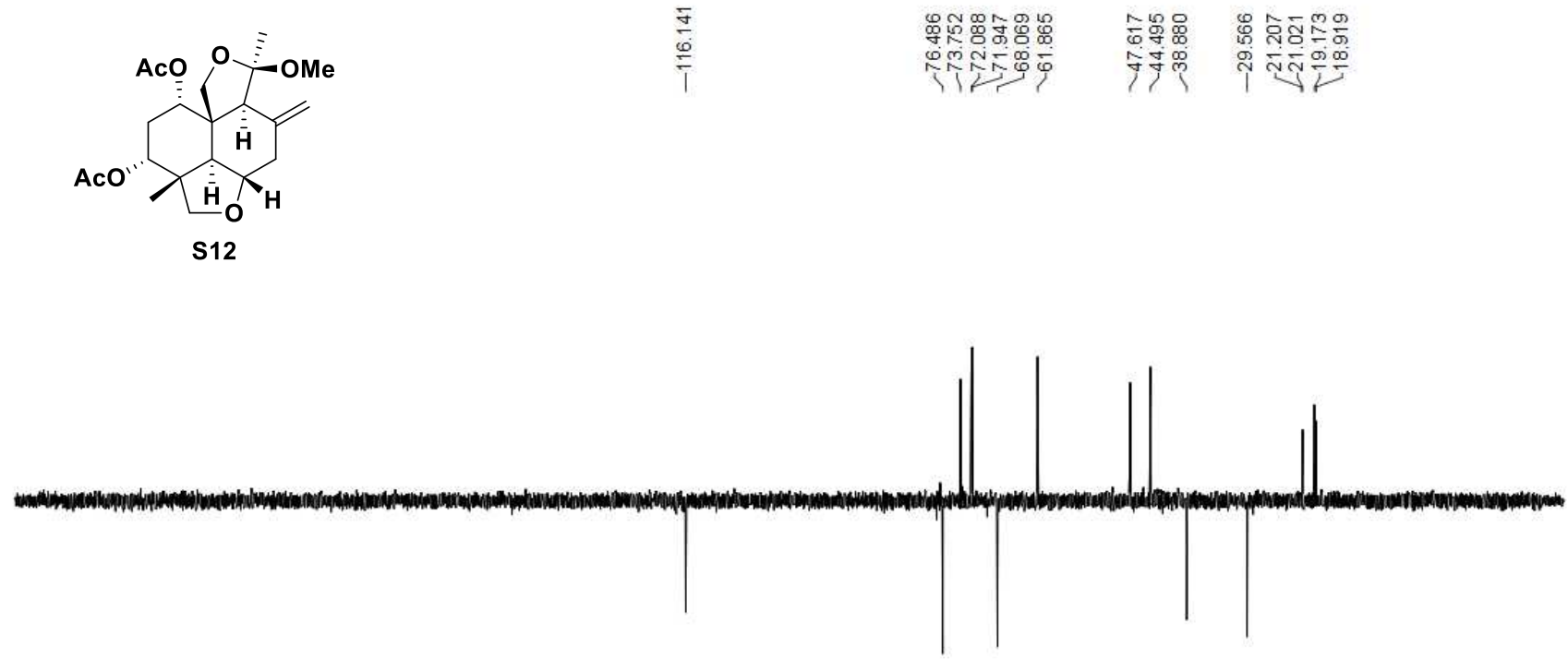

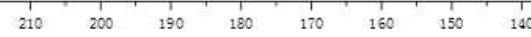

Dept135 NMR of compound S12 

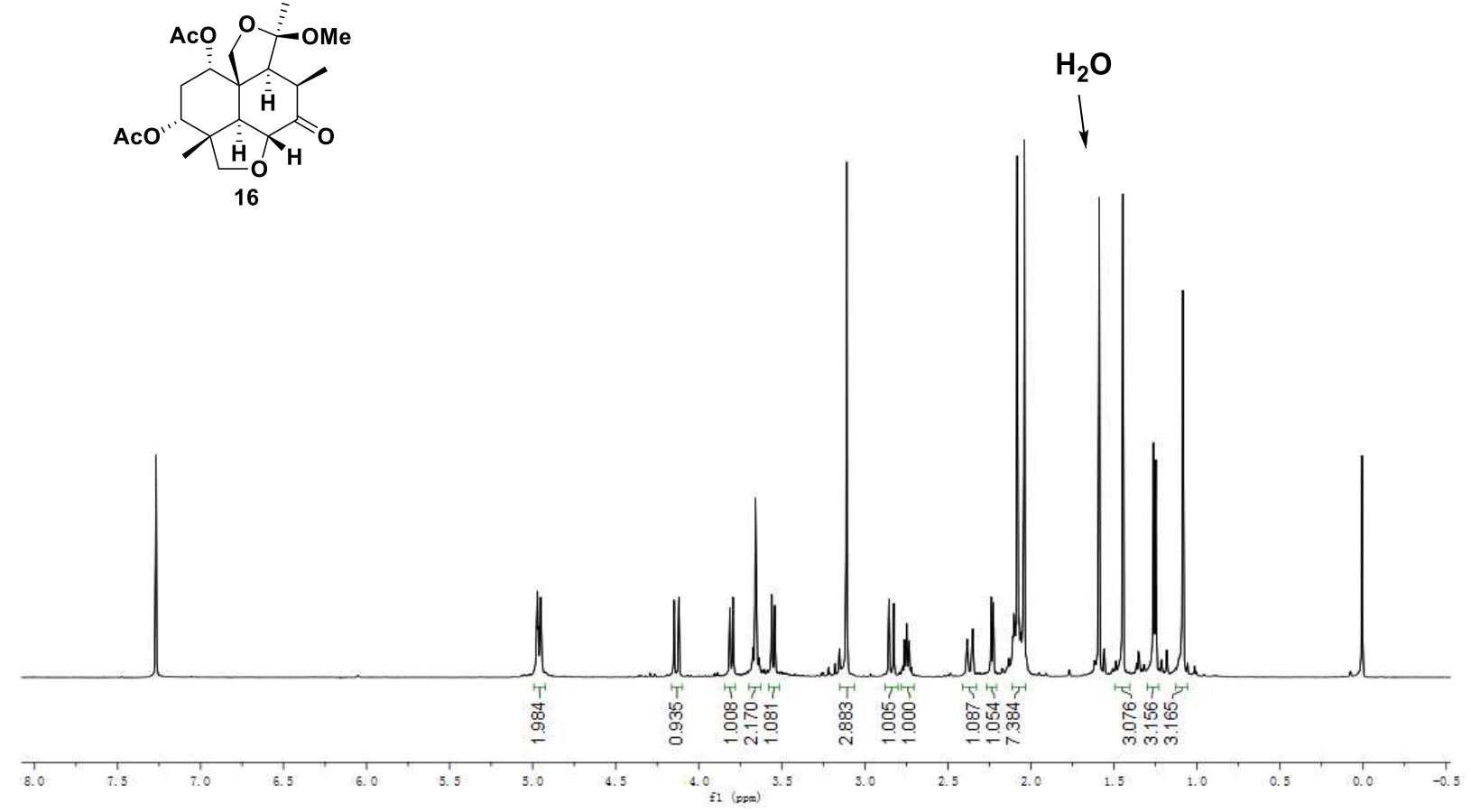

${ }^{1} \mathrm{H}$ NMR of compound $\mathbf{1 6}$
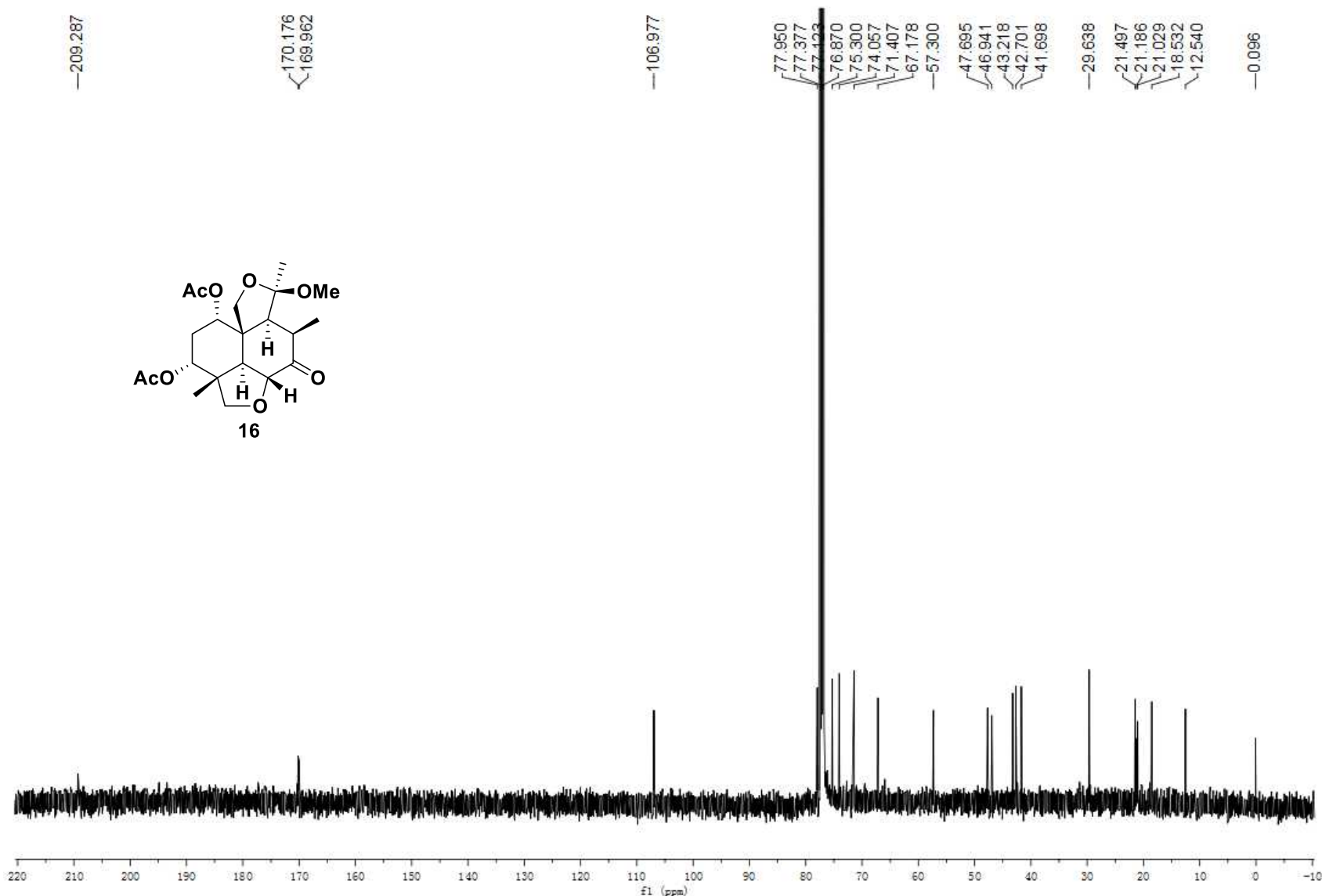

${ }^{13} \mathrm{C}$ NMR of compound $\mathbf{1 6}$ 

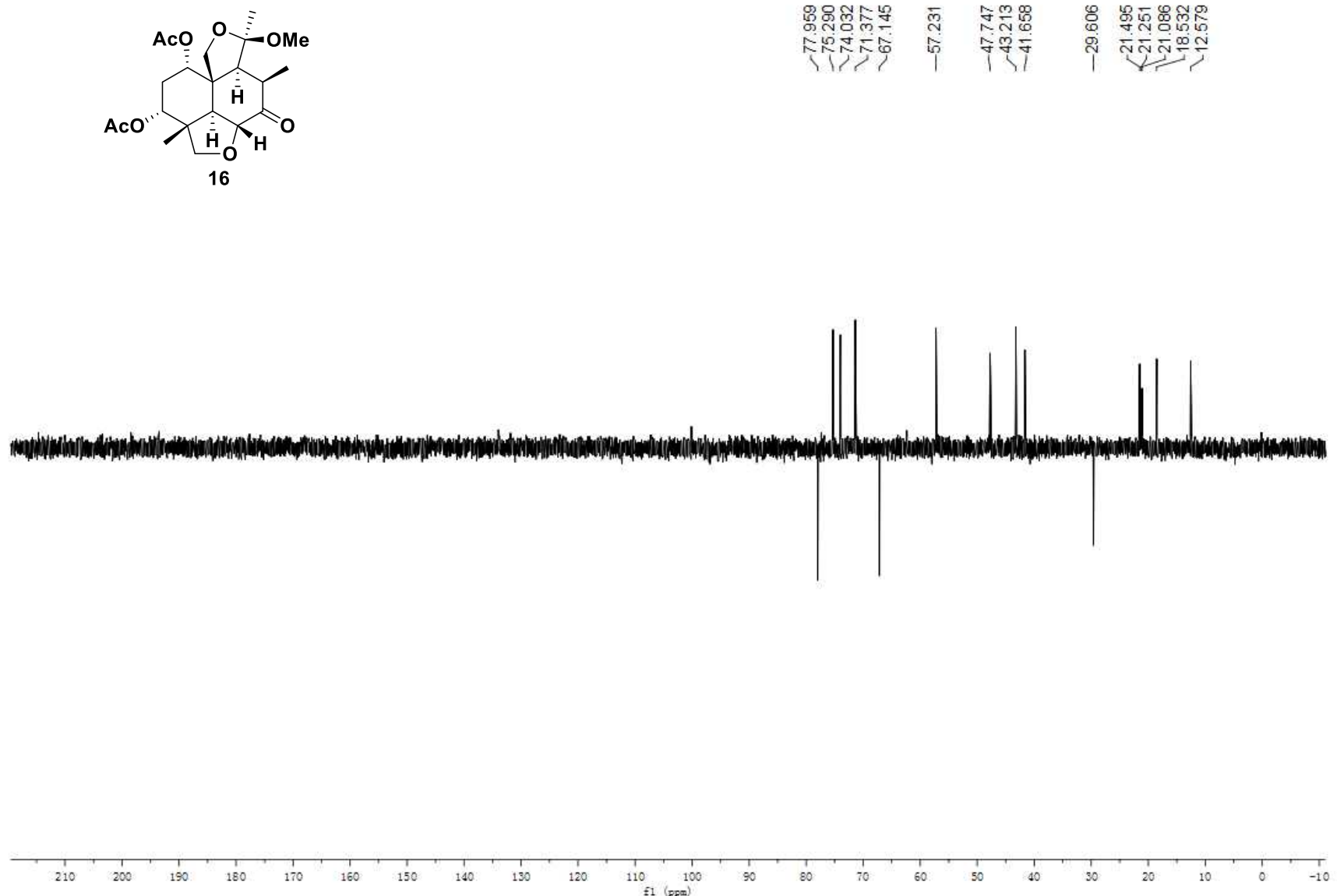

Dept135 NMR of compound $\mathbf{1 6}$

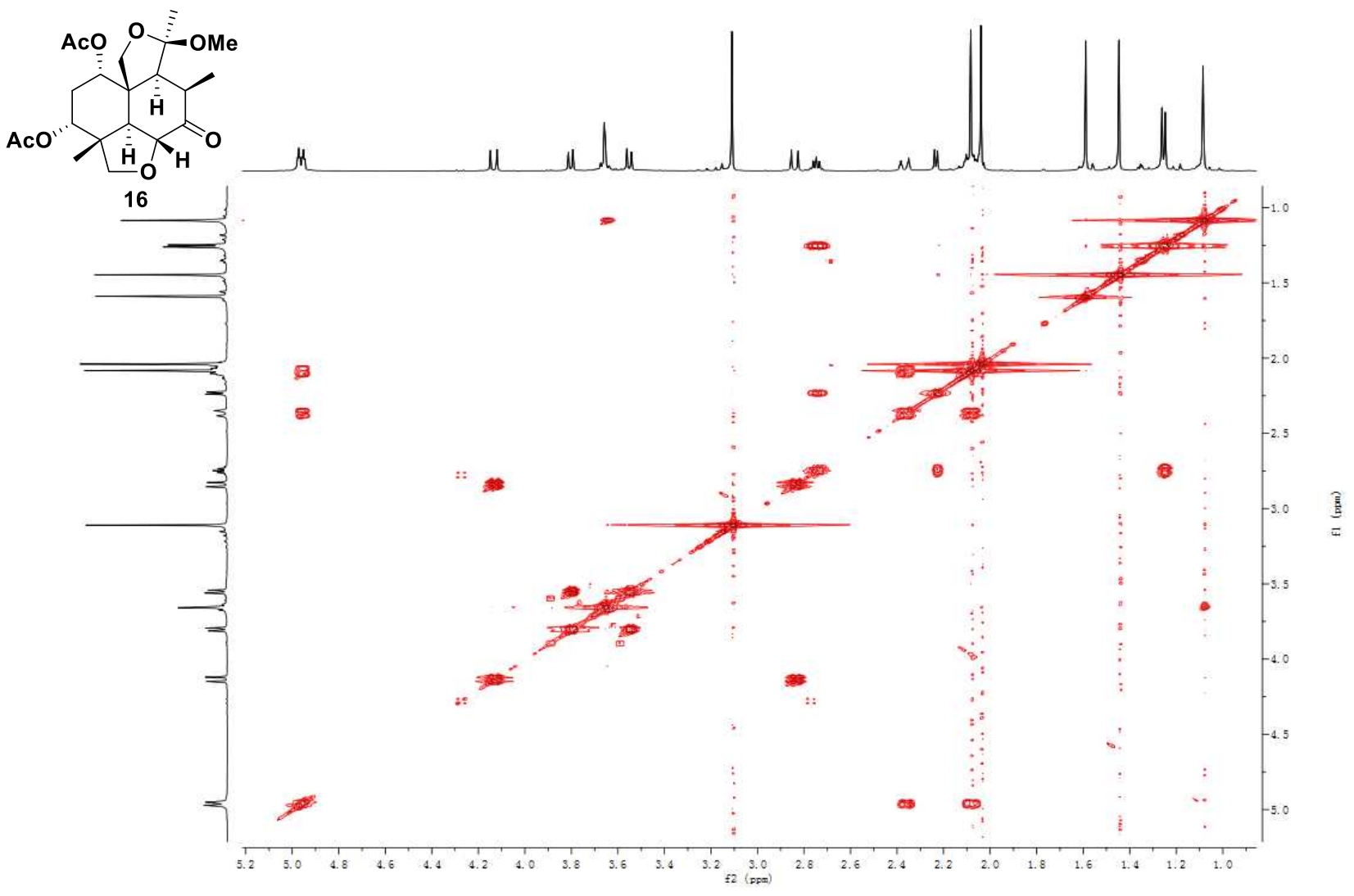

COSY NMR of compound $\mathbf{1 6}$ 


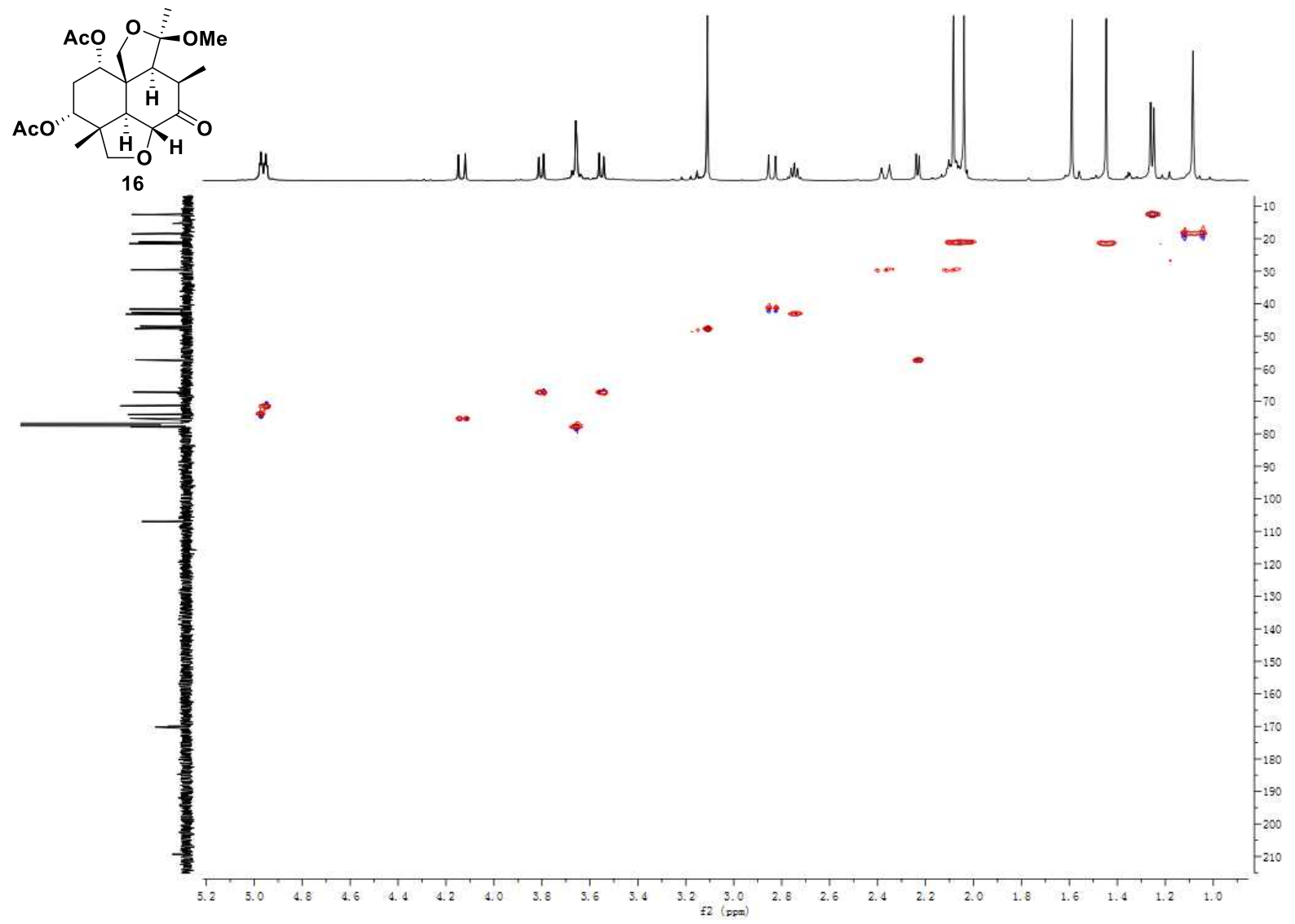

HSQC NMR of compound 16

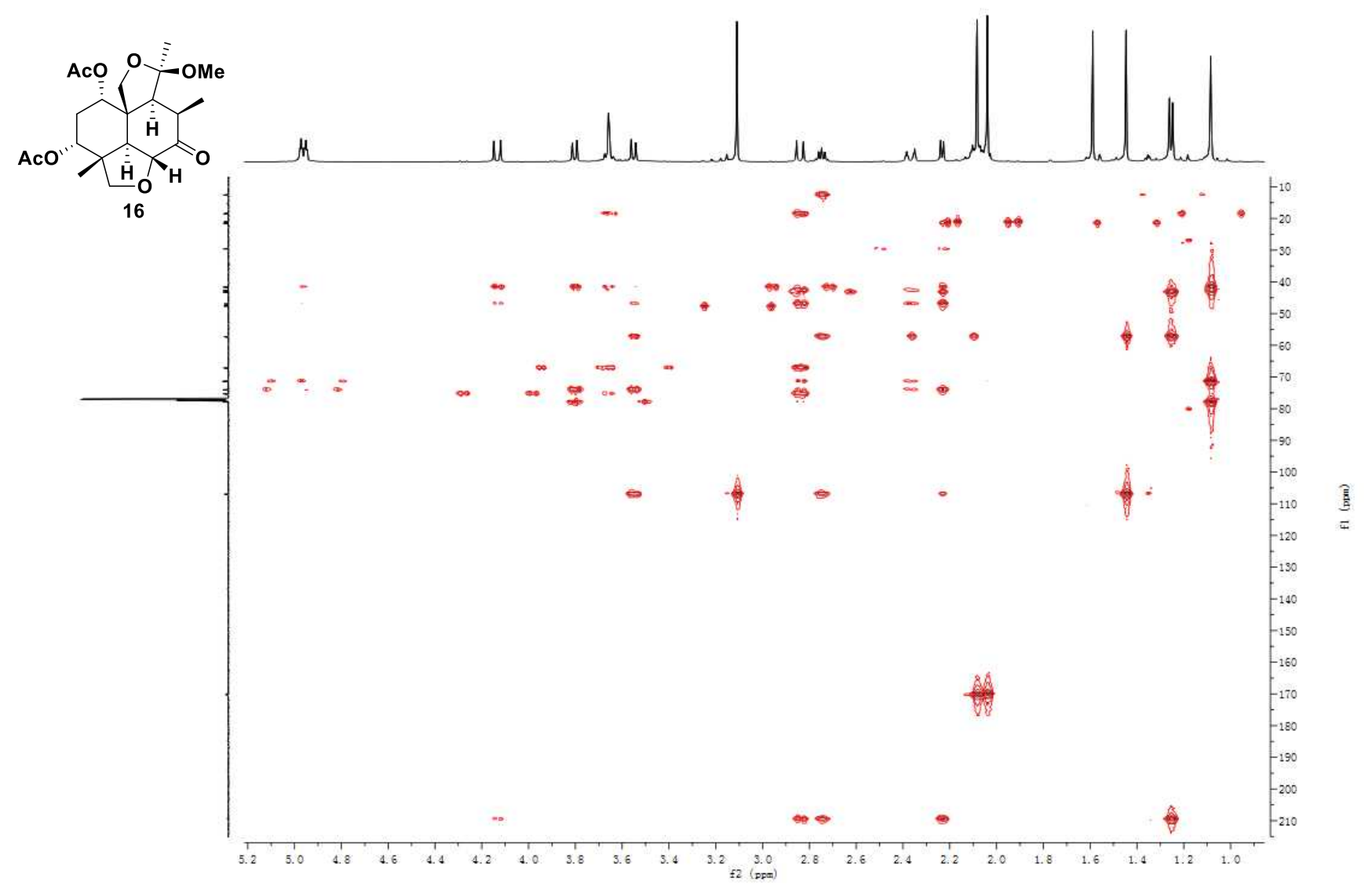

HMBC NMR of compound $\mathbf{1 6}$ 


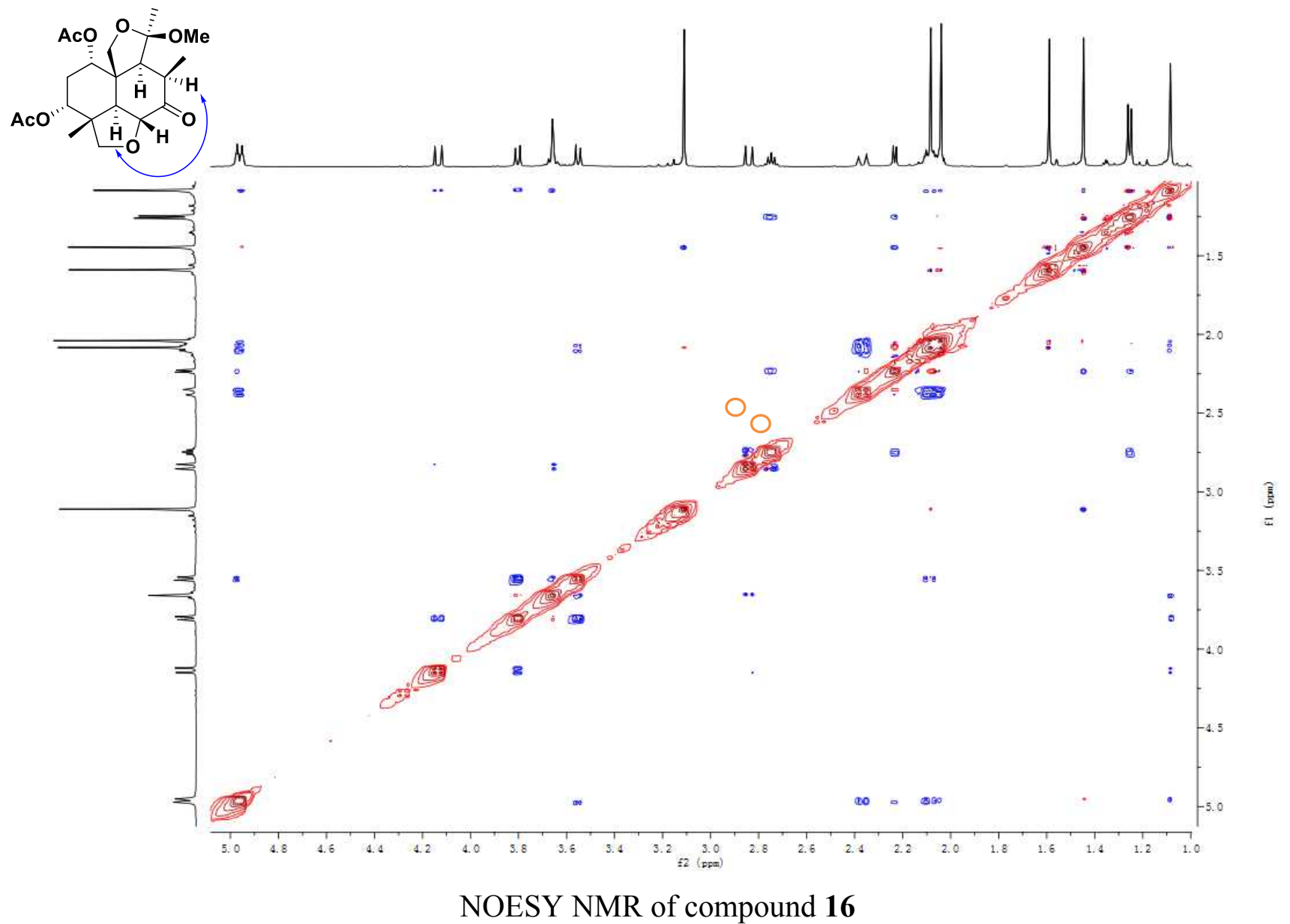




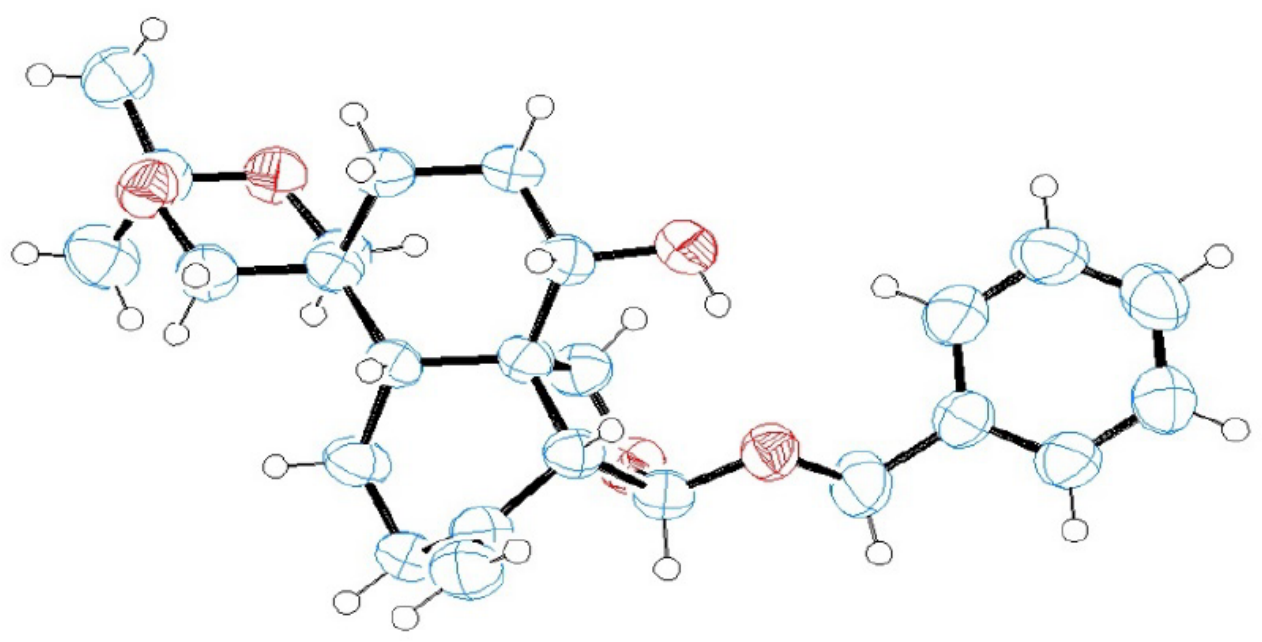

Ortep Plot of Compound 20a with 50\% ellipsoids

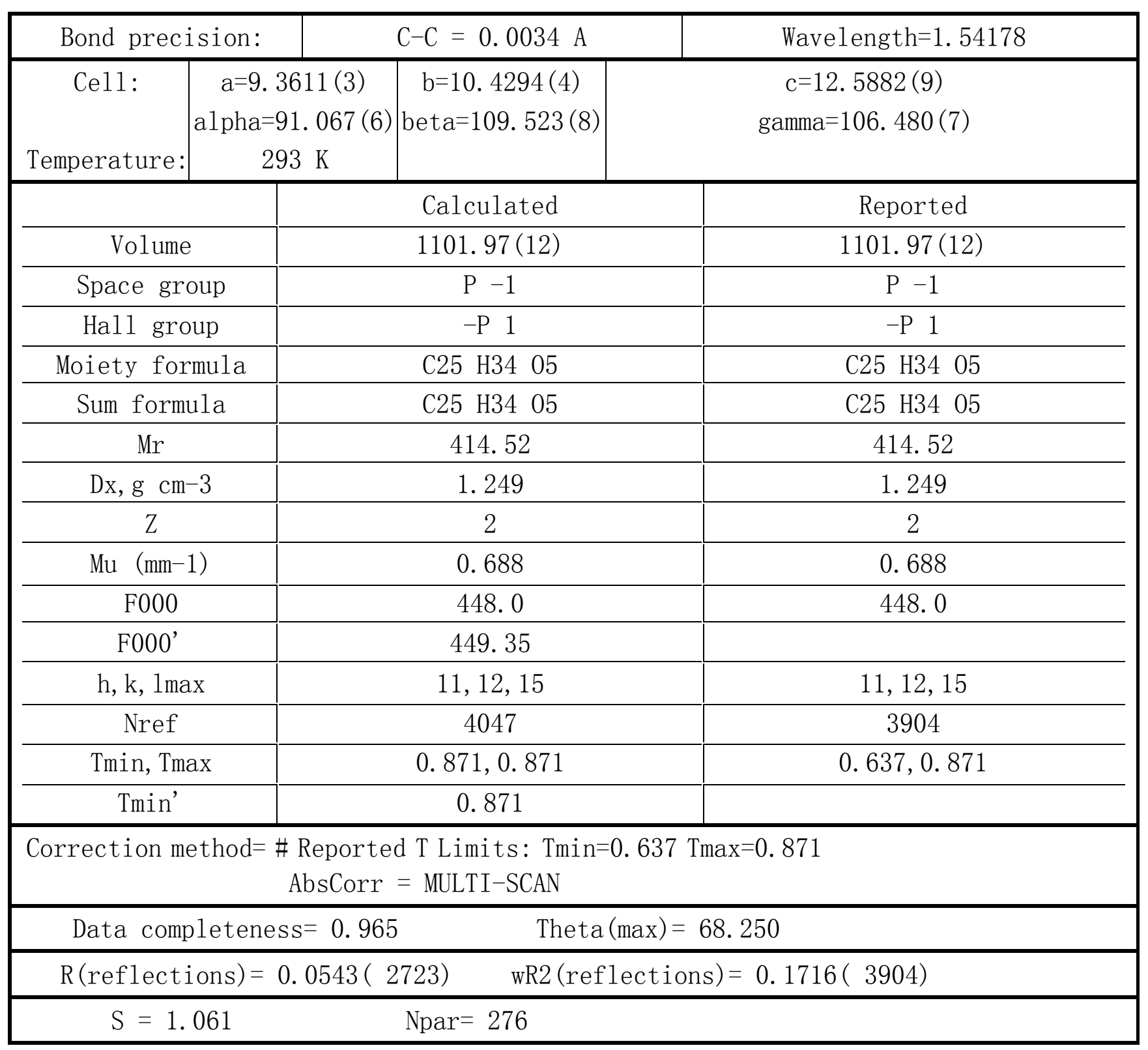




\section{Parameters of Compound $\mathbf{4 0}$}

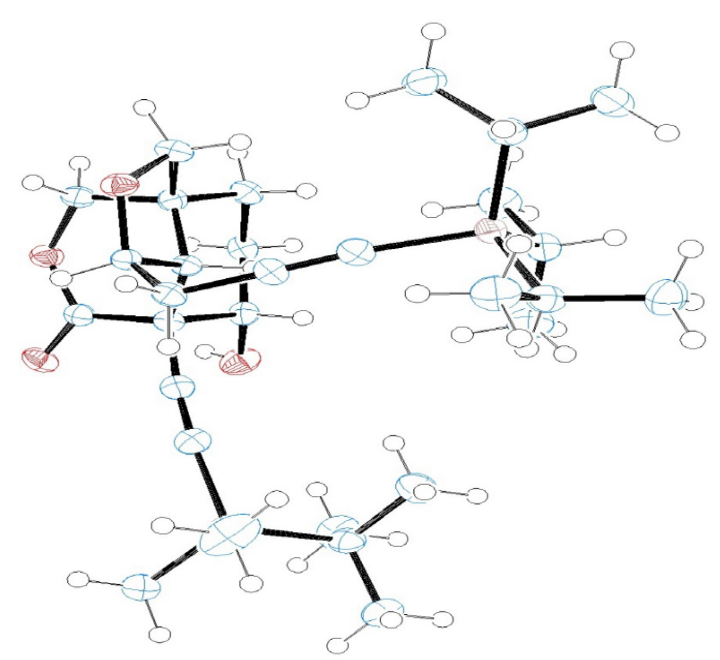

Ortep Plot of Compound $\mathbf{4 0}$ with 50\% ellipsoids

\begin{tabular}{|c|c|c|c|}
\hline \multicolumn{2}{|c|}{ Bond precision: } & $\mathrm{C}-\mathrm{C}=0.0040 \mathrm{~A}$ & Wavelength $=1.54178$ \\
\hline \multirow[t]{2}{*}{ Ce11: } & $\mathrm{a}=7.7056(1)$ & $b=31.3414(6)$ & $\mathrm{c}=12.9403(9)$ \\
\hline & alpha=90 & beta $=92.142(7)$ & gamma $=90$ \\
\hline \multirow[t]{2}{*}{ Temperature: } & $113 \mathrm{~K}$ & & \\
\hline & & Calculated & Reported \\
\hline \multicolumn{2}{|l|}{ Volume } & $3123.0(2)$ & 3123. $0(2)$ \\
\hline \multicolumn{2}{|c|}{ Space group } & $\mathrm{P} 21 / \mathrm{n}$ & $\mathrm{P} 21 / \mathrm{n}$ \\
\hline Hall group & & $-P 2 y n$ & $?$ \\
\hline \multicolumn{2}{|c|}{ Moiety formula } & C30 H50 04 Si2 & C30 H50 $04 \quad$ Si2 \\
\hline \multicolumn{2}{|c|}{ Sum formula } & C30 H50 04 Si2 & C30 H50 04 Si2 \\
\hline \multicolumn{2}{|l|}{$\mathrm{Mr}$} & 530.88 & 530.88 \\
\hline \multicolumn{2}{|c|}{ Dx, g cm-3 } & 1. 129 & 1. 129 \\
\hline \multicolumn{2}{|l|}{ Z } & 4 & 4 \\
\hline $\mathrm{Mu} \quad(\mathrm{mm}-1)$ & & 1.266 & 1.266 \\
\hline \multicolumn{2}{|l|}{ F000 } & 1160.0 & 1160.0 \\
\hline \multicolumn{2}{|l|}{ F000' } & 1164.86 & \\
\hline \multicolumn{2}{|c|}{$\mathrm{h}, \mathrm{k}, 1 \max$} & $9,37,15$ & $9,37,15$ \\
\hline \multicolumn{2}{|l|}{ Nref } & 5724 & 5614 \\
\hline \multicolumn{2}{|c|}{ Tmin, Tmax } & $0.815,0.881$ & $0.500,0.782$ \\
\hline \multicolumn{2}{|l|}{ Tmin' } & 0.739 & \\
\hline \multicolumn{4}{|c|}{$\begin{array}{c}\text { Correction method }=\text { \# Reported T Limits: Tmin }=0.500 \text { Tmax }=0.782 \\
\text { AbsCorr }=\text { MULTI-SCAN }\end{array}$} \\
\hline \multicolumn{4}{|c|}{ Data completeness $=0.981$} \\
\hline \multicolumn{4}{|c|}{$\mathrm{R}($ reflections $)=0.0600(4241)$} \\
\hline \multicolumn{2}{|c|}{$\mathrm{S}=1.099$} & Npar $=338$ & \\
\hline
\end{tabular}




\section{Parameters of Compound 49a}

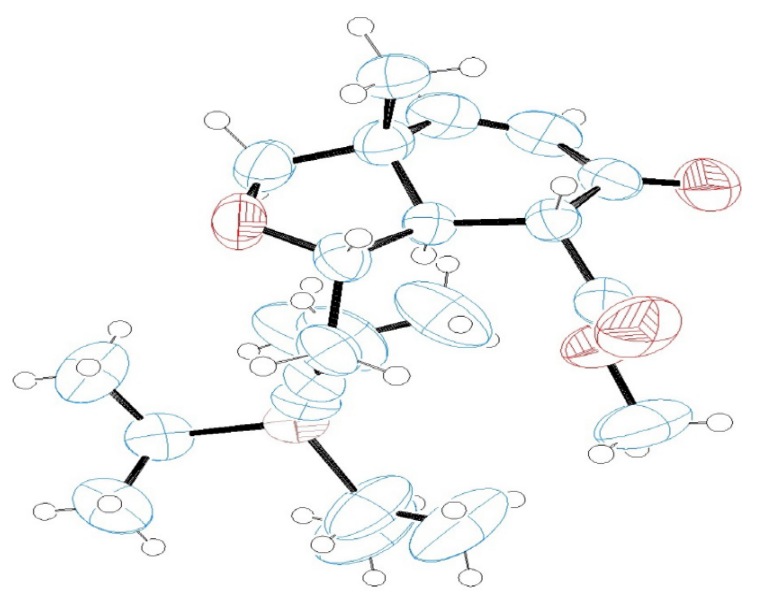

Ortep Plot of Compound 49a with 50\% ellipsoids

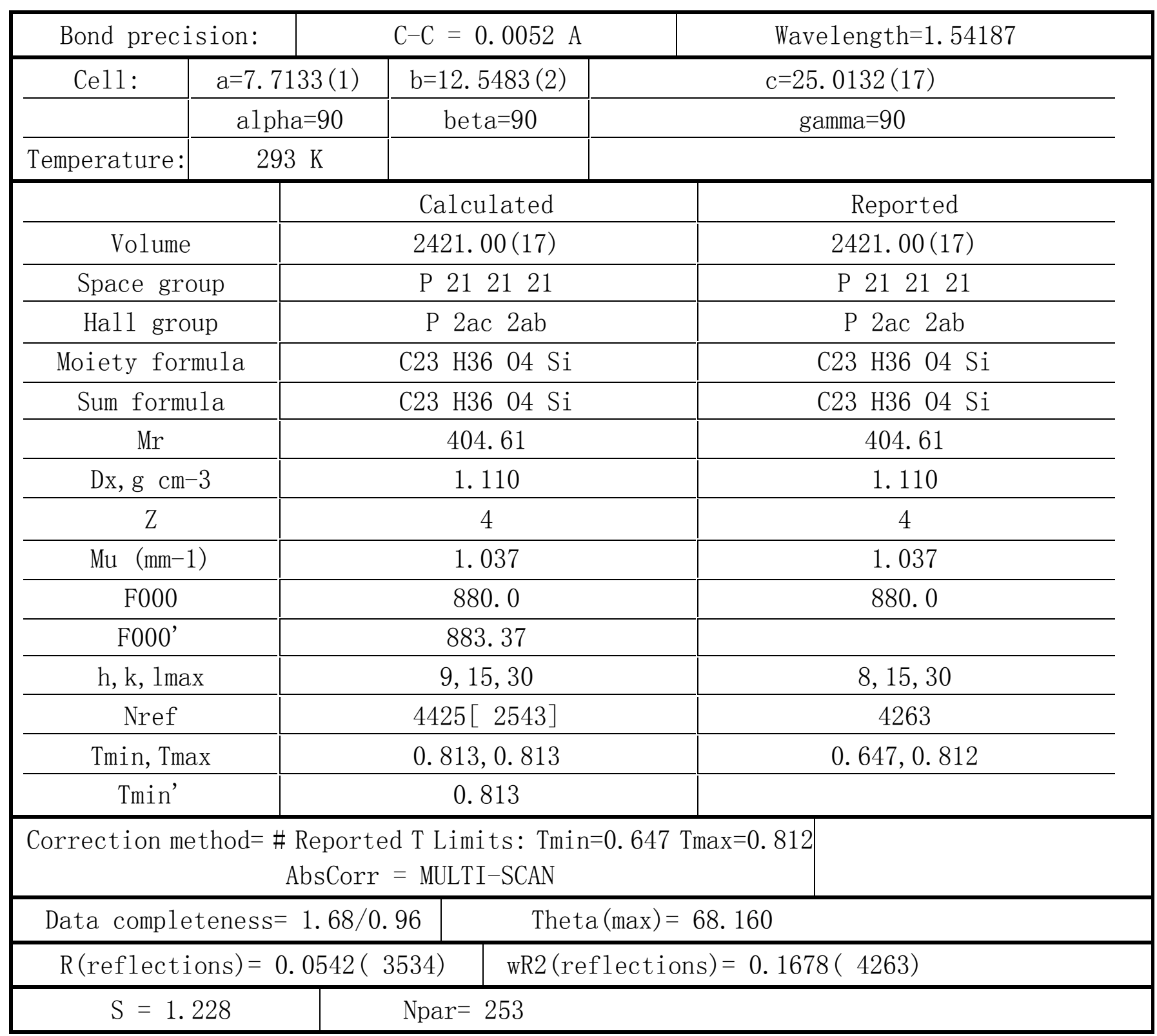




\section{Parameters of Compound 64}

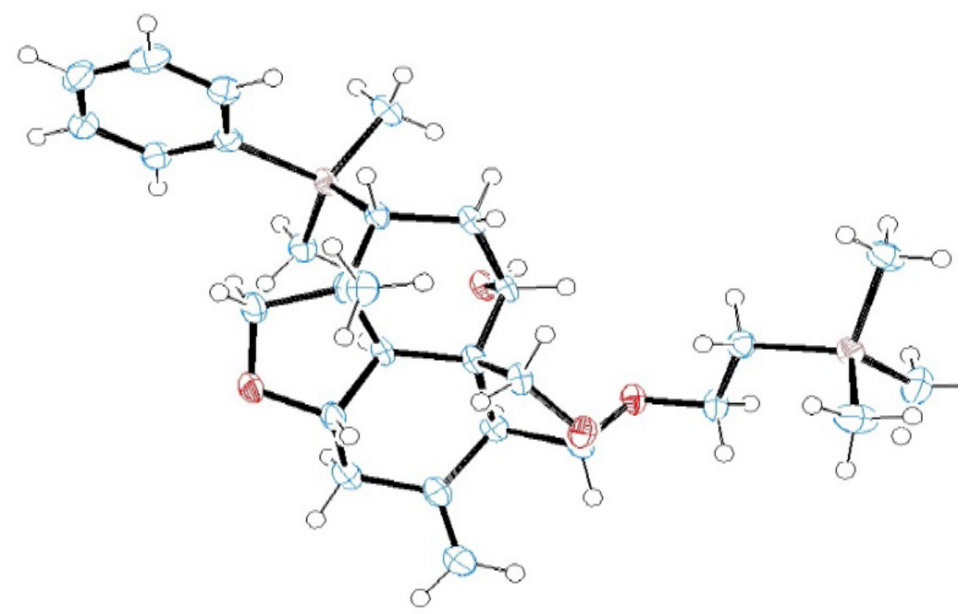

Ortep Plot of Compound 64 with 50\% ellipsoids

\begin{tabular}{|c|c|c|c|}
\hline Bond preci & ion & $\mathrm{C}-\mathrm{C}=0.0031 \mathrm{~A}$ & Wavelength $=1.54178$ \\
\hline \multirow[t]{2}{*}{ Ce11: } & $\mathrm{a}=7.7020(1)$ & $b=13.1321(2)$ & $c=27.4999(19)$ \\
\hline & alpha $=90$ & beta $=90$ & gamma $=90$ \\
\hline \multirow[t]{2}{*}{ Temperature: } & $113 \mathrm{~K}$ & & \\
\hline & & Calculated & Reported \\
\hline \multicolumn{2}{|l|}{ Volume } & 2781.4(2) & $2781.4(2)$ \\
\hline \multicolumn{2}{|c|}{ Space group } & $\begin{array}{llll}\mathrm{P} & 21 & 21 & 21 \\
\end{array}$ & P 212121 \\
\hline \multicolumn{2}{|c|}{ Hall group } & P 2ac 2ab & $?$ \\
\hline \multicolumn{2}{|c|}{ Moiety formula } & C28 H44 04 Si2 & C28 H44 04 Si2 \\
\hline \multicolumn{2}{|c|}{ Sum formula } & C28 H44 04 Si2 & C28 H44 $04 \quad \mathrm{Si} 2$ \\
\hline \multicolumn{2}{|l|}{$\mathrm{Mr}$} & 500.81 & 500.81 \\
\hline \multicolumn{2}{|c|}{ Dx, g cm-3 } & 1.196 & 1.196 \\
\hline \multicolumn{2}{|l|}{ Z } & 4 & 4 \\
\hline \multicolumn{2}{|c|}{$\mathrm{Mu}(\mathrm{mm}-1)$} & 1.395 & 1.395 \\
\hline \multicolumn{2}{|l|}{ F000 } & 1088.0 & 1088.0 \\
\hline \multicolumn{2}{|l|}{ F000' } & 1092.73 & \\
\hline \multicolumn{2}{|c|}{ h, k, 1 max } & $9,15,33$ & $9,15,32$ \\
\hline \multicolumn{2}{|l|}{ Nref } & $5090[2914]$ & 4975 \\
\hline Tmin, Tma & & 0.757 & $0.651,0.837$ \\
\hline Tmin' & & 21 & \\
\hline Correction me & hod & $\begin{array}{l}\text { ts: Tmin } \\
\text {-SCAN }\end{array}$ & 837 \\
\hline Data comple & enes & Thet & \\
\hline $\mathrm{R}($ reflecti & $n s)=$ & wR2 (re & $0.0861($ 4975) \\
\hline$S=1$. & & 317 & \\
\hline
\end{tabular}




\section{Parameters of Compound 79}

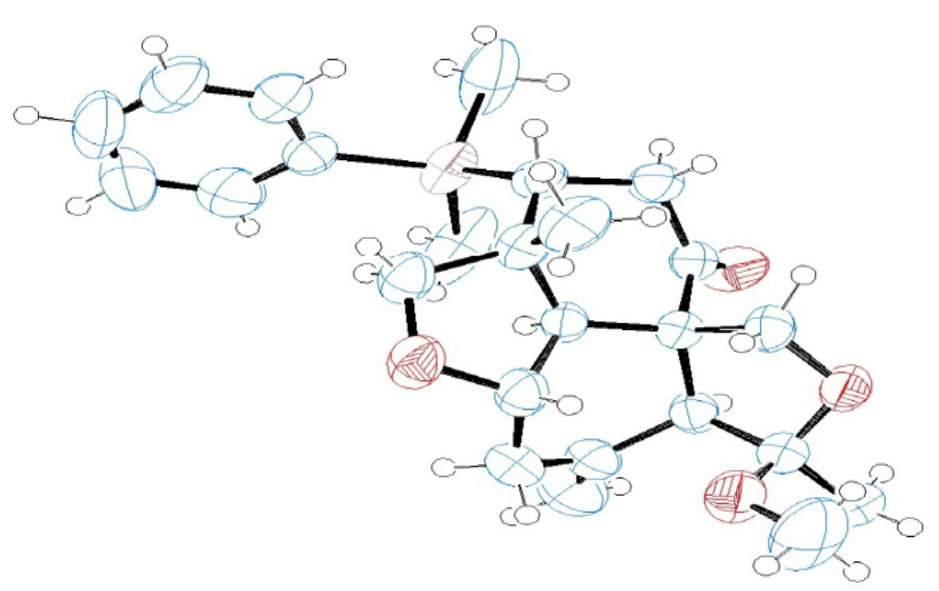

Ortep Plot of Compound $\mathbf{7 9}$ with 50\% ellipsoids

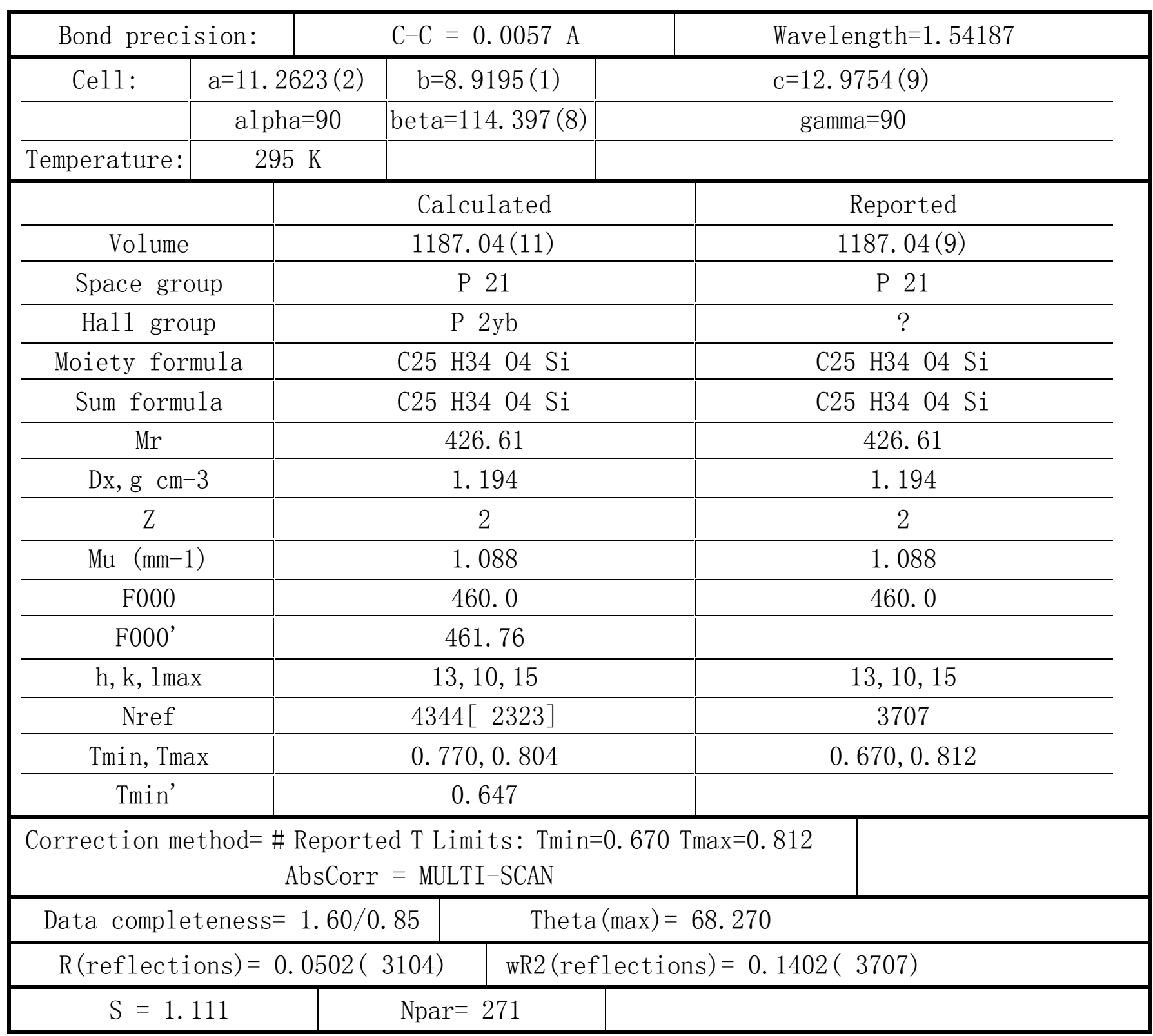


Reference 2e in the text: S. V. Ley, A. Abad-Somovilla, J. C. Anderson, C. Ayats, R. Bänteli, E. Beckmann, A. Boyer, M. G. Brasca, A. Brice, H. B. Broughton, B. J. Burke, E. Cleator, D. Craig, A. A. Denholm, R. M. Denton, T. Durand-Reville, L. B. Gobbi, M. Gçbel, B. Lawrence Gray, R. B. Grossmann, C. E. Gutteridge, N. Hahn, S. L. Harding, D. C. Jennens, L. Jennens, P. J. Lovell, H. J. Lovell, M. L. de la Puente, H. C. Kolb, W.-J. Koot, S. L. Maslen, C. F. McCusker, A. Mattes, A. R. Pape, A. Pinto, D. Santafianos, J. S. Scott, S. C. Smith, A. Q. Somers, C. D. Spilling, F. Stelzer, P. L. Toogood, R. M. Turner, G. E. Veitch, A. Wood, C. Zumbrunn, Chem.-Eur. J. 2008, 14, 10683-10704. 